\title{
SEX TRAFFICKING, VICTIMISATION AND AGENCY: THE EXPERIENCES OF MIGRANT WOMEN IN MALAYSIA
}

BY

Haezreena Begum binti Abdul Hamid
A thesis submitted to Victoria University of Wellington in fulfilment of the requirements for the degree of Doctor of Philosophy in Criminology

Victoria University of Wellington 2020 
This thesis is dedicated to my late mother, Ma'wanchik binti Pawan and my late grandfather, Pawan bin Mohd Hashim 


\section{Acknowledgments}

This PhD thesis is dedicated to my late mother who succumbed to cancer at the early age of 62. She was a strong and remarkable woman who always had faith in me and encouraged me to be fearless and fight for what I believe in. Also in memory of my late grandfather who showered me with lots of love and care, and who still remembered me even when he had dementia.

My sincere gratitude goes to the 29 women who have shared their stories of pain, sadness and hope with me. This thesis would not have been possible without them and I hope that I have done justice to their stories. Also, to the professionals who were kind enough to allow me to interview them, despite their busy schedules. Thanks also for the financial assistance provided by MARA (Malaysian People's Trust Council), VUW (through the University Research Fund and FHSS grants), and the support from the SOSC admin and library staff.

I would like to express my heartfelt gratitude and special appreciation to my supervisors, Prof Elizabeth Stanley and Prof Jan Jordan, for their continuous support of my PhD study. Their insightful comments, encouragement, and hard questions have led me to widen my research from various perspectives. I cannot thank you enough for your patience, motivation, and immense knowledge that has guided me throughout this PhD journey. Prof Stanley, you have inspired me in many ways and transformed me into a better version of myself. You are an excellent mentor and I am blessed to have you as my supervisor. Prof Jordan, you are such an illustrious scholar and an admirable person. Your advice on perseverance and thinking critically have become a mantra that motivated me to get to the finish line.

My PhD journey would not have been completed without the unwavering support of my husband, Lokman, and my children, Sarah Nabila, Farez Aslam, Darwisy Aslam, Saif Aslam. I have not been able to pay much attention to your lives for the past few years. Yet you have always remained understanding and supportive of me. Also to my sister Zahilda Begum and niece Alya, who have provided me with moral and emotional support throughout this tumultuous PhD journey. 
My sincere appreciation to Tim and Suriah Burns, who have always welcomed me warmly and spoiled me with delicious treats whenever I felt down or stressed. To Irma, Fairul, Adam and Aidan, a beautiful family who I found comfort in and who were there to listen to my problems. To Dane, who shared the same PhD struggle with me and has passed his viva with flying colours. To Dr Bianca who has cheered me up and had faith in me. To Sally who helped me out through difficult times and supported me emotionally and academically. To Bambi, Peter, Sara, Jordan, Cikgu Elias, Aunty Jasmin, Mamu Ahmad, and Nana Rahman who believed in me and gave me words of encouragement. To Anna and Marita who have been there for me since I arrived New Zealand. To my office mates Bryony, Genevieve and Ashley who witnessed my struggles and kept motivating me to the finish line. Also to all my other friends who supported me throughout this PhD journey - too many to mention, but you know who you are. 


\begin{abstract}
Malaysia has criminalised sex work. However, its geographic location, porous borders and proximity to major trade and traffic routes have ensured a growth in sex trafficking activities. As a result, the 'United Nations Office on Drugs and Crime' and the 'United States Trafficking in Persons Report' have categorised Malaysia as a destination, transit and source point for sex trafficking in Asia. In response to such categorisations, Malaysia has ratified the (Palermo) 'Protocol to Prevent, Suppress and Punish Trafficking in Persons Especially Women and Children' and structured its anti-trafficking laws around prosecution, protection and prevention (referred to as the ' $3 P^{\prime}$ ' policy).
\end{abstract}

This thesis shows that the enforcement of victim-protection policies is carried out in contradictory ways in Malaysia. Trafficked women are portrayed as victims in need of care and protection, but also as individuals who have violated immigration laws and engaged in 'immoral' acts. This results in state practices that (re)victimise women through policing, immigration and court processes which are often deeply stressful, traumatising and violent. Punitive practices - including 'state and rescue' operations and long-term detention - have been legitimised and branded as 'victim protection'. In this context, the thesis argues that current policies and practices represent a continuing form of violence against migrant women in Malaysia.

Based on in-depth qualitative interviews, the thesis draws upon the stories of twenty-nine women who have been arrested and detained on the basis of their sex trafficked status as well as the perspectives of twelve anti-trafficking professionals involved in delivering the 3P policy. In doing so, the thesis shows how women are subject to prolonged victimisation at the hands of both traffickers and state authorities. However, it also provides an understanding of the ways in which 'sex-trafficked' women exercise courage, strength and resiliency in the face of the continuing harms against them. By demonstrating the nuances of agency throughout women's migration experiences, the thesis challenges the stereotypical understanding of an 'ideal' victim of trafficking - commonly linked to images of passivity, weakness and worthiness. 
By providing an insight into women's experiences of sex-trafficking and state 'protection', the thesis develops a more nuanced account of agency. Thus, the thesis argues that the state's prevention of sex-trafficking as well as the protection of trafficked women cannot be progressively advanced without a fuller appreciation of women's dual 'victim' and 'agent' identities. The thesis explores the implications of these findings on developing 'anti-sex trafficking' policies towards women in Malaysia. 


\section{List of Acronyms and Other Terms}

ATIP

CAMA

CD

CEDAW

CPC

DG

ECOSOC

FC

GAATW

GDP

GSS

Guiding Principles

ILO

INR

IPO

JAHEIK

JPW

KLIA

MAPO

Ministry

NGO

NEP

NZD

OMCT
Anti-Trafficking in Persons and Smuggling of Migrants Act 2007

Communications and Multimedia Act 1988

Compact Disc

Convention on the Elimination of all forms of Discrimination Against Women

Criminal Procedure Code

Director General of Women's Development

United Nations Economic and Social Council

Malaysian Federal Constitution

The Global Alliance Against Trafficking in Women

Gross Domestic Product

The Good Shepherd Sisters

Ten Guiding Principles of Ethical and Safe Conduct of interviews advocated by the World Health Organization

International Labour Organisation

Indonesian Rupiah

Interim Protection Order

Kelantan's Islamic Affairs and Religious Department

Department for Women's Development

Kuala Lumpur International Airport

Council of Anti-Trafficking in Persons and Migrant Smuggling

Ministry of Women Affairs and Family Development

Non-Governmental Organisations

Malaysia's New Economic Policy

New Zealand Dollar

Office to Monitor and Combat Trafficking in Persons 


\begin{tabular}{|c|c|}
\hline Palermo Protocol & $\begin{array}{l}\text { Protocol to Prevent, Suppress and Punish Trafficking in Persons, } \\
\text { Especially Women and Children, Supplementing the United Nations } \\
\text { Convention against Transnational Organized Crime }\end{array}$ \\
\hline PDPA & Personal Data Protection Act 2010 \\
\hline $\mathrm{PO}$ & Protection Order \\
\hline PRA & Prostitution Reform Act 2003 \\
\hline RM & Malaysia Ringgit \\
\hline The Guidelines & $\begin{array}{l}\text { United Nations Recommended Principles and Guidelines on Human } \\
\text { Rights and Human Trafficking } 2002\end{array}$ \\
\hline SIS & Sisters in Islam \\
\hline STIS & Sexually transmitted infections \\
\hline SUHAKAM & The Human Rights Commission of Malaysia \\
\hline TIP Report & United States Trafficking in Persons Report \\
\hline TOC & $\begin{array}{l}\text { United Nations Convention Against Transnational Organized Crime } \\
\text { and the Protocols Thereto }\end{array}$ \\
\hline TVPA & Trafficking of Victims Protection Act 2000 \\
\hline UDHR & Universal Declaration of Human Rights \\
\hline UN & United Nations \\
\hline UNCRM & United Nations Convention on the Rights of Migrants \\
\hline UNODC & United Nations Office on Drugs and Crime \\
\hline US & United States of America \\
\hline USD & United States Dollar \\
\hline USOMCT & Unites States Office to Monitor and Combat Trafficking in Persons \\
\hline $3 P$ & Prosecute, protect and prevent \\
\hline
\end{tabular}




\section{List of Figures}

Figure 1: Malaysia Tier Ranking by year according to the 2018 US TIP Report Available: https://www.state.gov/documents/organization/282802.pdf [date accessed online: 30.10 .18 ]

Figure 2: Pictures of police raid advertised by Kosmo Online, a Malaysian magazine Available: https://www.kosmo.com.my/jurnal/perangkap-seks-wanita-asing1.638432 [date accessed online: 02.02.19] .94

Figure 3: Participants' country of origin and age range (own analysis)

Figure 4: Women's perception of their migration experience (own analysis). .141

Figure 5: Flow chart of how sexually 'trafficked' women are policed and processed. .162

Figure 6: Signboard with instructions to visitors attached to the shelter gate (own picture)

Figure 7: Barbed wire along perimeters of the shelter (own picture) .180

Figure 8: Barbed wire at the rear of the shelter (own picture). .180

Figure 9: Outside view of the shelter, barbed wire and the partially hidden guard post on the far left (own picture). 181

Figure 10: Front view of the shelter building partially hidden by trees (own picture) 181

Figure 11: Women's feelings towards their rescue (own analysis). .184 


\section{Contents}

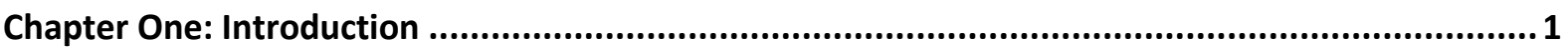

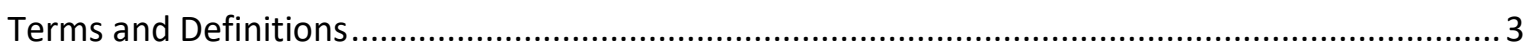

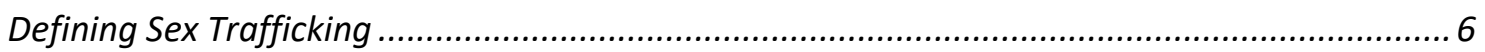

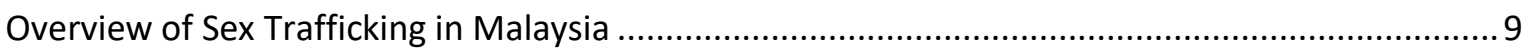

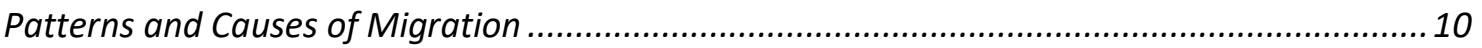

Demand

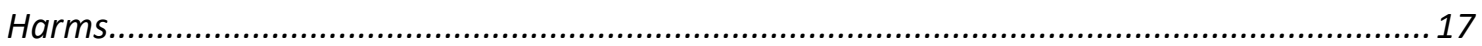

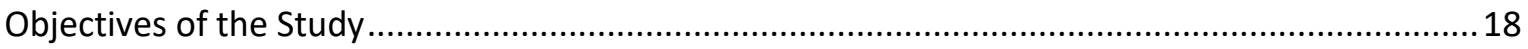

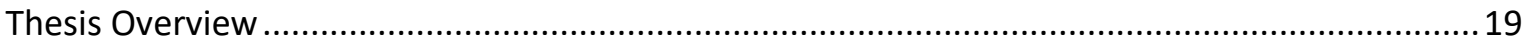

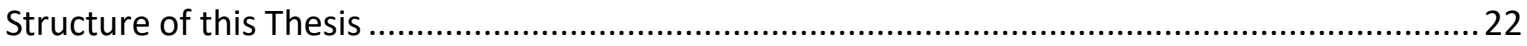

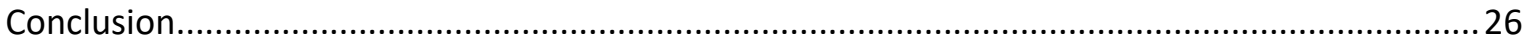

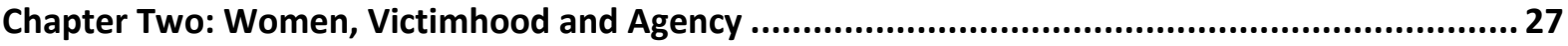

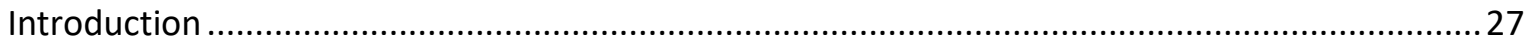

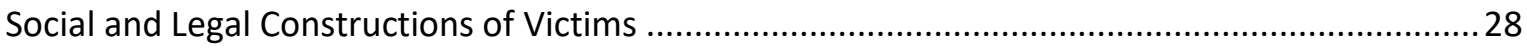

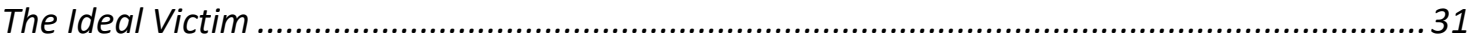

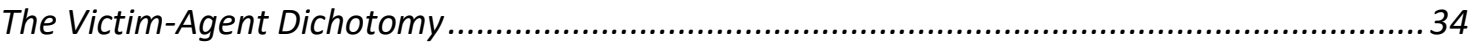

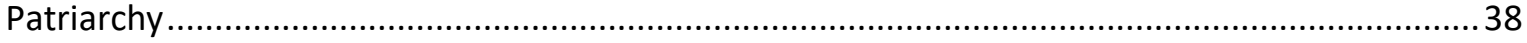

The Historical Development of Women as Male 'Property' ........................................................ 41

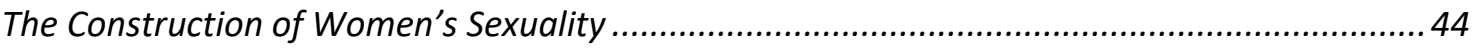

Cultural Acceptance of 'Everyday Violence' Towards Women ................................................. 50

Limited Criminal Justice Protection Towards Female Victims................................................ 52

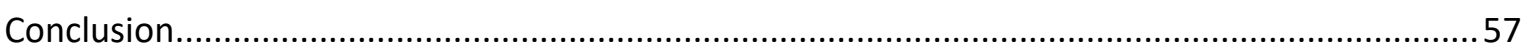

Chapter Three: Sex Trafficking, Agency and Victimisation........................................................59

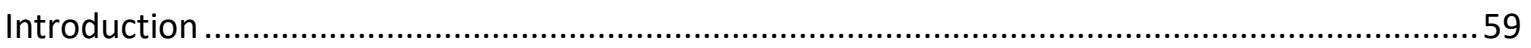

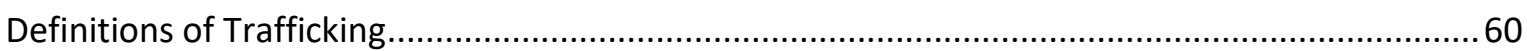

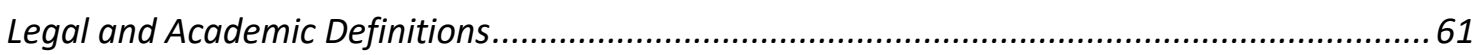

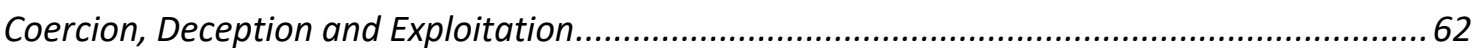

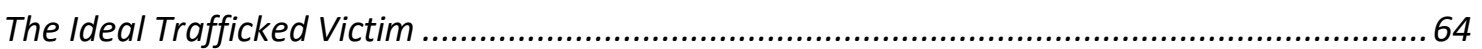

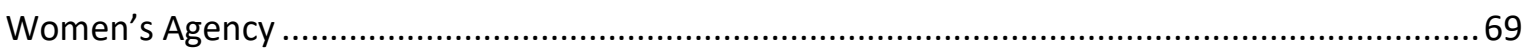

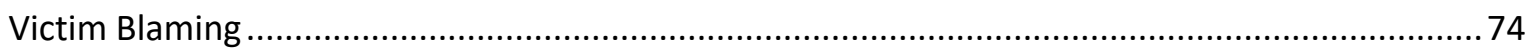

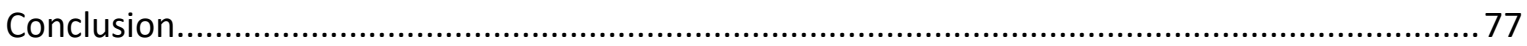

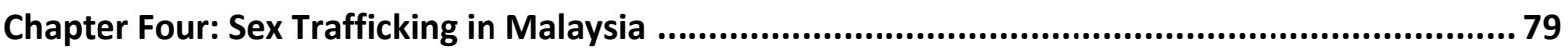

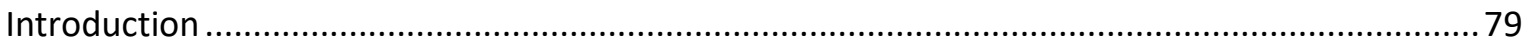




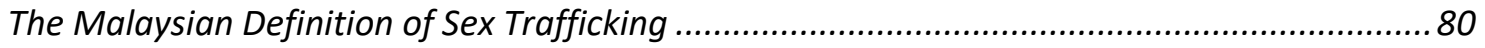

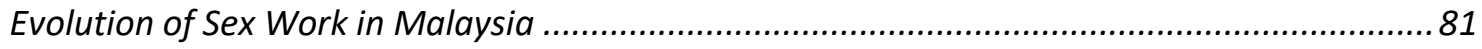

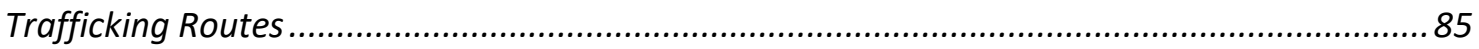

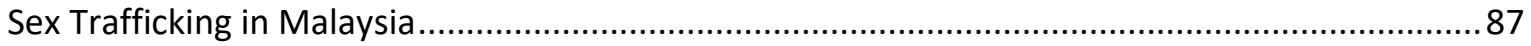

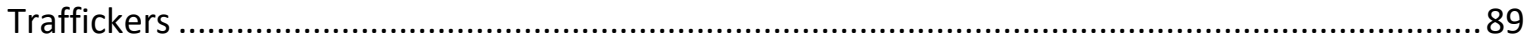

Media Representations of 'Trafficked' Women......................................................................... 92

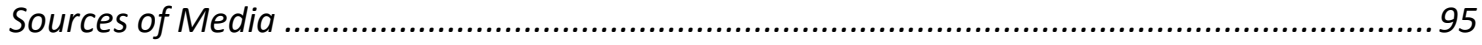

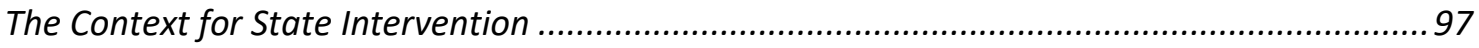

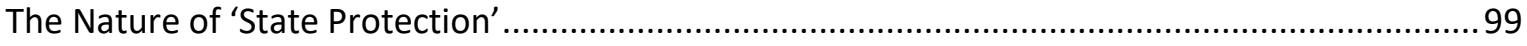

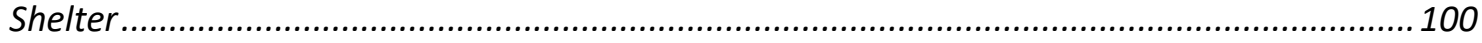

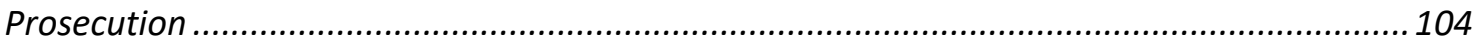

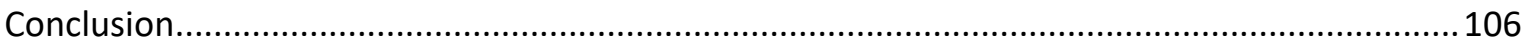

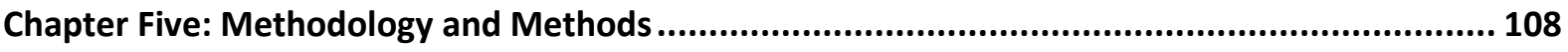

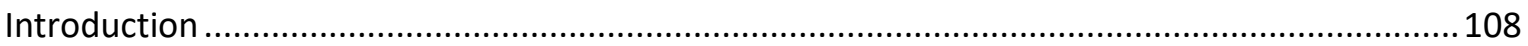

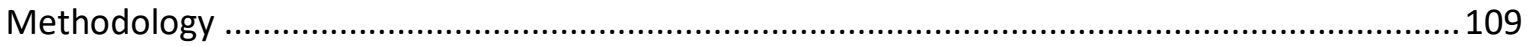

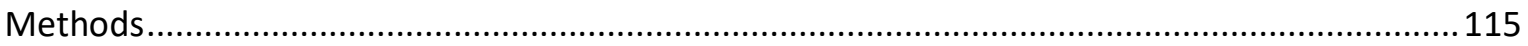

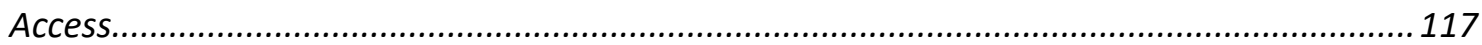

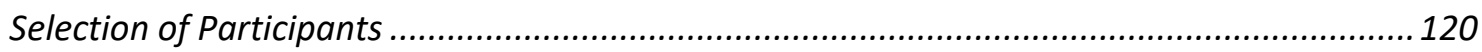

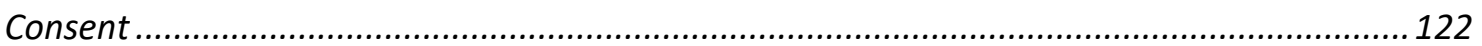

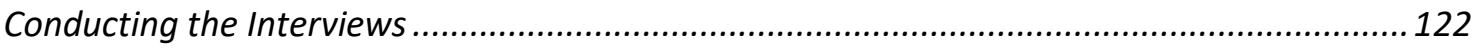

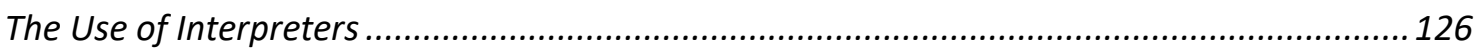

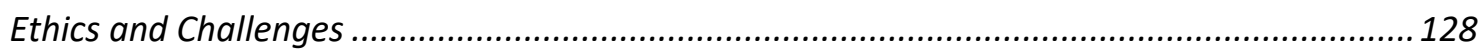

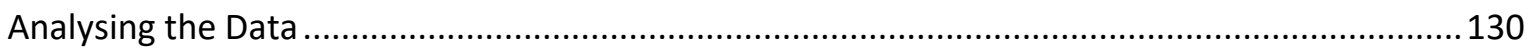

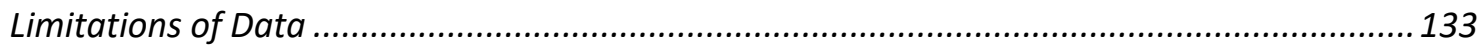

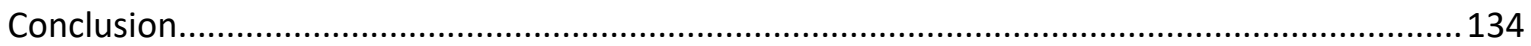

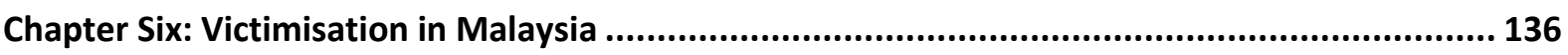

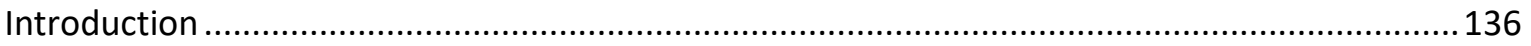

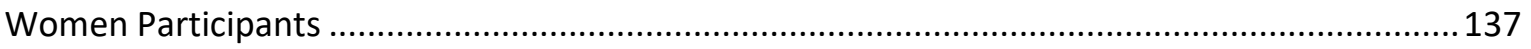

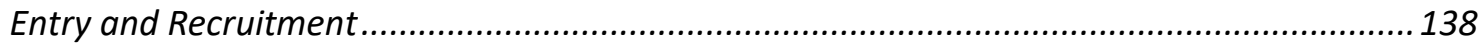

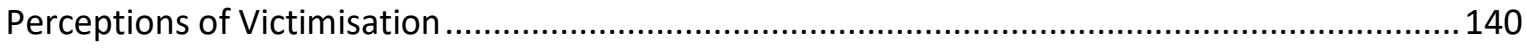

Partial Deception, Coercion, Harms and Exploitation............................................................ 142

Total Deception, Coercion, Harms, Exploitation and Implied Threats ..................................... 144

Total Deception, Coercion, Exploitation, Overt Threats and Harms ....................................... 145

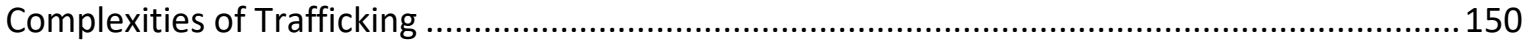

The Official Conflation of Coerced and Voluntary Sex Work ................................................. 150

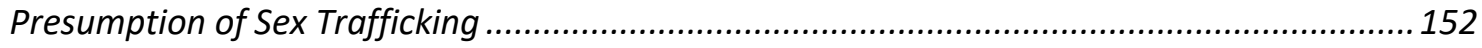


Perspectives of Migration and Sex Work

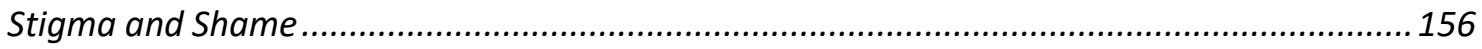

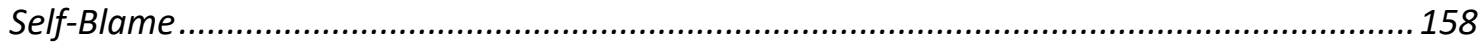

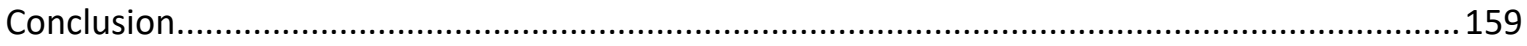

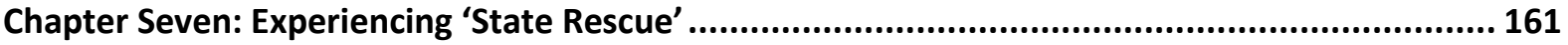

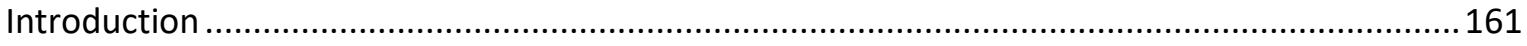

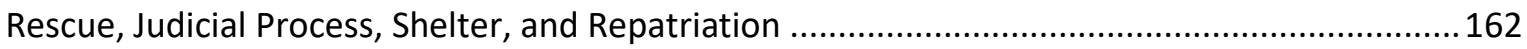

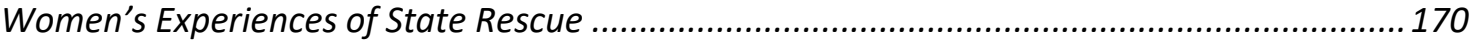

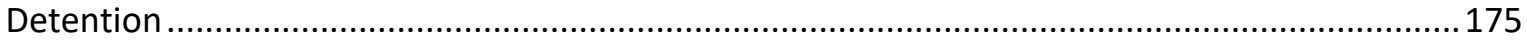

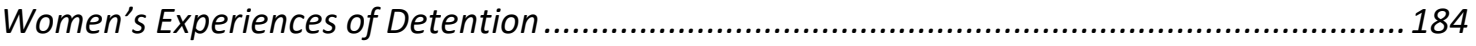

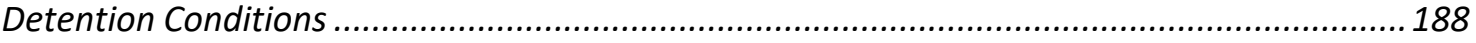

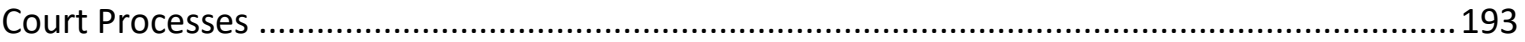

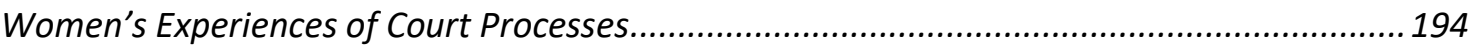

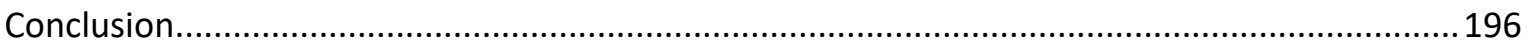

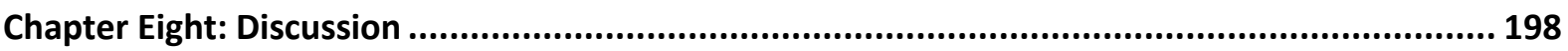

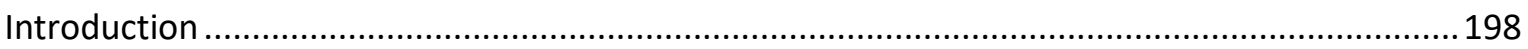

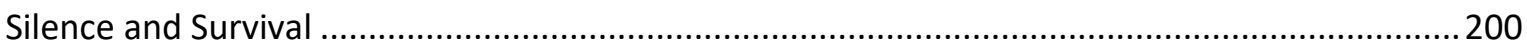

Silencing of Women During the 'Post-trafficking' Phase ….....................................................202

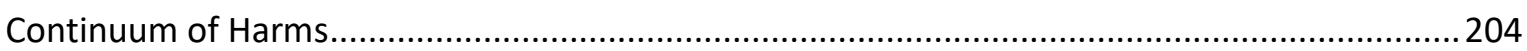

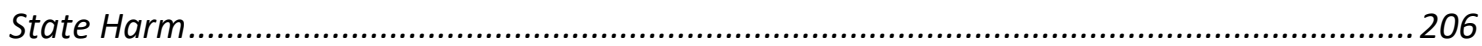

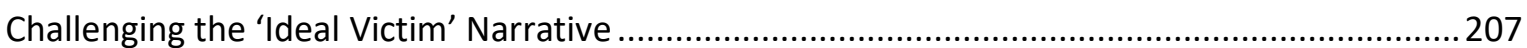

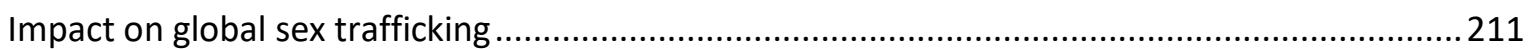

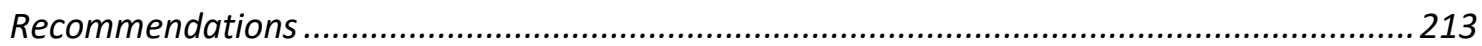

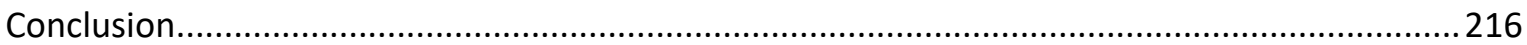

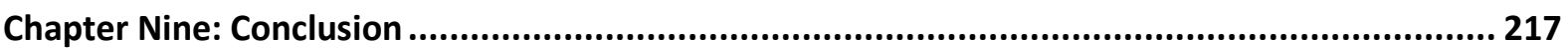

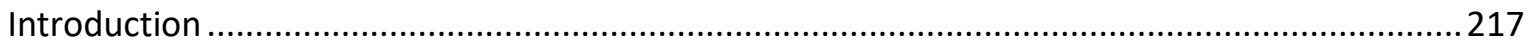

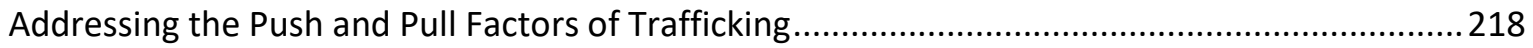

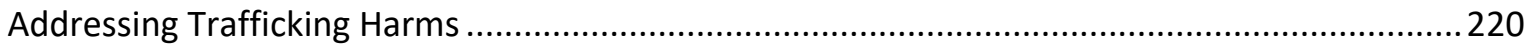

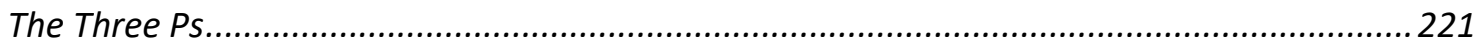

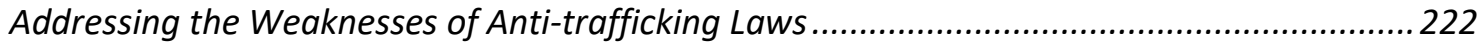

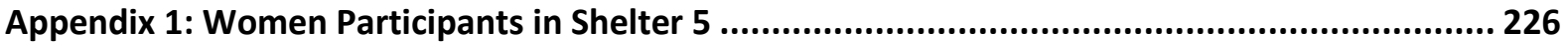

Appendix 2: Questions for Woman Participants in the Shelter............................................ 227

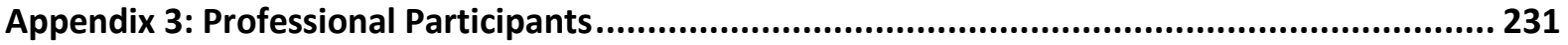

Appendix 4: Interview Questions (Professionals) .................................................................... 232

Appendix 5: Consent to Interview (Female Migrants) ................................................................ 236

Consent to Interview (Professionals)Appendix 6: Information Sheets ....................................... 237 
Appendix 7: Confidentiality Agreement.

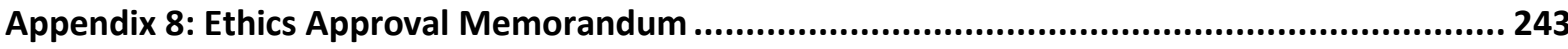

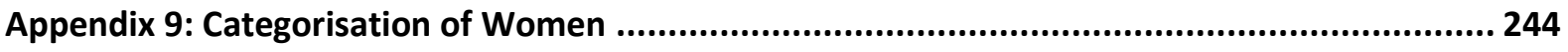

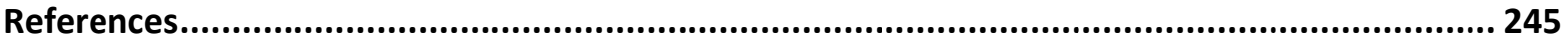




\section{Chapter One: Introduction}

Human trafficking, as defined in international law, can occur for diverse exploitative purposes such as for sexual exploitation, organ harvesting, domestic servitude (work in private households) and exploitation in numerous other licit and illicit labour markets. However, human trafficking is an imprecise and highly contested term (Salt \& Hogarth, 2000, M. Lee, 2011a; (Schauer \& Wheaton, 2006). This is because of the diverse views held by state officials, anti-trafficking scholars and non-governmental organisations particularly when it involves sex work (Soderlund, 2005). Theoretical perspectives ranges from 'abolitionism and neoabolitionism, to those that view trafficking on a continuum of migration, as a human rights issue, within a pro-sex work/labour framework, and an extension of religious/faith-based beliefs' (Soderlund, 2005, p. 70). However, despite these diverse theoretical perspectives, the definition of human trafficking tends to be dominated by state officials and other powerful groups who commonly position trafficking within a framework of crime control, and prevention (Chuang, 2006; Anderson \& Davidson, 2003).

Human trafficking is also regarded as a subset of illegal migration or smuggling as it often involves the breaching of immigration controls (M. Lee, 2011a, Lackzo, 2003). Due to such diverse understanding, human trafficking is sometimes conflated with illegal migration and smuggling (Kelly, 2005) which obscures and obstructs a clear definition of trafficking (A. Jordan). This has resulted in a host of methodological challenges, including a lack of consensus in determining how many persons are trafficked each year, and the absence of reliable statistical data (Kelly, 2005; Piper, 2005). This is because research data are often based on various trafficking definitions used by each individual agency (Laczko \& Gramegna, 2003). Further, Laczko \& Gramegna (2003) argue that data often only covers certain cases such as those who have participated in voluntary assisted return programmes. Therefore, researchers argue that the systematic process of collecting data on trafficking is problematic because it does not reflect the actual number of persons who have been trafficked or are involved in trafficking (Kelly, 2005; Piper, 2005; Tyldum \& Brunovskis, 2005). While quantitative researchers assert that governmental and non-governmental reports have grossly overestimated the number of trafficking victims (Tyldum \& Brunovskis, 2005; Kelly, 2005), 
qualitative researchers have pointed out how anecdotal evidence and moral ideologies have taken the place of reliable empirical data (Chapkis, 2003; Weitzer, 2007). As a result, Musto (2009) argues that the number of individuals involved in trafficking is unknown, making representative sampling frames impossible. Similarly, research on trafficked sex workers is further complicated by the stigma associated with migrants and sex work. This is because the focus of the trafficking field has always been directed towards sexual exploitation of women and girls regardless of the fact that human trafficking can occur in various forms (Cockbain \& Bowers, 2019). Therefore, this thesis seeks to interrogate, understand and critique the premises underlying many claims about sex trafficking, as well as efforts to rescue migrant sex workers from being exploited.

The chapter begins with a discussion of the term 'sex trafficking' and explores the key debates surrounding this term. Following this discussion, the chapter will discuss the complexities of defining a 'sex trafficked victim' and identifying a trafficked victim. The second part of the chapter sets out an overview of the trafficking scene in Malaysia and discusses the demand for women in the sex industry. The harms relating to trafficking will also be discussed and analysed. The third part of the chapter sets out the objectives of the thesis, the overview of the thesis, as well as the structure of the thesis. The chapter will conclude by asserting that in a bid to protect and rescue women from being exploited, many of them are victimised in the name of 'state protection'.

The act of recruiting women for the purpose of exploitation will be referred to as 'sex trafficking' in this thesis. The term 'sex trafficking' is by no means intended to single out sex work from any other type of work. Instead, the term is used as a short form for women who have been trafficked for the purpose of sexual exploitation. The terms 'sex work' and 'prostitution' will be used interchangeably throughout this thesis although the term 'sex work' will largely be used to reflect my liberal feminist stance which respects women's desire to engage in sexual labour. This will be discussed at length in the later part of the chapter and chapter three. Terms such as 'migrant sex workers', 'migrant women' and 'women' will be used interchangeably throughout this thesis. However, terms such as 'trafficked women' and 'trafficked victim' will still be used when describing the official (state) language of trafficking. 


\section{Terms and Definitions}

The term 'sex trafficking' is commonly used to describe activities which involves trafficking for sexual exploitation. In this regard, women who are exploited for their sexual labour are commonly referred to as 'sex trafficked victims'. Scholars argue that such labelling specifically singles out sexual labour from other forms of exploitative labour (The Global Network of Sex Work Projects, 2011; Weitzer, 2007). According to them, 'sex trafficking' should be considered a form of labour trafficking because women are exploited for their sexual labour. However, in order to attract attention and support from the public, the term 'sex trafficking' has been used by governments, media and non-governmental organisations to increase ratings (particularly for media), encourage funding, and promote political support (The Global Network of Sex Work Projects, 2011; Weitzer, 2007). Debates on sex trafficking are further complicated by debates regarding migration and sex work. While there is no single definition, a migrant sex worker is broadly considered to be anyone who moves from one place to another; anyone who crosses the state borders or remains within them; anyone that may have various legal statuses; and, anyone who engages in any form of sexual or erotic service in exchange for money, food, shelter, and resources (Butterfly) ${ }^{1}$. Conversely, a trafficked sex worker would include anyone who has been forced, coerced, coerced or deceived for the purpose of commercial sexual exploitation (Chapkis, 2003).

Definitions of sex trafficking have coalesced around contested positions on issues of sex work, individual agency, and consent (Lee, 2011a). For example, sex worker organisations in Spain, Thailand, and India have argued that trafficking is an issue introduced (or imposed) from outside the industry itself, propelled by a moralistic agenda (Lepp \& Gerasimov, 2019). In this instance, anti-sex work activists seek to generate widespread public concern about the trafficking problem and lobby political elites to either intensify punishment of offenders or criminalise commercial sex (Weitzer, 2007). In response to such lobbying and advocacy, many countries have taken measures to criminalise human trafficking and illegal border crossings (The Global Network of Sex Work Projects, 2011; Weitzer, 2007). This include constant

\footnotetext{
${ }^{1}$ Butterfly - Asian and Migrant Sex Workers Support Network was formed by sex workers, social workers, legal and health professionals. It provides support to, and advocates for, the rights of Asian and migrant sex workers.
} 
surveillance on the sex industry and frequent raids on sex work establishments (Lepp \& Gerasimov, 2019; The Global Network of Sex Work Projects, 2011). However, such measures have resulted in the conflation of trafficking and the voluntary movement of women across borders for the purposes of sex work (Bertone, 2004; Chapkis, 2003). In this respect, migrant women who engage in sex work are commonly categorised as 'victims of trafficking' despite the fact they have made conscious and rational decisions to cross borders with the knowledge that they will be selling sex (Agustin, 2007; The Global Network of Sex Work Projects, 2011). Therefore, the Global Network of Sex Work Projects (NSWP) argues that that the conflation of sex work and trafficking is not a misunderstanding of terminology but is a conscious attempt to abolish sex work and prevent women from migrating for sex work (The Global Network of Sex Work Projects, 2011). This, they argue, is made evident by the anti-trafficking legislation, policies, and interventions which targets sex workers (particularly migrant sex workers) (Ibid). For example, raids that are conducted by the police are specifically aimed at 'rescuing' sex workers from establishments that provide sexual services (Ibid). In this respect, women can either be categorised as a victim or criminal. Such categorisation violates women's right to work in the sex industry, and disempowers women in sex work (The Global Network of Sex Work Projects, 2011). It also undermines sex workers' security and ability to control their lives (Ibid).

In Malaysia, and elsewhere, migrant sex workers who are 'rescued' are forced to live in 'shelters' while those who 'choose' to work in the establishments will be categorised as offenders and charged in court for two counts - as illegal immigrants and illegal sex workers (Chin, 2013; Lepp \& Gerasimov, 2019; The Global Network of Sex Work Projects, 2011). Thus, sex workers groups such as The Global Network of Sex Work Projects (NSWP) critique such form of 'rescue' and argue that the raids on workplaces and establishments that offer sexual services are carried out in the name of trafficking but are aimed at eradicating sex work (The Global Network of Sex Work Projects, 2011). It is argued that such forms of 'rescue' create fear among migrant sex workers and isolate them from the mainstream society and generates distrust towards authorities (Ibid). As a result, women are forced to work in less safe environments (Ibid). Women may also become suspicious towards national sex worker organisations because they may feel that these organisations are acting as informants for immigration, or are simply masquerading as 'rescuers' (Ibid). This compromises women's 
access to support and services (Ibid). Thus, the sex worker rights movement (particularly in the global south) have continuously demanded recognition of sexual labour as labour: they challenge stigma, discrimination and all forms of violence, including by law enforcement; they seek to improve working conditions; lobby for full human, social, and labour rights; advocate for the decriminalisation of sex work; and provide peer-based support and services (Lepp \& Gerasimov, 2019). According to them, any policy designed to fight human trafficking must extend beyond criminalising traffickers to reinforce the rights of immigrants and workers (Ehrenreich \& Hochschild, 2002).

However, anti-trafficking laws in some countries may only define human trafficking in a particular context such as trafficking for the purpose of sexual exploitation or cross-border trafficking (M. Lee, 2011a). Such narrow definitions becomes even more complicated when it involves migration for the purpose of sex work (A. Jordan, 2001). As a result, there has been multiple, sometimes oppositional, and shifting understandings of sex trafficking (Lee, 2011a). Thus, Dunne (2012) argues that the different understandings of sex trafficking create confusion as attention is drawn away from the 'real victims of trafficking' towards voluntary sex workers. It also allows trafficking activities to flourish because of the multiple understanding of sex trafficking (Dunne, 2012).

Therefore, many sex worker groups argue that it is important to demarcate sex work and sex trafficking clearly (Healy, Bennachie, \& Marshall, 2012). This is because conflating sex work with trafficking infantilises women and portrays them as dependents without agency and decision-making power (Howard \& Lalani, 2008). Nevertheless, the confusion between sex work and trafficking remains a barrier to effective responses and identification of trafficked persons (Empower Foundation, 2012). Furthermore, there is a lack of clear structures on victim-identification and referral in many countries (M. Lee, 2011a). This shows that the policy and ideological contexts within which trafficking is considered are complex and ambiguous (Natalie, 2017). As a result, state officials are given a wide discretion to assess and identify victims of trafficking. Within this, many voluntary sex workers are misidentified as being 'trafficked' and some women who are 'trafficked' have been misidentified as 'voluntary sex workers' because they do not display the image of a stereotypical victim. 
Kempadoo, Sanghera \& Pattanaik (2015) argue that the lack of reliable data available on trafficking and the lack of conceptual clarity have both facilitated the perpetuation of stereotypes. According to Andrijasevic \& Mai (2016), '[t]he stereotypical image of the victim is of a young, innocent, foreign woman tricked into prostitution abroad. She is battered and kept under continuous surveillance so that her only hope is police rescue' (p.4). In mainstream media, journalists typically rely on stereotypical stories of horrendous abuse, torture, and exploitation as it 'guarantees a wider audience' in the fight against present injustice (Anker, 2004). This is because such stories could capture the attention of the public and policy makers and justify draconian solutions (Cwikel \& Hoban, 2005; Weitzer, 2007). Although there are cases of horrendous abuse (Kelly, 2003), the use of highly emotive images does not capture or reflect the ambiguous realities of the womens' lives and the purpose of their involvement in sex work (Lepp \& Gerasimov, 2019). Besides, many women are well aware of the nature of their job and have voluntarily migrated for the purpose of sex work (Cwikel \& Hoban, 2005). As Zimmerman and Watts (2003) notes that 'not all women who have been trafficked are traumatised, consider themselves victims, detest their captors, or wish to escape or go home (p.3).' On the contrary, women may view their 'traffickers' or 'recruiters' as employers or friends who have given them the opportunity to work abroad and earn an income. Therefore, this thesis will demonstrate that that not all women would identify themselves as victims of trafficking because some women may have voluntarily migrated to Malaysia to work in the sex trade.

\section{Defining Sex Trafficking}

As the above discussion highlights, sex trafficking is a complex form of crime that occurs within and across national borders (Segrave, 2013; Siddharth, 2017; United Nations Office on Drugs and Crime, 2019). Sex trafficking involves the recruitment, transportation, harbouring and/or exercising the control, direction or influence over the movements of a person in order to sexually exploit that person (International Labour Office, 2014; Segrave, Milivojevic, \& Pickering, 2009, p. 154; United Nations Office on Drugs and Crime, 2019). In most cases, the flow of movement is along the following lines: from rural areas to cities; from poor nations to relatively more affluent ones; and from less developed countries to developed countries (Samarasinghe, 2008; Wickramasekara, 2002). In this context, human beings are treated as 
possessions to be controlled and exploited in the commercialised sex industry (United Nations Office on Drugs and Crime, 2019).

Human trafficking is the second main source of illicit profits for organised crime (European Commission, 2010) with a 'yearly turn-over estimated at anywhere between 100 million Euro to several milliards of euros' (Lehti \& Aromaa, 2006, p. 188). The International Labour Organisation (2014) estimated that USD150.2 billion in illegal profits are generated per year from the use of forced labour worldwide. From this amount, USD99 billion came from commercial sexual exploitation, while the remaining USD51 billion was derived from forced economic exploitation including domestic work, agriculture and other economic activities (Ibid). Given the lucrative profits and exploitative nature of trafficking, this crime has been regarded as a crime against humanity in the Rome Statute of the International Criminal Court (Article 7.2c).

The 'Protocol to Prevent, Suppress and Punish Trafficking in Persons, Especially Women and Children' (the Palermo Protocol) which is attached to the United Nations Convention Against Transnational Organized Crime (TOC) is the first international anti-trafficking agreement treaty. It aims to address this transnational crime with tough law enforcement and victim protections. At present, the understanding of trafficking is highly gendered, racialised and limited to the sex work sector (Ham \& Pickering (2013). Within this United Nations focus on sexual exploitation, an emphasis is placed on women and children on account that they are primary victims (Agustin, 2005; Segrave et al., 2009; United Nations Office on Drugs and Crime, 2019). However, current knowledge based on sex trafficking is still exceptionally limited (Gan, Ha, Kao, \& Poch, 2014; Greenbaum \& Bodrick, 2017; Kelly, Lovett, \& Regan, 2005) particularly in Southeast Asian countries such as Malaysia (Sugimura, 2016). There is also an absence of women's voices and a shortage of empirical studies on trafficked women's lived experiences (Agustin, 2010; Gozdziak \& Collett, 2005; Kelly et al., 2005; Salt, 2005). This study offers an insight into trafficked women's lives and fills the research gap in the trafficking literature.

The current rhetoric in cases of trafficking 'reifies the same picture of the monolithic woman as pure victim, one who must be protected from "evil" and "predatory" forces because she is 
incapable of any acts of agency to defend herself' (Picart, 2003, p. 97). This is because prevailing official discourses on an 'ideal' victim demarcate agency on the opposing path from victimhood. This opposing path is disadvantaging and disempowering of women's capacity and achievement of agency within a trafficking experience. Therefore, this thesis disputes the monolithic representation of an 'ideal victim' and challenges the victim-agent binary that divides women into either agents or victims (Roces, 2009). Despite common understandings, agency and victimisation can intersect and occur simultaneously. As Moser \& Clark (2001, p. 5) put it:

The notion of agency attributes to the individual actor the capacity to process social experience and to devise ways of coping with life, even under the most extreme forms of coercion. Within the limits of information, uncertainty and other constraints that exist, social actors are 'knowledgeable' and 'capable'.

The thesis argues that women's agency oscillates between the extremes of a vulnerable victim to the most powerful agent. However, state authorities do not recognise women's oscillation of agency and consider agency incompatible with their victim status. In this instance, state authorities presume that women are weak, powerless, helpless and in need of rescue. Such presumption stems from anti-prostitution discourses that are often premised on ideas about vulnerability and the inability of women to consent to sex work (Ham \& Gerard, 2013). In these discourses, expressions of agency negate women's credibility to speak as sex workers (Lyon, 2011). Therefore, Ham \& Gerard (2013, p.301) argues that 'sex workers who assert themselves are considered not to be "real" sex workers because "real" sex workers are unable to assert themselves. Thus, the definition of agency as an inherent human capacity (rather than a quality that only some people have) is a more useful tool in analysing women's power in sex work.' Agreeing with Ham \& Gerard's contention, this thesis demonstrates how women identify themselves as (and often are) strong, independent, active agents, who are caught in the sex trafficking trap or who have been cheated out of money owed to them for their labour (Altink, 1995; A. Jordan, 2002). The anti-sex work perspective, which often refers to sex work as 'prostitution', centres around the morality of sex work in a commercial exchange while liberal feminists (advocates of the 'sex work is work' perspective) are less concerned with the 
moral implications of commercial sexual exchange and more concerned with women's autonomy and rights as workers. Therefore, this thesis adopts the liberal feminist approach and recognises sex work as a legitimate form of labour.

Women's experiences of harms during the 'post-rescue' phase have also received scant attention (Brennan, 2016). Studies that focus on the criminalisation of trafficked women mainly concentrate on the misidentification of trafficked women as offenders (Farrell, McDevitt, \& Fahy, 2010; Finn, Muftić, \& Marsh, 2015) while research on the harms emerging from victim-protection enforcement (rescue, shelter, judicial process) is relatively minimal. This is because those who are in state custody are generally presumed to be well protected. However, current practices clearly show that women are subjected to a plethora of rules, laws and policing before they can be repatriated. Therefore, this thesis investigates the effectiveness of anti-trafficking laws and its victim protection policies towards migrant women in Malaysia.

\section{Overview of Sex Trafficking in Malaysia}

Malaysia is a multicultural society, predominantly composed of a Muslim majority population. Islam is the official religion of Malaysia and the country practices a dual system of law, which enforces the 'sharia' (Islamic law) and the civil law to all Muslims (Article 121A of the Malaysian Federal Constitution). However, the sharia law is only limited to matters relating to matrimonial affairs, inheritance, custodianship and sexual offences such as khalwat (close proximity between man and woman who are not lawfully married or related through blood line), zina (sexual illicit intercourse), transgenderism, cross dressing and other sexual-related offences. Although the sharia law only applies to Muslims, Islam plays an important role in shaping government policies and strategies relating to sex and morality. Thus, sex work is considered 'immoral', and transgresses the definition of 'normal' or acceptable sexual activities. Despite the prohibition on sex work, Malaysia has been categorised as a destination, transit and source point for sex trafficking in Asia by the 'United States Trafficking 
in Persons Report”2 (TIP Report) and the 'United Nations Office on Drugs and Crime' (UNODC). However, the extent of the sex trade is difficult to assess because it operates illegally and is often underground. Current victim-protection policies deprive women of their fundamental rights because sex work is not regarded as a 'moral' and legitimate job. In this instance, their access to the justice system is severely limited, and their experiences of victimisation are often negated because of their irregular status. This means that they will be detained, fined, and deported without any access to services or redress. Despite such restrictive laws, the trafficking activities in Malaysia continue to flourish and the volume of migration into Malaysia continues to intensify. Thus, the following section will discuss the causes of migration as well as the harms related to trafficking in order to understand the extent of human trafficking in Malaysia.

\section{Patterns and Causes of Migration}

Malaysia is considered a middle-income country, and relatively prosperous compared with most other Southeast Asian countries (Rinehart, 2015). With a diverse ethnic and religious mix, Malaysia has enjoyed considerable political stability since it gained independence in 1957 and has become one of the major host countries in the Southeast Asian region for transnational migration since the 1990s (Kassim \& Zin, 2011b; Rinehart, 2015). Its strategic geographical and maritime location in the centre of the Southeast Asian region, highly open economy, small and affluent population, similar ethnic heritages with neighbouring countries, and global oriented economic policies have exposed the country to long-distance commerce and migration (Kassim \& Zin, 2011b). The urbanisation and employment policies through its New Economic Policy ${ }^{3}$ which sought to improve the socio-economic position of Malaysian citizens, have created a cheap labour force, which is highly dependent on foreign workers (Garce's-Mascaren, 2008). In this context, the employment of migrant workers from

\footnotetext{
2 The TIP Report is the US Government's principal diplomatic tool to engage foreign governments on human trafficking. Worldwide, the report is used by international organisations, foreign governments, and nongovernmental organisations as a tool to support survivors, prevent trafficking, and bring traffickers to justice. ${ }^{3}$ Malaysia's New Economic Policy (NEP) was announced in 1970 as part of a package of measures introduced after the political crisis of May 1969. It sought to 'eradicate poverty' and 'restructure society to eliminate the identification of race with economic function' to create the conditions for national unity. The NEP has been principally associated with 'restructuring', i.e. efforts to reduce inter-ethnic economic disparities between Bumiputera (Malays) and the non-Bumiputera, especially between ethnic Malays and Chinese (Jomo, 2005).
} 
neighbouring countries has underpinned economic growth and prosperity (Ibid). This resulted in a surge of employment opportunities and an influx of migrant workers into Malaysia in the 1990s.

According to Kaur (2010), the population of migrants mainly consists of nationals from Indonesia, Thailand, Cambodia, Nepal, Bangladesh and Philippines as well as other Asian countries. While some workers have entered and worked in Malaysia legally, others have entered Malaysia illegally or overstayed. Although it is impossible to assess the number of illegal migrants in the country (Ibid), the Human Resources Ministry reported that the number of overstaying illegal foreigners in 2016 was around three million (Lek, 2016). Malaysian Trades Union Congress president Datuk Abdul Halim Mansor further reported that there were about four million foreigners working illegally in various industries in 2018 (Yusof \& Shah, 2018). Migrants with irregular status include trafficked victims, undocumented migrants, refugees, asylum seekers and illegal migrants ${ }^{4}$ (Idris, 2012; Larsen, 2010; Tenaganita, 2012; United Nations Office On Drugs And Crime, 2015a, 2015b). At present, illegal migration seems to be an advantage to the migrant workers as it is faster, cheaper and less constrained than legal migration to Malaysia. This is because the Malaysian government regulates immigration entry through elaborate administrative frameworks that focus on border control while brokerage firms and labour recruiters carry out recruitment, transportation and placement of migrant workers (Kaur, 2006a, 2006b). These agents and recruiters actively recruit workers and promote employment opportunities by promising migrants good jobs and well paid incomes. As a result, there has been an unabated increase in the inflow of migrant workers who are attracted to the attractive wages in Malaysia.

\section{Demand}

Contemporary theories of international migration suggest that people move because of expected improvements that might include higher wages, employment, health and education. From an economic perspective, migration occurs because of the supply and

\footnotetext{
${ }^{4}$ Irregular migrants in this thesis refers to people who have travelled across state borders without authorisation and/or who, even after travelling with authorisation, have stayed in a state against the terms of that authorisation (Meyer \& Boll, 2018).
} 
demand of labour (Walmsley, Aguiar, \& Ahmed, 2013). Similarly, in trafficking, factors such as poverty, unemployment, gender disparities, low wages and political instability are characterised as 'push' factors while the demand for labour is categorised as a major 'pull' factor. The United Nations Statistics Division (2015) reports that women across the globe are more likely to be poorer than men when they have dependent children and do not have any partners to contribute to the household income or when their own income is non-existent or too low to support the entire family. Due to these circumstances, women are often compelled to migrate within or outside the country for better economic opportunities (Laczko \& Danailova-Trainor, 2009; Ryan \& Hall, 2001). However, women are generally less able to secure legal migration as are often unable to meet the administration demands from receiving states (qualifications and skills-sets) which makes women especially vulnerable to illegal migration (Orlova, 2004). Traffickers take advantage of women coming from this situation as they are considered low risk, able to generate lucrative profits, and will not raise too much alarm if they are deceived and exploited. This is because the demand for women has become a major 'pull' factor in the proliferation of sex trafficking.

The sex industry depends on the volume of demand and the supply of women (Cauduro, Nicola, Lombardi, \& Ruspini, 2009; Farley \& Seo, 2005; Grant, 2012; Kara, 2009; Marmo \& Forgia, 2008; Piper, 2005). The significance of demand is contained in Article 9 of the Palermo Protocol which calls upon nation states to reduce demand for trafficked labour (O'Brien, Hayes, \& Carpenter, 2013). The demand for women mainly comes from male clients as they come into direct contact with women (Anderson \& Davidson, 2003). This is echoed by Raymond (2004) who argues that demand is gendered and specifically fuelled by men. However, their identities remain concealed and kept with utmost secrecy (Hughes, 2005). Nevertheless, research shows that customers who purchase sexual services from females (for sexual gratification, entertainment and violence) are men of all ages, ethnicities, nationalities, and socio-economic backgrounds (Flowers, 1998; Hughes, 2005; A. Jordan, 1993; Sanders, 2008).

Such practices and perceptions stem from the deeply rooted patriarchal attitudes which are based on the belief that men are sexually entitled to women's bodies because of their 
biological need for sex, even if it involves degradation to obtain it (Perrin, Majumdar, Gafuik, \& Andrews, 2001). This illustrates a culture that tolerates or promotes sexual exploitation (Lagon, 2007; Smith \& Vardaman, 2010). It also shows the different levels and expressions of gendered power (Samarasinghe, 2008; VeneKlasen \& Miller, 2002), a point reflected in the relatively poor women who are lured into sex trafficking on the one hand, and the generally economically secure male customers who buy their services on the other (Samarasinghe, 2008). Men from wealthier countries create the demand for women to be used in the sex industry while women from poorer countries are being trafficked to service them (Kara, 2009; Samarasinghe, 2008). This is particularly significant in developing countries where women are regularly confronted with problems of poverty, unemployment, unequal or low wages, and cultural and religious restrictions (Austin, 2017; Habtezion, 2012). Due to these circumstances, women can be compelled to migrate within or outside the country for better economic opportunities (Laczko \& Danailova-Trainor, 2009; Ryan \& Hall, 2001) since many wish to escape the situation and perceive that there are no other options available to them. Consequently, many are victimised and trafficked into the sex industry (Ibid). This shows how continued disadvantage, poverty, unemployment and other factors serve as potent elements that push and pull women from their home countries towards others and invariably into the hands of traffickers (or others) waiting to exploit them (Kragten-Heerdink, DettmeijerVermeulen, \& Korf, 2017). Thus, for many women, there is a gradation of harms that continue throughout their lives (Ibid).

According to Hughes (2005), demand occurs when pimps are unable to recruit enough women to fill up the brothels, particularly in countries where sex work thrives. In this situation, pimps will have to bring in women from other places because pimps and traffickers need a steady supply of women to stay in business (Hughes, 2005). While some sex workers may work independently, many others are controlled by pimps (Williamson \& Cluse-Tolar, 2002). In this instance, the term 'pimp' itself have been highly contested by scholars and sex work advocates (Davis, 2013; Pheterson, 1993; Stella, 2013). For example, Pheterson (1993) argues that the definition of a pimp as someone who controls women and lives of their proceeds (Hughes, 2005; Williamson \& Cluse-Tolar, 2002) can be interpreted to include partners, boyfriends and even the male children of sex workers while excluding female pimps and male sex workers. Thus, identifying only some as pimps and neglecting other individuals who are 
pimps (Davis, 2013; Pheterson, 1993). Furthermore, the term 'pimp' does not recognise the range of third party roles, the services they provide nor the relationships they have with sex workers (Stella, 2013)5. In many instances, sex workers maintain a working relationship with the pimp or third parties for various purposes such as for advertising, driving, booking and maintaining clients or providing security. However, for the purpose of this thesis, the use of the term 'pimp' and 'trafficker' will reflect a particular relationship of coercion where an individual has direct control over a woman's work that will often, though not necessarily, involve financial exploitation and violence.

According to Hughes (2005), a pimp can only use a woman for a limited period of time before she needs to be replaced, usually because of poor physical or mental health or addiction. Therefore, pimps will place orders for women with their agents/recruiters who will lure women with promises of legal jobs and a cash advance, which are sometimes paid directly to the women's parents (Ibid). The tactics and psychological manipulation used by agent/recruiters to entice women into the sex trade have led to a call by anti-trafficking advocates and abolitionist activists to address the demand for sex workers (Baldwin, Fehrenbacher, \& Eisenman, 2015; Levy \& Jakobsson, 2014). This includes making men personally responsible and accountable for their behaviour because they are the ones that create the demand for sex workers (Hughes, 2005).

According to Aronowitz and Koning (2014), there is a general consumer demand for sex workers which is sometimes met by trafficked women. However, this does not mean that clients prefer to purchase the labour of trafficked women, but because trafficked women sometimes possess certain specific characteristics that are demanded by men (Aronowitz \& Koning, 2014). The demand may be for women from certain countries, ethnic groups or ages (particularly young children) or having a certain attribute (being a virgin) (Ibid). In this regards, the question of whether States are required to criminalise the use of the services of a victim of trafficking is unsettled (Gallagher \& Karlebach, 2011). Although the Palermo Protocol does not mention an obligation to criminalise, the European Trafficking Convention requires States Parties to consider criminalising the knowing use of the services of a victim of trafficking (Ibid).

\footnotetext{
${ }^{5}$ Stella is a community organisation based in Montreal, Canada and was created and run by and for sex workers (www.chezstella.org).
} 
The European Trafficking Directive for example, requires Member States to consider the possibility of imposing sanctions on the users of any service exacted from a victim, with the knowledge that the person has been trafficked (Ibid). The preamble to the Directive notes that such further criminalisation could cover the behaviour of employers of legally staying third-country nationals, as well as buyers of sexual services from any trafficked person, irrespective of their nationality (Ibid). In this regards, Sweden has introduced a sex purchase law or locally known as 'sexköpslagen' or the Swedish/Demand/Nordic Model since 1999 (Levy \& Jakobsson, 2014) where paying for sex is defined as a form of 'sexual abuse' (Harrington, 2005).

The Nordic model aims to abolish sex work through targeting the demand, while decriminalising those selling sex in an effort to protect sex workers (Ibid). The Nordic Model criminalises the purchase of commercial sex and offers women and children an exit strategy (Coalition Against Trafficking in Women, 2011). The Nordic Model has also been passed in Norway in 2009, Iceland in 2009 (Ibid), Canada in 2014, Northern Ireland in 2015 and France in 2016 (McMenzie, Cook \& Laing, 2019). However, the Nordic Model has been widely critiqued by scholars who argue that the Nordic model is merely a transfer of 'rhetoric and ideology' (Kingston \& Thomas, 2018, p. 423). Based on a research conducted in Sweden, Levy \& Jakobsson (2014) argue that the Nordic model law has failed to decrease levels of sex work, since there are no reliable data demonstrating any overall decline in people selling sex. Instead, the law has resulted in increased danger in some forms of sex work (particularly street-based sex workers) because women have less time to negotiate their transactions with clients before getting into a vehicle or leaving the street with the client to avoid police detection (Levy \& Jakobsson, 2014). Consequently, sex workers have less time to assess the potential risk of a client, to negotiate which services are to be provided, and to negotiate payment (The Global Network of Sex Work Projects, 2015).

While Sweden, Norway, Iceland, Canada and North Ireland continue to impose its sex purchase law, other countries particularly in Malaysia continue to criminalise sex workers including those who have been trafficked. Thus, the United States (US) has occasionally criticised the Malaysian government for its weak human rights protections, poor record on combatting human trafficking, and poor victim protection policies and has placed Malaysia at 
Tier Two Watchlist in its 2018 TIP Report. This is despite the fact that United States (except for some cities in state of Nevada) criminalises sex work and do not recognise the legal status of sex work (Gards, 2019). Malaysia's past records can be seen in Figure 1.

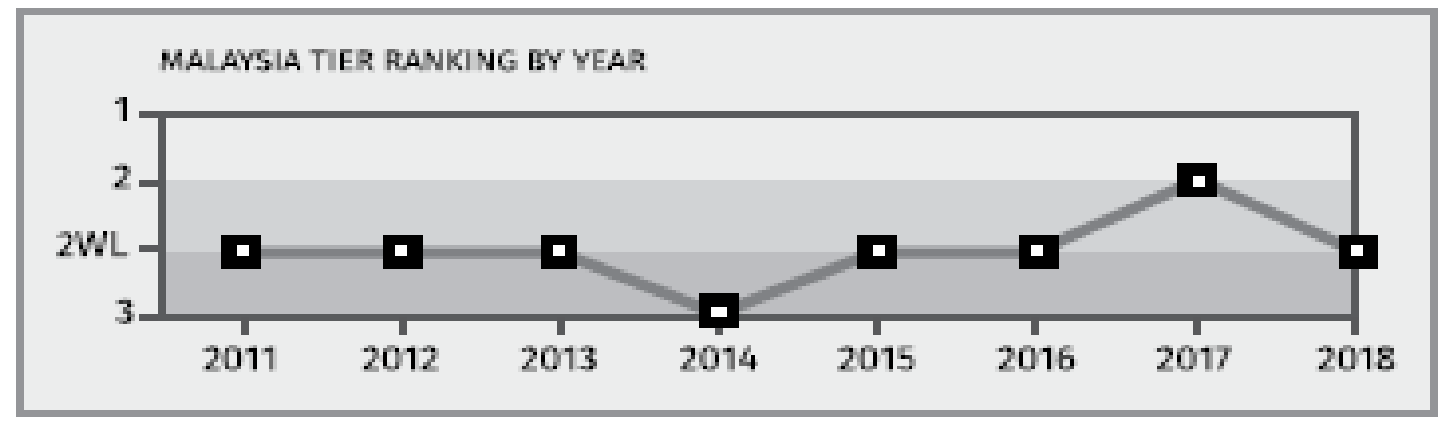

Figure 1: Malaysia Tier Ranking by year according to the 2018 US TIP Report

(U.S Department of State, 2018)

Figure 1 shows the US Tier ranking accorded to Malaysia from 2011 to 2018. In the TIP Report $^{6}$, the US Department of State places each country onto one of three tiers based on the extent of their governments' efforts to comply with the 'minimum standards for the elimination of trafficking' found in Section 108 of the Trafficking of Victims Protection Act 2000 (TVPA). The vertical line (left) shows the Tier ranking and the horizontal line shows the year. As seen in Figure 1, Malaysia's has been placed at Tier Two Watchlist in 2018 from Tier Two (in 2017) because of the poor standard of protection for victims as well as the ineffective strategies in combating human trafficking.

A Tier One ranking indicates that a government has acknowledged the existence of human trafficking, made efforts to address the problem, and complies with the TVPA's minimum standards. Tier Two ranking indicates countries whose governments do not fully comply with the TVPA's minimum standards but are making significant efforts to bring themselves into compliance with those standards. Tier Two Watchlist indicates countries that have failed to show their commitments or made significant efforts to combat human trafficking. This

\footnotetext{
${ }^{6}$ The US Department Office to Monitor and Combat Trafficking in Persons (USOMCT), undertakes a role to review trafficking internationally by assessing and ranking individual countries according to their policy responses and implementation outcomes, and by publishing the findings in the TIP Report annually. The assessment and monitoring of efforts are measured against US-defined minimum standards for the elimination of trafficking. These standards are seconded within the TVPA.
} 
includes the increasing number of victims, lack of investigation, prosecution, low number of convictions as well as poor victim protection policies. Tier Three ranking is the lowest ranking, which indicates countries whose governments do not fully comply with the minimum standards and are not making significant efforts to do so (U.S Department of State, 2018). Although the US has been criticised for its tier ranking, ${ }^{7}$ US defined norms have played a significant role in influencing governments to introduce anti-trafficking laws and policies (Carrington \& Hearn, 2003; Coomaraswamy, 2003). The weight of this review and assessment process has been sustained through the sanctions regime established within the Trafficking Victims Protection Act (2000) (TVPA). This authorises the withdrawal of financial assistance (excluding trade-related and humanitarian assistance) from countries that fail to comply and show no signs of addressing failures (Ibid). In light of such rankings and reports, this thesis discusses the actual state of Malaysia's victim protection policies as well as the treatment accorded to women are categorised as trafficked. The study explores how women are victimised through state policing, and the continuum of harms women are subjected to during state protection processes. Thus, the following section will demonstrate the types of harms inflicted on women throughout the trafficking process and the state's response in addressing those harms.

\section{Harms}

Since 2001, sex trafficking activities have gained notoriety in Malaysia (U.S Department of State, 2001) due to the high demand of sexual services, restrictive immigration policies, as well as the state's repressive treatment towards migrants with irregular status (Lyons \& Ford, 2013; U.S Department of State, 2015, 2016). The long-term exposure to physical threats and psychological manipulation instils fear in trafficking victims and facilitates the trafficker's ability to exert control over victims (Adams, 2011). Many women are also at high risk of unwanted pregnancy and sexually transmitted infections (STIs) (Prince et al., 2007; Cathy Zimmerman, Hossain, Yun, \& Watts, 2008). Women may also fear local police who may be complicit in trafficking and forced labour/slavery-like practices (Cathy Zimmerman, Hossain,

\footnotetext{
${ }^{7}$ The US TIP Report has been greatly criticised by nation states (Malaysia included) for being heavily political in nature and their biased assessment of countries (Hamid, Aziz, \& Amin, 2018).
} 
\& Watts, 2011). In these circumstances, women may fear the authorities as they are often told that they will be imprisoned, deported, or tortured if discovered by the police (M. Lee, 2014; Logan, Walker, \& Hunt, 2009; Z. Othman, 2006). Although the ATIP provides protection and immunity to victims of trafficking from being prosecuted for immigration offences, it also restricts immigration by prosecuting 'illegal entries', punishing migrants, and repatriating trafficked persons (M. Lee, 2014). Furthermore, current immigration practices focus on criminalising rather than protecting the migrant labour force (United Nations Human Rights Council, 2015). Therefore, redress for criminal offences perpetrated against migrants is unlikely as migrants would be at risk of being arrested if they attempted to lodge a report against their employers (Malaysian Bar Council, 2009). This indicates that 'illegal migrants' are at risk of being abused and exploited, not only by the traffickers/employers but also by the authorities (The Coalition of Malaysia NGO's in the UPR Process, 2009).

There are also instances where women may not have felt victimised by their employers/ traffickers but felt victimised by the police and state authorities for rescuing them and placing them under state protection. Women who have been rescued are exposed to physical harms, humiliation and trauma in police custody (Gallagher \& Pearson, 2010). After having experienced a range of previous violations, as a consequence of being trafficked, these new harms can have profound psychological impacts (Coomaraswamy, 2003), including excessive stress and even suicidal tendencies among women who have been 'rescued' (Huda, 2006). Therefore, the victim protection mechanisms in Malaysia have been heavily criticised by the United Nations and non-governmental organisations for violating human rights principles (Gallagher \& Pearson, 2010; Lyons \& Ford, 2013). These concerns are most readily identified in the law enforcement frameworks and the use of 'shelters' for those who are rescued.

\section{Objectives of the Study}

The purpose of this study is to provide a critical review of migrant women's experiences of the victim protection policies in Malaysia. Within the analysis, this thesis explores the notion of agency and examines the relationship between agency and women's victimisation. In this context, discussions will show how women's agency oscillates between the extremes of a 
vulnerable victim to the most powerful agent. It will also demonstrate how some women were able to exercise agency more than others and that women experience victimisation differently. Therefore, this thesis will show how women can exercise greater choice and agency in some contexts compared to others. The thesis argues that women's experiences of victimisation are diverse and that a monolithic understanding of agency and victimisation does not exist in reality. Thus, this thesis challenges some of the current language and terminology in the literature on trafficking and calls for a more nuanced understanding of the relationship between agency and victimisation.

As well as this, the thesis analyses the effectiveness of the anti-trafficking laws in protecting migrant women from further harm. Although the state is presumed to be the protector of women, existing literature has indicated that women can be harmed through 'state protection' (Hales \& Gelsthorpe, 2012; Segrave, 2009). This is because migrant women are often viewed through the lens of immigration, sex work and crime, which positions them both as victims and as criminals. Considering this fact, the thesis investigates how women are represented by media and harmed through 'state protection'. It explores how anti-trafficking laws and the criminal justice system, which forms the basis of the victim protection framework, penalises women, and fails to respect their rights under international and domestic laws. It challenges the perception of the 'ideal trafficked victim' who is deemed to be weak, powerless and deprived of agency. The findings of this study provide a comparison between stereotypes and reality, and challenge the victim-agent dichotomy as well as the understanding of state protection. Therefore, the thesis demonstrates the tension between choice (voluntary sex work) and coercion (trafficked sex work). It discovers the nuances and commonalities of women's migration and trafficking experiences, and exposes how the notion of 'protection' is used as a euphemism for state control.

\section{Thesis Overview}

Current stereotypes depict victims of human trafficking as innocent young girls from foreign countries who are manipulated, lied to, and often kidnapped and forced into sex work, and are eager to be rescued. However, research suggests that some women who have been 
identified as 'trafficked victims' may not identify themselves as 'victims' (Pickering, 2011; Segrave et al., 2009) and may not want to be 'rescued'. Therefore, this thesis reflects on the stereotypical images of trafficked victims (weak, passive, innocent, lacking agency, and wanting to be rescued) with how women in this study perceive their victim identity and migration experiences. It investigates how women were able to exercise their agency even when they were being forced or coerced into sex work and had limited choices.

The decision to specifically focus on women's agency and victimhood in this study emerged from the literature on sex trafficking, particularly on how sex workers can be regarded as either victims or offenders. This is based on the approach taken towards sex work and whether sex work is legalised or criminalised in a particular state. Besides the legality of sex work, I was also interested in exploring the relationship between victimisation and agency and exploring the links between the two. This is because migrant women (in particular) who engage in sex work are sometimes categorised as trafficked, regardless of the fact that they have consented to work in the sex industry. As a result, sex work is considered exploitative, regardless of the women's decision. To investigate and understand the relationship between agency and victimhood, the study focuses on two main research questions:

- $\quad$ How do women who are presumed to trafficked by the state officials perceive their victim-agent identity?

- How are migrant sex workers in Malaysia treated once they have been 'rescued' and how do they experience their official processing as 'trafficked women'?

The way trafficked women are portrayed in the Malaysian media appears to be unrealistic and does not make sense to me. On the one hand they are depicted as women in need of help, but on the other hand they are presented as 'immoral' individuals who need to be arrested and incarcerated (Dempsey, 2015; Malloch, 2015). This representation became clear after seeing women being escorted by police and chained together in the Magistrate's court in Malaysia. I could not understand why they were chained together and treated like criminals although they were said to be victims of trafficking. Based on these observations, I conducted my own research at the Malaysian Bar library (which I have access to as a lawyer), and 
discovered that victims of trafficking are immune from being prosecuted on violation of immigration and passport related laws under the Anti-Trafficking in Persons and Anti-Migrant Smuggling Act 2007 (ATIP). However, the ATIP and the Palermo Protocol do not define the word 'victim' and do not contain any clear guidance on victim identification. There was also no specific provision giving trafficked women the option to refuse state protection nor prohibit the state from placing victims in shelters or immigration detention centres. Further research also showed that victims of trafficking continue to be detained across the globe in prisons and immigration detention centres despite the guidelines and principles contained in international treaties ${ }^{8}$ (Malloch, 2015). Based on these findings, I decided to pursue my doctorate degree, and identify the flaws and weaknesses of the anti-trafficking laws that have victimised women.

From this PhD journey, two major issues became evident. Firstly, that women's agency is often irrelevant when it involves sex work. Such a perspective supports the pro-abolitionist movement which believes that sex work is not a legitimate form of work and women are not capable of consenting to sex work. Therefore, women who voluntarily engage in sex work are presumed by state officials to have consented out of naivety or passivity and are unaware that they are being exploited. Thus, stereotypes of trafficked victims are created by the state to satisfy societal beliefs on how women should behave and act. These beliefs are based on moralistic, cultural, and religious principles rather than the actual experiences of women. The state is authorised to make its own assessment and guidelines on determining who amounts to a trafficked victim. Common assessment is based on the assumption that agency is incompatible with victimhood and therefore a woman cannot exercise her agency if she is being trafficked. Therefore, I wanted to identify, analyse and understand issues relating to trafficked women's agency and their victim identity.

Secondly, that the criminalisation of traffickers by the state has by extension criminalised migrant women. Despite being categorised as victims, media, state officials such as the police,

\footnotetext{
${ }^{8}$ This refers to the United Nations 'Recommended Principles and Guidelines on Human Rights and Human Trafficking' (2002) (see Chapter Four), The Universal Declaration of Human Rights (UNDHR), and the United Nations Convention on the Elimination of all forms of Discrimination Against Women (CEDAW) which seeks to ensure that women's rights are protected (see Chapters Two and Eight).
} 
immigration, and politicians represent migrant women as 'promiscuous' and in need of rehabilitation because of their involvement in sex work. This justifies the need for women to be 'rescued', incarcerated and repatriated. Such policing conducted in the name of 'victim protection' does not reflect the true meaning and concept of 'protection'. Instead, the notion of 'protection' is just used as a euphemism for state control.

Based on the above foci, this thesis reflects on the ways in which trafficked women are represented and perceived by society. Although trafficked women are portrayed as victims in need of care and protection, they are also portrayed as individuals who have violated immigration laws and engaged in 'immoral' acts. Therefore, this thesis demonstrates how the enforcement of victim-protection policies is carried out in contradictory ways in Malaysia. Punitive practices - including 'state and rescue' operations and long-term detention - have been legitimised and branded as 'victim protection'. In this context, the thesis argues that current policies and practices represent a continuing form of violence against women in Malaysia. The thesis also contributes to the understanding of women's agency and how their agency operates even under the most extreme forms of coercion (Moser \& Clark, 2001). It contends that the victim-agent binary is flawed because women are still capable of exercising their agency even when they are trafficked. Given this, state protection does not necessarily serve the interest of women and, to some extent, harms women.

\section{Structure of this Thesis}

The following Chapter Two explores the meaning of the term 'victim' and how victims are socially constructed. It examines the multiple meanings of 'victim', focusing on how harms and victimhood are often portrayed. It establishes that the construction of victimhood has focused on homogenising women as victims, especially when referring to specific categories of women, such as those depicted as trafficked women. For women to be subjectively construed as victims, they need to be seen as passive, weak, helpless and devoid of agency as the exercise of personal agency raises doubts concerning their victimhood (Christie, 1986; 2007; Wijk, 2013; Wilson \& O'Brien, 2016). Although research shows that these stereotypes are untrue, such imagery is still used as a benchmark in determining the innocence and 
culpability of a victim. Thus, this thesis rejects and challenges stereotypes of victims and explores the complexities of women's victimisation experiences. Chapter Two also explores the victim-agent dichotomy and examines how oppressive gendered institutions constantly restrict women's agency. In this regard, states institutions often reproduce patriarchal attitudes, which normalise harmful patriarchal practices. These practices have, to a certain extent, become problematic because they create an idealised version of a victim, which inhibits the understanding of women's real lived experience of victimhood.

Chapter Three discusses the social and legal constructions of sex trafficking and the harms associated with trafficking. The chapter demonstrates the ambiguity of certain terms associated with trafficking practices, such as 'coercion' and 'exploitation' which have resulted in multiple interpretations and understandings of trafficking. It examines the relationship between agency and victimisation in sex trafficking and how state authorities perceive agency to be incompatible with victimhood. In this regard, the chapter demonstrates how antitrafficking laws can be used as tools to override women's consent and agency. For instance, trafficked women's consent is regarded as irrelevant under the Palermo Protocol. While such provisions may be enacted to safeguard women from being blamed by their traffickers, it has also overriden women's right to agency and consent. In Malaysia, women are forced to live in shelters and become witnesses for the prosecution. Thus, the chapter argues that women are victimised by different actors and state institutions in the name of protection and that women's agency can be overridden by the state in order to enforce state control.

Chapter Four analyses the proliferation of sex trafficking activities in Malaysia with a specific focus on local cultures, trafficking routes, and the role of traffickers. It provides an overview of how sex trafficking operates in Malaysia and how traffickers cooperate with state officials to carry out trafficking activities. Further discussions revolve around the continuum of harm experienced by women throughout the trafficking and post-trafficking stage. The chapter also explores how trafficked women are represented in the media in a way that makes them an easy target to be blamed for the proliferation of sex trafficking activities in Malaysia. Discussions will show how trafficked women are represented as a risk and security threat to the state and society because of their involvement in sex work. As a result, women are forcibly 'rescued' and detained in shelters in the name of 'state protection'. Thus, the chapter 
highlights the state's contradictory approach by showing how authorities project trafficked women to be helpless and in need of assistance but depict them as 'immoral' individuals who are seen as a threat to the society and the state.

The methodology and methods used in this study are outlined in Chapter Five. It highlights the importance of using feminist methodology, particularly in studies that explores women's experiences of victimisation in a migration experience. Feminist methodology involves the description, explanation, and justification of techniques (Fonow \& Cook, 2005) which aligns with the overarching goal of this feminist research - to capture women's lived experiences through their own voices and perceptions (Campbell \& Wasco, 2000). This includes analysing and understanding women's experiences of migration, policing and harms associated with trafficking. The chapter also illustrates the challenges faced in conducting this qualitative study. This includes the difficulties in obtaining permission to interview women, the challenges in interviewing migrant women in shelters, and the disconnection between professionals' views of victim protection with the lived experiences of women living in shelters. The difficulties show the complexities and challenges in conducting this study as well as the steps taken to ensure the smooth process of the interviews.

Chapters Six and Seven contain the findings from the primary research. Chapter Six highlights women's experiences, and their understanding of their own agency and victimhood. Examples of women's experiences of harm and migration are reflected along two main lines: (i) women who did not indicate any experience of threat, coercion or harm and exploitation (referred to as 'knowing participants'), and (ii) women who were coerced, deceived, threatened, harmed or exploited. In both circumstances, women were able to exercise a certain form of agency even if they had limited information or were under some form of constraint. Many of them would rather work in exploitative conditions than be rescued by the authorities because they needed the money to support their families. Given this, different woman may experience victimisation differently. While some women may perceive themselves as victims of traffickers, others may not feel victimised. Therefore, the chapter discusses women's experiences of migration and harms, and argues that the idealised image of a trafficked victim does not reflect the reality of women's lives and experiences. 
The next Chapter Seven explores how state officials enforce the anti-trafficking laws. It illustrates women's experiences of state rescue and protective custody. The chapter demonstrates how state policing has victimised women and that state protection is carried out in punitive ways. The chapter focuses on three main areas: (i) the policing of migrant women and the state's perception of a 'genuine trafficked victim'; (ii) the various harms experienced by the women during the post-trafficking period; and, (iii) how women are disempowered by the state which has control over them. The chapter analyses the lack of options given to women while in custody, including the lack of opportunity to consider their legal options and make informed choices. The chapter argues that instead of alleviating women's hardship or providing them with some form of relief during the post-trafficking period, women are forced to endure distressing policing process and are subjected to prolonged victimisation.

Chapter Eight reflects on the main findings of the research and its contributions to the key issues of the case study: the relationship between victimhood and agency, and the state's infliction of harm on migrant women in the sex trade. These two points are fundamental to the contribution of knowledge because they challenge the mainstream perceptions of the 'ideal trafficked victim' and the notion of 'women as victims'. The chapter asserts that women experience a variety of harms throughout their migration period and they use various strategies to prevent and minimise harms. Women are victimised by various actors (traffickers/employers/customers) during the trafficking phase and are later victimised through the state's actions during the post-trafficking phase. However, the criminal justice system in Malaysia has denied women's voice, and neglected to deal with the question of trafficked women as ordinary individuals. Therefore, the thesis argues that state institutions inflict harm on women and deny their agency by creating an unequal social order and by construing the lives of women narrowly.

Chapter Nine concludes with an assertion that the myths of the 'ideal victim' have impacted on representations of 'trafficked victims'. This is because the myths created does not represent the reality of women's experiences. Therefore, the chapter argues that such myths need to be corrected before appropriate action can be taken to combat sex trafficking (Milivojevic \& Copic, 2010). Within this discussion, the chapter contends that the victim-agent 
binary is flawed because women are still capable of exercising their agency even when they are trafficked. This is based on findings showing that women demonstrated their agency in their identity, decision making and actions.

\section{Conclusion}

With highly original data, this study illustrates the experiences of migrant women who are categorised as 'trafficked' by the state. While it focuses on the harms and victimisation they experienced, the study also explores women's exercise of agency during their migration experience, even under limiting constraints. In doing so, it challenges the popular cultural and legal constructions of victimhood that positions agency as the simple binary opposite of victimisation (Connell, 1997; Picart, 2003).

Women who are deemed to be trafficked often occupy dual identities: of victims and offenders. There are many migrant women who are seriously victimised through sex trafficking. At the same time, countless other women rationally choose sex work for their livelihood despite its illegality in many countries. These diverse experiences are reflected in contradictory approaches by state authorities towards women who are deemed to be trafficked. On the one hand, state officials often associate women's involvement in sex work with their victimisation, their lack of agency and helplessness. As a result, attempts will be made by state officials to rescue women in the name of 'protection'. On the other hand, state authorities also regard trafficked women as 'immoral' individuals who pose a risk to the state and society, and who require secure containment, punishment and expulsion. Thus, Chapter Two will lay out the theoretical framework of this thesis to demonstrate the underlying causes of women's victimisation and how women's agency is perceived by society and the state. 


\section{Chapter Two: Women, Victimhood and Agency}

Introduction

The representation of an 'ideal victim' as conceptualised by Christie $(1986$, p. 18) refers to 'a person or category of individuals who when hit by crime is most readily given the complete and legitimate status of being a victim'. Based on such depiction, Christie (1986) portrays an 'ideal victim' to be a female or those who are weak in comparison to the offender. The victim is also depicted as an individual who is engaged in legitimate activities, unknown to the perpetrator and essentially blameless (Christie, 1986). Although research shows that these constructions are untrue, such imagery is still used as a benchmark in determining the innocence and culpability of a victim (Ibid). Thus, this chapter explores the meaning of the term 'victim' and considers how victims are socially constructed. It examines the stereotypical version of an 'ideal victim', focusing on how discourses of victimhood have focused on homogenising women as victims, especially when referring to specific categories of women, such as those depicted as trafficked women. For women to be socially construed as victims, they need to be seen as passive, weak, helpless and devoid of agency, as the exercise of personal agency raises doubts concerning their trafficking experience (Christie, 1986; 2007; Wijk, 2013; Wilson \& O'Brien, 2016).

The chapter begins by exploring the various definitions of a 'victim' from social and legal perspectives. It discusses the notion of an 'ideal victim' and considers factors that contribute to victim stereotypes such as innocence, respectability or women's culpability. The chapter asserts that the portrayal of an 'ideal victim' relies on societal beliefs rather than reality. These beliefs are heavily influenced by patriarchal practices, which have historically condoned women's subjugation and are heavily embedded in religion, culture and social practices. Through these avenues, women are expected to remain subservient to men, which reinforces men's social dominance over women. Women are also expected to adhere to the characteristics of an 'ideal woman' and conform to gender roles. Those who violate, challenge or defy the social values, norms, or beliefs of dominant social groups are at risk of being labelled as social, sexual or gender deviants (Downes, Rock, \& McLaughlin, 2016). Within this 
discourse, the Madonna/whore dichotomy will be explored to understand the two extremes of how women are characterised. The thesis argues that the double standard of morality imposed on women is unjust and has exacerbated the victimisation of women in all aspects of life.

The chapter also explores the notion of agency and examines the relationship between agency and women's victimisation. It considers the various ways in which women are oppressed and controlled through state laws and policies. It discusses how laws constantly oppress and restrict women's agency to the extent that it is seen as natural. In this respect, the chapter asserts that the prolonged effect of state control over women has caused internalised gender roles and the disregard of certain forms of harm and victimisation. The chapter concludes by asserting that social practices are problematic because they perpetuate stereotypes and do not recognise the nuances of women's victimhood.

\section{Social and Legal Constructions of Victims}

The term 'victim' is commonly used to describe a person who suffers from the injurious actions of other people, things, or events (Fattah, 1991; Shapland, 2009). It inspires 'pity, sympathy, compassion, and commiseration' (Fattah, 1991, p. 89). It denotes a person who may have been degraded and devalued, and who may need help and assistance (Miers, 1990). It indicates a person who is vulnerable (Christie, 1986), helpless, and lacking agency (Schneider, 1993; Stringer, 2014). In criminal law, the victim is defined according to the criminal encounter and positioned as someone who has been injured or suffered harm perpetrated by an offender (Fattah, 1991; Shapland, 2009). This is synonymous with notions of vulnerability and passivity, and presumptions that the victim is free from culpability and blame (McDowell, 2007).

How victims are defined has been subject to contentious debate amongst scholars (Leisenring, 2006; Strobl, 2004). Govier (2015, p. 371), for example, objects to the use of the term 'victim' if it is interpreted as 'implying that the person harmed is nothing but a passive party in an act in which she or he was hurt by another'. This is because such an interpretation reinforces the idea that victims are weak or lacking in agency and responsibility, and need to 
be protected by the state (Schneider, 1993). Although serious injuries may endure and affect one's life in significant ways, those harmed are never merely victims; rather, they are persons with many qualities and capacities (Govier \& Verwoerd, 2006).

Further, the identity of a victim depends on the person's definition of the situation and not entirely on the society and state (Christie, 1986). As Christie $(1986$, p.18) puts it:

Being a victim is not an objective phenomenon. It will not be the same to all people in situations externally described as being the 'same'. It has to do with the participants definition of the situation. Some will see victory (I dared to participate) where others see victims (I was cheated).

Christie (1986) further states that a person's victim identity can be investigated both at the personality level and at the social system level. According to Christie (1986, p.18):

Some might have personalities that make them experience themselves as victims in most life situations while others tend to define life according to other dimensions. The tendency to see oneself as a victim might in the perspective be called a personality trait. At the level of social systems, some systems might be of the type where a lot of victimization is seen as taking place, while others are seen as being without victims.

In some cases, individuals may have had negative or traumatic experiences, the cumulative effect of which may be a sense of not deserving approval or affection (Dodsworth, 2013). Some individuals may have normalised an abusive experience or experiences, internalised negative self-worth, or have low expectations of themselves (Ibid). For example in cases of domestic violence, Lundgren (2004, p. 29) claims a battered woman may internalise the violent man's rationalisations for his violence, and 'starts to see herself with his eyes'. Internalisation in this sense means that the reality of violence is inside the woman and she identifies with it' (Ibid). Similarly, in cases of trafficking, victims have described how their traffickers constantly berate them and tell them that their only their only value is their ability 
to provide sexual services (Wilson \& Butler, 2014). Many of them and also forced to remain naked or dress in revealing outfits (Sukach, Gonzalez, \& Pickens, 2018). Over time, victims internalise the message that they are a sexual commodity (Karandikar \& Prospero, 2010; Sukach et al., 2018) and dismiss their other competencies (Fredrickson \& Roberts, 1997). However, this does not necessarily mean that women are passive recipients of abuse because women use a wide range of strategies to avoid harm, and many struggle to resist their abuse (Wilcox, 2006). Some women may also externalise violence and rebel against their offender (Ibid). This, however, does not mean that women cannot be victimised or do not view themselves as victims (Ibid). Therefore, how victims view themselves depends on their own lens and perception (Christie, 1986).

Apart from victim's experiences, the status of a victim is determined by the perception of those who come into contact with them and have the power to affix or reject such a label, such as the police and courts (Heath, Braimoh, \& Gouweloos, 2016; Hoyle, Bosworth, \& Dempsey, 2011). According to Tyler (2006), government authorities maintain their power to apply and deny the 'victim' label because people accept and obey the authorities dictates, laws and policies. This is particularly true for the police, because people generally accept the police's right to dictate appropriate behaviour - not only when they feel a duty to obey officers, but also when they believe that the institution acts according to a shared moral purpose with citizens (Jackson et al., 2012). Furthermore, many criminal policies are premised on the idea that compliance is secured by the presence of formal policing and sanctions for wrongdoers (Tyler, 2007). Through this, the state is able to assert and maintain control over its citizens. In the context of sex work, for example, state control is carried out in several ways, such as classifying sex workers as victims who are in need of state care and protection (Lobasz, 2009), or as offenders who should be penalised as law-breakers (Doezema, 2002). However, the victim/offender category might not apply to countries where sex work is decriminalised, such as New Zealand. ${ }^{9}$ This is because sex workers are often regarded as active agent workers. Therefore, how sex workers are perceived by the police would depend on the existing social systems. It is also premised on certain norms which set a certain standard in society (Miller,

\footnotetext{
${ }^{9}$ Prostitution, sex work, brothel-keeping, living off the proceeds of someone else's prostitution, and street solicitation are legal in New Zealand under the Prostitution Reform Act 2003 (PRA). Coercion of sex workers is, however, illegal under the PRA.
} 
2009). Through these norms, stereotypes of victims are created, which can lead to the belief that the victims themselves are primarily responsible for their predicament. Therefore, Quinney (1975) argues that the term 'victim' is a social construction because it is conceived as a social status that is ascribed to a person according to formal and informal rules.

\section{The Ideal Victim}

The 'ideal victim' is commonly portrayed as someone who is virtuous, weak in relation to the offender, engaged in legitimate activities, unknown to the perpetrator, and blameless for whatever has happened (Christie, 1986). The 'ideal victim' is typically understood as the 'deserving' victim and is thereby constructed in opposition to the 'undeserving victim' (Russell, 2015; Spalek, 2006). Christie's archetypal ideal victim bears the image of a 'little old lady who after having cared for her sick sister gets robbed by a big and hooded drug addict in clear daylight' (Wijk, 2013, p. 160). This depiction is shaped by popular images about what is criminal, who is more likely to commit a crime and who is more likely to become a victim (Madriz, 1997).

Women in particular, are sometimes portrayed as helpless individuals who are trapped in violent situations and in need of sympathy and compassion (Hoijer, 2004; Moeller, 1999). They are often constructed as passive agents who are exploited by diametrically-opposed 'ideal offenders' (Wilson \& O'Brien, 2016). Females who fit the 'ideal' victim category may attract compassion and drive significant changes to social and criminal justice policy and practice (Greer, 2007). However, constructing the image of a victim as female creates a form of bias and perpetuates gender stereotypes (Christie, 1986; Eigenberg \& Garland, 2008). These have, over time, resulted in a fictitious image of victimhood (Ibid). These stereotypes fail to recognise or value the capacity of women for agency and responsibility for action (Stringer, 2014). As a result, understandings of victimisation and agency are often translated into constructions of 'deserving' and 'undeserving' womanhood (Connell, 1997).

Hudson (2002) disputes the identity of the 'ideal victim' as belonging to only females, and asserts that it lacks credibility, given that females can offend and males can be victimised too. However, men rarely achieve the 'ideal victim' status because men are not expected to be 
victims, vulnerable, hurt, damaged, emotional or sensitive (Javaid, 2018). Such traits contradict the dominant gender expectations and social ideals of men (Connell, 2005). Women who do not fit the criteria of 'ideal victim' are often discredited through strategies of 'victim blaming' (Walklate, 2007). Examples can be seen in cases of rape, sexual assault, and domestic violence (Newburn, 2013; Strobl, 2010) where female victims are commonly blamed and shamed for their own victimisation (examples in sections below). In cases of trafficking, traffickers often blame the victim and minimise their involvement in the abuse or exploitation (Toney-Butler \& Mittel, 2019). They let the victim think that it was their fault for their current situation (Ibid). Traffickers also sometimes convince the victim by saying that they would have been neglected and suffered more harm if it wasn't for the trafficker's assistance, love and kindness (Ibid). Victims are also repeatedly told how worthless they are and that they are too weak to survive without their trafficker's help (Ibid). As a result, many victims tend to blame themselves when they are caught in a trafficking situation (Ibid). When the cause of the violence is attributed to the victims, incidents are more likely to be trivialised and seen as understandable or deserved, and hence as less unjust or more admissible (Flood \& Pease, 2009). Besides blaming, shaming is also another common strategy used by traffickers to control women (Toney-Butler \& Mittel, 2019). In this instance, traffickers may threaten to expose or shame the victim by releasing sex tapes, nude photos, or by exposing their drug addiction or participation in violence or sex acts with clients (Ibid). As a result, women may feel tremendous shame and guilt and that they have no other option but to continue working for their traffickers (Ibid). Such attitudes serve to excuse and partly absolve the perpetrators of violence and add to the notion that women's victimisation is sometimes justified (Ibid). This will be further illustrated through examples in the below section and Chapter Three.

Further, the term 'crime' is an idiom that serves to legitimise the fear of strangers and unknown persons, perceived as dangerous (Madriz, 1997). For example, immigrants can become easy prey to all kinds of swindlers (Hentig, 2009) because they are not used to the culture and laws of their host country, or may not speak the local language (Madriz, 1997). In this context, migrant trafficked sex workers can also be easily victimised (Chapkis, 2003). This is because 'strict regulations and criminal sanctions on sex work forces women into high-risk modes of work such as street and escort work', which makes them particularly easy targets for violence (Treleaven, 1995, p. 300). However, many of them are reluctant to seek help from 
the authorities for fear of arrest and deportation. Furthermore, women with illegal labour status will not be accorded the same protection and rights as citizens of the host country (Aleinikoff \& Klusmeyer, 2002; Engstrom, 2006). They are subject to stigmatisation because they are considered by the state to be engaged in 'a crime against morality' (Scambler \& Scambler, 1999, p. 11). Therefore, some trafficked persons may be seen as less deserving than others in a hierarchy of moral worthiness and victim credibility within the predominant criminal justice framework (M. Lee, 2011a). In this context, those who transgress normative expectations of what victims look like, how they act, or what they need, may be denied legitimate victim status (Ibid).

According to Meyers (2011), most women who are trafficked are not naïve, or fully deceived about their employment prospects abroad. Rather, many come from victimising situations of poverty with limited avenues of economic opportunities in their home countries (Ibid). Studies have also found that although trafficked women (particularly those working in the sex trade) are under a debt bondage and are exploited through their sexual labour, many of them have control over their movement and could earn a good income (Doezema, 2010; Marjan Wijers \& Lap-Chew, 1997). Therefore, it is important to acknowledge that trafficked women are still capable of making active choices even if there is a constraint on their agency/choices (Kelly, Coy, \& Davenport, 2008). As Jeffreys (1997, p.156) points out, 'women also exercise agency, but it is "an anguished agency" when contextualised within the personal and socioeconomic circumstances of their lives'. However, mainstream discourses do not recognise and acknowledge the relationship between agency and victimisation in women's lives (Mahoney, 1994). This is because agency is usually constructed in opposition to victimisation and women's oppression is often analysed in terms of victimisation (Ibid). Therefore, in the following section this thesis aims to analyse the relationship between trafficking and agency and discuss how victimisation and agency reinforce each other. Discussions will challenge the victim-agent binary and demonstrate that the emphasis on women's victimisation has limited the appreciation of women's agency and their efforts to protect themselves and minimise harm. 


\section{The Victim-Agent Dichotomy}

Agency refers to the condition of activity rather than passivity (Hewson, 2010) - the experience of acting, doing things, making things happen, exerting power, being a subject of events, or controlling things (Ibid). Agency refers to a continuous flow of conduct and not just a series of discrete acts combined together (Giddens, 1984). In this thesis, women's agency often refers to the ability of women to make strategic life choices under evolving constraints (Kabeer, 1999; Yount, VanderEnde, Dodell, \& Cheong, 2016). It also refers to their 'agency freedom', which means their ability to define choices and construct the conditions of choice (Sen, 1999).

Popular cultural and legal constructions of victimhood position agency as the simple binary opposite of victimisation (Connell, 1997; Picart, 2003). It imagines agency and victimhood as incompatible (Wolf, 1993). This is because agency is commonly associated with a person's will and autonomy (Benner, 2002). However, such presumptions fail to notice social conditions and human relationships (Ibid). Thus, Mahoney (1994) objects to such a depiction as it suggests that a person must either be 'a pure victim or a pure agent' and not both. According to Mahoney (1994), a person can experience both oppression and resistance because victimisation and agency are not static and should be not be viewed in isolation. For example, in cases of rape, the behaviour of female victims will be interpreted and assessed based on their resistance towards the perpetrator (Amir, 1971; Hockett, Smith, Klausing, \& Saucier, 2016). This includes the proportion of strength used in resisting the perpetrator and if resistance occurred instantly (Estrich, 1987; Holmstrom \& Burgess, 1991). West \& Loeffler (2015, p. 2) (2015, p. 2) define resistance as:

...a normative response stemming from ambivalence in the face of a life change. Further, resistance can be conceptualised along a spectrum of reactions ranging from overt behaviour, such as running away, to more subtle forms of behaviour, such as avoiding feelings within a psychotherapy session.

However, women who do not resist their attacker or remain quiet as a strategy to minimise harm are often not believed by the police and public (Ahrens, Campbell, Ternier-Thames, 
Wasco, \& Sefl, 2007). They are often blamed for not showing any resistance (Bongiorno, McKimmie, \& Masser, 2016). Therefore, when incidents of rape occur, women are highly unlikely to report to the police but may choose to share their experience with someone who can give them emotional support, such as friends (Bongiorno et al., 2016). Similarly, in cases of trafficking, the idea that victims would willingly stay or return to an exploitative or abusive situation may be attributed to the fact that they are stigmatised and viewed as 'criminals' or 'illegal immigrants' by the public (West \& Loeffler, 2015). In Malaysia, for example, sex workers experience visible discrimination and stigma from the public which may continue to pressure them and cause feelings of uncomfortable tension and shame (Nasira et al., 2010). More so for foreign sex workers who are positioned negatively by the government and media because of their 'illegal migrant' status, and their trade (Suppiah, Kaur, Arumugam, \& Shanthi, 2019). Many members of the society may also 'view sex workers as immoral and worthless' (Bell, 2009, p. 2) regardless of whether they voluntarily participate in sex work or have been forced into the trade (Suppiah et al., 2019). In response, victims may look for a way out by returning to their traffickers (United Nations Office of Drugs and Crime, 2019). Kabeer (2005) argues that these forms of behaviour do not reflect 'choice', but are based on the denial of choice. Nevertheless, not all choices are equally relevant to the definition of agency (Kabeer, 2005). Some have greater significance and consequences than others. Therefore Kabeer (2005) argues that it is important to differentiate between 'passive' forms of agency (action taken when there is little choice), and 'active' agency (purposeful behaviour). Thus, Bumiller (2009) rejects the necessity of 'resistance' and points out that women who are sexually attacked are more concerned with their survival than demonstrating their non-consent or rejection. In this regard, active resistance could worsen women's victimisation, which indicates women's strategy in minimising harm and the exercise of agency to halt, change or cope with violence (Lempert, 1996). Therefore, agency and victimhood can go hand in hand in particular circumstances. Given this, Govier \& Verwoerd (2006) argue that the victim/agent dichotomy is not exclusive because some people are both victims and agents.

Thus, Kelly (1988) who worked with women experiencing sexual assault critiques the victimagent dichotomy as being unreal because it does not reflect women's lived and emotional realities. According to Kelly $(1988$, p. 165): 
The agency of day to minute decisions, choices and actions taken by women are to ensure survival. It is precisely these aspects of women's experience that demonstrate that women do not expect or accept sexual victimisation, and which provide the basis for women's struggle for autonomy.

Kelly (1988) also observed how the victim-agent dichotomy neglects the agency of strategies deployed at the time of abuse for coping and resisting. Instead, women's exercise of agency is either considered non-existent when they are experiencing violence and harm or they will be blamed for causing their victimisation. This is not something new. The tendency for victim blaming, particularly of women in situations of sexual violence, has a long and pervasive history within the criminal justice process (see below). Thus, agency can be exercised under various circumstances and even when women experience oppression, struggle, and resistance in their daily lives (Schneider, 1993). In many instances, as this thesis will demonstrate, women use a combination of strategies which could actively resist structural limitations and inequalities (Zakar, Muhammad, \& Krämer, 2012). For example, in a study conducted in Pakistan on domestic violence ${ }^{10}$, Zakar, Muhammad, \& Krämer (2012) found that the majority of the women used emotion-focused strategies, especially spiritual therapies, which somehow reduced the violence and provided them with psychosocial solace. The study also found that women were reluctant to use problem-focused strategies, such as seeking help from formal institutions, as these strategies could lead to overt confrontation with their husbands and could result in divorce, the outcome least desired for Pakistani women (Ibid). This shows how women respond to violence and engage in strategies which are most beneficial to them.

However, theoretical and policy debates are dominated by misleading dichotomies regarding both agency and victimhood. This dichotomy also exists in sex work where sex workers are seen as either 'free to choose [agents], or as victims' (Bettio, Giusta, \& Tommaso, 2017, p. 5). Schneider (1993) argues that the portrayal of sex workers as solely victims or agents is neither accurate nor adequate to explain the complex realities of sex worker's lives. This is because

\footnotetext{
10 The study was conducted in 2012 in Lahore and Sialkot, Pakistan. Twenty-one in-depth interviews were held with married women of reproductive age (15-49 years) who were currently or had been in an abusive intimate relationship (Zakar, Muhammad, \& Krämer, 2012).
} 
women's involvement in sex work is often seen as a survival strategy against poverty and unemployment (Dodsworth, 2013). Under these circumstances, women may not identify themselves as victims of sexual exploitation but 'have demonstrated resilience and exercised agency in choosing to sell sex or to swap sex for monetary payment' (Dodsworth, 2013, p. 186). Therefore, Sullivan (2007) and Pearce (2010) suggest that it is critical to maintain the sex worker as an 'agentic subject' who is capable of exercising their own choice in consenting to sex work. However, sex worker agency becomes blurred in practice because of the tension that exists between the notions of 'choice' and 'coercion' (Basu, 2007; Beeks \& Amir, 2006; McCabe \& Manian, 2010; Zimmerman, 2011). This tension is amplified when coercive factors become the basis of a woman's decision to engage in sex work. For example, strict immigration policies have caused women to seek the services of traffickers (who may operate under the guise of work agents) to migrate and seek employment abroad. Under these circumstances, women may comply with abusive and exploitative working conditions (Kim, 2007, 2011).

Therefore, although women may seem to be consenting, the consent given is subject to other factors. In this instance, a woman's consent may be nullified, which changes her status from a non-victim to a victim (Bergelson, 2014; Fattah, 1991). The Palermo Protocol, for example, considers a person to be a victim of trafficking if the person is found to be forced or coerced into sex work. By over-emphasising the existence of victimhood, other forms of agency in navigating multiple social structures, expectations and pressures in women's daily lives are minimised (Mahoney, 1994). Thus, women's agency is not seen as a 'human quality embedded into subjects, rather, is formed through a process of interaction between the individuals and the larger social mechanisms operating on them' (Sehlikoglu, 2018, p. 92).

In reality, women are 'capable' of exercising their agency even if it is within the limits of information, uncertainty and other constraints (Moser \& Clark, 2001). Thus, Nussbaum (2001) argues that agency and victimhood are not incompatible but only the capacity for agency makes victimhood 'tragic'. This is because people are not only dignified agents, but can also, be victimised through no fault of their own (Nussbaum, 2001). Yet, the victimisation-agency dichotomy persists and existing victim paradigms in the literature (particularly in law) fail to provide a nuanced understanding of victim agency (Meyers, 2013). In fact, a false stoic 
assumption is made that acknowledging victimhood negates the person's strength and agency (as discussed through the examples above) (Benner, 2002). Thus, feminist scholars in particular have questioned the concepts of agency and the capacity for individuals to make their own decisions because the constructions of agency focus on an unequal power divide between agency and victimhood. In addition, current constructions of women's victimhood reinforces notions of female dependence on men and sustains the cultural and legal constructions of victimhood. This process maintains patriarchal control and results in the marginalisation of women at the hands of those who support the existing power structure.

\section{Patriarchy}

The discussions have so far shown that popular literature propagates various stereotypes, such as the idea that 'ideal victims' are weak and passive individuals who are deprived of agency. However, the emphasis on victimisation has failed to take into account women's exercise of agency. This is because the exclusive focus on women's agency is shaped by liberal visions of autonomy without the larger social context of victimisation (Schneider, 1993). Therefore, the concepts of women's victimisation and agency become overly simplistic because it fails to take into account women's active efforts to make decisions that may protect them from harm (Ibid). The above discussions have also shown that women made strategic decisions despite their marginalisation and unequal opportunities (Zakar et al., 2012). However, women's selection of strategies often reflects the prevailing cultural norms and status of women in any given society (Ibid). Given the weaker and subordinate position of women in Asia, women are more likely to use strategies which are less covert and less confrontational because of the patriarchal ideals that are instilled in men and women. Therefore, this section will show the influences of patriarchy in women's daily lives and how patriarchy has succeeded in supporting male domination and female exploitation.

Patriarchy is a system where men dominate women; the form and degree of oppression has varied considerably in different cultures over time (Kandiyoti, 1988; Samarasinghe, 2008; Walby, 1990). It justifies male dominance by maintaining women's inferiority and instability (Mumtaz, Shahid, \& Levay, 2013). The concept of patriarchy is embedded in social structures 
and has become a defining feature of societal structures (Stromquist, 1991). States often reproduce patriarchal attitudes and sustain male dominance and power in society (Ibid). Accordingly, women are placed in subordinate positions, which conveys the message that their ability to make decisions cannot be trusted (McFadyen, 2000). This perpetuates women's dependency on men and sustains men's dominance and power over women. To sustain the patriarchal system, gendered identities are formed through processes of socialisation within families, schools, religious institutions, government agencies and media (Carter, 2014). These institutions, among others, instil culturally appropriate attitudes and behaviours in individuals and maintain practices of gender hierarchy by generating conformity and compliance through systemic and structural control (Ibid).

Based on research conducted in Malaysia, Indonesia, Pakistan and Bangladesh in 2015, it was found that primary schools overly relied on 'masculine' ${ }^{11}$ textbooks for girls' education (Islam \& Asadullah, 2018). Given that textbooks play an important role in the education system, it is presumed that whatever is printed in the textbook needs to be practiced by both male and female students (Ibid). The study found that 'teacher' is the most stated profession in textbooks for girls because it is traditional, and lower than boys/men in terms of prestige and income (Ibid). The study also confirmed that female occupations are mostly traditional and less prestigious while the characters have predominantly introverted and passive personality traits (Ibid). Women were also shown in textbooks to be mostly involved in domestic and indoor activities while men had a higher presence in professional roles (Ibid). Another recent case can be seen in Malaysia where a school textbook for nine-year-olds was found to contain an infographic requiring girls to protect their modesty or risk being shamed and ostracised by friends and family (Lin, 2019)..$^{12}$ Such forms of education not only perpetuate the victimblaming culture, but also normalises violence against women.

The overall findings from these studies, as discussed above, show broadly similar patterns of gender stereotypes over time and across countries. These also fit the concept of an 'ideal woman' who Vicinus (1972, p. ix) envisioned as 'the "perfect wife," a woman who, as well as

\footnotetext{
${ }^{11}$ Masculine textbooks in this thesis refers to masculine generic constructions or merely male referenced, and the association between all masculine generic nouns and pronouns.

12 The textbook has not been recalled even after complaints were made by NGOs, but the Ministry of Education has sent out a sticker to cover up the graphic (Lin, 2019).
} 
being a mother, provided all the goods and services necessary to the maintenance of the male-headed household'. The inequalities between male and female roles are further obscured by perceiving such roles as 'natural' or 'normal' (Martin, 1981). By normalising gender roles, women internalise society's norms of the 'ideal woman' (Gordon, 1998) and they become part of the psyche (Joseph, 1996). Similarly, in Southeast Asian countries such as Malaysia, Indonesia and Brunei, where the majority of the population are Malay Muslims, the marginalisation of women is intertwined or synonymous with the Malay cultural traditions, values and language, and Islamic precepts and teachings (Chin \& Daud, 2015; 2018). Within the gender binary and divide, man is 'naturally' dominant in both identity and status (Ibid). As Kalthom, Noor, \& Wok (2008, p. 454) points out:

Women's role is oriented more towards family matters rather than selffulfilment implying that when faced with having to make a choice between career and family, family is always given priority. In a way, the present Malay women are caught in a dilemma between the modern challenges of life and traditions. While many are now employed, they are still expected to be responsible for the family and to maintain the traditional perception of a woman.

As a result, women teach and police other women to conform to the attributes of an 'ideal woman' to produce a society in which male power necessitates the subordination of women. In a study conducted on 401 sex workers in Malaysia in 2010, it was found that most sex workers who participated in the study had low self-esteem and Muslim sex workers had lower self-esteem compared to non-Muslim sex workers (Nasira et al., 2010). Although many of them tried to justify and rationalise their 'immoral behaviour' by saying that they were poor and did not harm anyone, it still did not make them feel good about themselves and their behaviour (Ibid). This mindset is acquired from patriarchal practices in social structures and norms, which have survived over centuries and are still prevalent today. Thus, the arguments have shown the challenges women face in societies that are highly patriarchal and religious or partly religious, in which women are forced to accept and perpetuate a principle based on moral, customs, or religious grounds rather than on personal choice. The following section 
will unpack the historical development of patriarchy and the impact of patriarchal influences on women's lives.

\section{The Historical Development of Women as Male 'Property'}

The inequalities between male and female originates from patriarchal mindsets which often undermine women's ability and knowledge. According to traditional views of Judaism and Christianity, women and children are regarded as the property of men, and women's value was measured largely by their sexual 'purity' (Noor, 2010; Ruether, 1974; Vickery, 1993). A woman's sexual purity is measured through her innocence and her sexual unawareness which are essential to the family wellbeing and honour (Doezema, 2000). Thus, rape was regarded as a property crime against a woman's husband or father (Burgess-Jackson, 1999). This is derived from women's property status and the lack of legal identity (Burgess-Jackson, 1999; J. Jordan, 2012). Similarly, in Islam, the purity and honour of the daughter reflects that of her mother and, thereby, the honour of the father (Pitt-Rivers, 1965). The honour of a man obliges him to defend his honour and that of his family; and the honour of a woman obliges her to maintain and protect her purity (Doğan, 2011). Islam's paternalistic concern for the moral and economic security of women can also be seen by the creation of access to property for women in Islam, and the emphasis in divine law on the status of women versus men (Noor, 2010). Muslim women are regarded as 'protected persons' and should be obedient to the men related to them through blood or marriage (Pastner, 1978). This is because Islam gives men the rights and responsibilities to protect their women and property (Ibid). Therefore, women's lives are framed in a similar ideology of family, honour and chastity (Warnock, 1990). These types of practices undermine women's autonomy, deprive them of control over their bodies, and jeopardise their physical and emotional safety (Easteal, 2001).

Brownmiller (1975) claimed that the patriarchal system of gender inequalities, which empowers men and oppresses women, has a long-standing history and is therefore resistant to change. According to her, these systems function at both interpersonal and societal levels as prescribed beliefs shared by individuals, and are embedded in social institutions (Brownmiller, 1975). As of 2018, one in four countries still do not have specific laws against 
domestic violence (World Bank, 2018). Although 125 countries outlawed domestic violence, 127 countries do not explicitly criminalise rape within marriage (Ibid). These countries assume that no crime has been committed when a man forces intercourse upon his wife (BurgessJackson, 1999). This is because husbands are recognised in law as possessing control over their wives (J. Jordan, 2004). For example, the Malaysian law does not recognise the concept of rape within marriage. However, the husband can be charged under section $375 \mathrm{~A}^{13}$ of the Penal Code if he 'uses harm or threat of violence to obtain sex from his wife, or any other person'.

Another example is the continuing practice of wives acquiring their husbands' names when they marry, which has lived on for centuries in marriage ceremonies and legal codes (J. Jordan, 2004). This, as Lerner (1987) suggested, is attributed to the fact that women are predominantly determined by their relationship to men because of their dependence on, and subordination to, men. The dependency on men has resulted in 'male supremacy' or 'male dominance' and created patriarchal stereotypes. Generally, dominant stereotypes position women as weak, inferior, passive, fragile, soft, vacillating, dependent, reliable, intuitive rather than rational, castrated and handicapped; while men are presumed to be aggressive, controlling, strong, superior, proud, independent, venturesome, competitive, hard and athletic (Manimekalai \& Veeramani, 2018). These stereotypes are internalised by women who perceive men as naturally aggressive (Grosu-Rădulescu, 2016) while women on the other hand are expected to guard and police themselves from being assaulted by men (Fredrickson \& Roberts, 1997). According to the UN Special Rapporteur on violence against women, these stereotypes contribute to the violation of human rights and fundamental freedoms for women (United Nations Human Rights, 2014). Thus, activists, feminist advocates, and scholars have continuously argued against patriarchal stereotypes and called for greater respect and justice for women in all social and state institutions. An example can be seen in the \#MeToo Movement which revived complaints about widespread harassment and assault on women (Tippett, 2018). The term "metoo" was used to express solidarity with girls and women who experienced sexual assault (Ibid). This is supported by data from the World Bank that found that 35 percent of women worldwide have experienced either physical and/or sexual intimate

\footnotetext{
${ }^{13}$ Conviction under section $375 \mathrm{~A}$ carries an imprisonment term up to five years.
} 
partner violence or non-partner sexual violence; seven percent of women have been sexually assaulted by someone other than a partner; 38 percent of murders of women are committed by an intimate partner; and 200 million women have experienced female genital mutilation/cutting (World Bank, 2018).

Although these figures show the severity of violence against women, many of the crimes committed against women originate from misogynist mindsets which originate from patriarchal practices, which are regularly legitimised through state institutions. In this regard, Walby (1990) contends that patriarchy functions in private spheres (household) and public (in civil society). Under public patriarchy, women are allowed roles in the public sphere, but remain oppressed by gender inequalities in paid employment, education, economic conditions or health opportunities (Heimer, 2000; United Nations Development Programme, 2016). The Global Gender Gap Index ${ }^{14} 2016^{15}$ (GGPI) revealed that the gender gap exists across 144 countries, with Iceland having the lowest gender gap (0.874) and Yemen having the highest gender gap (0.516). This means that the disparities between gender are highly significant in Yemen because their constitution, based on the Sharia (Islamic law), contains provisions that discriminate against women in many areas including the personal status law, the penal code, the citizenship law and the evidence law (UNICEF, 2011). Under Yemeni law, a woman is not considered a full person and their testimony is only worth half that of a man or not valid in some cases (e.g., in cases of adultery and retribution) (Ibid).

The Southeast Asian countries examined include: Vietnam ranked at 65 with a gender gap of 0.736; Thailand ranked at 71 with a gender gap of 0.770 ; Indonesia ranked at 88 with a gender gap of 0.598; Malaysia ranked at 106 with a gender gap of 0.666 . This means that women remain poorly represented in economic as well as political spheres in Malaysia. It also reflects women's involvement in the job market (Islam \& Asadullah, 2018) because women may not

\footnotetext{
14 The Global Gender Gap Index examines the gap between men and women in four fundamental categories (subindexes) and 14 different indicators that compose them. The subindexes are Economic Participation and Opportunity, Educational Attainment, Health and Survival and Political Empowerment. There are three basic concepts underlying the Global Gender Gap Index, forming the basis of how indicators were chosen, how the data is treated and the scale used. First, the Index focuses on measuring gaps rather than levels. Second, it captures gaps in outcome variables rather than gaps in input variables. Third, it ranks countries according to gender equality rather than women's empowerment (The World Bank, 2019).

${ }^{15}$ The highest possible score is 1 (equality) and the lowest possible score is 0 (inequality).
} 
be given the opportunity to choose their salary scale and the type of work they like. According to a 2016 Salary and Wages Survey Report, six out of ten wage earners were men and the average gender pay gap is 21 percent (Department of Statistics of Malaysia, 2016). ${ }^{16}$ On average, women in Malaysia get paid 79 sen (NZD0.29 cents) to Malaysian Ringgit (MYR) 1 (NZD0.36) earned by men (Department of Statistics of Malaysia, 2016). The results suggest that 'discrimination' favouring men in Malaysia is still quite prevalent (Ibid).

Overall, the lack of power held by women in society demonstrates the institutionalised nature of patriarchy, upheld by state agencies (Hearn, 1992). As such, Hearn (1992) asserts that public patriarchy sustains the patriarchal system and perpetuates women's dependency on men. It includes the possibility of voluntary acceptance of subordinate status in exchange of protection and privilege (Sultana, 2012). Although all the power and authority within the family, the society and the state may largely remain in the hands of men (Ibid), women are also in control of the household. However, many wives have accepted the traditional conjugal roles and believe that these should be maintained and husbands should be the dominant partner (Edgell, 1980). In general, women do not try to challenge these normal 'biological' ideas (Ibid) because if they do they are seen as odd. Therefore, women would try to retain whatever little authority they have and perpetuate patriarchal practices through messages, values and attitudes to their children. Through this, men are able to control women's rights, freedom, bodies and regulate their sexuality.

\section{The Construction of Women's Sexuality}

Control over female sexuality has been a focus in many countries, serving to strengthen male authority and sustain patriarchal norms (Ong, 1990). In the works of St Augustine entitled 'On the Good of Marriage' (De Bono Coniugali, written in $401 \mathrm{CE}$ ), three points of marriage were set forth: the objective of procreation (offspring); the faithful observance of chastity (fidelity); and the sacramental bond (which means that Christians are prohibited from divorcing and

\footnotetext{
${ }^{16}$ The gender wage gap also exists in Western countries and 'economically advanced countries'. For example in New Zealand, until the Equal Pay Act 1972, it was legal to set separate rates of pay for men and women, and exclude women from certain types of work. However, the introduction of equal pay and anti-discrimination legislation has improved women's pay rates and access to jobs although women's earnings are still less than men's and women are still in different types and levels of jobs (Employment New Zealand, n.d).
} 
remarrying during the spouse's lifetime) (Brooten, 2003). However, St Augustin overlays the Christian concept of sin by not limiting sex to only marriage and allowing for a number of extra-marital sexual acts, particularly by men (Ibid). The situation is, however, different for women. While women are expected to guard their chastity and conform to 'man-made' moralities, some are expected to deviate from those norms and satisfy men sexually (Young, 1993). In this context, St Augustine considered prostitution as a problematic existence yet a necessary evil (Corbin, 1987) and a preventive measure against homosexual indulgence (Gilfoyle, 1999), adultery and the taking of mistresses (Chappell, 2014). He considered prostitution as 'an outlet that would destroy society/civilization if not released' (Corbin, 1987, p. 213). However, St Augustine argued that prostitutes cannot be honoured for the sacrifices they make for the society because it would debase and corrupt honest women (Corbin, 1987).

The existence of this bipolar sexual code for women as suggested by St Augustine have been referred to as the Madonna/Whore complex (or duality) (Conrad, 2006). This label stems, in part, from the Western and Christian fusing of ideas about sex and the body with notions of gender (Conrad, 2006). As Conrad (2006, p. 310) stated:

The Madonna, or the 'good girls' who do not engage in active sexual relationship too often, too quickly, with too many men while the Whore or the 'bad girls' are those who proudly defy this standard, but only to find they have been played as pawns in a sexual game conceived and controlled by men.

The Madonna/Whore dichotomy defines a woman to be either respectable or sexually desirable, but not both (Young, 1993). The archetype of Madonna resembles 'a virgin whose grace derives from her marital chastity, and the Whore, an unmarried woman, who exudes sexuality' (Ruether, 1974, p. 274). The Madonna/Whore dichotomy is evident in Christianity through the projection of Mary and Eve, where Mary is portrayed as the Madonna who is the epitome of purity and chastity (Morgan, 2005). According to Tumanov (2011), 'Mary requires no mate, guarding, effort or jealousy while Eve becomes the embodiment of the whore: both attractive in the context of the promiscuity strategy and repulsive in terms of paternal uncertainty: "Death by Eve, life by Mary"' (p.507).This suggests that reinforcing the 
Madonna is desirable as a good wife and mother as she becomes the symbol of an 'ideal woman' who preserves her femininity and purity (Vicinus, 1972).

Like Christianity, Islamic views on women's chastity are not only limited to the physical virginity of women and the physical hymen, but also to a whole set of rules and regulations which act as a moral code for women (Abu-Odeh, 2010). Women's respectability would highly depend on the judgements made concerning women's moralities, public behaviour and appearance (Jordal, Wijewardena, Öhman, Essén, \& Olsson, 2014). According to the interpretation of the Qur'an in verse An-Nur, 24:31:

And tell the believing women to lower their gaze [from looking at forbidden things], and protect their private parts [from illegal sexual acts] and not show off their adornment except only that which is apparent [like both eyes for necessity to see the way, or outer palms of hands or one eye or dress like veil, gloves, head-cover, apron, etc.], and to draw their veils all over Juyubihina [i.e. their bodies, faces, necks and bosoms] and not to reveal their adornment except to their husbands, or their fathers, or their husband's fathers, or their sons, or their husbands' sons, or their brothers or their brothers' sons, or their sisters' sons, or their [Muslim] women [i.e. their sisters in Islam], or the [female] slaves whom their right hands possess, or male servants who lack vigour, or small children who have no sense of feminine sex. And let them not stamp their feet so as to reveal what they hide of their adornment (Translation of the meanings of the noble Qur'an in the English language, 1984).

Sisters in Islam $(\mathrm{SIS})^{17}$, a Muslim women's rights group in Malaysia, views such forms of interpretation as patriarchal, oppressive, and influenced by cultural practices and values

\footnotetext{
${ }^{17} \mathrm{SIS}$ is a civil society organisation committed to promoting the rights of women within the frameworks of Islam and universal human rights. Its efforts to promote the rights of Muslim women are based on the principles of equality, justice and freedom enjoined by the Quran. SIS work focuses on challenging laws and policies made in the name of Islam that discriminate against women. As such it tackles issues covered under Malaysia's Islamic family and sharia laws, such as polygamy, child marriage, moral policing, Islamic legal theory and jurisprudence, the hijab and modesty, violence against women and hudud ('laws relating to crimes and punishment that are laid down in the sharia' (Islamic law)(Faruqi, 2005, p. 263)).
} 
(Sisters In Islam, 1991). This is because the Qur'an was revealed more than 1400 years ago and within a particular socio-historical context (Ibid). Instead, SIS argues that Muslim women and men are equal participants in all aspects of Islamic life based on verse At-Taubah, 9:7172 of the Qur'an:

The Believers, men and women, are Auliya' [helpers, supporters, friends, protectors] of one of another; they enjoin [on the people] Al-Ma'ruf [i.e. Islamic Monotheism and all that Islam orders one to do], and forbid [people] from Al-Munkar [i.e. polytheism and disbelief of all kinds, and all that Islam has forbidden]; they perform As-Salat [prayer], and give the Zakat [charity], and obey Allah and His Messenger [Prophet Muhammad]. Allah will have his Mercy on them. Surely Allah is All-Mighty, All Wise. Allah has promised the believers - men and women, - Gardens under which rivers flow to dwell therein forever, and beautiful mansions in Gardens of 'Adn [Eden/Paradise]. But the greatest bliss is the Good Pleasure of Allah. That is the supreme success (Translation of the meanings of the noble Qur'an in the English language, 1984).

Based on the above verse, SIS argues that it is not Islam that oppresses women, but human beings with all their weaknesses who have failed to understand Allah's (God's) intention' (Sisters In Islam, 1999 p. 1).

However, the Islamic revivalism in Malaysia which started in the late 1980s (following the Iranian revolution in 1979) or known as the dakwah movement (Nagata, 1984; Narlı, 1991) adopts the strict interpretation of women's modesty and chastity based on verse An-Nur 4: 31 (see above). The above interpretation seems to ignore the similar standard of modesty and chastity for men even though men are first mentioned as having to observe their modesty through verse An-Nur, 24:30 in the Qur'an 'tell the believing men to lower their gaze [from looking at forbidden things], and protect their private parts [from illegal sexual acts]. That is purer for them. Verily Allah is Well-Acquainted with what they do' (translation of the meanings of the noble Qur'an in the English language, 1984). 
Therefore, claiming that the above Quranic verse only applies to women is untrue and highly disputed. Thus, the thesis argues that the oppression of Muslim women originates from the isolation of a Quranic verse from its context and turning it into a universal rule or moral injunction towards women (Sisters in Islam, 1991).

The Islamisation of Malay Muslims is manifested in public rhetoric, policy formulation, the media, and public education programmes organised or promoted by individual Islamists and religious authorities (N. Othman, 2006). Islamic fundamentalists and political Islamist movements strive to islamise society by dictating and monitoring women's movements and sexuality in order to control women and to ensure women remain subservient to men (Healey, 1999; N. Othman, 2006). Classical Islamic traditions such as the covering or veiling of women (tudung), and gender segregation are the first two objectives of most Malaysian Islamic movements (N. Othman, 2006). These objectives are based on the belief that uncovered and uncontrolled women in the public sphere are the cause of social problems such as the increase in the incidence of rape in Malaysian society (Ibid). Muslim men on the other hand are not required to cover their heads or wear a veil. For example, in a recent case in Malaysia, the Kelantan's Islamic Affairs and Religious Department (JAHEAIK) issued notices to thirty-nine women for dressing sexily and behaving indecently in public during the month of Ramadhan. However, no summons were issued to men who failed to guard their modesty by lowering their gaze as commanded by Islam (see above). Denouncing such actions, SIS argued:

...not only does this practice humiliate and degrade the value of women, but the compulsive need to control what women wear also implies that she is mentally, physically and spiritually defective and a danger to the moral order of society. This discrimination unfairly suggests that women are exclusively to be blamed for social and moral ills within the community (reported in Malaymail dated 13/5/2019).

This shows the sexual morality double standards, which are reflected in laws and attitudes towards male and female sexual behaviour (Smart, 2013). It also puts women at risk of marginalisation and social exclusion (United Nations Population Fund, 2011). However, state 
laws, regulations, and fatwas (Islamic orders) that control women's choices, movement and freedom (N. Othman, 2006) are considered to be protecting women from leading a 'sinful' life. Thus, women who defy or reject these rules are seen as rejecting their heritage, their identity, and may even be accused of rejecting their religion (Al-Sharmani, 2014; N. Othman, 2006). In this regard, women's voice or the act of speaking out is considered defiant and 'unislamic'. Those who are outspoken are variously silenced by criticising their appearance as a way to diminish their arguments and being condescended to (such as being talked down to) or patronised because of the stereotypical view of a Muslim woman (Carland, 2012). For example, SIS which is vocal in women's rights and aims to expose the general Malaysian public to alternative progressive thinking in Islam has been berated and ridiculed by the Islamic Party PAS and Islamist activists who are mainly male (N. Othman, 2006). These groups constantly berate and accuse SIS of deviating from traditional Islamic teachings by spreading Western feminist values and liberal Islamic teachings on Muslims and the ummah (nation) (Ibid). Scare tactics and continuous calls to ban SIS by Islamists are among the tactics used to silence 'lay' female Muslim scholars from engaging publicly in the discourse on Islam in Malaysia (Ibid). As a result, women's voices have been denied or limited in matters concerning culture, religion, education, justice and governmental policies (Alamgir, 2014). The silencing of women stems from age-old traditions, religion, cultural practices, stereotypes and attitudes about women and their role in society (Ifechelobi, 2014). Silence is also used as a weapon of control by patriarchal institutions to subjugate and control women (Slee, 1989).

The silence of women is often a prominent feature of religious doctrines. For example, the Holy Bible says in 1 Timothy chapter Two verse 11-12, 'let a woman learn in quietness, in entire submissiveness. I allow no woman to teach or to have authority over men; she is to remain in quietness and keep silence' (Ifechelobi, 2014, p. 22). Similarly, in the Qur'an, women's voices are considered aurah $^{18}$ and should be inaudible to men (Maududi, 1991). This injunction stems from the prohibition of stamping of feet, which prevents women from revealing the ornaments they are wearing (see verse An-Nur, 24:31 above) and also the fact that only men could make the call for Azan (the call to prayer) (Ibid). This injunction is sometimes used to police women's voices within Muslim communities and women who live

\footnotetext{
${ }^{18}$ Women are to be covered from head to foot, and no part of the body is to be made visible except for necessity (Maududi, 1991).
} 
in Muslim-dominated countries such as Malaysia. Such forms of control amount to discrimination, which has directly or indirectly resulted in women's oppression in Malaysia. It has also degraded women and reduced their capacity as persons with agency (Covington \& Bloom, 2006). However, women's oppression is often concealed, rendered 'private', and powerfully normalised through patriarchal ideologies which are embedded in culture, religion and social structures (Forbes, 1995). The traditional tendency to consider women as subordinate to men has led to the perception of justification of traditional violent practices and gender-based violence as a form of control or 'protection' of women.

\section{Cultural Acceptance of 'Everyday Violence' Towards Women}

Feminist scholars have long demonstrated how cultural and social structures are a product of male dominance, especially in how they maintain women as victims (Brownmiller, 1975; Burt, 1983; Dobash \& Dobash, 1979; Kelly, 1988). Jordan (2004, p. 196) argues that 'the patriarchal influence in one's culture plays a great role in shaping a person's view and belief' of victims. This is applied to the extent that even violent and harmful practices are viewed as religious, cultural or traditional rituals (Erez, 2000; Lee \& Hadeed, 2009). One example would be the practice of 'honour killing', which is still prevalent across South Asia and Middle Eastern countries despite laws criminalising such acts (Abu-Odeh, 2010; Lodhi \& Siddiqui, 2014; United Nations, 2000). The roots of 'honour killings' lie in tribal social norms, which dictate the behaviour of women in particular (Lodhi \& Siddiqui, 2014). Women have been shot, stabbed, mutilated, stoned, set alight and strangled by their family members if they are accused of bringing shame, or dishonour to their families (Abu-Odeh, 2010; Chesler, 2010), or have violated the principles of a community or a religion (United Nations, 2000). This could mean anything from refusing an arranged marriage, engaging in or being suspected of engaging in sexual practices before or outside of marriage, helping friends elope, or being the victim of rape and sexual assault (Abu-Odeh, 2010; Lodhi \& Siddiqui, 2014). Therefore, women develop individual mental maps of defence and learn to live in an atmosphere of fear and obedience given that the most abusive forms of violence take place in their homes (Tarar \& Pulla, 2014). 
Consequently, women become exposed to 'everyday violence' and develop a sense of inferiority, which can be later internalised (Stanko, 1990). 'Everyday violence', according to Stanko (1990) relates to how women manage their danger on a daily basis and experience violence as a common occurrence. As a result, women do not realise that they have been abused or harmed because they have become tolerant of the abuse they face (Kandiyoti, 1988; Samarasinghe, 2008). By internalising 'everyday violence', women do not always regard themselves as victims, even though they have been objectively harmed (Hoijer, 2004; Rimonte, 1991). Furthermore, many incidents which women experience as abusive are not legally defined as crimes (Kelly, 1988). For example, in countries such as Malaysia and Singapore, domestic violence is seen as a private matter and considerations of family, culture, or religion tend to prevail over women's interests (Amirthalingam, 2005). Although both countries ratified the Convention on the Elimination of all forms of Discrimination Against Women (CEDAW) and have enacted laws against domestic violence, the enforcement of such laws appear to be lacking because domestic violence has been culturally accepted and tolerated to some degree (Amirthalingam, 2005; Awang \& Hariharan, 2011; Jahanfar et al., 2007). In some instances, victims of domestic violence are treated as patients with 'medical problems' and in need of 'medical care' instead of the focus being on the underlying problems of violence against women (Colombini, Mayhew, Ali, Shuib, \& Watts, 2013). This stems from traditional and religious beliefs (such as Islam and Christianity) that the husband is the ruler of the family and is regarded as the formal authority to whom the wife and children must respond and comply with (Sakalli, 2001). For example, the interpretation of verse An-Nisa, 4:34 of the Qur'an said:

Men are the protectors and maintainers of women, because Allah had made one of them to excel the other, and because they spend (to support them) from their means. Therefore the righteous women are devoutly obedient (to Allah and to their husbands), and guard in the husband's absence what Allah orders them to guard (e.g., their chastity, their husband's property). As to those women on whose part you see ill-conduct, admonish them (first), refuse to share their beds (next), (and last) beat them (lightly, if it is useful); but if they obey you, seek not against them means (of annoyance) (Translation of the meanings of the noble Qur'an in the English language, 1984). 
Based on the above verse, a representative from Pusat Islam (an Islamic centre run by the Malaysian government) claimed that the Qur'anic verse on 'nushuz' (disobedience) gives the power to a Muslim man the divine right to beat his wife, and that no human law could deny him that right (Sisters in Islam, n.d). As Muslims were taught to believe in a just God and a just Islam, it was difficult for women to believe that God could sanction injustice, oppression and violence towards them (Ibid). For these reasons, women often police and discipline their own bodies and behaviours (Heidensohn, 2002; Smith, 2005), and police other women too (Kandiyoti, 1988). This self-policing is argued to be well-established in developing countries, small towns, and rural areas or in city slums where women's oppression, gender inequality, and lack of power are prevalent (Antrobus, 2008; Ashurst, 2011; Samarasinghe, 2008). Under these circumstances, women will often lack medical care and also be subject to economic exploitation and deprivation (B. Lee, 2016; Stanko, 1990). They face discrimination due to gender and status disparities (Ibid). These 'harms' are commonly overlooked as normal difficulties that need to be faced in an ordinary course of life (B. Lee, 2016). As a result, women's violence and oppression continues and becomes normalised in everyday life.

The prevalence and impact of sexual violence in women's lives is still not publicly acknowledged despite the enactment of laws to protect women from violence. This is because cultural practices and religious beliefs have been used to subjugate women and ensure that women remain subservient to men and can be controlled by the state. Therefore, states tend to offer only limited criminal justice towards female victims to ensure that women conform to the moral codes of the 'ideal woman'.

\section{Limited Criminal Justice Protection Towards Female Victims}

The public and policy makers tend to expect the victim to be sexually blameless (Doezema, 2000). That is, women whose behaviour violates traditional gender norms (such as by engaging in risky behaviour like casual sex, consuming drugs or alcohol, or hitchhiking) are often considered to be partially responsible for their own victimisation (Grubb \& Turner, 2012; Holmstrom \& Burgess, 1991; LaFree, 1980). The consequence of such an approach is to place culpability for any victimisation onto victims themselves (Newburn, 2013). Blaming the 
victim allows the victimisers to convince themselves that the victim is guilty of some injustice (Fattah, 1991). Rape myths ${ }^{19}$ for example, allow the offender to justify rape to minimise personal vulnerability (Burt, 1983). It also shifts the blame from the perpetrators to victims (Ibid). This allows the offender to transform the victim into a person deserving of suffering and justifies the conscience of potential victimisers (Fattah, 1991). Victim blaming strategies have also been institutionalised, including in courts (Fattah, 1991; Walklate, 2013). For example, defence lawyers often seek to discredit victim's statements so that they can be blamed for the incident that has occurred (as earlier discussed) (Christopher, 2008; Fattah, 1991). This is conducted through vigorous questioning in court to establish any provocation or culpability on the part of the victim (Walklate, 1989b) and also by making insinuations about the victim's morality (Boyer, Allison \& Creagh, 2018).

For sex workers who are often regarded as criminals, sexually deviant, socially inept, and/or mentally deficient (Smart, 2013), their complaints about rape are frequently trivialised or minimised. In some cases, such complaints will be not be regarded as rape, but 'theft of services' (Williams, 2015). This is because there is a presumption that a sex worker who has consented to sexual acts for money does not have the right to forfeit her consent (Ibid). Therefore, those who complain of being raped or attacked face difficulties in convincing the authorities and are likely to be disbelieved by them because of the stigma that is attached to sex workers (Goffman, 1963). They are also perceived as 'undeserving victims' and will typically be treated as someone who contributed to their own mishaps (Miers, 1990; Pollak \& Kubrin, 2007). In this instance, the legal system perpetuates discrimination and denies access to legal protection or recourse (Sallman, 2010).

Further, Amir (1971) suggested that crimes such as rape would not have happened if not without the victim's aid or cooperation, and that there is usually some form of reciprocal action between the offender and the victim. This victim precipitation theory is founded on the myth that victims can prevent attacks by not engaging in risky behaviours (Stringer, 2013). This stems from the deeply rooted patriarchal attitudes towards sex and women's morality. For example, in a case involving an American postgraduate student of Indian origin in Delhi

\footnotetext{
${ }^{19}$ Burt (1983) defined rape myths as false beliefs about rape, rape victims and perpetrators.
} 
who was raped in 2015, the Delhi Lower Court convicted Mahmood Farouqi (the accused), a Bollywood filmmaker, and sentenced him to seven years imprisonment (as reported in Voice of America dated 29/9/2017). However, on appeal, the Delhi High Court Judge set aside the conviction and ruled that 'a "feeble no" could indicate willingness on the part of the victim' (Ibid). Although the woman had told the court that the accused forced himself on her and ignored her 'no', she stopped resisting after some point, fearing that she may be harmed (Ibid). The Delhi High Court Judge (Ibid) ruled 'in an act of passion, actuated by libido, there could be myriad circumstances, which can surround a consent, and it may not necessarily always mean yes in case of yes or no in case of no.'

The women's rights activists denounced the Judge's statement, stating that it reinforced stereotypes that a rape was usually the woman's fault and the onus of preventing assault lies on her (Ibid). As Smart (Smart, 1990) earlier noted 'doubts about the complainant's testimony are routinely generated and women's experiences of sexual abuse discredited when the events of the rape are reproduced as a pornographic vignette' (p.16). As in this case, the complainant (victim) 'is re-scripted as a precipitating agent within a sexualised scenario, effectively disqualifying her from victim status and obviating the accused's responsibility for the events in question' (Larcombe, 2002, p. 135). Therefore, the concept of victim precipitation places unreasonable requirements on victims to demonstrate that they are 'real' and 'deserving victims' (Kelly et al., 2005) and revamps the way responsibility and blame are accorded (Walklate, 1989a, 1989b). Furthermore, examining victim's behaviour for their role in the perpetration of a crime may constitute blaming the victim, thereby holding them responsible for their plight (Walklate, 1989b). It also shifts prevention responsibility from the offender to the victim (Stringer, 2013). In this instance, an individual may find it difficult to ascribe to the title of a victim if found to be partly responsible or complicit in certain acts (Christie, 1986; Lamb, 1996). In such cases, the judiciary may refuse to recognise that the victim has been victimised or deserves the title of a victim (Matthews, 2015).

Overall, the notion of 'blaming the victim' for their own victimisation is problematic because its shifts the focus of the crime committed by the perpetrator to the victim (Walklate, 2013). An example is a rape case involving a first-year law student who was gang raped by three final-year law students inside the private university campus in Sonepat district of Haryana, 
India (as reported in Voice of America dated 29/09/2017). According to the victim, one of the accused abducted her from the local market on Wednesday afternoon in an SUV (Ibid). She was then raped by all three accused in the vehicle until Thursday before she was dumped near the gate of her varsity (Ibid). The victim also revealed that one of the accused blackmailed her by saying that if she revealed the incident to anyone, then pics will be uploaded on social media' (Ibid). The trial court convicted all the accused and sentenced them to seven years imprisonment in March 2017. However, on appeal, the judges in the Punjab and Haryana High Court (Ibid) agreed to suspend the sentencing term and ruled:

The victim had a promiscuous attitude and a voyeuristic mind, and that her narrative does not throw up gut wrenching violence that normally precede or accompany such incidents. The testimony of the victim suggests that there was an alternate story of casual relationship with her friends, acquaintances, adventurism and experimentation in sexual encounters.

The rulings of the Judges in the above cases suggests that the judiciary is inclined to preclude a person from claiming or being accorded the victim status should there be any evidence or suggestion of 'immoral' behaviour, or if the victim does not display an attitude which fits the imagery of an 'ideal' woman: chaste, responsible, and cautious. As Smart (1995) noted '[t]he process of the rape trial can be described as a specific mode of sexualisation of a woman's body' with the precise and intended effect of disqualifying her testimony and experience of sexual assault'(p.84).

Larcombe (2002, pp. 134-135) points out that 'the legal discovery of rape becomes a test of the complainant's [victim] character and credit, particularly in terms of her sexual morality but also in relation to her moral integrity and trustworthiness as a witness' (pp. 134-135). Similarly, in this case, the victim's characteristics and personal lifestyle were sensationalised to shame and blame her. This shows how victim-blaming strategies are used in judicial systems. By using such strategies, women are constantly kept under control, while men are given the benefit of the doubt even in extreme cases such as the one above. This sustains men's dominance over women and ensures women remain inferior. Similar situations occur in human trafficking cases. According to Anne Keyworth, a social activist who has 
continuously advocated for stricter enforcement of the law in the east Malaysian state of Sabah (a destination for thousands of economic migrants from the Philippines and Indonesia):

Some [victims] get fed up and withdraw their complaint while those who persevere feel they are treated as the accused and not as victims. Some employers and agents are wealthy or well-connected and suddenly there is no case. Or the employer may offer to help the victim in exchange for silence during prosecution (as reported in La Croix International 22/8/2016).

In this instance, women see the justice system as corrupt (Ibid) and gender biased (Moossy, 2009). Although the justice system may be criticised for being gender biased, particularly in cases involving sexual violence (Larcombe, 2002), Zedner (2002) argues that the victim plays a significant role in the criminal justice process, 'without the co-operation of the victim in reporting crime, furnishing evidence, identifying the offender and acting as a witness in court, most crime would remain unknown and unpunished' (p.435).

Similarly, in human trafficking cases, Article 6(2)(b) of the Palermo Protocol states:

That state parties should ensure that its domestic legal or administrative system contains measures that provide trafficked victims with assistance to enable their views and concerns to be presented and considered at appropriate stages of criminal proceedings against offenders, in a manner not prejudicial to the rights of the defence.

However, state institutions, including criminal justice agencies, often disregard victims' interests and/or uses victims to achieve professional outcomes, such as using women as prosecution witnesses in court cases (Walklate, 1989b; B. Williams, 2002). Some scholars suggest that these institutions promote a selective justice system, which only acknowledges women who fit the description of a 'legitimate' or 'real' victim (Estrich, 1987; LaFree, 1980, 1981). According to Walklate (1989a), such selectivity is meant to uphold patriarchal beliefs about women (as illustrated in the two examples above). This is obvious in cases relating to 
sexual violence and sexual exploitation where patriarchal norms are applied to determine the victim's credibility (LaFree, 1981; Walklate, 2007). Although there may be laws that restrict evidence of a witnesses 'bad character' or sexual history, this does not prevent the defence from introducing evidence, or asking questions that can be extremely distressing to witnesses (Ward \& Fouladvand, 2018). This shows that legislation on its own does not necessarily translate into justice for victims (Ibid).

The patriarchal norms discussed in this chapter become the basis of women's identity and victimhood. These norms have been instilled through various structures, and are reinforced through generations. As such, women are constantly battling with patriarchal ideas and beliefs in order to justify their identity and rights, even their own victimhood. The law has invariably colluded to oppress women, and this has been done through principles that advantage men and disadvantage women. Those who conform more towards the ideals of the Madonna are more likely to be accepted as legitimate and 'ideal victims' deserving of sympathy, while those who do not fit into this image may be considered unworthy or blamed for their victimisation.

\section{Conclusion}

The myth of an ideal victim has been maintained over time through institutionalised sociocultural practices. Images of women who are weak, suffering, and in need of help have become part of ordinary citizens' perceptions of a 'true victim' (Hoijer, 2004). Concepts of female virtue such as purity and chastity have been useful in controlling sexual behaviour. Following Christie (1986) and Walklate (2007), the identification of an 'ideal victim' is connected with characteristics such as vulnerability, innocence, respectability and lack of agency. The nearer an individual fits the ideal stereotype, the more attention they are likely to receive from victim support workers, the criminal justice process (Walklate, 2007) and from the media (Greer, 2007). Currently, women who do not fit into the image of an 'ideal victim', such as sex workers, are not perceived as innocent and respectable. Instead, such women are presumed to have made 'immoral' choices and are considered as being individually deficit, thus rendering any claim to victim status highly problematic (Walklate, 2007). Such 
presumptions are based on moral judgments which are derived from norms or beliefs which have set certain standards in society. Therefore, this thesis argues that patriarchal practices are oppressive because they normalise harm and violence against women. However, due to the powerful effect of patriarchy, any challenge to the system will be considered as a challenge to the social norms (Silberschmidt, 2001).

Stereotypes of an ideal victim are problematic because they can be unrealistic and static. They do not usually allow any change and mask cultural variations (Ibid). However, stereotypes continue to be used as a benchmark in determining women's victimhood. These stereotypes have assisted in naturalising inferiority and have been internalised by women (Ibid). Due to gender differences and inequalities, women are often treated as passive victims without agency. Within the domain of male/female interactions, the patriarchal system is embedded in structural conditions; historical, political, economic, judicial, social and cultural constraints have patterned stratification systems of gender inequality. While social institutions have promoted 'traditional' values of gender hierarchy and practices, women have continuously sought to challenge these structures and demonstrate their agency and rights. Thus, a more nuanced understanding of victims, that acknowledges patriarchal effects on culture and societal norms, needs to be adopted in understanding women's victimhood, which will be discussed in the following chapter. 


\section{Chapter Three: Sex Trafficking, Agency and Victimisation}

\section{Introduction}

So far, this thesis has established how patriarchal practices have successfully influenced the construction of victimhood and state practices. It has demonstrated how women's agency under patriarchal rules and systems is fundamentally constrained in ways that male freedom is not (A. Sen, 1999). Based on these arguments, this chapter discusses the social and legal construction of sex trafficking and explores the existence and impact of women's agency in sex work. Within this, the chapter expands the concept of agency by considering women's freedom to economic security, as well as their capacity to define choices and to construct the conditions affecting their choices (A. Sen, 1999).

The chapter begins by exploring the legal and academic definitions of trafficking, coercion and exploitation. This is important because to characterise certain conduct as 'trafficking' has significant and wide-ranging consequences for the alleged perpetrators of that conduct, and for the alleged victims (United Nations Office on Drugs and Crime, 2014). Following this, the chapter demonstrates that the ambiguity of certain words associated with trafficking practices, such as 'consent', 'coercion' and 'exploitation' have resulted in multiple interpretations and understandings of trafficking. Furthermore, there is currently a tension between those who support a conservative or even restrictive interpretation of the concept of trafficking, and those who advocate for its expansion (Ibid). The former position embodies a concern that too wide a definition may encompass practices that do not meet the high seriousness threshold expected of 'trafficking' (Ibid). The latter position embodies a different concern: that too narrow a definition may impede investigations, prosecutions and convictions related to practices that should indeed fall under the rubric of 'trafficking' (Ibid). Such divided views have created confusion among authorities who are regularly unable to draw a clear distinction between women who have been sexually trafficked and voluntary sex workers (Chin, 2013; Saunders, 2005). Consequently, women who voluntarily engage in sex work are sometimes categorised as 'trafficked' and they are 'rescued' by the state in the name of protection. While such a form of 'rescue' may prevent women from being exploited by 
their employers, this type of official intervention can also harm and victimise women through the repressive rules and regulations they subsequently experience (an issue identified in the findings for this thesis). Thus, this chapter will discuss the difficulties in assessing victims of trafficking as well as the harms associated with trafficking.

There are two factors that contribute to the confusion and uncertainty of identifying trafficked victims. Firstly, media and anti-trafficking awareness campaigns (by NGOs and states) depict victims of human trafficking as innocent young girls from foreign countries who are manipulated, deceived, or kidnapped and forced to engage in sex work. The 'ideal' victim of trafficking is reified in the characteristics of passivity, weakness and worthiness, whereas exhibiting signs of agency is regarded as a form of 'deviant' behaviour. This legitimises the need for women to be rescued and rehabilitated. Secondly, the concept of 'consent' and 'coercion' has been a highly contentious topic between feminist groups. Abolitionist feminist groups $^{20}$ in particular argue that all forms of sex work, regardless of consent, should be considered trafficking (McCabe \& Manian, 2010; O'Brien et al., 2013) while liberal feminist groups insist that coercion is a necessary element to any definition of trafficking (Davies, 2010; Ferguson et al., 1984). The diverse understandings and interpretations of 'consent' and 'coercion' in sex work has produced polarised understandings among feminist groups. While these debates continue to focus on women's rights to consent to sex work, the demand for sex workers continues to escalate and traffickers take advantage of this situation and exploit women for profit.

\section{Definitions of Trafficking}

The UN Convention on the Rights of Migrants (UNCRM) defines migration as the voluntary movement of persons across borders for personal reasons. The movement of persons is also essential in acts of smuggling and trafficking (Lyons \& Ford, 2013). While smuggling usually involves payment of fees from the migrant to the smuggler to facilitate illegal border crossing,

\footnotetext{
${ }^{20}$ Abolitionist feminist groups consist of individuals and evangelical groups who argue that prostitution is exploitative of women and that without eliminating prostitution, sex trafficking will not be eliminated (McCabe \& Manian, 2010; O'Brien, Hayes, \& Carpenter, 2013). The 'abolitionist feminist' argues that the sex industry should be entirely eliminated because of its objectification and oppressive treatment of women, considered to be inherent in 'sex for sale' (Weitzer, 2007, p. 450).
} 
human trafficking involves the movement of people internally or trans-nationally for the purpose of exploitation at the intended destination (Kelly, 2003; "Resolution 20/3 on Human Rights of Migrants," 2012; Salt, 2000 ). As such, trafficked persons are usually referred to as 'victims of human trafficking' whereas smuggled persons are regarded as 'offenders' because they are in violation of immigration laws (Iselin \& Adams, 2003). Although the interpretation of migration, smuggling and trafficking seems to be clear and easily distinguishable based on the above definitions, the assessment of each of these acts is often more complicated and problematic. This is because exploitation can occur at any point of migration. For example, women may initially consent to migrate and engage in sex work, however, once they start working are then exploited by their traffickers/employers. Exploitation can also occur in cases where women cooperate with their smugglers to attain jobs, but eventually become trafficked by the smugglers or new employers (Kelly, 2003). This overlap between smuggling and trafficking (Kelly, 2003) has led to confusion in identifying women who have been trafficked. As a result, migrant sex workers are sometimes defined as trafficked sex workers regardless of consent and conditions of labour (Chapkis, 2003). To understand this confusion, the following sections examine the definitions of trafficking as well as the elements that form the trafficking crime in order to identify the difficulties and ambiguities of the trafficking definition.

\section{Legal and Academic Definitions}

According to Article 3(a) of the Palermo Protocol, trafficking consists of three main elements. They are: (i) the act, which includes the recruitment, transportation, transfer, harbouring or receipt of persons; (ii) the 'means', which includes threat or use of force, coercion, abduction, fraud, deception, abuse of power or vulnerability, or giving payments or benefits to a person in control of the victim; (iii) the purpose, which includes exploiting the prostitution of others, sexual exploitation, forced labour, slavery or similar practices and the removal of organs (United Nations, 2003). Based on these elements, scholars define sex trafficking as a form of commercial sexual exploitation which involves the movement of persons, across or within borders, under deception or coercion, for the purpose of sexual exploitation (Fergus, 2005; Gallagher, 2004; Segrave et al., 2009). Sexual exploitation is defined in the United Nations 
Glossary on Sexual Exploitation and Abuse (2016) as an act or attempted abuse of position, power or trust to derive gains or profit from the sexual exploitation of an individual.

The US Department of State (2012a) defined a sex trafficked victim as a person who is forced, coerced or deceived into prostitution, or maintained in prostitution through one of the 'means', even after initial consent. In this instance, any consent made by a person will be irrelevant if the person ends up being exploited at any point of time by her traffickers or employers (Giusta, Tommaso, \& Strom, 2008; Iselin \& Adams, 2003). Similarly, Article 3(b) of the Palermo Protocol states that the consent of a victim of trafficking in persons to the intended exploitation shall be irrelevant when any of the (above) 'means' have been used. While such provision is aimed at preventing traffickers from using the victim's consent as a defence, it has also given the judiciary the right to override victim's agency on the grounds that they have been categorised as 'trafficked'. In this instance, the state has the unfettered right to decide if any element of coercion or exploitation exists. This becomes problematic because it can obscure the realities of consent versus coercion and further problematise the existing definitional (mis)understandings.

\section{Coercion, Deception and Exploitation}

'Coercion' is defined by the United Nations Office of Drugs and Crime (2009) as the use of threat of serious harm or physical restraint or abuse of authority against any person through physical, legal, or psychological means. Psychological means would thus include, but not be limited to, situations where a person is not free to leave his or her work because of threats to harm the person's family or fear of being reported to the authorities (Dando, Walsh, \& Brierley, 2016). It also includes the deprivation of psychological needs (e.g., no medical care; restricted food and water; limited sleep), or the denial of privacy (e.g., overcrowded living and working conditions) all of which physically humiliate and degrade victims, and induce physical exhaustion (Dando et al., 2016).

In many cases, traffickers will be prepared to advance all of the costs of travel, food, and lodging, and the women will be required to pay off their debts (plus interest) in the destination country (Ryan \& Hall, 2001). In addition to these expenses, traffickers also create 
debts purportedly incurred through their transportation, recruitment, and living expenses, the protection money paid to police or other officials (Bedoya, Bedoya, \& Belser, 2009), or even their sale (Bedoya et al., 2009; Coomaraswamy, 2003; Kempadoo, 2005; Nagaraj \& Yahya, 1998; The Sun Daily, 2014; Samarasinghe, 2008; Sandy, 2009) which are impossible to repay. This can lead to a state of complete hopelessness and despair in women (Bedoya et al., 2009). As a result, women are left with significant debts and are forced to continue working to settle them. Thus, debt-bondage becomes a common technique which is used to control women and to ensure that they remain obedient to their traffickers.

Deception is another common strategy used by traffickers to ensure that women remain working for them (Villacampa \& Torres, 2015). This is often achieved by giving women false hope that they will be able to return home soon or can work their debts off quickly (Ibid). Most commonly, traffickers entice women with false promises of good jobs and high salaries, as well as promises of a better life (Poudel \& Smyth, 2002). Once recruited, many women are forced into sex work or controlled through debt bondage, as well as violence and threats (Ibid). Other forms of control include limitations on women's mobility through direct employer control, unsafe and unsanitary working conditions, lack of legal protections, underpayment or non-payment of wages, failing to provide regular holidays, and other forms of work-related severe mistreatment (Campana \& Varese, 2016; United Nations Human Rights Council, 2015).

To prevent women from escaping before they pay their debts in full, passports and other immigration documents (if any), are often confiscated and kept by the traffickers (Destefano, 2007). As Shelley (2007, p. 131) describes it:

Loss of identity is key to the dehumanisation of the victim. It also has very practical implications. If trafficking victims escape, they cannot even command the protection of their own country's embassy as they have no proof of their citizenship.

Scholars such as Doezema (2002) and Campana \& Varese (2016) insist that the use of force or coercion needs to be present as it has been included as an essential element of trafficking in 
the Palermo Protocol. However, Kim (2011) argues that coercion would be difficult to prove because it frequently consists of threats that need to be corroborated by victim or witness testimony. Notwithstanding Kim's arguments, states have often used victims' testimonies to implicate traffickers (Cusveller \& Kleemans, 2018; United Nations Office on Drugs and Crime, 2017a). Furthermore, expert medical opinions may only attest the existence of bruises or injuries on the victim's body, but psychological coercion such as restrictions of freedom, isolation, humiliation, and threats to report to authorities can only be witnessed through victim's testimony (United Nations Office on Drugs and Crime, 2017a). Therefore, victim's testimony is not only a necessity but a legal requirement in most states (Farrell, Owens, \& McDevitt, 2014). For these reasons, women who are identified as trafficked by the state are usually compelled to give evidence in court (Ibid).

Besides coercion or deception, evidence of exploitation is also required to prove the existence of trafficking. Although the term 'sexual exploitation' is not specifically defined in the Palermo Protocol, the United Nations (2017, p. 6) defines 'sexual exploitation' as an 'act or attempted act of abuse of position of vulnerability, power or trust for the purpose of obtaining monetary profit through sexual exploitation of an individual'. Evidence of sexual exploitation would normally involve visible evidence such as condoms, sex toys, lubricants, log books, and account statements which would normally be confiscated by enforcement officers during their raids (Kim, 2011). However, these items can also be used as evidence to prosecute migrant women who voluntarily engage in sex work, particularly in countries that criminalise sex work. This becomes complicated in situations where coerced sex workers are found working with voluntary sex workers in the same establishment. In these instances, the case often depends on the victim's testimony and trafficked victims are expected to give stories which fit into the idealised version of a trafficked victim.

\section{The Ideal Trafficked Victim}

Questions and understandings of sex trafficking are embedded in social consciousness and moral/ethical paradigms (Santos, 2010). According to Santos (1995, p. 45), societies are 'the image they have of themselves, reflected in the mirrors they construct to reproduce dominant identifications at any given time in history'. It is these mirrors that include the laws, norms 
and legal institutions that allow routines to be created to ensure the functioning of society (Santos, 2010). Thus, stereotypes and pre-conceptions can both be detected in the legislation relating to trafficking and in its application (Ibid). These stereotypes are also used by the media to create a visual image of an 'ideal trafficked victim' (United Nations Office On Drugs and Crime, 2016). For example, the stereotypical image of an 'ideal' sex trafficked victim (see also previous discussions) is typically portrayed as a young, unsuspecting woman being deceived or told they will have a legitimate job, but who is subsequently sold to pimps and pressured through violence into prostitution (Bruinsma \& Meershoek, 1999; Caldwell, Galster, \& Steinzor, 1997). Similarly, official anti-trafficking discourse assumes that those who are truly victimised are innocent, naive and powerless women and children in need of rescue from ruthless and sadistic men operating organised crime networks (Davidson, 2006; Hoyle et al., 2011; Munro, 2008; Pickering, Bosworth, \& Aas, 2014).

By constructing the victims of human trafficking as entirely passive actors who lack agency, states can position themselves as protectors of the weak and innocent, thereby expanding their internal and external policing powers (Wilson \& O'Brien, 2016). This influences official behaviours, from the top down (Dando et al., 2016). While some women may be deceived by traffickers, many others migrate and engage in sex work wilfully, but end up being exploited at a later stage (Shalit, Heynen, \& Meulen, 2014). However, dominant stereotypes portray women's victimisation to occur from the point of departure. Although there may be individuals who resist or question such stereotypes (Dunton \& Fazio, 1997), many others will judge trafficking situations in relation to these (Santos, 2010). Therefore, the public and officials may be reluctant to empathise or offer any form of assistance because of the consent that was initially given. For example, reports that 41 Lao women who were forced to work as prostitutes in brothels and karaoke bars in southern Thailand were rescued by the Thai police and transferred to a home for trafficking victims in Surat Thani, Thailand (Radio Free Asia, 2011). However, only 21 of them were forced to migrate and work in brothels while the remaining 20 entered Thailand voluntarily (Ibid). According to a Thai human trafficking official, the 21 women would be given shelter and vocational skills such as sewing or baking cookies (Chandran, 2019) while awaiting legal proceedings while the 20 women would not be provided any assistance, and would be deported because they entered the country voluntarily (Ibid). This shows how state officials identify trafficked women based on their point of 
departure even though not every case of movement across borders is forced (Desyllas, 2007). It also shows how women are thought to prefer to sew or bake cookies than letting them make their own decisions (Chandran, 2019; Healy et al., 2012).

According to Butterfly, an Asian and Migrant Sex Workers Support Network, migrant sex workers (particularly Asians) are excluded, isolated, oppressed and marginalised because of the sexism, racism, classism, nationalism and 'whore-phobia' of society (NSWP, n.d, Butterfly, n.d). Migrant sex workers are also faced with issues such as xenophobia, precarity due to their immigration status, lack of access to health and other services, vulnerability to exploitation and violence, and the risk of detention and deportation (Lepp \& Gerasimov, 2019). Thus, many sex worker organisations such as NSWP organise and support migrant sex workers in an effort to address the challenges they confront (Ibid). However, the crucial role of these organisations in promoting the rights, safety, and security of sex workers and addressing working conditions in the industry have largely gone unrecognised by national and international policymakers, donors, and some non-governmental organisations (Ibid). This is because sex worker organisations are routinely discredited and dismissed by state governments (Fedorkó, 2019). They are not given access to formulate their own views on issues affecting them neither are their voices heard at policy-making levels (Fedorkó, 2019; Global Alliance Against Traffic in Women, n.d). For example, not one sex worker organisation has been allowed into the European Union Civil Society Platform against Trafficking in Human Beings, which contains over 100 participants, despite many groups' efforts to join (Ibid). The situation is even worst for migrant sex workers groups. As Lam \& Gallant (2018, p. 293) argued:

Sex workers have been pushing hard to have their voices heard in the media, in the academy, and in community spaces ... However, because of isolation, racism, language differences, and anti-immigrant xenophobia, migrant sex workers' voices are still missing from these conversations - both within the broader society and within the sex workers movement itself.

As a result, decisions made towards sex work have always been made without sex workers input and women in the sex trade are presumed to be in need of rescue and protection. 
Furthermore, as stated by sex workers in Thailand in the Empower Foundation Hit \& Run report $(2012$, p. i):

Instead of respect for our basic human rights under the United Nations Human Rights Council we are given 'protection' under the United Nations Office on Drugs and Crime. We are forced to live with the modern lie that border controls and anti-trafficking policies are for our protection. None of us believe that lie or want that kind of protection. We have been spied on, arrested, cut off from our families, had our savings confiscated, interrogated, imprisoned and placed into the hands of the men with guns, in order for them to send us home... all in the name of "protection against trafficking". It's rubbing salt into the wound that this is called helping us. We are grateful for those who are genuinely concerned with our welfare ... but we ask you to listen to us and think in new ways.

Consequently, the ideologies, assumptions, and agendas that fuel the anti-trafficking industry have resulted in the exclusion and silencing of sex workers when it comes to the development of policies that directly affect their lives and work (Gerasimov \& Lapp, 2019). Therefore, Fedorko (2019) argues that sex workers should be the driving force behind anti-trafficking policies because they have an in-depth knowledge of the sex industry as they are the only ones to have experienced life as a sex worker. Due to the absence of their voices, there is a distorted understanding of sex work and sex trafficking. Sex worker organisations such as Empower Thailand and Butterfly argue that the concept of 'sex trafficking' has become problematic and subject to various interpretations ever since the adoption of the UN Palermo Protocol (Fedorkó, 2019). In addition, highlighting the word 'prostitution' in the Palermo Protocol implies that 'prostitution' is the crux of the problem (Empower Foundation, 2012). What should remain the centre of focus is whether women are forced or exploited within 'prostitution' (Ibid). Empower Foundation further argue that 'sex trafficking' is an unnecessary concept that was forced onto the global south by the global north (Fedorkó, 2019; Lam, 2018; Stevenson, 2019). In this regard, sex work activists argue that migrant sex workers, especially Asian sex workers, are often viewed as being the victims of human 
trafficking and are being controlled and exploited by traffickers and transnational crime rings (Ibid). As Lam notes (2018, p. 27):

\begin{abstract}
Anti-trafficking campaigns and investigations focuses on racialised communities, and portray sexual exploitation as a product of 'foreign populations.' The rhetoric of protecting vulnerable women is used as a guise for racial profiling, with law enforcement and border officials using ethnicity and country of origin as a factor in determining whether or not someone should be suspected as a trafficker or trafficking victim.
\end{abstract}

State funding of anti-trafficking campaigns and NGOs tends to reinforce these (stereotypical) discourses channelling resources to groups whose positions align with the state, or directing resources to limited projects (Shalit et al., 2014). This has resulted in massive 'raid and rescue' operations by the police and NGOs who often use laws related to migrant workers and trafficking to fine, detain, prosecute and deport sex workers (Chandran, 2019). It has led to oppressive measures such as police repression, wider human rights violations, and ultimately the criminalisation of sex work and migration (Stevenson, 2019). For example, in a documentary entitled 'In Rights Not Rescue', 'rescued' female sex workers in Cambodia or known as Women's Network for Unity (WNU) demanded the Cambodian government, NGOs, labour unions, and donors to address workers' rights, and the root causes of human trafficking and sexual abuse instead of forcefully rescuing them and depriving them from earning a living (Stromberg, 2013). The documentary exposed the worldwide 'rescue Industry' organisations which includes NGOs, international churches, government/bilateral donors, some women's groups, fundamentalists, and charities who receive millions of dollars each year based on the number of victims they rescue (Ibid). According to Connelly (2015), these actors combine to form a 'rescue industry' in which 'social helpers' aspire to save women from 'sex slavery', but in so doing, limit migrant women to the role of passive victim (p.154). Through the construction of the passive victim, the rescue industry's intervention into the lives of migrant women can be justified and they are able to control migrant women's bodies and behaviour (Connelly, 2015). 
Scholars and sex work advocates argue that such operations have caused harm to women which is contrary to the purported goal of assisting women (Ahmed \& Seshu, 2012; Lam, 2018). In this regard, women are placed in a hostile environment and confronted with harmful conditions (Stevenson, 2019). The 'raid and rescue' process also undermines and ignore sex workers' agency as well as their legitimate demands for better working conditions and human, social, and labour rights (Lepp \& Gerasimov, 2019). Sex workers are caught between exploitation in the industry and the misguided policies designed to help them (Fedorko, 2019). Thus, Connelly (2015) asserts that 'the rescue industry is characterised by paternalistic attitudes in which the non-Western "Other" requires the righteous Western saviour to intervene for 'her own protection' (p. 156). As a result, women are sometimes forcibly rescued and categorised as 'trafficked victims' despite consenting to engage in sexual labour (Giusta et al., 2008). Those who do decline assistance can therefore be blamed for causing their own victimisation and may also be regarded as offenders while those who made voluntary choices to migrate may be scrutinised and presumed to be irrational for making such a decision. Thus, women's agency has become a contentious subject, particularly among feminists who have integrated more complex accounts of human nature and agency. This includes women's decisions to improve their financial situation by traveling abroad to work, weighing their options, discussions with family and friends, taking advantage of opportunities offered, and continuing to exercise judgment along the way.

\section{Women's Agency}

Combating human trafficking has become an increasingly important political priority for many international governments. At a national level, greater efforts and resources are being devoted to combating this problem. However, such efforts regularly penalise women, neglect their well-being, and ignore their rights to freedom of movement (United Nations High Commissioner For Human Rights, 2002). As well as this, the degree of power or agency that women exhibit throughout their migration experiences is non-existent in anti-trafficking laws (Stoebenau, Heise, Wamoyi, \& Bobrova, 2016). In addition, existing literature on trafficking tends to revolve around women's exploitation rather than their empowerment and control of their working conditions (Weitzer, 2005, 2007). Despite this, women are still able to 
exercise their agency and make strategic life choices within precarious and complex situations (Angelis, 2012). Thus, this section considers women's agency on two levels: one of their ability to exercise agency - particularly sex work; and the other being their agency freedom - their ability to make choices and construct the conditions of choice (Sen, 1999). To show this, the section explores competing arguments on 'choice' and 'agency' between scholars and feminist groups on the choice of selling sex. These arguments demonstrate the unsettled understanding of women's involvement in sex work and how these views influence the construction of a sex trafficked victim.

Radical feminists such as MacKinnon (1987) and Jeffreys (1997) argue that women in patriarchal societies are not free to refuse sex with men, and therefore their participation in sex with men is not fully consensual. Similarly, the Coalition against Trafficking in Women (CATW) questions the notion of 'choice' in the context of sex work (Radovanovic \& Kartusch, 2001; Zheng, 2010). It aspires to abolish sex work entirely, and views prostitution as violence against women and a violation of human rights. CATW and anti-sex work activists argues that sex work is exploitative, even in the absence of deception or force (Bindel, 2019; Jeffreys, 1997; Raymond, 2003). According to them, sex work is a form of sexual exploitation caused by patriarchal and capitalist exploitation, which is considered harmful to women and a violation of women's rights (Limoncelli, 2009). The group argues that sex work is therefore inherently exploitative of women and that without eliminating sex work, sex trafficking will not be eliminated (McCabe \& Manian, 2010; O'Brien et al., 2013). CATW also views the sex industry as violent in nature and argues that this undermines women's sexual agency by reducing their capacity to personally choose and refuse sexual acts (Jean, 2015). According to CATW, women would never willingly choose to be sex workers (Coalition Against Trafficking in Women, 2011) and any woman who migrates for the purpose of sex work (whether coerced or not) is a trafficked victim. Therefore, all forms of transportation and recruitment for sex work, should be viewed as a violation of human rights (Coalition Against Trafficking in Women, 2011). Abolitionists seek to reduce the level of sex work and sex trafficking by tackling the supply and demand in the sex industry (Ibid). According to them, such measures will discourage women from entering the sex industry and would eradicate sex trafficking activities (Ibid). However, Hedlin (2016) argues that criminalising the sale of sex could lead to even more sex trafficking compared to the legalisation of sex work. This is because it would 
result in the decrease of voluntary sex workers, which would increase the purchase price of sex (Ibid). This would heighten trafficking activities as traffickers will take advantage of the shortage of sex workers and traffic more women in order to meet the demand for sexual services (Hedlin, 2016). The abolitionists groups also seek to eradicate sex work and sex trafficking by tackling the demand for sexual services (Ibid). According to them, criminalising the purchase of sexual services and decriminalising the sale of sex (The Demand Model) may decrease the levels of sex work and sex trafficking (Ibid). They argue that reducing the demand for paid sex may make it much less profitable for traffickers to stay in business (Ibid).

However, as detailed above, research in Sweden have shown no convincing evidence that levels of sex work have decreased since introducing the sex purchase ban in 1999 (Östergren \& Dodillet, 2011; Socialstyrelsen, 2008). Instead, the levels of danger for sex workers have increased because sex workers have less time to negotiate their terms with clients due to the client's fear of being arrested by the police (Ibid). The Nordic Model is also said to be counterproductive in terms of reducing sex trafficking activities because women can still be forced, deceived, coerced and exploited by traffickers for the purpose of sexual exploitation (Hedlin, 2016). This is because criminalising the purchase of sex may not affect the trafficker's behaviour in the sex industry (Ibid). Instead, criminalising the purchase of sex provides an incentive for traffickers to increase their activities in order to meet the demand for sexual services (Ibid). Therefore, scholars argue that criminalising clients does not help to reduce the demand for sex work neither does it reduce the prevalence of sex trafficking (Hedlin, 2016; Östergren \& Dodillet, 2011). As well as this, sex workers groups argue that such approaches diminish the safety of sex workers in other ways (The Global Sex Workers Network Projects, 2011). For example, it diminishes the opportunities for sex workers in abusive or trafficked situations to seek assistance from trusted clients to alert the police or local authorities (Ibid).

Although pro-abolitionist sex groups emphasise the violence and danger to women who sell sex, they tend to ignore the fact that migrant women may sometimes be independent agents who decided to engage in sex work to improve their economic stability (Agustin, 2005). Voices of sex workers, claiming agency to engage in sex work, have been excluded from the mainstream anti-trafficking discourse (Levy \& Jakobsson, 2014). As result, those in the sex industry are generalised and regarded as unstable, traumatised, passive and exploited (Farley, 
2004; Jeffreys, 1997; Raymond, 1998). Such views undermine women's agency and their decision to become a sex worker (Levy \& Jakobsson, 2014).

Farley (2003) claims that women cannot exercise free will in sex work because the conditions that permit genuine consent - physical safety, equal power with buyers and realistic alternatives - are not present. According to Farley (2003), structural inequalities, such as a lack of shelter, food and income, should not be considered valid grounds to consent to sex work. However, Agustin (2006) argues that women should not be held responsible for such factors beyond their control. Instead, women should be able to make their own conscious decision to enter the sex trade and improve their economic situation and lifestyle within these structural constraints (Agustin, 2006; Chapkis, 1997; Samarasinghe, 2008; Weitzer, 2007; Zheng, 2010). Thus, liberal feminist scholars acknowledge women's rights to engage in sex work (Beran, 2012; Nussbaum, 1999). They argue that sex work should be viewed as a legitimate form of work and women should have the capacity and right to consent to sex work (Ibid). As noted by Sanghera (2016, p. 66):

\begin{abstract}
It...became clear to me, through many long hours of reflection and discussions with colleagues as well as women in prostitution, that the only way to break the stigma and marginalization of prostitutes was to accept the work they do as exactly that - a form of work, with its own specificities of risks and benefits, but no more or less special than other forms of work.
\end{abstract}

The Global Alliance against Trafficking in Women (GAATW) ${ }^{21}$ asserts that sex work should not be seen as a different category or a different type of labour from agricultural or sweatshop

${ }^{21}$ GAATW is an alliance of more than 80 non-governmental organisations from Africa, Asia, Europe, Latin American countries and North America (Global Alliance Against Traffic in Women, n.d). It coordinates activities, collects and disseminates information, and advocates at regional and international levels (Ibid). Member Organisations include migrant rights organisations; anti-trafficking organisations; self-organised groups of migrant workers, domestic workers, survivors of trafficking and sex workers; human rights and women's rights organisations; and direct service providers (Ibid). GAATW sees the phenomenon of human trafficking intrinsically embedded in the context of migration for the purpose of labour (Ibid). GAATW promotes and defends the human rights of all migrants and their families against the threat of an increasingly globalised labour market and calls for safety standards for migrant workers in the process of migration and in the formal and informal work sectors - garment and food processing, agriculture and farming, domestic work, sex work - where slavery-like conditions and practices exist (Ibid). GAATW also has a special consultative status to the Economic and Social Council (ECOSOC) of the United Nations (Ibid). 
labour (Outshoorn, 2015). According to GAATW, trafficking only exists if there is the use of force or deception (Ibid). Its stance reflects recent research that indicates that many women enter or re-enter the sex industry wilfully, and that not all sex workers are trafficked victims (Basnyat, 2014; Kaya \& Erez, 2018). Thus, Ericsson (1980, p. 343) pointed out that women do not need to be protected from themselves but, instead, need to be protected from 'detrimental factors in the social environment, especially the hostile, punitive, or condescending attitudes of so-called respectable citizens'. Ericsson (1980, p. 343) further states that 'it is not the hooker who should be changed, reformed, or rehabilitated but the social milieu in which she works'. For these reasons, GAATW scholars suggest that women's equality and freedom would best be reflected by destigmatising sex work and refining the conditions of employment for sex workers, including for those who have been trafficked but do not wish to leave sex work (Halley, Kotiswaran, Shamir, \& Thomas, 2006; Meyers, 2014; Santos, 2010). Such views have been echoed by liberal feminists such as Nussbaum (1999) and Schwarzenbach (1991) who argue that almost all of the seriously objectionable aspects of sex work is a direct consequence of an unreasonable moral and legal stigma against sex workers.

As demonstrated above, feminist debates around sex work have been focused on women's choice and decision to enter into and/or remain in sex work. While the abolitionist feminist refuses to acknowledge women's agency in sex work (Ibid), the liberal feminists argues that women are capable of exercising their agency in sex work. Although scholars and feminist groups have differing views on sex work, both acknowledge that women are capable of exercising their agency but are turned into 'passive objects in male sexual practices' (Jean, 2015, p. 55). They also recognised the fact that sex workers often show courage, strength and resilience even though they are faced with oppressive practices (Jean, 2015). Despite this recognition, some groups assume that women who work for a third party are automatically subject to abuse and exploitation compared with those who work individually (Brock, Gillies, Oliver, \& Sutdhibhasilp, 2000). However, Brock et al. (2000) refuted this assumption by arguing that women's satisfaction with their working conditions would depend on the particulars of their work environment, the work they have to do, their understanding of what the work involves and the payment they receive. Therefore, the focus should be on their empowerment and whether they are in control of their working conditions. For example, 
increasing educational levels, or disseminating legal information on labour rights, and legal assistance in a language that is easily understood by women is essential to empower women and ensure that they are informed about their rights and penalties under the law.

Thus, the concept of 'trafficking' itself has created a significant misrepresentation of migrant sex work that impedes women's ability to engage in work that can improve their economic position (Brock et al., 2000). Many women can rationally decide that sex work can be their best economic option and their only way to feed their children and pay their rent (Jean, 2015). They can also develop different strategies such as trying to avoid engaging in certain sexual acts, or refraining from practices that would expose them from contracting sexual transmitted diseases (Ibid). Therefore, the labelling of women as trafficked erases their active participation in the daily survival of their families and themselves - it renders their labour invisible (Brock et al., 2000). In reality, these women's experiences are much more complex as they challenge the binary representation of either complete coercion or individual freedom of choice. However, trafficked women who exercise their agency are often scrutinised and disbelieved (as previously discussed). They are often blamed for causing their own victimisation. This is because there is a general assumption that women who remain in violent relationships violate pervasive cultural codes of victimisation, given everyday assumptions that rational people do not willingly subject themselves to violence (Straus, 1992). Similarly, in trafficking, those who demonstrate any form of agency are often blamed for being exploited by their traffickers (as previously discussed). In addition, women who are trapped in a violent or exploitative situation are also trapped in violent relationships by socialstructural constraints such as gender inequality and a patriarchal criminal justice system (Dunn \& Powell-Williams, 2007) that does not respond to them and, instead, blames them for their own victimisation.

\section{Victim Blaming}

Kim (2011) asserts that the relentless portrayal of an 'ideal trafficked victim' is unfair as it places a high degree of pressure upon women to prove that they have been trafficked. While some voluntary sex workers may be misidentified as trafficked sex workers, there are also 
those who need to establish and prove that they have been trafficked - for instance, women who do not display visible signs of stress or marks of physical violence even though they have been forced or coerced to do sex work (Davidson, 2006). As a consequence, those who have experienced a lower degree of physical victimisation (Espinoza, 2014) or who are unable to present sufficient evidence that they have been trafficked may be blamed by the judges, juries, media, community, or the legislature for causing their own victimisation (Erez, 2013; Ingraham, 1996). In these situations, women are blamed because they do not conform to stereotypical constructions of an 'ideal trafficked victim'.

One particular case in Florida, United States, is that of Jeffrey Epstein, a billionaire who was accused of soliciting 40 women including minors for the purpose of sexual exploitation (Swaine, 2015). Epstein was accused of having sexually trafficked one particular victim (a 28year-old woman) when she was 15 (Ibid). The victim claimed that she was working as a towel girl at Trump's posh Palm Beach club when she was recruited into sexual slavery by Epstein's girlfriend (Gerstein, 2017). She further claimed that the accused forced her to have sex with his friends (Ibid). One of them was Alan Dershowitz, a famous defence attorney and a former professor at Harvard Law School, who condemns the allegations as 'outright false' and 'thoroughly disproved' (A. Joseph, 2015). No charges were laid against Dershowitz. However, Epstein pleaded guilty to two charges: solicitation of prostitution and soliciting a minor for prostitution (Gerstein, 2017). He served 13 months in a county jail and paid financial settlements to many of the roughly 40 women the $\mathrm{FBI}$ deemed to be his victims, including the 28-year-old (Ibid).

In this case, Dershowitz contended that the victim made her own decision to be a sex worker and was never trafficked by the accused (A. Joseph, 2015). The judge in this case struck out the victim's affidavit, which contained details of her sexual allegations and clients, and sanctioned her lawyers from filing it (Gerstein, 2017). Thirty-eight Harvard Law School professors tried to protect Dershowitz and Epstein by releasing an open letter lauding Dershowitz's 'courage' (Ibid). Deshowitz was also given the opportunity to speak to the media and defend himself while $A B C$ News cancelled their plan to show an interview with the victim, citing that she was not a credible person (Meier, 2015). This shows how offenders can be quickly construed as 'the victims' within public discourse, and more importantly, how victims 
are at risk of being blamed and shamed by the professionals and communities in cases of sex trafficking. This shows too how victims' statements can be trivialised, negated and dismissed in courts. It also insinuates that a woman's word is questionable where she is a victim of sexual violence (J. Jordan, 2004). As Scutt (1997, p. vol II. xvi) notes:

For a woman to retain 'credibility' in such a system, she must remain silent about the crimes that are committed against her, particularly where those crimes are perpetrated by powerful men and are directed against her because she is a woman. Yet if she remains silent, she will never gain redress for the wrongs she has suffered, and her reality - the truth - remains covered, unrecognised, ignored.

This case shows how a female victim can easily be disbelieved in sexual violence cases. The victim was also not given equal opportunity to claim her innocence. This is unlike Dershowtiz who could openly advocate and garner support for himself because he was a male powerful figure and had open access to the media. Therefore, Richardson \& May (1999, p. 309) suggest that the 'gender of the victim is significant in terms of expectations of "behavioural responsibility" because of how we understand and explain violence differently in relation to "who" the victim is, rather than the circumstances in which the crime occurs'. Therefore, if two individuals are exposed to identical experiences or suffered identical harm, people would perceive it differently depending on the victim's status, gender, ethnicity, sexual preference, profession, and her/his pre-existing relationship to the perpetrator (Reiss \& Roth, 1993). Although the Palermo Protocol does not categorise victims according to their 'guilt', society's prejudice towards sex workers has resulted in tougher enforcement measures and less safety for women because they have been constructed as 'women of ill repute' (J. Doezema, 2010). To deter 'immoral' activities, states that criminalise sex work ${ }^{22}$ such as Malaysia (Nasira et al., 2010), Indonesia, Myanmar, Thailand and China (Beyrer \& Stachowiak, 2003; Lean, 1998) enact laws that criminalise sex workers, thereby serving as societal reinforcements of stigma, which serves as an example of structural discrimination

\footnotetext{
${ }^{22}$ Sex work is considered immoral and illegal in 109 countries. However, it is legal in 77 countries (N. Y. S. Chan, 2016).
} 
(Pheterson, 1993). For example, a woman who earns money through sex is often seen as selling her honour, and in many countries may lose her civil liberties and human rights as a result of negotiating her sexuality (Ibid). In Malaysia for example, s. 8 of the Immigration Act $1956 / 63$ prohibits the entry of sex workers or any individual who intends to become a sex worker. Such forms of prohibition dictate the loss of a person's freedom to travel or emigrate and the right to sexual self-determination and sexual privacy (Pheterson, 1993). Sexual selfdetermination and sexual privacy in this instance would refer to the right of being entitled to sexual activities without being discriminated against or treated as unequal or criminal (Abraye, 2014).

The outright discrimination towards sex work and sex workers has resulted in trafficked women being isolated. As a result, many become heavily dependent on their traffickers for resources and can form attachments to their traffickers (Espinoza, 2014). In some cases, women may blame themselves for being tricked by their agents (Brunovskis \& Surtees, 2012). They may also fear being perceived as criminals if they attempt to seek help from the authorities because of the sexual activities they are engaged in (Logan et al., 2009). For these reasons, women may be unable or unwilling to jeopardise their lives by reporting or seeking help from the relevant authorities.

\section{Conclusion}

The discussion in this chapter has shown that the legal definition of trafficking is unclear and states face many challenges when trying to link formal definitions of sex trafficking with the experiences of women who are exploited by migration or sex trafficking activities (Skilbrei, 2010). This is because of the pre-conceptions and stereotypical images of 'ideal victims' that are used by state institutions such as the police and judiciary to determine the victim's innocence. As previously discussed, female victims of sexual violence have been continuously blamed by the court because they were unable to prove their 'innocence' to the satisfaction of the court. This shows the unequal power relations that exist in state institutions that serve to undermine those who are poor and prioritise those who are rich and powerful. This suggests that those who are poor and vulnerable may not be able to receive justice and are 
viewed as independent agents. Similarly women who exercise their agency and choose to engage in sex work are often viewed as 'immoral' and 'promiscuous', while those who demand sexual services are seldom blamed for the proliferation of sex trafficking activities. Instead, men's demand for female sex workers is considered natural and masculine. Given this double standard of morality, there is reluctance to accept women's agency, particularly in sex work.

While abolitionist feminists argue that sex work is harmful and exploitative to women, they have not provided an alternative for women who are poor, unemployed, or uneducated to improve their financial situation. Therefore, liberal feminists contend that women have the right to consent to sex work and that women are entitled to make decisions on their own bodies. Furthermore, sex work provides an opportunity for women to work and earn an income in order to escape poverty (Lagon, 2007). However, traffickers take advantage of women's economic desperation and exploit women for their own benefit. This will be discussed by using Malaysia as a case study. Thus, the following chapter will discuss how the state authorities and public view migrant sex workers and the factors that contribute to the proliferation of sex trafficking activities. Within this discussion, the chapter will explore the challenges the authorities face in implementing the anti-trafficking laws and how state intervention is carried out in the name of victim protection. 


\section{Chapter Four: Sex Trafficking in Malaysia}

\section{Introduction}

The previous chapter discussed the tenets of sex trafficking and how sex trafficking operates. It has also discussed women's agency and how women are often blamed for exercising their agency. Thus, this chapter will demonstrate the failure of Malaysian state agencies to respect women's agency and how state actions limit women's opportunities for action, particularly after rescue. The chapter explores the trend of sex trafficking in Malaysia, and the media representation of trafficked women. It will analyse the harms associated with trafficking and state practices that harm women. The chapter focuses on three main points. The first shows how trafficked women are deprived from exercising their agency. The second relates to how trafficked sex workers are represented - as threats, sex offenders, and foreign invaders (Suppiah \& Kaur, 2018). The third discusses the harmful nature of 'state protection' in Malaysia. However, institutional harms are not 'seen' and not associated with trafficking harms, because they operate in the name of 'protection'.

Given these factors, the first part of the chapter explores the definition of sex trafficking in the Malaysian context and how sex trafficking activities have evolved over time. It charts the history of sex trafficking. It focuses on specific local cultures, trafficking routes, and the role of traffickers in the proliferation of commercial sex in Malaysia. The second part of the chapter analyses the continuum of harm experienced by women throughout the trafficking and post-trafficking stages. It explores how trafficked women are represented in the media and highlights the discrimination faced by women engaged in sex work. Such portrayals may influence societal perceptions of the nature of sex trafficking and the characteristics of (dangerous) victims, particularly as discussions are led by powerful definers. The third part of this chapter demonstrates how the Malaysian government has effectively dismissed and denied women's agency through anti-trafficking laws and practices. It also explores the contradictory approach taken by state authorities that depict trafficked women as helpless and in need of assistance but also as individuals who need to be 'rescued' and detained in shelters. Although such acts of 'rescue' may be thought to relieve women from misery, this 
thesis later demonstrates how women were traumatised, victimised, and violated of their rights through state protection.

\section{The Malaysian Definition of Sex Trafficking}

The Anti Trafficking in Persons and Anti-Smuggling of Migrants Act, 2007 (ATIP) does not specifically define the meaning of 'sexual exploitation' but defines 'exploitation' to include 'all forms of sexual exploitation, forced labour or services, slavery or practices similar to slavery, servitude, or any illegal activity or the removal of human organs' (s2). The meaning of 'any illegal activity' in section 2 of ATIP is rather vague. This suggests that it may refer to any form of sex work including voluntary sex work, given that sex work is illegal in Malaysia. This contradicts the meaning of trafficking which specifically requires the element of 'means' to be present apart from the 'act and 'purpose' (see Chapter Three). The 'means' in this context would refer to acts of force, coercion, deception, or abuse of power (s2 ATIP) which includes social isolation, passport confiscation, limited freedom of movement, threats, or physical, sexual or psychological assault (Segrave et al., 2009; Zimmerman et al., 2011). Based on these definitions, sex trafficking in the Malaysian context would refer to all actions involved in acquiring or maintaining the labour or services of a person through coercion, and includes the act of recruiting, conveying, transferring, harbouring, providing or receiving a person for the purpose of sexual exploitation.

While legal and academic definitions are crucial in understanding the act of trafficking, proving an act of trafficking remains difficult especially when it involves coercive acts, such as threats and false promises (Kim, 2011). At present, the main form of evidence that can be used to implicate the traffickers of their crime is through the women's testimony in court. However, this may cause a negative impact upon the women as they would have to endure vigorous questioning from court officials and relive their traumatic experiences. It may also expose them to embarrassment and humiliation, especially if their identities or other private held information is revealed (Ejalu, 2006) (see also Chapters Two and Three). This shows how judicial proceedings can cause emotional distress and re-victimise women (Ibid). 
Given that women's testimony is vital for the prosecution's case, section 16 of the ATIP treats the consent of trafficked persons as irrelevant. This means that although women may have consented to their migration and work, their consent cannot be used as a defence to absolve the traffickers from their crime. This includes cases where women have initially agreed to migrate and work but were later deprived of their freedom of movement (Campana \& Varese, 2016). Under these circumstances, the consent of an individual at one stage of the process cannot be taken as consent at all stages of the process. Without consent at every stage of the process, an act of trafficking would be deemed by the state to have taken place (United Nations Global Initiative to Fight Human Trafficking, 2008). Whilst this may prevent or reduce any act of victim blaming, it also overrides women's agency to a certain extent because women are thought to be incapable of making their own decisions (Harrington, 2005). This is because stereotypical images of trafficked victims consider agency to be incompatible with victimhood. Based on such a presumption, trafficking overlaps with the act of migration, which also causes an overlap between voluntary and coerced sex work. For example, migrant women who voluntarily engage in sex work may have agreed to a certain amount of deduction of fee to their pimps. However, such an arrangement is considered to be illegal and exploitative by state laws. In this instance, the women could be categorised as trafficked victims because there is a presumption that trafficked women are naïve and are unaware that they are being trafficked. Therefore, the following sections will demonstrate how the sex industry has evolved over the years in Malaysia, the routes used by migrant women to enter Malaysia, and the different technics used by traffickers to convince women to migrate and work in the sex trade.

\section{Evolution of Sex Work in Malaysia}

Sex work has both historical and cultural specificity in Malaysia. According to Manderson (1997), its composition, character, and structure developed in response to particular local economies and demographies. The involvement of Malay women in sex work in the peninsular Malay states can be traced to the pre-colonial period (late 16th Century - early 18th Century)(Hasan, 2005). During this era, sex workers were mainly Malay women who were slaves, mistresses/concubines (Brown, 2000), and female followers of kings and Malay royalty (Hasan, 2005). These women were under the control and protection of the king and 
his lords and provided sexual services to powerful rulers to satisfy their master's sexual pleasure (Ibid). At the same time, some of them were also exploited and forced to earn money for the rulers. As Gullick (1970) in his study on the pre-colonial period, quotes one of the slaves of a Malay lord as saying 'tonight we can be prostitutes, and give some earnings to the king... if we fail to do so we will be beaten with a big cane' (pp. 166-167).

This shows the element of threat, coercion and exploitation that were used by powerful rulers upon women. These sexual practices changed during the colonial period (late $18^{\text {th }}$ century to the 1940s), when brothels emerged to cater for male's sexual demands and were more accessible to all classes (Loos, 2009; Stoler, 1997). During this period, Chinese nationals were brought into Malaya (now known as Malaysia and Singapore) by the British to work in the tin mining fields, and Indian nationals, in the rubber and sugar plantation (Nagaraj \& Yahya, 1998). The number of Chinese nationals in Malaya was estimated to be 230,000 in the 1880 s (P. Lee, 1978) while Indian nationals were estimated to be 75,000 (Arasaratnam, 1979). Those who were recruited were primarily males and were brought in under the indentured system ${ }^{23}$ that provided little room for having a wife and family (Nagaraj \& Yahya, 1998).

According to Purcell (1948), there was a disparate ratio of 100 Chinese males to less than 10 Chinese females in 1901, and 18 Indian women to every 1,000 men in Malaya and Singapore in 1891 (Nagaraj \& Yahya, 1998). The shortage of women resulted in a surge in demand for sex workers, particularly in the tin mining state of Perak and the rubber plantations in Johore (Ibid). During this period (late $19^{\text {th }}$ century), many brothels emerged and were allowed to operate freely (Ibid). Women, particularly from China, India, Thailand and Malaysia were kidnapped, deceived, lured and forced to work in brothels. According to Manderson (1997, p. 383):

In Malaya, the Philippines, and elsewhere in Southeast Asia, many Chinese and Japanese women were seduced or kidnapped into prostitution. However, some of them were knowingly recruited and worked in the brothels because

\footnotetext{
${ }^{23}$ A system of semi-forced labour where workers were normally indentured for two or three years (600 days actual labour) and were required to pay back the cost of their sea passages out of their wages (Kaur, 2006a). Breaches of these contracts were regarded as criminal offences (Ibid).
} 
they wanted to support their poor families and fulfil their economic and related kinship obligations.

These sexual practices later expanded during the Japanese occupation of Malaya in World War II (Hirofumi, 1998). Throughout this period, military prostitution thrived and sexual services were institutionalised (Ibid). During the Japanese era (early 1940 to 1945), women were recruited within Malaysia and also from occupied Japanese territories such as Korea, Taiwan, China, Myanmar, Philippines, Indonesia, East Timor, Thailand, and Pacific Islands to work as sex workers and satisfy the sexual demands of the Japanese Imperial Army (Michiko, 2001; Soh, 1996). Many were kidnapped, coerced or tricked into believing that they would be working as nurses with high paid salaries, but were forced to work as 'Comfort Women'24 upon their arrival in Singapore (a part of Malaysia before 1963). These 'Comfort Stations' were set up by the Japanese government 'to prevent the rape of local women by the Japanese soldiers, to limit anti-Japanese resistance in occupied areas, to protect the Japanese soldiers from venereal disease, and to avoid international disgrace' (Michiko, 2001, p. 582). However, 'Comfort Stations' was a euphemistic term used to describe World War II rape centres, as women were forced to work as sex slaves (McDougall, 1999).

In the wake of World War II, the scale of commercial sex developed and became integrated into the economic, social and political life of Southeast Asian nations (Lean, 1998). The sex business assumed the dimensions of an industry and directly or indirectly contributed to employment, national income and national growth (Ibid). Together with the development of urbanisation and industrialisation in Southeast Asia, the pattern and pace of migration intensified (Ibid). Men and women from rural areas migrated to cities in search of better jobs, with men typically receiving better incomes than women (Kassim \& Zin, 2011a). As a result, the purchase of sex became more affordable and Penang became the second most popular destination, after Bangkok, on the 'sex tourist map' in Southeast Asia (Ariffin, 1986, p. 29). There have also been newspaper reports suggesting Kuala Lumpur as the next sex capital of Asia (Deccan Chronicle, 2017; Hunter, 2015).

\footnotetext{
${ }^{24}$ A 'Comfort Woman' means a prostitute or 'professional camp follower' attached to the Japanese Army for the benefit of the soldiers.
} 
However, there is a reluctance by the police ${ }^{25}$ to acknowledge the size of the sex industry in Malaysia (Cheng, 2014). Indeed, they deny that a sex industry even exists (Ibid). Therefore, assessing the size of the sex industry is difficult because the trade is largely illegal and often underground (World Health Organisation, 2001). Furthermore, sex outside the confines of marriage is considered unacceptable in the official codes of most Asian societies, although men's purchase of commercial sex is tolerated and, in some instances, may be actively encouraged by local definitions of masculinity (Ibid). This suggests a strict sexual double standard operating throughout Malaysia. There are no statistics available to quantify the clients who purchase commercial sex, however, transport workers, medium-waged earners and professionals, seafarers, businessmen, and men who are separated from their families and communities are reported to be regular clients and also the ones creating the demand (Ibid).

In cities like Kuala Lumpur, sex services are currently available in massage parlours, pubs, karaoke bars, and private houses, all of which usually operate under the guise of entertainment outlets, spas, salons, reflexology or health centres (Hunter, 2015; R. Lee, Lai, \& Raman, 2013). Sex services are also available via online booking and social networks such as Facebook, Twitter, Whatsapp, and WeChat (Caspari, 2015; Chan, 2016; Mstar, 2017). Women's ethnicities, body measurements, and photos are advertised through websites and social apps for easier bookings and to evade detection by the authorities (Kunze, 2010; Shahrudin \& Asyraf, 2016). Although Malaysia's 'Communications and Multimedia Act 1988' $(\text { CAMA })^{26}$, and the 'Personal Data Protection Act 2010 (PDPA)'27 are used to monitor and prevent criminal and commercial sexual activities over the internet (Leng, Khan, \& Rahim, 2014), the sex industry continues to thrive and traffickers advertise and exploit women with impunity using these platforms (Kuo, 2000). As a result, Malaysia is categorised as a source,

\footnotetext{
${ }^{25}$ The Head of the Secret Societies, Gambling and Vice Division of the Royal Malaysian Police denied this in a local newspaper (Cheng, 2014).

${ }^{26}$ Section 233 of the CAMA states that any person who solicits and initiates the transmission of, any comment, request, suggestion or other communication which is obscene, indecent, or provides any obscene communication for commercial purposes to any person commits an offence and shall, on conviction, be liable to a fine or to imprisonment for a term not exceeding one year or to both.

27 Section 113 and section 24 of the PDPA states that a warrant may be issued by the Magistrate who may authorize the search and seizure of any computer, book, account, computerized data or other document which contains or is suspected to contain information to any offence and upon conviction, may be liable to a fine or to imprisonment for a term not exceeding one year or to both.
} 
transit, and destination country for human trafficking activities (Lyons \& Ford, 2013; U.S Department of State, 2015, 2016, 2018). Furthermore, the multiple routes and entry points into Malaysia have allowed traffickers to use different techniques and strategies to traffic foreign women into Malaysia.

\section{Trafficking Routes}

Southeast Asia has a long coastline with undefended borders and the sea surrounds all of the countries in the region, except landlocked Laos (N. Othman, 2006). Although the MalaysiaThailand border is estimated to be $656 \mathrm{~km}$, only $111 \mathrm{~km}$ is gated, and most areas are not monitored by the authorities (Aslam, 2018). In addition, the close proximity from one state to another makes it convenient for traffickers to traffic women across borders. According to the United Nations Office of Drugs and Crime (2015a), some women are trafficked into Malaysia through Thailand using motor vehicles through forest and jungle areas. This is to avoid detection by border authorities because sex workers are categorised as prohibited migrants according to section 8 of the Immigration Act 1959/63 (Ajis, Askandar, \& Awang, 2015).

Although some women may have entered Malaysia illegally or were accompanied by their traffickers, many travel independently and do not show signs that their movements are being controlled (Segrave et al., 2009). This makes it hard to detect human trafficking activities at the border (Pickering \& Ham, 2013). Furthermore, travel to Malaysia has been made easy through the visa-free policy that grants nationals from most Southeast Asian countries 30-day visa free entry into Malaysia (Official Portal of Immigration Department of Malaysia, 2018). Given this, most women travel to Malaysia using commercial air carriers, buses and ferries. Among the popular routes are via Kuala Lumpur International Airport (KLIA) (air), Sungai Golok (Thailand) (land/sea), Danok (Thailand), Singapore (land/sea) and Bay of Bengal (Bangladesh) (sea) (Murdoch, 2015; Sopapong, 2012; Ullah, 2009). Analysing and tracking these trafficking routes is difficult as they overlap with normal commercial travel routes (Buang, 2017; Stanslas, 2010). This is particularly evident when trafficked persons are transported using the normal commercial air carriers (Buang, 2017). 
Given the cheap and affordable air fares offered by low-cost carriers, air travel has become the preferred mode of travel, particularly for women originating from Indonesia, Thailand, Vietnam and Bangladesh (Ajis et al., 2015). Their entry into Malaysia is sometimes facilitated by the help of immigration officials who collaborate with their traffickers (Buang, 2017). According to Transparency International (2018), corruption is present at every stage of the trafficking process, beginning with a victim's recruitment and transport, through to their exploitation. Pay-offs to police and other public sector officials result in state institutions being willing to turn a blind eye to trafficking gangs or even to cooperate with them (Transparency International, 2018). Once the victims reach their destination and the exploitation begins, traffickers rely on police corruption to maintain their silence and avoid arrest (Ibid). As a result, state institutions become weak and may only offer limited protection (Ibid). Thus, Phil Robertson, Asia's deputy director of Human Rights Watch claims that the Malaysian government has created a system where unscrupulous labour brokers, corrupt police, and abusive employers are able to operate with impunity (Hodal, 2014).

One example of this can be seen in a case that occurred in 2016 where a significant number of immigration officials were found to have been involved with corrupt practices at Malaysian airports (Buang, 2017; Rozanna \& Chow, 2016; The Star Online, 2016). This was carried out through the deliberate disabling of passport checks at checkpoints and ongoing technical faults, which allowed hundreds of passengers to enter Malaysia without undergoing normal procedures (Ibid). As a result of official investigations into hundreds of immigration officers, 600 officers were transferred out of the department, 15 immigration officers were charged with corruption and abuse of powers, and 15 were suspended, while 22 others faced disciplinary action (Buang, 2017; Rozanna \& Chow, 2016). The then Deputy Prime Minister, Datuk Ahmad Zahid Hamidi, stated that there were at least 100 officials involved in sabotaging Malaysian passport controls (Leong, 2017). As a result, Kuala Lumpur International Airports have been categorised as destination hubs for traffickers to carry out their human trafficking activities (Buang, 2017). 


\section{Sex Trafficking in Malaysia}

In Malaysia, the government's approach towards sex work is influenced by the abolitionist approach and their identification and perception of sex trafficked victims is based on the assumption that all sex workers are potential victims of trafficking (Segrave et al., 2009). Therefore, migrant women who are found to be working in establishments that provide sexual services are regularly 'rescued' by the police and immigration officials. According to official reports, the majority of female migrants who had been trafficked into Malaysia are from neighbouring countries such as Indonesia, Thailand, Myanmar, Cambodia, the Philippines and Vietnam (U.S Department of State, 2014b). The influx of women from neighbouring countries is attributed to several factors such as the demand for women in the sex trade, poverty, low income, unemployment, gender biases, as well as the need to improve their economic situation (Beyrer, 2001; Nasira et al., 2010; Othman, 2006).

In addition, the similar culture, characteristics, religion, and lifestyle that exist among people in Malaysia and some Southeast Asian states, for example Indonesia, make it easier for women to adapt to their surroundings (Z. Othman, 2006). In 2015, forty percent of Indonesian population lived below the international poverty line (US\$1.90 per day), and the majority of the poor are females who live in rural areas (Asian Development Bank, 2015). The poverty levels and inequalities in Indonesia are both associated with a lack of good paying jobs in the economy (Ibid). According to recent reports, factory workers in the manufacturing industry can only earn an average of 942506.80 IDR per month (USD62.51) (Trading Economics, 2019), compared to the minimum wage in Malaysia which is RM5.05 (US\$1.24) per hour or US\$270 per month (from 1 January 201928) (Asian Development Bank, 2019; New Straits Times, 2018). According to a Malaysian local newspaper, sex workers with degrees could earn between RM250 (NZD91) to RM500 (NZD183) an hour ${ }^{29}$ (The Star Online, 2019). In countries like Malaysia, Thailand, Indonesia and the Philippines, sex work provided significantly higher earnings than other forms of unskilled labour. For example, The Immigration Director in

\footnotetext{
${ }^{28}$ Before 1 January 2019, the minimum wage in Malaysia was RM900 (USD221) in Peninsular Malaysia or an hourly rate of RM4.33 (USD1.06) (Joo-Ee, 2016). Foreign workers (other than domestic servants) are also entitled to the minimum wage (Ibid).

${ }^{29}$ As reported in the local newspaper by the principal assistant director, Royal Malaysian Police, Bukit Aman (Anti-Vice, Gambling and Secret Societies Division) “local women are more popular than foreigners".
} 
Malaysia stated that a foreign sex worker in Malaysia could earn up to USD6,000 a month (NZD9,200) (Reuters, 2010) and estimates that sex workers could support between five and eight other people with their earnings (Global Network of Sex Projects, 2017). Thus, the International Labour Organisation (ILO) states that sex work is usually better paid than most of the options available to young, often uneducated women, despite the stigma and danger attached to the work. In many cases, sex work is often the only viable alternative for women in communities coping with poverty, unemployment, failed marriages and family obligations in the nearly complete absence of social welfare programmes (International Labour Organization, n.d). For single mothers with children, it is often a more flexible, remunerative and less time-consuming option than factory or service work (Ibid). Thus, household heads in Indonesia have become aware of the income potential in overseas sex work and encourage their daughters to migrate to Malaysia to work (Elmhirst, 2004; Silvey, 2004). Those who are poor and intend to migrate and work in Malaysia will usually acquire loans from their relatives, friends, or intermediaries involved in the migration industry, so they can afford to travel (Kaur, 2006b).

Similarly in Thailand, daughters are expected to contribute in any way they can to support their parents (Roux, 2010). This expectation occurs in conjunction with a well-known and understood economic structure that provides relatively high rewards for work in the sex industry (Lean, 1998). For example, Empower Foundation (2017) reports that sex workers who work in massage parlours could earn an average of USD2000 (NZD3,100) per month (wages and tips) and would often send money back home to their families in rural areas (International Labour Organization, n.d). Recent newspaper reports also state that sex workers could earn between RM450 (NZD164) (for 45 minutes) to RM7,000 (NZD2,556) (per night) per customer (Basri, 2018). The worker would be entitled to 60 percent of the amount while the remaining 40 percent would be paid to the employer (Ibid). Although there are varying accounts on wages, traffickers often advertise high salaries to entice women across the globe. In this instance, women are attracted to the lucrative salary sex work has to offer.

Therefore, becoming a sex worker often satisfies women's expectations of themselves as breadwinners for their families (Simpkins, 1998). Traffickers take advantage of such expectations and sexually exploit women for profits (Raymond, 2002). This recruiting of 
foreign women into the sex trade has had a long history in Malaysia and has evolved over time, with methods of trafficking becoming more intricate and complex to evade detection by the authorities. The following section explores some of the underlying factors that have contributed to the proliferation of sex trafficking in Malaysia.

\section{Traffickers}

Women coming from a situation of poverty or unemployment are highly unlikely to be able to afford to travel between or across continents and find jobs in foreign countries (Kelly, 2003; Ryan \& Hall, 2001). Thus, many will seek the assistance of family and friends for employment and finance (Kelly, 2003). Some may also engage the services of intermediaries or agents to assist them in obtaining employment and facilitate their overseas travel (Ibid). Recruiters or agents can transport the women to places of work or to pimps (Cauduro, 2009; UN.Gift, 2008) but they may also be employers or owners of businesses such as brothels, massage parlours, spas, karaoke bars, entertainment outlets or clubs. In some cases, recruiters may also be individuals who work for employers, and they are normally involved in managing the sex trafficking operations or guarding the women (Ibid).

Traffickers and their victims often come from the same place, speak the same language or have the same ethnic background (Brock et al., 2000; Molland, 2012; Samarasinghe, 2008). In terms of nationality, recruiters in origin countries are usually citizens of those countries, while traffickers in destination countries are either citizens of those countries, or have the same citizenship as the victim(s) they traffic (Ibid). Such commonalities help traffickers generate trust from their victims (Segrave et al., 2009). They can also easily control their victims because victims may not know the language or laws of the new country in which they reside (Hagstedt et al., 2009). While women are most likely to be victims, there are also those who act as traffickers (United Nations Office On Drugs And Crime, 2012, 2017b). Statistical analysis conducted by the United Nations Office on Drugs and Crime (2012) on 46 countries worldwide shows significant female participation in sex trafficking offences. This clearly challenges the 'ideal victim' perception where only men can be perpetrators and not women, unless they are exceptionally aberrant (Broad, 2015). Female traffickers are commonly used to recruit 
women and girls for the purpose of sexual exploitation in Southeast Europe (Surtees, 2008) and Asia Pacific countries (Broad, 2015; Brock et al., 2000; Miccio-Fonseca, 2017). They are used to recruit children (under 18 years of age) because children are not seen as dangerous, risky or a threat to human trafficking operations (Bindel, 2013; United Nations Office On Drugs And Crime, 2017b).

Female recruiters/agents are often selected for their ability to quickly establish trust with victims because they are perceived to be credible and authoritative (United Nations Office On Drugs And Crime, 2008). In some cases, female recruiters are former 'victims' and once their 'debt' has been paid to their employers, they have realised the financial gains that can be made from these criminal enterprises and become traffickers themselves (Bindel, 2013; United Nations Office On Drugs And Crime, 2006). This shows how women internalise their own victimisation and may normalise their own harmful experiences. Foreign women who intend to migrate to Malaysia and work are normally introduced to traffickers through recommendations from acquaintances, friends, relatives, or through formal or informal work agents (Molland, 2011). Brokerage fees differ according to the job offered (Cambodian Women's Crisis Centre, 2005). Usually, women who are deceived about the nature of work will only need to pay a nominal fee of US\$100 to the agent, who could receive an amount of US\$3,500 (per person) from selling them to brothels, spas, or massage parlours (Ibid). The amount of US\$3,500 paid to the agent would become the basis of the woman's debt and she will be held on debt bondage until she repays the amount owed to her employer or trafficker by providing sexual services to customers each day (Ibid). ${ }^{30}$ In some cases, women are given the option to quit their jobs if they can recruit another person as a replacement (Chin, 2013). Hence, they may recruit their own family members, relatives or friends to work in the sex industry. Through this system, the traffickers receive a steady supply of women without having to recruit any women themselves.

The Royal Malaysian Police reports that sex trafficking activities in Malaysia are largely operated by transnational organised crime groups (Ramayal, 2013; Zinin, 2010). However, research elucidating the 'organisation' of human trafficking is diverse and contradictory

\footnotetext{
${ }^{30}$ Although this report was made in 2005 , an extensive search on the internet has resulted in no recent comprehensive reports.
} 
(Finckenauer, 2011). Finckenauer (2011, p. 172) argues that trafficking represents 'crime that is organised' rather than 'organised crime'. Although there are indicators that some traffickers might be associated in structurally and hierarchically criminal groups and networks, the International Centre for Criminal Law Reform and Criminal Justice Policy (2011) contends that there is not much evidence to support the fact that trafficking is carried out by largescale criminal networks in countries worldwide. Therefore, this link is 'presumed' rather than based on reliable evidence (Farrell et al., 2010). This thesis demonstrates (in Chapters Six and Seven) that traffickers comprise a range of individuals as well as agencies, including family members, relatives, friends, neighbours and work agents who may or may not be connected with a bigger organisation. Those who are connected with bigger organisations usually operate massage parlours and brothels (Chin, 2013; Finckenauer, 2011). In most cases, traffickers arrange for women's travel to Malaysia, including their travel documents and visas (United Nations Human Rights Council, 2015). The UN Human Rights Council (2015) reports that once in Malaysia, traffickers confiscate women's passports and force them to provide sexual services to repay the debts incurred for their travel. Women are also constantly watched and accompanied by their traffickers (United Nations Human Rights Council, 2015). Traffickers seem to operate with impunity because women do not have access to or understand the legal protection services available to them. As a result, they become more isolated and dependent on their traffickers.

Traffickers normally employ female migrants to work as masseurs in spas and massage parlours, or as social escorts in entertainment outlets (Hunter, 2015). These establishments operate under the guise of legal businesses and pay revenue to the government, thus strengthening their appearance of legitimacy. According to the World Health Organization (2001), the sex industry in four Southeast Asian countries (Malaysia, Thailand, Indonesia and the Philippines) is estimated to account for between 2 and 14 percent of Gross Domestic Product (GDP). It has also been reported that human trafficking activities are essential to Malaysia's economy, given that Malaysia heavily relies on slave labour and migrant women (Malaymail, 2015). Therefore, Hodal (2014) suggests that the government may likely be in favour of protecting the businesses, employers and agents that employ trafficked women rather than addressing issues of corruption and malpractice. As a result, women remain at risk of being prosecuted for immoral activities while perpetrators often evade controls or 
punishment for their actions. This is evident through media reporting where women become the centre of attention while there is minimum disclosure about the traffickers. Thus, the following section will examine the way voices of enforcement officers are brought into news texts to represent trafficked women as illegals, threats, and victims in specific contexts - and will also demonstrate how this in turn reduces focus on traffickers.

\section{Media Representations of 'Trafficked' Women}

Rodríguez-López (2015) contends that the way the media portrays human trafficking has a significant influence on the construction of social perceptions and, consequently, on the development of a legal framework to fight this crime. Stereotypical ideas, based on the existence of an 'ideal victim', oversimplify the complexities of human trafficking and leave potential victims unprotected (Ibid). Thus, scholars argue that constructing trafficked women as victims fails to recognise the ways in which they are also agents making choices (Brunovskis \& Surtees, 2008; Jean, 2015). Such distinct representation creates tension between the victimisation and agency of trafficked women. This tension is central to this analysis and the understanding of the social construction of trafficked women. In Malaysia, sex trafficked women are portrayed in contradictory ways. They are not only cast as victims who are deceived, exploited, and need to be rescued, but also depicted as 'immoral' and promiscuous individuals who must be detained and deported. They are also presented as a threat to the country because they have tarnished its image through engaging in sexual activities. Suppiah \& Kaur (2018) note that sex-trafficked women are portrayed as voluntary sex workers who are equated as criminals in the newspapers. This is because Malaysian newspapers portray trafficked sex workers as offenders rather than victims because of their illegal migrant status, making them doubly discriminated against (Suppiah, Kaur, Arumugam \& Shanthi, 2019). However, Malaysian newspapers also represent trafficked women as weak, passive and helpless individuals who are forced to work against their will. Depictions of human trafficking in movies, documentaries, and television episodes and human trafficking campaigns in Malaysia commonly follow a rescue narrative, where innocent and powerless victims are saved from harmful predators (Austin \& Farrell, 2017). These narratives maintain the patriarchal authority through the continual representation of men saving helpless women 
from traffickers (Baker, 2014). These diverse representations have shaped stereotypical images of a sex trafficked victim and resulted in confusion about identifying trafficked victims or understanding their experiences.

For example, a local newspaper reports:

Police rescued 19 female migrants who were used as sex slaves and confined in a massage parlour in Kuala Lumpur. The women, aged 23 to 35 who were nationals from China, Vietnam and Thailand were promised jobs as therapeutic masseurs but were sexually exploited by their traffickers (BH Online dated 13/7/2017 translated from Malay to English).

In the above report, the journalist has represented women as 'sex slaves' which implies that the women were forced to engage in sex work and that they were 'confined', thereby totally under the control of the traffickers ${ }^{31}$ (Mohammad, 2015).

While being portrayed as 'sex slaves', sex workers are also portrayed by the media through images or descriptions that are frequently demeaning and degrading (Allen, 2004; Ariffin, 1986; Greer, 2007). They are often portrayed as 'immoral' women who deserve to be dehumanised, denigrated and stigmatised by society. For example, a local newspaper, 'My Metro' headline read 'Vietnamese chicken didn't get enough chance to crow' (literal translation from Malay to English, dated 03/08/2018) which means that the migrant sex worker was arrested before she could make some profit (Shafiee, 2018).

Further examples can be seen through the figures and reports in local media:

\footnotetext{
${ }^{31}$ However, the US Department of State reports that migrant sex workers are indiscriminately labelled as trafficked victims by the enforcement agencies, if found working in bars and massage parlours (2017). This is because most foreign women voluntarily migrate to Malaysia in search of greater economic opportunities (U.S Department of State, 2014b).
} 


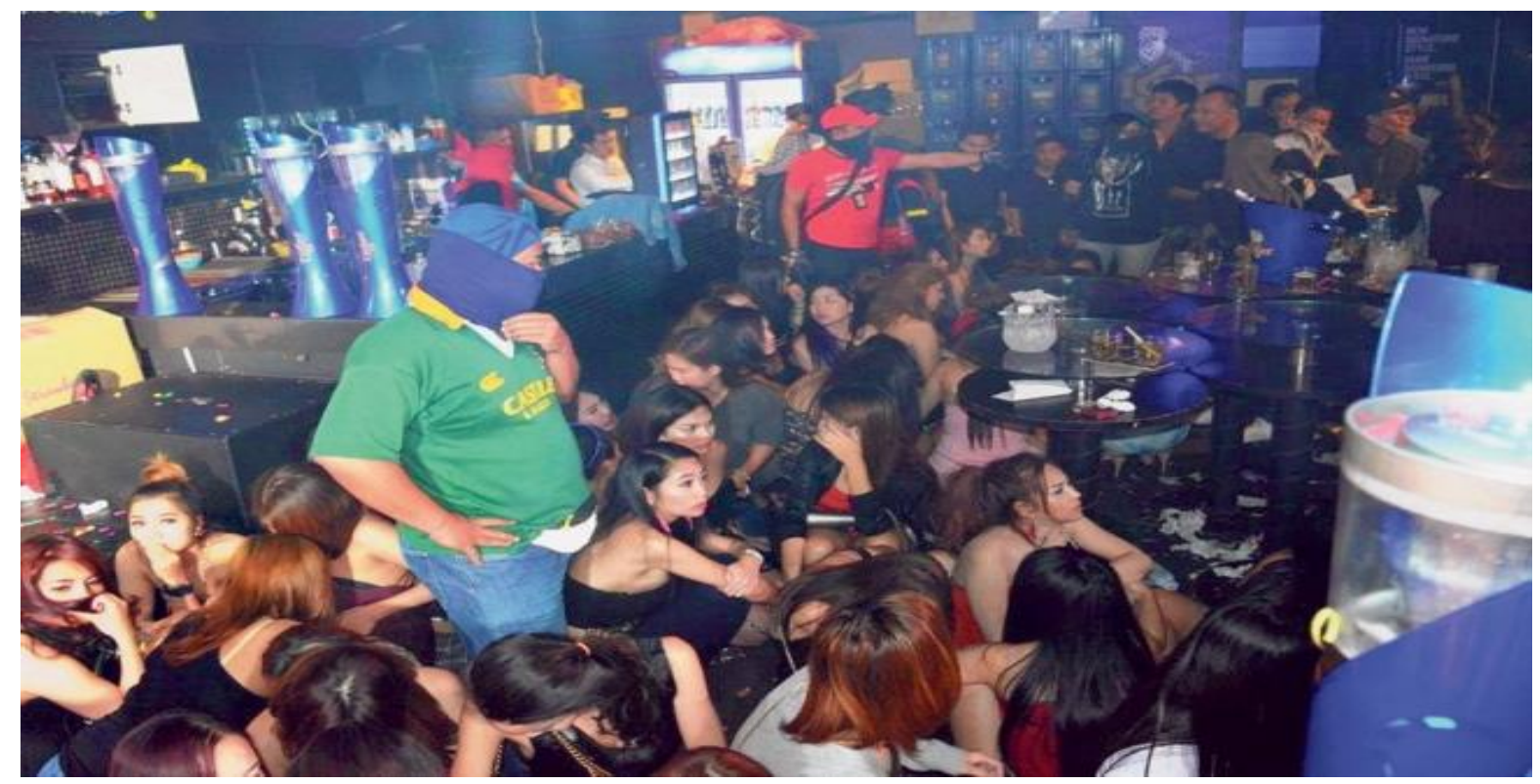

Figure 2: Pictures of police raid advertised by Kosmo Online, a Malaysian magazine

(Basri, 2018)

Figure 2 was taken from Kosmo Online, a local magazine with the headlines 'Migrant sex workers trap' (translated from Malay to English) (Basri, 2018). According to the report, while some of the women were deceived and exploited, some voluntarily engaged in sex work and could earn a lucrative income (Ibid). However, the report also quoted a Malaysian criminologist, Datuk Shahul Hamid Abdul Rahim, who accused sex workers as the cause of social problems such as marriage breakdown, fighting, and birth of illegitimate children, which could not benefit the country (Ibid). His statement coincides with the imagery on an 'ideal woman' in the reified Malay family who believes that 'uncontrolled' women in society and the public sphere are the cause of social problems (N. Othman, 2006). In addition, generalised statements (such as evidenced above) have blurred the distinction between trafficked versus voluntary sex workers, and reinforced the criminalisation of, and stigmatisation towards, migrant sex workers. Such portrayals are unrealistic because they do not assist the public in understanding the realities and complexities of sex trafficking.

The magazine also reports that from June 2013 to June 2017, 25,086 raids had been conducted by the police on brothels (Basri, 2018). Within that period, 51,594 migrant sex workers had been arrested for being involved with prostitution (Ibid). According to the report, the five countries with the highest number of arrests are: Vietnam $(19,342)$, Thailand 
$(14,591)$, China $(9,602)$, Indonesia $(3,867)$ and the Philippines $(1,126)$ (Ibid). The high number of women originating from these countries is based on the demand for Asian women who are perceived to be 'submissive' and 'obedient' (Surtees, 2003). This reflects the strong patriarchal influences in Malaysian society which believes in female subordination and the superiority of men. It also reflects the patriarchal ideology which is propagated within media representation as well as the exoticisation of women from Southeast Asia.

\section{Sources of Media}

Media reports primarily frame trafficking as a moral and crime problem, with journalists relying on law enforcement officials as sources (Cwikel \& Hoban, 2005) and, in some cases, religious activists. According to Zhang (2000, p. 5), framing involves 'a process of how politicians, policymakers relay their messages to attract media attention and put the best face on the events, how journalists construct messages under organisational guidelines and professional values, and how audience members interpret, think, and reassess those media messages'. Therefore, the news media's framing is influenced not only by journalists and editors but also by those providing information to news media, such as policy makers and interest groups (Sanford, Martínez, \& Weitzer, 2016). Access to the media gives the state authorities 'the possibility of having' their will enforced 'against the will or interests of others' (Reisigl \& Wodak, 2009, p. 88). How their views and opinions are reported reflects not only their dominant positions but also the ideological and political practices of journalism in Malaysia (Don \& Lee, 2014). This illuminates the link between media and state agendas. For example, a local newspaper reports:

Seven migrant sex workers from Vietnam, Thailand and Laos who were offering sex services via We Chat application were arrested on Monday at 10:30 pm at a hotel in Rangoon Road, Georgetown, Penang. According to the Head of Immigration Department in Penang, the women were controlled by a crime syndicate and were in breach of their social visit passes. They will be transported to the Juru immigration depot for further action. Immigration officers also seized condoms, lube and cash from the hotel rooms which are 
believed to have been used for sexual activities (Sinar Harian dated 28/11/2018 translated from Malay to English).

Another report from a local newspaper states:

Pas [a Malaysian Islamic political party] Pahang urge the government and local authorities to take strict action to curb prostitution related activities involving migrant women in Kuantan. The party's Head of Information officer said that such immoral activities could taint the image of the city. In response to such outcry, the Head of Islamic Religious Department of Pahang stated that drastic measures will be taken to stop such type of activities with the help of other agencies (Sinar Harian dated 15/02/2016 translated from Malay to English).

The above examples reflect how the media plays an important role in defining what problems are worthy of public and government attention (Sanford et al., 2016). Media companies in Malaysia are mostly controlled by the government (Wok \& Mohamed, 2017) and are frequently used to promote official agendas for the purpose of maintaining their political survival. Thus, trafficking has been framed as a moral and crime problem as well as a threat to state security instead of a crime against the individual women involved (Mattar, 2006). This approach shifts the focus away from the problem being one of violence against women to emphasising their illegal entry and stay, so that ultimately it is the state who is perceived as the victim rather than the trafficked person (Haynes, 2007). Details of raid and rescue processes, judicial procedures, and protective measures will be presented in Chapters Six and Seven of this thesis, informed by interviews with migrant women and government officials.

The prejudices towards migrant sex workers, as evidenced by the media reports, are likely to affect political discourse, personal beliefs, and people's self-perception on women's role and image (Ariffin, 1986). This is because the media subtly impart a negative idea that sex work is a moral and social crime that is committed by foreign women (Suppiah et al., 2019). Therefore, readers are likely to formulate their own interpretation according to what is written because readers may not be aware of the reality of sex trafficking (Ibid). As Boots and Heide (2006) have argued, 'the public draws conclusions from cases about which they become 
familiar [and] legislators, similar to their constituents, often formulate policy on what they know about a phenomenon, particularly when it is one that inflames passion' (p.435). This is likely to be particularly true about sex-trafficking news. This perception likely stems from religious patriarchal norms in Malaysia, which focus on controlling women's sexual activities and maintaining their 'purity' and value as assets. In this culture, women are valued for their ability to reproduce and the 'ideal woman' is respected as a symbol of purity (Blackburn, 2001). Therefore, the thesis argues that social and cultural aspects play roles in cultivating beliefs and attitudes in the perception of sexuality, gender role expectations, sexual behaviours, and the reinforcement of sexual norms (Merghati-Khoei, Ghorashi, \& Smith, 2014; Rahman \& Jackson, 2010). Given that religion is deeply embedded in political and social realms (Shaw, Saifi, Lim, Saifuddeen, \& Kamarulzaman, 2017), women's involvement in sex work is considered shameful and all attempts are made to stop women from being involved in sex work.

\section{The Context for State Intervention}

One of the dominant themes in this chapter is the representation of trafficked women who are considered to be a threat to the state and society. Trafficked women who provide sexual services and labour are often the subjects of discriminatory, often criminalising, policies, laws, and ideologies (Kempadoo, 1998, 2001; Pickering \& Segrave, 2011; Segrave et al., 2009; Stumpf, 2006). In Malaysia, they are often blamed for tarnishing the image of the country and violating its religious and cultural values (as discussed above) (Lasimbang, Tong, \& Low, 2016). Thus, in an effort to uphold the 'dignity' of women, 'strict laws' have been enforced to ensure that the pollution of culture, religion, and morality does not occur (Ariffin, 1986; Lean, 1998). For example, state officials have been given the authority to arrest sex workers on the grounds of protecting the sanctity of religion and Asian values (Barmania \& Aljunid, 2017). Section 372B of the Malaysian Penal Code prohibits any person from soliciting for the purpose of prostitution or any immoral purpose in any place and those who are found guilty of such act can be punished with imprisonment for a term not exceeding one year, or with a fine or with both. The punishment is even more severe for Muslim sex workers where they can be fined, imprisoned or caned. For example, Section 21 of the Syariah Criminal Offences (Federal Territories) Act 1997 states: 
Any woman who prostitutes herself shall be guilty of an offence and shall on conviction be liable to a fine not exceeding five thousand ringgit or to imprisonment for a term not exceeding three years or to whipping not exceeding six strokes or to any combination thereof.

The above provisions clearly criminalise sex workers and single out women sex workers. It shows how the Islamic laws are used to inflict harsh punishment and fines on women engaged in sex work. The above provisions stem from the prohibition of $z i n a^{32}$ (illicit intercourse) in Islam and thus, sex work is considered as an act of zina. The punishment for zina in the Qur'an can be found in verse An-Nur 24: 2:

The fornicatress and the fornicator, flog each of them with a hundred stripes. Let not pity withhold you in their case, in a punishment prescribed by Allah, if you believe in Allah and the Last Day. And let a party of the believers witness their punishment. This punishment is for unmarried persons while married persons should be stoned to death (Translation of the meanings of the noble Qur'an in the English language, 1984).

Although the above verse includes men, the Syariah Criminal Offences only apply to women, which shows the double standard of morality that is being enforced through these laws. Such guidelines underpin the views of enforcement officers and judiciary towards women engaged in sex work (United Nations, 2006). Given that Islam plays a strong role in influencing gender and sexuality (Shah, 2013), as well as an individual's behaviour (Mahathir, 2009), women who are deemed to be 'immoral' will be heavily policed and given religious counselling by religious agencies. Women's activities are codified and their bodies are considered aurah or prohibited to men other than their husband (N. Othman, 2006). For example, Muslim women in Malaysia are prohibited from competing in beauty pageants according to the fatwa (decree/edict) given by the National Fatwa Religious Council in 1997. That ruling still exists today, and any Muslim woman who contravenes the ruling will be charged in the Sharia courts where they

\footnotetext{
${ }^{32}$ Zina is an Islamic legal term meaning illicit sexual relations (Khan, 2003). Zina refers to sex outside of marriage - both adultery and fornication (Ibid).
} 
can be imprisoned and fined. The guarding of women's bodies and dignity symbolises protection of Islamic identity, communal dignity and social and cultural continuity (Moghissi, 1999).

The concept of 'human dignity' is also encapsulated under Article 8 of the Malaysian Federal Constitution (FC), which prohibits any form of discrimination on the basis of gender 'except as expressly authorized by the Constitution'. In a recent legal case, ${ }^{33}$ the Court of Appeal ruled that it is the fundamental right of every person within the shores of Malaysia to live with common human dignity. Gopal Sri Ram JCA (one of the judges in this case) stated that a person who is deprived of his/her reputation is also deprived of his/her right to life according to Article 5(1) of the Federal Constitution. ${ }^{34}$ As such, the right to reputation becomes a part of human dignity. ${ }^{35}$ Based on such a principle, sexual offences and exploitation have been condemned as the 'gravest crime against human dignity', because of the feelings of humiliation, degradation and guilt endured by the victim. ${ }^{36}$ Although such condemnation is meant to protect women from being sexually exploited, it has also provided a pathway for state institutions to control women's bodies and behaviour.

\section{The Nature of 'State Protection'}

As previously discussed, trafficked women are often represented in newspapers and magazines as 'immoral' individuals who pose a risk to the state and society. Such representations reflect their ideological positioning (Don \& Lee, 2014). Therefore, factors that underpin state intervention and responses towards trafficked women are made in line with ideas of 'ideal victim' as well as safeguarding the society from moral 'danger'. Women who have been 'rescued' from their traffickers are detained in shelters, forced to undergo judicial processing, and are expected to adhere to all rules and regulations before they are repatriated. The act of 'rescue' and detaining women in shelters is thought to be the 'ideal' mode of protecting them. For example, a newspaper report considered 'shelter homes a

\footnotetext{
${ }^{33}$ Lembaga Tatatertib Perkhidmatan Awam, Hospital Besar Pulau Pinang v Utra Badi A/L K Perumal (2000), 3CLJ 224, 39(CA).

34 Ibid.

35 Ibid.

${ }^{36}$ Mohamed bin Senik v Public Prosecutor (2005) 1 LNS 74, p. 24.
} 
temporary haven for sex-trafficking victims' (Malay Mail Online dated 18/04/2016) (Edward, 2016). In reality, these 'shelters' resemble a carceral institution which restricts women's mobility and communication, and imposes punitive rules and regulations (Gallagher \& Pearson, 2010). Therefore, 'state protection' is used as a euphemism for 'state control' through which 'victims' are deprived of exercising their human rights. The next section assesses the type of 'protection' given to trafficked women, and considers how such forms of protection have victimised women and effectively denied women's rights and agency.

\section{Shelter}

The Ministry of Women, Family, and Community Development (Ministry) operates the shelters for trafficked women. These shelters are armed with high levels of security, including barbed wire fences and security guards, which are intended to prevent women from escaping rather than to protect them from harm (U.S Department of State, 2012b, 2014b; United Nations Human Rights Council, 2015). According to the ATIP, trafficked women are given an initial 21-day interim protection order (for suspected trafficking victims) and/or a subsequent 90-day protection order (for certified trafficking victims) from the court. The period of detention may also be extended by the Court to facilitate the prosecution's case against the traffickers, since the prosecutors mainly rely on the cooperation and testimony of the women (U.S Department of State, 2014b, 2016). Although the term Protection Order is closely associated with the 'welfarist language or rehabilitation and protection', treatment accorded to women in shelters is punitive and violates their rights. Gallagher (2010) and M. Lee (2014) describe these shelters as resembling immigration detention centres and not complying with the guidelines contained in the 'Recommended Principles and Guidelines on Human Rights and Human Trafficking' (2002)(the Guidelines). Guideline 1(6) states that all anti-trafficking measures should protect trafficked victim's freedom of movement and should not infringe upon victim's rights. Guideline 6 ensures that shelter provisions should not be made contingent on the willingness of the victims to give evidence in criminal proceedings and victims should not be held in immigration detention centres, other detention facilities or vagrant houses. However, the Malaysian government does not seem to adhere to the Guidelines. They deny that victims of trafficking are subject to detention but instead assert 
that victims have agreed to restrictions on their freedom of movement (Gallagher \& Pearson, 2010). Thus, Nowak notes (2005, pp. 224-226):

\begin{abstract}
Deprivation of liberty provided by law must not be 'manifestly disproportional, unjust or unpredictable. The manner in which someone makes a decision to deprive an individual of his or her liberty must be appropriate and proportional in light of the circumstances of the case. Importantly, a detention situation that was originally not arbitrary might become so if the detention continues without proper justification.
\end{abstract}

In this regard, state authorities often claim that the detention of victims is necessary to secure their presence and cooperation in the criminal prosecution of their traffickers (Gallagher \& Pearson, 2010). This shows how shelters are being forced upon trafficked women and being made contingent upon women testifying in court, which contravenes Guideline 6 (see above).

Sheltered women are forced to wear uniforms, required to undergo multiple interviews or interrogation with government officials, held under strict surveillance, prohibited from communicating with anyone outside the shelter, and are deprived of medical, legal, translation and psychological services (M. Lee, 2014; U.S Department of State, 2014). As a result, women feel victimised and stressed having to live in the shelters. In response to the repressive treatments accorded to trafficked women, non-governmental organisations such as The Human Rights Commission of Malaysia (SUHAKAM) ${ }^{37}$ and Tenaganita $^{38}$ have undertaken the complex task of monitoring the violations of human rights with respect to human trafficking and abuse of migrants that occur in these settings (Official Portal Human Rights Commission of Malaysia, 2013; Tenaganita, 2012). Over the years, NGOs have raised concerns about overcrowding, poor living conditions, restriction of movement, and physical and verbal abuse towards migrants detained in the shelters (Gallagher, 2010; Official Portal Human Rights Commission of Malaysia, 2013; Tenaganita, 2012). They have continuously

\footnotetext{
${ }^{37}$ SUHAKAM was established by Parliament under the Human Rights Commission of Malaysia Act 1999, Act 597. The Act was gazetted on 9 September 1999 http://www.suhakam.org.my/

${ }^{38}$ Tenaganita is a Malaysian human rights organisation dedicated to assisting, building, advocating and protecting migrants, refugees, women and children from exploitation, abuse, discrimination, slavery and human trafficking http://www.tenaganita.net/our-story/
} 
imposed pressure on the Malaysian government to adopt non-punitive practices and to improve treatments and conditions. SUHAKAM also urged the government to address the restricted rights of victims of human trafficking to protect victims and to deter human trafficking with the aid of civil society groups, diplomatic missions and relevant stakeholders (Yunus, 2014). In response, the Malaysian government has appointed a few local NGOs (Suka Society ${ }^{39}$, Good Shepherd ${ }^{40}$, Persatuan Salimah ${ }^{41}$, Tenaganita ${ }^{42}$ ) to conduct various sports activities, counselling and religious programmes in the shelters (SUKA Society, 2015; U.S Department of State, 2017). These NGOs are given a funding allocation by the government to organise activities for trafficked women but they cannot offer any legal advice nor advise the shelter on improving its human rights standards (U.S Department of State, 2017). Even foreign embassies who are expected to coordinate with shelters on their national's care and welfare do not play a significant role in ensuring that women's rights are protected while in state custody (U.S Department of State, 2014b). Embassy officials are bound by the shelter rules and are required to obtain consent from the Director General of Women's Development (DG) if they wish to visit their nationals in the shelters (Ibid). In most cases, the embassies do not interfere with the affairs of the shelter or the police in order to preserve diplomatic relations. Given this, women's access to embassy officials remains difficult (U.S Department of State, 2017). In some cases, delays of repatriation are caused by delays in obtaining passports from victim's respective embassies (Ibid). This could be interpreted as an indication of the lack of interest of foreign embassies in expediting the repatriation process of trafficked victims.

To improve victim protection policies, the Malaysian government introduced new laws in 2015, allowing trafficked persons to work (section 51A (1) (b)) or move freely (section 51A (1) (a)) after they have been rescued (U.S Department of State, 2016). The right to work allows trafficked persons to work and reside outside of the shelter. However, they are required to

\footnotetext{
${ }^{39}$ SUKA Society's main aim is to help survivors cope with the effects they are going through. This is done through therapeutic programmes that help survivors learn how to deal with their trauma and stress http://www.sukasociety.org/protecting-trafficked-survivors/

${ }^{40}$ The Good Shepherd Sisters (GSS) is a worldwide Congregation of religious women present in 73 countries in six continents. GSS provides residential programmes to women and girls who have experienced crisis, and provides temporary shelters to enable them to heal and recover from their traumatic experiences https://goodshepherd.my/about-us

${ }^{41}$ Persatuan Salimah is an Islamic faith NGO group that aims to preach, unite and educate Muslims on Islamic teachings and among the campaigns organised are Hijab campaigns and outreach programmes to promote Islam.

${ }^{42}$ See footnote 38.
} 
undergo a stringent risk assessment process, which involves security and medical examinations, and approval by the 'Council of Anti-Trafficking in Persons and Migrant Smuggling' (MAPO) (section 51A (2), ATIP) (U.S Department of State, 2017). Bureaucratic delays (including a lack of counsellors able to complete required mental health evaluations), risk-averse and paternalistic attitudes towards victims, as well as a lack of victim interest in available work opportunities due to low wages, have resulted in a very low number of trafficked persons being granted the right to work (U.S Department of State, 2017). In 2016, only six people ${ }^{43}$ were issued with work visas out of 1,558 identified victims and all six eventually declined the work because they wanted to return home to their origin country or were not satisfied with the salary offered (U.S Department of State, 2017). The number of work visas reduced to two in 2017 out of 721 identified victims, because the majority of the victims declined to participate in the programme and preferred to return home (U.S Department of State, 2018).

In 2017, the Malaysian government issued 91 special immigration passes to trafficked women that would authorise their freedom of movement (Ibid). ${ }^{44}$ However, in practice, authorities sometimes limited movement outside the shelter to occasional trips with a chaperone, two to three times a month (U.S Department of State, 2017). The freedom to move freely does not include the right to work as the latter need to be applied separately. This shows how the state authorities control women's mobility, even though they are entitled to their freedom of movement under Article 13 of the Universal Declaration of Human Rights (UDHR). ${ }^{45}$ The complexities associated with obtaining freedom of movement suggest that legislation and policing are not protecting women (Brock et al., 2000), but are being used to control women. This is because the police focus on prosecuting traffickers, and women's testimony is vital to prove the prosecution's case and convict the traffickers (Hamid et al., 2018). Therefore, certain measures have been taken to restrict women's individual rights and freedom (Gallagher, 2015). A common example of this is that support or assistance is made conditional on a trafficked person testifying in court as a prosecution witness (Gallagher, 2010, 2015).

\footnotetext{
43 The government did not clarify the categories of victims who received the temporary work permits.

${ }^{44}$ Compared to 12 passes in 2016 (U.S Department of State, 2018).

${ }^{45}$ Article 13 UDHR - Everyone has the right to freedom of movement and residence within the borders of each State. Everyone has the right to leave any country, including his own, and to return to his country.
} 
This raises the question as to whether trafficked women are genuinely perceived and treated as 'real victims' or merely used as a tool to assist the state to combat sex trafficking. Although supporters of shelter detention commonly justify detention with the need to protect victims of trafficking, detention of trafficking victims is not a universal practice ${ }^{46}$ (Gallagher \& Pearson, 2010). In many countries, the right of victims of trafficking to freedom of movement is respected, ${ }^{47}$ and the provision of support and protection is based on genuinely informed consent (Ibid). However, this is not the case in Malaysia as the provision of living in the shelter is compulsory for women who have been classified as trafficked (section 51 (3), ATIP). Therefore, shelter detention has become one of the most problematic practices that is justified by the anti-trafficking imperative.

\section{Prosecution}

Malaysia adopts the 3P approach (prosecute, protect and prevent). However, the focus is on prosecution of traffickers because human trafficking is considered to be a threat to national security (Mattar, 2006; Suppiah \& Kaur, 2018). The protection of victims and the prevention of trafficking are listed as secondary priorities (Cho, 2015). While prosecuting the traffickers may be a positive step towards eliminating the act of human trafficking, it does not necessarily help to relieve or ease the grief of women who have been trafficked. In some cases, women do not wish to go through the court process, or to witness their traffickers in the criminal justice system (Segrave et al., 2009). This often happens when women are detained in the shelter for a long period of time awaiting trial, as they tend to become emotionally unstable and stressed in those conditions (Hamid et al., 2018). In this instance, their credibility is easily challenged by the defence counsel and their testimonies are not always useful in court (Hamid

\footnotetext{
${ }^{46} \mathrm{An}$ increasing number of the major destination countries for trafficked persons, including Australia, the United States, and most countries of Western Europe, now provide special visa arrangements for victimwitnesses. Such arrangements often include a provision for victims to take some time - 'a reflection period' to think about whether or not they wish to be involved in criminal proceedings. At the end of this reflection period, the most generous schemes envisage granting residence permits to victims of trafficking who choose to cooperate. This approach, pioneered by the European Union through Council Directive 2004/81/EC, 2004 O.J. (L 261), has now been adopted as the European legal standard through the European Trafficking Convention (art. 13). Within the European Union countries, twenty-three member states have transposed the Directive into national legislation (Austria, Belgium, Bulgaria, Cyprus, Czech Republic, Estonia, Finland, France, Germany, Greece, Italy, Latvia, Lithuania, Luxemburg, Hungary, Malta, Netherlands, Poland, Portugal, Romania, Slovakia, Slovenia and Sweden).

${ }^{47}$ Shelters are open and victims are free to come and go as they please (Gallagher \& Pearson, 2010).
} 
et al., 2018). In some cases, women fear the consequences that may occur following the prosecution of their traffickers (Bjerkan, Dyrlid, Nikolic-Ristanovic, \& Simeunovic-Patic, 2005; Segrave et al., 2009). Such risks include the danger of being beaten, kidnapped, raped, or killed by other members of the syndicate (Segrave, 2009). They may fear for the safety of their families and worry about being re-trafficked (Ibid). Women's reluctance to testify against their traffickers can adversely affect the prosecution's case, given that the victim's testimony is material in a trafficking trial. As a result of these barriers to testifying, the number of convictions for human trafficking offences has been relatively low compared to the number of victims identified by enforcement agencies (Human Rights Commission of Malaysia, 2016; Human Rights Commission of Malaysia SUHAKAM, 2004; United Nations Human Rights Office of the High Commisioner, 2014).

In 2017, the Malaysian government identified 2,224 potential trafficking victims nationwide compared to 1,558 victims in 2016. According to the 2018 US Trafficking in Persons Report, the Malaysian government conducted 556 trafficking-related investigations in 2017, compared to 581 investigations in 2016, and 158 in 2015. The rapid increase of trafficking investigations since 2015 suggests that the government has been vigorously conducting trafficking raids in order to combat trafficking activities. However, there seems to be a significant decline in the prosecution rate as only 80 individuals have been charged under the ATIP compared to 175 in 2016 (U.S Department of State, 2018). Nevertheless, an increase can be seen in the conviction rate since 45 traffickers have been convicted under ATIP in 2017: 13 for forced labour and 32 for sex trafficking. This is an increase from 35 traffickers being convicted in 2016: 18 for labour trafficking and 17 for sex trafficking (U.S Department of State, 2017).

Despite the increase in prosecutions and the government's efforts to improve its victim protection mechanisms by offering 'freedom to work' to trafficking victims (which have not been successfully implemented), the country has been downgraded to Tier 2 Watch List in the 2018 US Tier Report from Tier 2 (in 2017) for not fully complying with the United States TVPA minimum standards, ${ }^{48}$ although the country is seen to be making significant efforts to comply

\footnotetext{
${ }^{48}$ See Chapter One.
} 
with those standards (U.S Department of State, 2017). In response to the downgrade, activists and NGOs such as Tenaganita and The Human Rights Commission of Malaysia (SUHAKAM) have imposed further pressure on the government to improve its treatment towards trafficked women such by addressing issues of discrimination and unequal treatment, and adhering to the guidelines contained in the United Nations Recommended Principles and Guidelines on Human Rights and Human Trafficking. Yet, unless there is an ideological shift in Malaysian politics and media, the pressure from NGOs may remain unsuccessful.

\section{Conclusion}

The International Organization for Migration (2010) reports that Malaysia does not have adequate knowledge, expertise, or bureaucratic capacity to fight human trafficking and this hinders effective law enforcement processes. Women who engage in sexual labour are portrayed by the media in a way that makes them an easy target to be blamed for the proliferation of sex trafficking activities in Malaysia. Although they may be portrayed as 'sex slaves' or individuals forced to engage in sex work, they are also positioned as a threat to society due to the perceived immorality of sex work. The authorities echo such sentiments, as evidenced in their punitive treatment and low standards of victim protection. As such, the US Department of State and NGOs such as SUHAKAM and Tenaganita contend that the government's victim protection efforts remain largely inadequate because trafficked women are still subject to 'hardline' policing and repressive treatment by the authorities.

Historical demand suggests that vices indulged in by consenting adults are not likely to be eradicated by law (Chudakov, Ilan, Belmaker, \& Cwikel, 2006). However, the demand for sex trafficked workers needs to be addressed because women who are trafficked are exploited for the purpose of profits. Issues of poverty, gender inequalities, unemployment and low wages remain vital to understanding the pushes into sex trafficking. However, this can only be achieved through greater political will from all government sectors and agencies. The UN Human Rights Council stressed that it is the obligation of States to protect the human rights of migrants, regardless of their status (Global Migration Group, 2013). ${ }^{49}$ Despite such

\footnotetext{
${ }^{49}$ This Resolution was adopted by the Human Rights Council on 16/7/2012, A/HRC/RES/20/3.
} 
recommendations, trafficked women continue to be policed and victimised through state practices. This is because the Malaysian government appears to be more focused on imposing stringent punishment on migrant sex workers and has retained immigration laws which criminalise foreign sex workers. As a result, women fear the authorities and many feel victimised during state custody. Thus, the following chapter will discuss the approach taken to understand women's experiences of victimisation as well as the research process conducted in this study. 


\section{Chapter Five: Methodology and Methods}

\section{Introduction}

The preceding chapters reviewed literature chosen for its value in shaping and re-theorising women's victimisation and agency in a way that recognises agency under limited constraints. To establish the theory of relationship between victimhood and agency, this study uses feminist principles and methodology. According to Ramazanoglu \& Holland (2002), the feminist research process can cover how specific people experience sexuality and reproduction, masculinity and femininity, and the boundaries and interstices between them, and also variable cultural categories for conceptualising what is lived and thought (Ramazanoglu \& Holland, 2002). By using a feminist research process, this study seeks to challenge the victim/agent binary as an overly simplistic conceptual model in which 'victimisation implies the one-way exercise of power, harm without strength [and] agency implies freedom from victimisation' (Mahoney, 1994, p. 62). Thus, this chapter explains the feminist approach used in this thesis to research women's stories of victimisation and agency, and introduces the women and professionals who participated in the research.

As stated in previous chapters, the purpose of this research is to explore the women's understanding of their victim-agent identity as well as the effectiveness of the protection given to trafficked women by the Malaysian state. To pursue this goal, the thesis uses a postcolonial feminist approach and engages in the qualitative methods of semi-structured interviews and participant observation. The advantage of qualitative methods is that they provide a depth of understanding of social phenomena, experiences and understandings in specific social, cultural and political settings (Mohajan, 2018). For instance, they allowed me to understand and identify the victim-agent relationship that the women articulated as well as details of how their agency was refused. The data obtained from the interviews were analysed using thematic analysis. Thematic analysis is a method for identifying and analysing patterns in qualitative data (Clarke \& Braun, 2013) which offers an accessible and theoretically flexible approach to analysing qualitative data (Braun \& Clarke, 2006). This flexible method can provide a rich and detailed, yet complex, account of data (Ibid). Given these features, 
thematic analysis was used to explore and understand women's migration and trafficking experiences including the intricate details about the harms and victimisation they suffered. The details of these research processes are discussed in this chapter as well as the challenges in conducting this study.

\section{Methodology}

At the start of this thesis, I intended to capture and analyse women's experiences through a liberal feminist lens (Gelsthorpe \& Morris, 1990; Harding, 1987; Ramazanoglu, 1992). Liberal feminism, according to Davies (2010), views 'men and women as equal, emphasizing the similarities between them and arguing that women can be as capable and as rational as men' (p.3). It allows room for the different experiences of men and women to have equal play, but does not imply that women will seek to become like men (Donner, 1993). It is also premised on the belief that women experience subordination on the basis of their sex, and works towards the elimination of that subordination (Gelsthorpe \& Morris, 1990).

However, much criticism has been directed towards liberal feminist theory as being the product of white, middle-class, Western women, who are heavily influenced by Western values of individualism and individual rights (Lâm, 2002). According to critics, liberal feminism is based on the idea of equal opportunity between sexes in the developed world (Barberet, 2014; Barberet \& Rodriguez-Spahia, 2017). Liberal feminists see inequality in terms of gender, but not in terms of 'race' or 'ethnicity' (Spelman, 1988). Spelman (1988) argues against the 'gender realism' and asserts that viewing all women as the same to one another is a mistake because 'womanness' is socially constructed and social construction differs from one society to another. Therefore, the features women are presumed to have in common are in fact features that only some women have in common and does not apply to all women (Mikkola, 2006). 
Given this, I had to reconsider my intended approach because my participants were mainly trafficked women from mainly Southeast Asian ${ }^{50}$ countries who possess their own traditions, ethnicities, thoughts and cultures (Cunneen \& Stubbs, 2004). It was also important to acknowledge the traditional, patriarchal ideas about women's roles and male privilege in their countries, which are often reinforced through social practices, culture and religious teachings (Hefner, 2001; Hirschman, 2016). I understood this predicament as I am a Malay Muslim woman who originated from and lived in Malaysia for most of my life. I was (for the greater part of my life) taught to believe that men were the superior sex and must adhere to patriarchal religious norms. Those who do not believe in these norms are often ostracised by their family and friends. I was also taught in schools and religious classes to prioritise family's needs over my own needs. In this respect, women's roles are more oriented towards family matters rather than self-fulfilment, and they are usually caught in a dilemma between the modern challenges of life and traditions (Andaya, 2001; Hirschman, 2016). Therefore, it was important for me to acknowledge that women's subordination is multifaceted, intertwined with culture and religion, and related to other aspects of identity (Barberet \& RodriguezSpahia, 2017).

Based on the above grounds, I chose to adopt a postcolonial feminist approach in order to produce a more realistic and accurate study on trafficked women. This is because the postcolonial feminist approach addresses differences pertaining to class, race, feelings, and settings of women from once colonised territories (Mishra, 2013; Mohanty, 1991). Although postcolonial countries have been liberated from the previous colonial methods of direct military control, there have been debates about how capitalism and globalisation have increased the gap between the rich (developed) and the poor countries of the world (Nkrumah, 1965). Thus, postcolonial theory draws upon feminism, ecology, social justice, economics, literary theory, political and cultural theory (Anderson, 2002). It aims to address racism and oppression by including voices, stories, histories, and images from people traditionally excluded from European/western descriptions of the world (Bauchspies, 2007). Post-colonial feminism seeks to transform the political and psychological conditions of the

\footnotetext{
50 The term 'Southeast Asia' (including Myanmar, Thailand, Laos, Cambodia, Vietnam, the Philippines, Singapore, Brunei, Malaysia, and Indonesia) can be dated to World War II, when it was used to refer to the theatre of operations between China and India (Andaya, 2001).
} 
countries that can crudely be termed the 'Rest' as opposed to the 'superior West' (Treacher, 2005). It provides another perspective on the knowledge production process, and redefines who has the right to produce knowledge (Anderson, 2002). Therefore, adopting a postcolonial perspective challenges ideas of there being a universal standpoint on knowledge development (Ibid). Post-colonial feminism respects the desires and needs of women from developing countries to accumulate economic gains and social capital through the act of migrating to work (Cwikel \& Hoban, 2005; Mohanty, 1991). It allows women to engage in progressive practices such as to migrate and work and live their lives in different and better ways (Grossberg, 1987). By using this strand of feminism, I was able to identify the nuances of women's migration experiences and discover how culture and religion has affected them.

This is particularly evident in Southeast Asia where women engaged in sex work may find it difficult to express their experience freely because they are ashamed, or in fear of being judged as immoral (Kotiswaran, 2011). They may also, instead of expressing their identity as sex workers, refer to their work arrangements as working 'on contract', doing 'secret' sex work or may just regard themselves as labourers (Ibid). I could understand the emotions and sensitivities of the women due to a similar upbringing in Southeast Asia that emphasises religious and cultural values (Sim, 1984). These values include guarding one's own self, heritage and identity, policing one's own behaviour, and guarding one's respectability and morality (as discussed in Chapter Two). Therefore, I understood that women from this region are expected to conform to moral codes while still being a breadwinner for the family (Bose, 2008; Mohanty, 1991).

I was also reminded that even if women are categorised as 'victims of trafficking', some may still consider themselves as economic migrants and regard sex work as a legitimate form of work (Chapkis, 2003). However, Sharma (2005) argues that women sometimes accept the label of trafficking and represent themselves as victims in order to legally stay in the country. Based on such claims, I was intrigued to uncover and understand women's experiences in the sex industry and the world in which they live (Holloway, 1997). Given the focus of this thesis - on the harms inflicted upon trafficked women from multiple processes - I wanted to discover how women perceive their own 'victim' identity, and to question if they felt victimised and, if so, by whom. I wanted to focus on women's migration experiences, how 
they were treated by those who were deemed to be their traffickers and state authorities, and how they should be understood in context (Barberet, 2014; Chesney-Lind \& Morash, 2013). As well as this, I was mindful of interviewing women in the shelter that resembles a 'prison like' settings where the women were isolated and hidden from the broader community. As stated by Gill, Conlon, \& Moran (2014, pp. 239-240):

'Carceral space' is not only confined to traditional prisons but all the grades and varieties of confinement that are possible outside formal prison systems. This includes ...immigration detention, as well as ... electronic monitoring, surveillance and securitized public spaces' where irregular migrants and 'refused' asylum seekers are detained, ostensibly pending decisions on admittance or repatriation.

Therefore, Silverman (2015) argues that 'carceral spaces' such as immigration detention centres divide the world into strictly controlled and immobilized spaces; they deny people the enjoyment of liberty and freedom. The women were removed from their normal environment, and incarcerated in an unfamiliar institution where their movements are severely restricted (Jewkes, 2002). For those who have been detained for a period of time, a sense of isolation is common (Bosworth, Campbell, Demby, Ferranti, \& Santos, 2005).

According to Schlosser (2008), 'interviewing in prison presents a unique set of obstacles and "methodological landmines" of which inexperienced researchers may be unaware' (p.1501). This is because the women live under almost constant surveillance, and are subject to periodic checks by shelter staff (Jewkes, 2002). They are also exposed to sudden searches, checks or interrogations/interviews by shelter, welfare or police officers (Ibid). Therefore, researchers must be innovative, persistent, and have some insights into the challenges and complexities women may face while giving interviews in the institution. From a researcher perspective, it is also important to ensure that they have voluntarily consented to be interviewed (Ibid).

However, Gill, Conlon \& Moran (2013) argue that the limited freedom and state confinement does not transform detainees into inactive participants. Even under restrained conditions, detainees are able to assert agency. At the same time, according to the International 
Committee of the Red Cross (ICRC) (2004), interviews with captive population sometimes give participants a break from prison routine, one in which they can speak freely about what matters most to them and be sure of being heard. Furthermore, 'making a connection with someone new outside might help the person feel a bit closer to home, a bit more like a human being and a bit less like a prisoner' (Bosworth et al., 2005, p. 257). Similarly, in this study, I wanted the women to speak to me freely as I wanted to find out about their migration experiences, the conditions of detention and the treatment they received from the state officials.

It was crucial for me to explain to the women that I was not a state official and that I was a researcher who was conducting a study (Ibid) to analyse their migration experiences. I also needed to explain to them that I was only allowed to interview the women during office hours and had to abide to certain rules and regulations of the shelter so that they understood that I was bound by certain rules and regulations of the shelter. From this position, I sought to establish a relationship with the women which could provide an atmosphere of confidence and trust (UNHCR, n.d). Having all this in mind, I slowly sought to establish connection and trust with the women.

While I acknowledge the differences between the Malay culture and the other cultures that exist in Southeast Asia, I believed that my appearance as a Malay woman and knowledge about Southeast Asian cultures might give me an advantage of framing my questions differently (keeping in mind the sensitivities of culture and religion), rank priorities differently and define problems differently (Smith, 2012). Thus, I was optimistic that I could try to establish a connection with the women because of my origin, my understanding of Asian culture, and the multilingual skills that I possess (English, Malay, Indonesian and various versions of Pidgin English). By using these approaches in this study, it was pertinent for me to adopt a suitable approach to capture the nuances of perception and understanding of victimhood and agency. Methodology according to Ramazanoglu \& Holland (2002) comprises rules that specify how social investigation should be approached. In this regard, I wanted to use a non-hierarchical approach: that is to shift the balance of power away from the researcher towards the research participants. Positivist methods in the social sciences view the participant as a subject instead of merely a participant, creating more of a subject and 
interviewer relationship (Stanley, 1990). This is due to the hierarchical approach that is deeply embedded in the relationship between the participant and the researcher (Ibid). Harding (1987) argues that traditional positivist theories have been applied in ways that make it difficult to understand women's participation is social life. These approaches have often ignored women and issues concerning women, or of concern to women (Oakley, 1981; West \& Zimmerman, 1991). Findings from research on men are used to generalise women's experiences by 'adding' women to male knowledge (Mies, 1983; Stanley \& Wise, 1993). To address this partiality, feminist scholars have suggested a focus on gender relationship and women's experiences of oppression and/or agency (Comte, 2014; Cwikel \& Hoban, 2005). Therefore, l opted for a feminist methodology to understand the participant's interpretations of agency and victimhood.

A key feature of feminist methodology is the implication that the relevant rules can provide criteria in judging competing knowledge claims (Campbell \& Wasco, 2000). It attempts to eradicate sexist bias in research and to find ways to capture women's voices that are consistent with feminist ideals (Ibid). This aligns with the overarching goal of feminist research to capture women's lived experiences in a respectful manner that legitimates women's voices as sources of knowledge (Ibid). Given the postcolonial feminist approach in this study, this methodology offers a re-examination of Western feminist theories that have been produced based on positions of power and privilege in the West (Mohanty, 1991). As Banu (2012) suggest '....postcolonial feminist approaches, through their different analyses, bring to visibility the diversity of postcolonial subjects experiences and material conditions under which they live' (p.573).

Feminist methodology is based on narratives of life experiences and non-positivistic methods (Harding, 1987). It involves the description, explanation, and justification of techniques used in feminist research and is a classification that refers to a variety of methodological stances, conceptual approaches, and research strategies (Fonow \& Cook, 2005). This includes the recognition of the exploitation of women as objects of knowledge and emphasis on the empowerment of women (Cook \& Fonow, 1986). Therefore, feminist methodology not only respects the autonomy of women in decision-making but also recognises women who have been victimised and the harms they may have suffered (Meyers, 2014). Based on the 
aforementioned grounds, I was convinced that feminist methodology would lead me to discover the harms inflicted on the women who participated in this research and if victim protection policies have protected women from further harms. Furthermore, feminist methodology promised a more interpersonal and reciprocal relationship between researchers and those whose lives are the focus of the research (Bloom, 1998). It also seeks to break down barriers that exist among women as well as the barriers that exist between the researcher and the researched (Ibid).

In line with postcolonial feminist aims of critiquing standard forms of knowledge and producing 'autonomous, geographically, historically, and culturally grounded feminist concerns and strategies' (Mohanty, 1991, p. 51), one specific aim of this study is to explore identity narratives based on gender, ethnicity, and class relations. In this context, postcolonial feminism methodology aims to highlight marginalised experiences and let individuals 'speak for themselves'. Given the focus of this thesis that aims to capture women's voices, emotions and understanding of their own victimhood, I decided to use qualitative methods in this study. The advantage of qualitative methods is that they provide a depth of understanding of social phenomena, experiences and understandings in specific social, cultural and political settings (Richard, 2013; Schutt, 2012). Therefore, the following section will discuss the methods engaged in this study as well as the challenges faced in carrying out this study.

\section{Methods}

According to Harding (1987), methods consisted of different techniques for gathering data which are generally divided into quantitative or qualitative. Qualitative methods according to Jayaratne (1983) are 'research procedures which produce descriptive data such as people's own written or spoken words and observable behaviour' (p.145). Some feminist scholars argue that quantitative methods attempt to translate women's experiences into predetermined categories, which can result in distorting or silencing women's voices (Keller, 1985; Mies, 1983), whereas qualitative methods can capture women's stories and legitimise experiences as sources of knowledge (Jayaratne \& Stewart, 1991). This thesis does not intend to consider the quantitative/qualitative divide but argues that different feminist issues will 
require different research methods. For the purpose of this study, a qualitative method seemed to be the most appropriate to analyse women's experiences and the harms that have been inflicted upon them. This is because qualitative methods allow women to be the 'experts' about their own experiences (Montell, 1999). It seeks to show that women have the capacity to influence the condition and terms of the everyday life of a community or society (Bhavnani, 1989).

Based on the above characteristics, I concluded that the best and most instinctive way to gather information to provide answers to my research question was by conducting semistructured interviews with all of the participants. This is in line with the conceptual framework of this thesis which focuses on the nuances of women's migration experiences and victimhood. Given this, questions in the interviews were framed to allow for a focused, conversational, and two-way communication (Case, 1990). In this instance, the researcher and participant could both give and receive information (Ibid), although I framed the issue for study and composed the questions, while the participants provided information about their particular experience (Montell, 1999).

Using this technique, I interviewed 29 women held in Shelter 5, Kuala Lumpur about their migration experiences (see Appendix 1). The questions focused on: their life before migration; personal background; their reasons for migration; work experiences and problems they encountered; experiences of being 'rescued' by the enforcement officers from their workplace (or traffickers); the administrative process they had to go through which placed them in the shelter; any harms or injuries that they experienced, and their thoughts for the future (see Appendix 2). Alongside these interviews, I also interviewed 12 professionals to gain a clearer understanding of policing, judiciary and protection processes in Malaysia (see Appendix 3). Questions revolved around their perception of trafficked women and how they viewed trafficked women as well as policing and court processes (see Appendix 4).

As well as interviews, I spent a total of 25 days in the shelter but used the first four days to observe the situation and learn about the activities of the women in the shelter. During these four days, I observed and took notes of women's activities in the shelter, their daily routines, how they interacted with one another and the shelter staff. I had a small notebook where I 
recorded women's activities and the activities of the shelter. Among the things that I recorded were the daily chores that woman had to do. This included cleaning, sweeping, mopping, drying clothes, serving food, and watering the plants. I also observed the way the staff communicated with the women and how the shelter staff responded to women's questions. I noted down the regular visits made by the police and officers from the Ministry of Women and Family Development (Ministry). I noted down whatever I did in the shelter such as having casual conversations with the women or shelter staff, and incidences that occurred in the shelter (further details are discussed in the section below).

The four-day observation gave me a general idea on how women lived and were treated in the shelter. Observation, particularly participant observation, has been used in a variety of disciplines as a tool for collecting data about people, processes, and cultures in qualitative research (Kawulich, 2005). Marshall and Rossman (1989) define observation as 'the systematic description of events, behaviours, and artefacts in the social setting chosen for study' (p.79). Participant observation is the process that enables researchers to learn about the activities of the people under study in the natural setting through observing and participating in those activities (Kawulich, 2005). Thus, through participant observation, I was able to learn about women's day-to-day routine activities and understand the rules and regulations of the shelter as well as how women responded to these rules.

\section{Access}

The process of attaining access was incredibly difficult given the levels of bureaucracy involved. The process started in March 2015 when I first contacted a counsellor from the Ministry, whose contact details I found on the Ministry's website. She responded and appeared to be receptive to my idea of interviewing trafficked women in the shelter. She advised me to obtain permission from the 'Director General of the Department of Women Development' (DG) and even allowed me to quote her name in order to obtain the approval. Following her advice, during November 2015, I wrote several emails and letters to the DG's Office and the 'Council for Anti-Trafficking in Persons and Anti-Smuggling of Migrants' (MAPO) seeking permission to interview women held. However, I did not receive any response from either organisation, despite sending reminders. Their non-responsiveness prompted me to 
seek further assistance from a contact who has connections with the Attorney General's (AG) office. However, even that was to no avail.

I made telephone calls to the DG's Office and MAPO's Secretary Office in early January 2016. My first few messages were left unanswered. After these attempts, I finally managed to speak to the Secretary of MAPO, where she questioned my research intentions. The Secretary felt that it was too dangerous to allow me to interview women in the shelter and stressed that the women were detained for a reason (although she did not clarify what this reason was). With some reluctance, she eventually advised me to seek approval from the DG. After assuring her that I would not cause any harm to the women and would abide with any official rules and regulations, she agreed to assist me to gain access to a few professional interviewees on the condition that I would give her a copy of the completed thesis. Following this conversation, I obtained email approval from MAPO (dated 4 January 2016) giving me permission to interview three professionals from the 'Anti-Trafficking Unit Department' who were attached to the police, immigration, and the Ministry. The MAPO's Secretary also advised me to find more professional participants from the police or the Ministry whom I could interview for my study and to liaise with them directly.

Obtaining the approval from the DG's office to conduct fieldwork was equally strenuous. I was unsure of the number of shelter homes that existed in Malaysia as there was not much information available on the government agencies website for security reasons. The numerous calls and messages left with the DG's office remain unanswered until I finally managed to speak to the Deputy DG. The Deputy DG interviewed me over the telephone and questioned my research intentions. I assured the Deputy DG that I would observe the principle of 'do no harm' as contained in the 'Ten Guiding Principles of Ethical and Safe Conduct of interviews' advocated by the World Health Organization (the Guiding Principles) (see Ethics section) and was granted verbal approval to access the shelter and interview those held. As with MAPO, approval was subject to the condition of providing the completed thesis and abiding by all terms and conditions imposed by the shelter, which I gladly accepted. I was also informed that I was the first external researcher to receive approval to interview women in the shelter. 
I finally obtained written approval from the DG's office (in a letter dated 25 January 2016). This allowed me to interview women from Shelter 5, in Kuala Lumpur from 18 April 2016 to 30 April 2016, which was subsequently extended to 15 May 2016 (letter of approval dated 16 March 2016). I was told that Shelter 5 is the biggest shelter home for trafficked women (out of the seven shelters in Malaysia) and the majority of women were foreign nationals who had been sexually trafficked and rescued by the authorities. I was also given permission to interview the Shelter Officers, Protection Officers, and the wardens. However, the location of the shelter was only made known to me at a later date as they were very cautious about maintaining secrecy to avoid trafficker presence around the shelter. Apart from the government professionals, I emailed SUKA Society, an NGO that conducts activities in the shelter seeking permission to interview their representative. They did not reply to my request formally but told me verbally (over the phone) to contact their representative who would be at the shelter on most weekdays and seek her approval (which I later did).

Given these approvals, I contacted workers to set a date for their appointments. This was another daunting task as some did not respond to emails and I had to make numerous telephone calls to set appointment dates. I was also requested to give the police officer and the immigration officer a set of questions that I intended to ask before the interview date (see Appendix 4). Besides this, I had to make numerous telephone calls to the shelter as I wanted to establish good relationships with shelter officers. I wanted to ascertain certain facts regarding the women in the shelter in order to prepare. I needed to clarify the number of women who had been categorised as sexually trafficked in the shelter as the number fluctuates according to the raids conducted by police. It was crucial to ascertain the women's nationalities and their ability to converse in Malay/Indonesian or English language because I needed to engage interpreters for the purpose of interviews. I also needed to clarify if I would be given a private space to conduct the interviews and the freedom to choose my own participants. The shelter officer was very cooperative and forthcoming as she implied that I would be able to choose my own participants from the shelter. My final task was to obtain approval from the NGOs, which was successful and less complicated as I had already obtained approval from the DG. 


\section{Selection of Participants}

To gain an insight into migrant women's lives and trafficking experiences, I wanted to select those who had experienced working in the sex trade in Malaysia. Therefore, the shelter seemed to be a suitable place to find participants that would accurately fit the criteria. ${ }^{51}$ The shelter was located at a secluded place in the heart of Kuala Lumpur and could not even be accessed by GPS. The shelter was meant to house migrant women and local women who have been trafficked and exploited for commercial purposes. However, no local women were held during the weeks of my fieldwork, except for the last three days I was there. Interviews were held across a span of four weeks (from 18 April to 15 May 2016). Of the 202 women in the shelter during my fieldwork, an overwhelming number were categorised as sexually exploited ( $n=168)$, followed by cases of labour exploitation $(n=34)$, which includes unpaid wages $(n=14)$, working without permit ( $n=6)$, forced labour $(n=12)$ and maid abuse $(n=2)$. Of the 168 women detained for being sexually exploited, 29 women (women participants) were selected to interview (see Appendix 1 for further details).

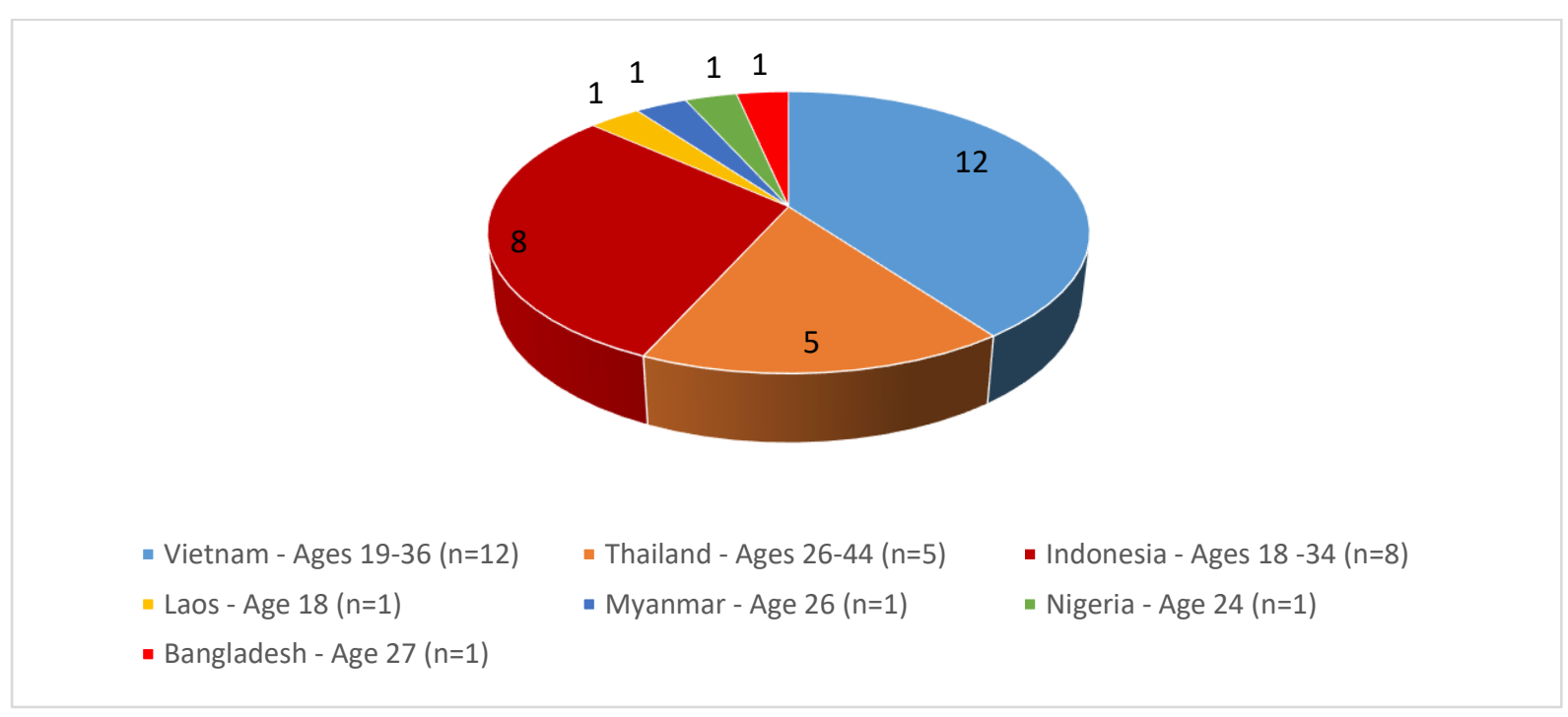

Figure 3: Participants' country of origin and age range

As shown in Figure 3, the women participants originated from Vietnam, Thailand, Indonesia, Laos and Myanmar, Bangladesh and Nigeria. Their ages ranged from 18 to 44 years old, and

\footnotetext{
${ }^{51}$ Women who have been categorised as sexually trafficked, 'rescued' and detained in the shelter.
} 
they were rescued from massage parlours, brothels, entertainment centres and private dwellings throughout Peninsular Malaysia.

For the professionals, three names were given to me by MAPO (one police officer, one immigration officer, and one protection officer) and the remaining nine were shelter officers, protection officers, enforcement officers and NGOs whom I encountered during the shelter fieldwork. They comprised five shelter officers/wardens, two police officers, one Ministry protection officer, and one NGO protection worker (see Appendix 3). The police officials were selected because they have been actively involved in raids and court processes while the NGO protection worker and shelter officials were involved in shelter activities, court processes and the administration and care of trafficked women.

The shelter manager and officers were very helpful and cooperative. The shelter manager offered me the private counselling room, complete with mineral water and tissues, to conduct my interviews. She also gave me two lists of names containing details of the women, their names, ages, identifying numbers, passport numbers (if any), countries of origin, classifications of cases, and the dates they entered the shelter. The latter issue was important, as entering on the same day meant that women were more likely to have been rescued in a group during the same raid and would have been working in the same place (although this may not be definite). The first list included women who had obtained a court Protection Order and had lived in the shelter for more than 21 days (to three months), whereas the second listed those who had been given an Interim Protection Order and had lived in the shelter for less than 21 days. From both lists I selected a total of 31 women, on the basis that they reflected the diverse nationalities and ages in the shelter, the varied time-periods in shelter detention, and different dates of entry. I wanted to obtain a diverse sample of women who would be able to give me their own nuanced accounts of the policing and detention process. All agreed to be interviewed except for two who declined as they were concerned about their cases in court. 


\section{Consent}

Informed consent (see Consent Form in Appendix 5) was obtained before the start of all 41 interviews. I explained the Information Sheet (see Appendix 6) in detail and allowed the women participants to ask any questions before I obtained their signatures on the Consent Form. I clarified my position as an academic researcher from a university, and that I was not in any way connected to government officials. I disclosed the objectives of my interview, that it was intended to be used for the preparation of a thesis. I also informed them that their narratives are intended to assist other women from experiencing any hardship in the future, as the findings would be disseminated to key professionals working in the area. I informed the women participants that I would not disclose their identity and that they would be identified by a pseudonym. I also stressed the fact that their participation in the interview was voluntary and that it was the women's privilege to refuse to answer any questions are directed to them (Giallombardo, 1967). Such assurance gave them the confidence that I was not a threat, and made them feel at ease to engage in a conversation with me. Similar explanations were given to professionals and I gave them the opportunity to use a pseudonym if they wished to do so. However, all of them agreed to disclose their original name in the thesis, except for two shelter wardens ${ }^{52}$ who preferred to be referred to by a pseudonym but agreed to have their designation recorded.

\section{Conducting the Interviews}

Conducting the interviews with women participants was done in accordance with the Guiding Principles advocated by the World Health Organization, which is based on the principle of 'do no harm' (Zimmerman \& Watts, 2003). Among The Guiding Principles were: to not make promises that cannot be fulfilled; to adequately select and prepare interpreters and coworkers; to ensure anonymity and confidentiality; to obtain informed consent; to listen to and respect each woman's assessment of her situation and risks to her safety; to not retraumatise a woman; to be prepared for emergency intervention, and to use the information

\footnotetext{
52 There were only two shelter wardens interviewed in this study. The other shelter officers were not aware of the particular wardens I interviewed because I had informal conversations with all of the wardens when I was in the shelter.
} 
obtained wisely' (Zimmerman \& Watts, 2003, p. 4). These Principles were used as a guide in drafting my questions for the interviews (see Appendix 2).

I was aware that the women had already progressed through a series of interviews with different government officials before they were greeted by my presence in the shelter. I was also aware of my position as a university researcher who had the freedom to leave the shelter at any time, whereas the participants had no option to leave the shelter except for court visits and had to obey to the rules and regulations of the shelter. In these instances, a power imbalance between myself and the participants would be inevitable (Mason \& Stubbs, 2011). Therefore, I sought to build trust more slowly by participating in activities such as sitting down in the lounge with them and joining them for meals for about four days so that they would get used to my presence before I started interviewing. This technique has been used by researchers such as Giallambardo (1967. P.319) (in her study with women prisoners) who said:

In so far as it was possible for me to do so, I tried to approximate the living existence of the inmate; namely, by my continuous presence day after day at the formally scheduled functions for the inmates, and by spending many hours with them in the cottages and on the prison grounds. This procedure was consistent with the inmates' belief that it is not possible to understand the inside or prison world by making a few isolated visits to the prison.

As in this study, I was mindful of the fact that the women may be sceptical of my presence and might fear that the police or shelter staff was checking up on them, and, that any information obtained might be used to the disadvantage of the women. Therefore, it was important for me to assure the women that I was not a state official, a shelter staff or a journalist (Giallombardo, 1967). To emphasise that this research interview would not be like other interviews, a small gift comprising of a notebook and pen as was given to add professionalism to the process.

The women were aware of my presence and some of them spoke to me. Most of the women who spoke to me were Indonesians because they could communicate in the Malay language. 
Women from Vietnam and Thailand who could speak English or Malay also spoke to me and invited me to watch television with them, which I did. Many of them wanted to know where I was from and what I was doing in the shelter. I explained that I was a researcher from the University and was at the shelter to conduct some interviews for my study. They nodded and started to have casual conversations with me. Many of them talked about fashion, hairstyle, weight, and the type of food served in the shelter. Some of the women invited me to join them for lunch, which I did on the $20^{\text {th }}$ of June after obtaining the approval from the Shelter Manager. ${ }^{53}$ The atmosphere was calm and the food tasted delicious. I could see the rush and excitement of the women during meal times as there were not many activities in the shelter. One woman came up to me and told me that she finished her lunch and showed me her empty plate. One Indonesian women told me that she was mentally unwell because her former employer tortured her and used to beat her head repeatedly when she was working as a domestic maid.

Apart from the women's daily routines, there were not many activities to do in the shelter and many of them took naps and just congregated in groups to talk and gossip. The shelter was very noisy because of the overcrowding and therefore yelling became part of the norm. I could see that many of them felt stressed living in a confined space with no access to telecommunications and not knowing what to do in the shelter. My four-day observation period helped to establish rapport with the women and it at least gave them the chance to observe my demeanour before I started interviewing them. As noted by Giallambordo (1967, '...in as much as inmates are committed daily, as well as released, the problem of establishing and sustaining rapport becomes a constant and integral factor of prison research' (p. 318).

Therefore, my role as a researcher was based largely upon the participant's conception of my affiliations. In this instance, I carefully explained to my participants that I was a PhD student who was conducting research on their migration experiences and they nodded indicating that they understood my position. From here, the interviews were conducted in a conversational style (Becker, 1971) and were audio-recorded. I emphasised at the start of the interview that their participation in the research would in no way shorten or lengthen their stay in the

\footnotetext{
${ }^{53}$ The Shelter Manager instructed the caterer to prepare extra food since I was having lunch with the women.
} 
shelter. I also clarified that the women would not receive any direct benefit from the study but pointed out that their participation would not be harmful to them.

At the start of the interview, I would usually have a light conversation with them and talk about things that they liked, such as movies, actors, or food or use some humour to make them feel at ease (Bergold \& Thomas, 2012). I listened attentively (Clough \& Nutbrown, 2007), paused, probed and prompted (Ritchie \& Lewis, 2003) in order to encourage the participants to talk freely. Besides interviewing the participants, I was also actively observing their demeanour during the interview and their behaviour in the shelter. Through this, I noted if I thought they were depressed, worried, lost, angry, bored, resentful or cheerful. I could also note their agreement and disagreement through their body language, through the nodding or shaking of their head, or by other utterances that could not be picked up by the audio recorder. These observations allowed me to construct my questions carefully and anticipate questions that may be distressing to them, such as questions about their police rescue. My approach and interviewing technique appeared to be successful, as some of them stated that the interview felt therapeutic as they were able to express their feelings and thoughts freely.

The duration of the interview sessions with the participants varied from 20 minutes to 1 hour and 45 minutes. Some of the women participants' interviews were shorter as these women were not very conversational, and expressed confusion about the events that had happened to them. It was important to read the situation carefully and go gently, only continuing if it was not causing them distress. Almost all of the women participants became emotional when they were talking about their experiences of migration and being policed. Many of them vented their frustrations and anger towards the police and broke down in tears while talking about their family, and the way they were treated by the police and shelter staff. I anticipated these responses, and developed practices that minimised negative effects on participants by giving them short breaks and having a short casual chat in between interview questions. I also reminded them that they could choose to discontinue the interview at any time they desired. On the whole, most of the women expressed their relief gained from participating in the research compared to the stress and unsettled feelings of living in the shelter. They were happy that they were able to express themselves and speak openly about their feelings. 
Semi-structured interviews with the investigating officers, enforcement officers, protection officers, government officers, NGO workers and shelter officers were conducted across their workspaces (police headquarters, immigration headquarters, Shelter 5 and the Ministry). I was mindful of the fact that as professionals they were working for the government, and I reminded them that they were not obliged to answer any questions that they were not comfortable with. In positions of authority, some identified their expertise in the area. Almost all professionals appeared to be very optimistic about their scope of work and the victim protection policies. However, they also felt restrained with the limited knowledge and resources available. Thus, they were more than willing to talk about the weaknesses of the current anti-trafficking policies that have created tension and problems throughout different departments. All were cooperative and many gave me documents comprising data, statistics and reports to assist me with the study. This included the anti-trafficking legislation, shelter rules, plans, statistics of the inflow and outflow of trafficked migrants into the shelter and the country. However, my request to obtain a copy of the Standard Operating Procedure (SOP) for handling trafficking victims was denied by the police and immigration on the grounds of confidentiality.

\section{The Use of Interpreters}

The use of interpreters was crucial in this study because of the language barrier that existed between most of the trafficked women participants and myself. External interpreters had to be recruited since there were no in-house interpreters available in the shelters or from the Ministry. It would also be inappropriate to use interpreter from the shelter or the Ministry (if available) because the women may not trust them or feel able to speak freely since they are complicit in their detention. Even though the shelter wardens could only speak in Malay and English, the women were able to understand the instructions given with the help of their peers who understood the language. However, for the purpose of this study, it was vital for me to recruit external recruiters so that the participants did not feel cautious or anxious to talk, knowing that the interpreters were not government officials or working in the shelter. One Thai and three Vietnamese interpreters were employed to assist me in interviews. Their interpretation services were used for interviewing trafficked women participants from 
Vietnam, Thailand, Laos and Myanmar. Research participants in this study from Myanmar and Laos could speak the Thai language.

The interpreters were all women who had experience as freelance interpreters in court. This helped as they were used to hearing and interpreting accounts of harmful and violent acts. There was no specific reason for engaging female interpreters but it helped in making the women feel comfortable, acknowledging the sensitivity of certain issues, especially when they were describing explicit details about sex work. The interpreters were all given the necessary briefing, where they were told to transmit the statements given by the participants accurately without withholding any information so that statements given would not be lost in the interpretation process. The interpreters were also requested to sign a confidentiality agreement (see sample of agreement in Appendix 7) before the interviews where they agreed to not disclose information. Interpreters are considered to be key informants who provide information about the social setting under research and mediate between the researcher and the participant, they are viewed as active producers of knowledge (Edwards, 1998). Aranguri, Davidson, \& Ramirez (2006) argue that in the interpretation context, more is being said than is getting translated and, furthermore, interpreters change meanings by omission, revision, and reduction of content. Therefore, the interpreter's control of content would be inevitable. In some interviews, the interpreter listened and translated as the person was still completing their sentence and there were times where the interpreter started translating after the participant had completed their thought, sentence or phrase.

The participants appeared to be comfortable with the interpreters chosen, and cooperated with them well. The process of interpreting went very smoothly, although in one instance an interpreter appeared to be obtrusive during the interview, as she suspected that a particular participant was not telling the truth. This happened when the participant stated that she changed her Vietnamese currency to Malaysian Ringgit at Ho Chi Minh airport. The interpreter, who is Vietnamese and frequently travels back and forth from Malaysia to Vietnam, was not aware of any counter that provided change for Malaysian Ringgit. I was quick to interject during this situation and reminded the interpreter to focus on the responses that were given by the participant and not to ascertain the veracity of their statements. I also reminded myself that I was conducting feminist social research where I wanted women to 
speak freely and narrate their own lived experiences from their own perspective, as opposed to my legal investigating techniques, which mainly focus on establishing a solid defence in court in order to rebut the prosecution's evidence. I also learnt that office attire worn by the interpreters might trigger an instantaneous response from the participants. This is because the participants looked a bit curious when they saw one particular interpreter who was formally dressed (jacket, pants and hair bun) as opposed to the other three who were casually dressed. However, this particular interpreter introduced herself to the participants and she was very friendly and respectful towards the women. Her relaxed demeanour made the participants feel comfortable and the interview was carried out without any problems or complications.

Twelve participants who could converse in Malay, Indonesian or English were directly interviewed by me while the remaining 17 who spoke Thai (including participants from Laos and Myanmar) or Vietnamese language were interviewed with interpreters. All the Indonesian participants spoke Indonesian and one particular Thai participant could converse in Malay fluently. Those who spoke in Malay, Indonesian and English were able to express themselves clearly and understood my questions. I find conversations using Pidgin English challenging as Pidgin English differs according to each country. However, given my exposure, knowledge and experience in using Pidgin English, I was able to understand the various accents of Pidgin English used by the participants although it required a lot of attention. The professional participants did not require any interpreters as the participants were well versed in either Malay or English.

\section{Ethics and Challenges}

Ethics Approval was obtained by the Victoria University Ethics Committee (11 April 2016, Approval no. 21767) (see Appendix 8). A small gift in the form of a pen and notebook (as earlier stated) was given to all participants after the interview as a gesture of appreciation. The interviews in the shelter went smoothly but there were many challenges during this time. The shelter was severely overcrowded as, with an official capacity of 70 women, it housed 202 women during the fieldwork period. This overcrowding resulted from the fortnightly police raids on massage parlours, private dwellings operating as brothels, nightclubs, and 
karaoke bars which forced the shelter to accommodate extra people. There were only two bathrooms and toilets in the shelter and water supply was scarce in one of the toilets.

The shelter was noisy from overcrowding, and frequent fights erupted amongst the women due to their confinement. This caused the women in the shelter a lot of stress. Women would usually congregate in groups or lie on the floor, and I had to weave through them to get to the counselling room. The counselling room was situated behind the television area and women would usually watch Vietnamese and Thai soap operas for long hours. The noise from the television was sometimes deafening and, due to this, I had to reschedule some interviews for later times. Authorities would frequently bring in women who had been 'rescued' and interview them in Malay and English despite the language barrier (see Chapter Seven). It was very difficult for me to watch how women were being treated and to restrain myself from interfering, because I was mindful of my position as an independent researcher. In this situation, I knew that my intervention would not benefit the women because they were under a court order and had to adhere to all instructions given by the shelter officers. Furthermore, the Guiding Principles have stated that I should assess the women's situation and risks to her safety. Therefore, I decided to record my observation and use my observation wisely as recommended by the Guiding Principles. I was also subject to the rules and regulations of the shelter, where interviews could only be conducted from 9 am to 5 pm (weekends included) for security purposes.

A further issue was that the interviewees, and a few other women in the shelter, requested personal favours such as wanting to borrow my mobile phone, or wanting me to buy a particular CD. Some asked for snacks and herbal ointment, and some asked me questions about their cases. Unfortunately, I had been warned by the shelter officers to not discuss any cases or entertain any requests from the women. Therefore, I tried to give the women neutral answers about their cases, but I bought snacks (chocolates, sweets, biscuits) and herbal ointment for the women upon approval from the shelter warden.

There were also some incidents that occurred that placed me in a dilemma. One particular event was when I witnessed, through a glass door, a male police officer being massaged by one of the women in the shelter. I alerted one of the shelter officers who went to inspect 
what was happening but they did nothing, and in turn told me that the woman was just giving a 'Thai' massage to an exhausted police officer. It was difficult to witness the ignorance of the shelter staff who did not react to such acts. In another incident, I saw a male police leaning his shoulder against a detained woman's shoulder. I did not want to confront the police officer in either incident but informed the Shelter Manager about the incident where she assured me that she would address the matter.

Some of the shelter officers spoke to the women very roughly and it made me feel very uncomfortable. Women were treated like small children even though they were adults. The women were yelled and shouted at by the shelter wardens during meals and activities. This appeared to be a norm, and the women were spoken to very roughly when they were given instructions to do a particular chore or act. The tone in which they were spoken to also appeared to be very demeaning and disrespectful. The shelter officers did not entertain women's requests for medicine, phone calls, or updates on their case. There were also times where women's complaints of being sick were ignored by shelter officers. The way women are treated in the shelter questions the effectiveness of the Malaysian anti-trafficking laws in providing protection for trafficked women. Based on the above examples, it can be seen that women are still exposed to harms through state protective custody.

\section{Analysing the Data}

This qualitative research resulted in large amounts of richly detailed data which was processed to identify major themes or categories that described the women's perspectives of their own victimhood and the harms that they endured (Saldana, 2009). For transcriptions, I used the Nvivo Plus version 11 software to transcribe the interviews. The transcribing process took almost three months to complete. There was a lot of noise in the background of the recordings because the interviews were held in the counselling room directly behind the television. Added to this, I had to translate conversations which were conducted in Malay to English, Indonesian to English and Pidgin English to formal English. The translation from Pidgin English to formal English took more time than the rest because each participant spoke with 
different accents and styles. This required intense concentration and literacy skills as I needed to translate the interviews accurately.

From here, the data was coded and categorised into themes and sub-themes (Braun \& Clarke, 2006) such as agency and harms. Thematic analysis was used to search for pre-established concepts such as 'victimisation' or trafficking harms. I used this method to identify, analyse, organise, describe, and report themes found within a data set (Braun \& Clarke, 2006). The method also emphasised the organisation and description of the data within the whole data set (Ibid). According to Braun \& Clarke (2006), thematic analysis is useful in capturing the intricacies and enhancing the meaning within the data. Codes were framed around meanings of choice, coercion, deception, exploitation and state harms. I retrieved all the text coded with the same label to understand women's migration experience. These codes stemmed from my research questions and the interview questions (see Appendix 2). As pointed out by Gibbs (2007, p. 38):

Coding is a way of indexing or categorising the text in order to establish a framework of thematic ideas about it. Coding is how you define the data you are analysing about ... You can retrieve all the text coded with the same label to combine passages that are all examples of the same phenomenon, idea, explanation or activity. This form of retrieval is a very useful way of managing or organising the data, and enables the researcher to examine the data in a structured way.

After retrieving the text codes, I proceeded to analyse the data. Coffey \& Atkinson (1996) recommended three steps in analysing the codes: 'noticing relevant phenomena, collecting examples of those phenomena, and analysing those phenomena in order to find commonalities' (p.29). I used this method to examine the perspectives of different research participants while highlighting the similarities and differences in their experiences (Braun \& Clarke, 2006; King, 2004). I divided the participants into two categories: those who were deceived or coerced into migrating to Malaysia to work in the sex trade; those who made their own choice and were willing to become a sex worker. I was also able to conclude that 
all the participants exercised some form of agency throughout their migration experience and that all of them experienced harm either in the hands of the traffickers or state officials.

While some concepts were postulated based on existing literature, some were developed from the 'ground up' (Glaser \& Strauss, 1967). In particular, the study focused on the human perspective and on the structures, processes, and social relations that shaped events and outcomes for the women (Oliver, 2012). I engaged a constructivist grounded theory ${ }^{54}$ perspective in order to develop and reconstruct the themes I have established. According to Guba \& Lincoln (1989, p. 43):

Constructivism is a research paradigm that denies the existence of an objective reality, 'asserting instead that realities are social constructions of the mind, and that there exist as many such constructions as there are individuals' (although clearly many constructions will be shared).

As Charmaz (2000, p. 527) points out:

My version of grounded theory fosters the researchers' viewing the data afresh, again and again, as he or she develops new ideas. Researchers can code and recode data numerous times... posing new questions to the data results in new analytic points. I go back and forward between the data and the drafts of chapters or papers many times. I take explicit findings in certain interviews and see if they remain implicit in other interviews.

In constructivist grounded theory, participants are active in the construction of knowledge (Charmaz, 2014). In this regard, I could connect meanings and actions to larger discourses. For example, I could identify the differences in their exercise of agency. While some women had more agency and could make decisions pertaining to their lives, others had limited agency and didn't have much choice. Following this, I used the Nvivo Plus 11 software to categorise my data into themes and concepts (Bazeley \& Jackson, 2013; Marvasti, 2004). The objective

\footnotetext{
${ }^{54}$ Theory is 'a strategy for handling data in research, providing modes of conceptualization for describing and explaining' (Glaser \& Strauss, 1967, p. 3).
} 
of this categorisation is to transform a large unorganised set of data into a recognisable framework of ideas (Marvasti, 2004). Although I had identified certain themes from the literature review such as concepts regarding 'agency', 'victim' and 'harms', I was able to identify new themes from the data. By using 'grounded up' theory as a guide, I used open codes to organise the data in ways which led to expand the concept of agency. This includes the nuances of experiences, the different forms and degree of harms and victimisation, as well as the diverse ways in which women negotiated their lives and exercised agency during their trafficking experience. The themes allowed me to identify the various phases of victimisation felt by the women. Some may have felt victimised during the rescue and policing process, while others were relieved to be rescued from their traffickers but came to feel victimised by their shelter experience. The postcolonial feminist approach taken towards this research has assisted me, particularly in the interviews and the analysis used to interpret the data and to understand the matters relating class, gender and race. I was able to conduct interviews without causing undue harm to women. I was able to identify and understand how Southeast Asian women as well as women from other postcolonial countries perceive their victimisation and agency. I could understand their concern about family relationships and their religious and cultural beliefs. Women were focused on their roles as breadwinners of their families and their family's well-being. They were fearful of the shame and stigma arising out of sex work. For example, I could understand the dilemma faced by women who engaged in sex work but felt uneasy or shameful because they were Muslims as sex work is categorised as a 'grave sin' in Islam. I could understand their feelings of sadness when they blamed themselves for not being able to provide for their families. Therefore, the postcolonialism approach has offered feminism the conceptual toolbox to see multiple sites of oppression and to reject universalisms about women in sex work. It challenges prevailing assumption that the white Western middle-class woman is the norm and at the same time aims to eradicate stereotypes about 'ideal' trafficked victims.

\section{Limitations of Data}

It is important to note that all research approaches have their limitations. From the outset, then, I am mindful of the limitations and weaknesses of this study. The limitation includes the language used in the interviews and the interpretations of women's interviews. Given the 
familiarity and experiences of the interpreters, their translation was considered correct and accurate and was not double-checked by another interpreter. It is also to my best knowledge that I have interpreted the interviews I conducted correctly. As pointed out by Willig (2017, p. 284):

The purpose of evaluating an interpretation is not to establish its absolute truth. Instead, evaluating an interpretation involves careful scrutiny of the balance between bottom-up (or participant-led) and top-down (or researcher-led) contributions to the meanings contained in the interpretation followed by reflection on the extent to which this balance is congruent with the researcher's declared approach to interpretation. Strategies designed to increase the trustworthiness of interpretations such as participant validation or member checking are not appropriate to all types of interpretations.

Apart from the language limitation, I am also aware that I may not fully understand the experiences of the women because I was not personally involved with their lives and experiences. However, I could understand their emotions and sadness, particularly relating to family, culture and religion. Furthermore, this research is based on a personal belief that victimisation in all its forms should be acknowledged and, preferably, responded to in ways that will alleviate its causes and conditions. I was also aware of the fact that the study was based on the narratives of the women and considered their narratives as the truth. Furthermore, my intention was to explore their migration and victimisation experiences and not to build or prove their cases in court. Rather, my intention was to understand and explore how women perceive their victim identity and if they could exercise their agency.

\section{Conclusion}

This research is led by a postcolonial feminist framework, which offers a re-examination of Western feminist theories in terms of their epistemological assumptions as such theories have been produced based on positions of power and privilege in the West (Mohanty, 1991). Although women may have certain commonalities, they do not share similar experience of oppression. Therefore, the representation of women from Third World or postcolonial 
countries as 'trafficked victims' who have suffered excessive violence and who lack agency or capability further marginalises women (Kempadoo, 2001). In this sense, the postcolonial feminist approach is able to demonstrate the diversity of postcolonial subjects' experiences and conditions under which they live. The chapter has also demonstrated how I have used feminist methodology to conduct research for women and issues concerning women (Ramazanoglu \& Holland, 2002). This thesis makes women visible, raises their consciousness (Holloway \& Wheeler, 2010) and acknowledges the emotionality and their experiences of harm. This is in line with the common feature of feminist methodology, which seeks to address women's lives and experience in their own terms, and create theories grounded in the actual experiences and languages of women (Hammersley, 1992). By using qualitative data collection and analysis, I captured the experiences of women who have been trafficked and analysed their experiences of harm. Thus, through this methodology, the following Chapter will demonstrate women's experiences of agency and victimisation throughout their migration period. 


\section{Chapter Six: Victimisation in Malaysia}

\section{Introduction}

These findings explore the various facets of victimhood based on the narratives of migrant women, held in 'Shelter Five' in Kuala Lumpur. They show that common understandings of trafficking have reflected stereotypical images of 'victims' who are typically projected as innocent, naïve, virginal women who have been abducted and forced into sexual slavery (Doezema \& Kempadoo, 1998; Doezema, 1996). In reality, the lived experiences of migrant women are far more complicated and nuanced. Therefore, the chapter seeks to debunk the stereotypical image of an 'ideal' trafficked victim. It focuses upon three main findings. First, that women are active agents who seek to provide economic security for themselves through sex work. Although some may be coerced or deceived into sex work, this does not mean that they are solely reduced to weak or helpless individuals who are devoid of agency. Second, while exercising agency and making choices, many migrant women have experienced coercive and exploitative practices within their voluntary participation in the sex industry. This had led enforcement officers to tend to equate women's participation in the sex industry with coerced sex work, and to believe that women are incapable of consenting to sex work. Third, there are women who would rather work in exploitative conditions than be rescued by the authorities because they need the money to support their families. Many women fear being 'rescued', detained and deported on economic grounds. These three findings challenge the implicit and explicit assumptions made about women migrating for sex work and their victimhood, by exposing their agency and their ability to comprehend their own migration experiences. It also illustrates how migrant sex workers are viewed as 'immoral' and a threat to the state and Malaysian society.

To assess the relationship between migration, sex work and victimisation, this chapter analyses women's experiences, and their understanding of their own agency and victimhood. As Christie (1986) argues, 'it is often useful within the social sciences to rely on personal experiences, or at least take this as our point of departure' (p.17). The diverse women in this study challenge the stereotypical presumptions of trafficked victims and provide a nuanced 
account of victimhood and agency. They show how the complexities of victimhood have not been understood or acknowledged by legislators, enforcement officers, or the judiciary.

The chapter begins by exploring and analysing women's experiences of working in the sex industry in Malaysia, their reasons for engaging in sex work, as well as the harms that have been inflicted upon them. Following this analysis, the chapter will discuss women's migration experiences, including their perspectives of being rescued by the authorities. Their diverse experiences of the women will reveal the multiplicities and complexities of choices they had to make in order to improve their economic situation. Their perspectives challenge the victimagent dichotomy and demonstrate the nuances of their agency throughout their trafficking experience. Therefore, this chapter provides insights into women's migration experiences, their desire to improve their economic situation, their perception of their own victim identity, and the choices they made to reduce and navigate harms.

\section{Women Participants}

Earlier discussions in the thesis have explored how agency is presumed to be incompatible with victimhood. In this instance, a woman who is considered to be 'trafficked' cannot be said to have exercised her agency. However, the literature has shown that women are capable of exercising their agency (though limited) even if they were being victimised (see Chapter Two). Such perspectives demonstrate the nuances of women's agency and how women are able to control their lives and exercise strategies to reduce harm. A similar complexity is evident in this research as women participants provided multiple views about their decisions to migrate and engage in sex work, while officials assumed that they had been continually coerced and exploited.

In a study conducted in Patpong, Thailand, researchers found that no qualifications were required for women to become a sex worker except for being a young woman who is willing to sell sex (Skrobanek et al., 1997). This suggests that the recruitment of women into the sex industry is often relatively easy and straightforward. In this regard, traffickers heavily rely on women's willingness to migrate and work, and take advantage of their situation. Therefore, traffickers normally convince women that they will be able to earn a lot of money if they 
engage in sex work but do not disclose the risks attached to sex work. For example, in this study, six women (namely Ngoc, Liana, Hong Phan, Da, Nun and Gena) stated that they were not informed by their recruiters or their employers of the risk of being confronted and apprehended by authorities while working. Although some women may be aware of the illegality of sex work, some women becomes convinced that they will not be violating any laws (Haynes, 2007). While the former often become overly dependent on their traffickers for fear of being arrested by the authorities, the latter would likely remain compliant to their traffickers and hence are less likely to flee (Ibid). Women's obedience to their traffickers also stems from patriarchal influences, which perpetuates female subordination and dependency (reliance) on men. Furthermore, traffickers use a variety of strategies to establish trust with the women. Among the strategies used is to allow them to travel independently to Malaysia. This gives women a kind of assurance that they will be working for a reliable employer. Furthermore, the process of entering Malaysia is relatively easy and the official detection of women being trafficked at the border is highly unlikely when women travel on their own via legitimate means. This is because traffickers may not have exploited the women yet because they are still travelling and have not reached their workplace.

\section{Entry and Recruitment}

The recruitment process normally involves either one or more of the following: the initial invitation to migrate by a friend, acquaintance, partner or family member ('recruiters'); the shock of realising the actual nature of the work or conditions of work upon arrival; and the gradual socialisation process into selling sex (Molland, 2011). Some of the women in this study arranged for their own passports and travel tickets, while others were assisted by their friends, neighbours, relatives or work agents before travel. Twenty-seven out of 29 participants entered Malaysia using a valid passport and were given a one-month 'social visit pass' or a 'tourist visa', which does not allow them to work in Malaysia. However, all twentyseven were unaware of such restrictions and were not informed by their recruiters (as earlier mentioned) of the risk they faced if they engaged in sex work in Malaysia. The remaining two women entered Malaysia using different channels. One participant, Mon, had a student visa attached to her passport while another participant, Fon, did not have a passport and entered 
Malaysia through the jungle bordering Thailand and Malaysia, guided by a friend of her trafficker.

Most ( $n=22$ ) participants travelled to Malaysia on their own and were given instructions by their traffickers on how to reach their workplace (details of how women find out about their work is explained below). The remaining seven travelled to Malaysia with their friends (3), boyfriend (1), sister (1) or work agents/acquaintance (2). This independent form of travel facilitates the trafficking operations by appearing like legitimate travel and thus avoiding any authority detection of suspicious activities. Of the 29 women in this study, only one was a freelance sex worker. Putri used to solicit clients in hotels and engage pimps to look for customers in hotels in Johor Bharu. Twenty-eight other women were recruited by different individuals while they were in their hometown. Most were recruited through friends or acquaintances (14) while some were recruited by their boyfriends (2), sisters (2), neighbours (4), cousins (1), work agents (3) and acquaintances known through social media (2). The recruiters were from their hometown or were residing in the same country while those who recruited the women through social media were said to be working in Malaysia.

For example, Hong said:

My neighbour approached me while I was working in the market in Vietnam and offered me to work as a masseuse in Malaysia. She asked me to contact a person on Facebook to get the address of the workplace which I did. The person responded and told me about the job and how to get to Malaysia. My neighbour had contacts in the immigration department and helped me to arrange my passport and travel to Malaysia.

Similarly, Ngoc was offered work in a factory in Malaysia by a friend. She said:

Lei [an acquaintance], bought my flight ticket and travelled with me to Malaysia. Upon arrival in Malaysia, we took a taxi and arrived at a massage parlour where I was introduced to a person in charge of the massage parlour. He asked for my passport and confiscated it. 
Hong and Ngoc's cases show the different number and different roles of people involved in facilitating their migration, and the local connections that their friends and acquaintances have with the massage parlours in Malaysia. This reveals the systematic structure of the trafficking operations where many individuals play a part in ensuring the smooth operation of the commercial sex trade. It shows the continuum of arrangements within the trafficking process from start to finish. However, the women did not appear to be perturbed with these arrangements because they were focused on migrating and obtaining a job to support their families and improve their financial situation. Women's understanding of victimhood varied while many women focused on factors such as economic security as well as freedom to exercise their agency.

\section{Perceptions of Victimisation}

Women's perceptions and understanding of their own victimhood is important as it gives an insight into their views of their agency and how they understand their own migration experiences. Among the questions that were posed to the women during the interview was if they felt victimised by their employers. Some felt victimised because they were immobilised and subject to certain restrictions imposed by their employers, while others had no complaints and did not indicate any experiences of victimisation while they were working.

The Palermo Protocol and the ATIP do not provide clear guidelines on the type and degree of exploitation, deceit, force, or threats (Anderson \& Davidson, 2003) that are necessary to constitute an act of trafficking. Given this, and the methodological approach of this thesis, any understanding of trafficking victimisation has to be contingent on the women's own lived experience and perceptions. In this study, women reflected their migration experiences along two main lines:

(a) Women who did not indicate or expressed any form of threat, coercion or harm and exploitation ('knowing participants'). They voluntarily migrated to Malaysia to work in the sex trade and were aware of the nature of the work 
they were going to do and had no complaints of about the working conditions or their employers.

(b) Women who indicated or expressed some form of coercion, deception, threat, harm or exploitation

Of the 29 women in this study, two women did not engage in sex work but were exploited for other purposes (student and labour trafficked). This will be discussed in the later part of the chapter. Thirteen women stated that they voluntarily migrated to Malaysia to engage in sex work, and did not indicate any form of deceit, threat, coercion or harm, while 14 women complained of being coerced and/or deceived, and that they were being subject to exploitative working conditions. Further illustration can be seen in Figure 4 below. The presence of these situations indicate that the women had been trafficked for the purpose of exploitation (see also Adams, 2011; Haynes, 2007; Larsen, Andrevski, \& Lyneham, 2013; O'Connor, 2017).

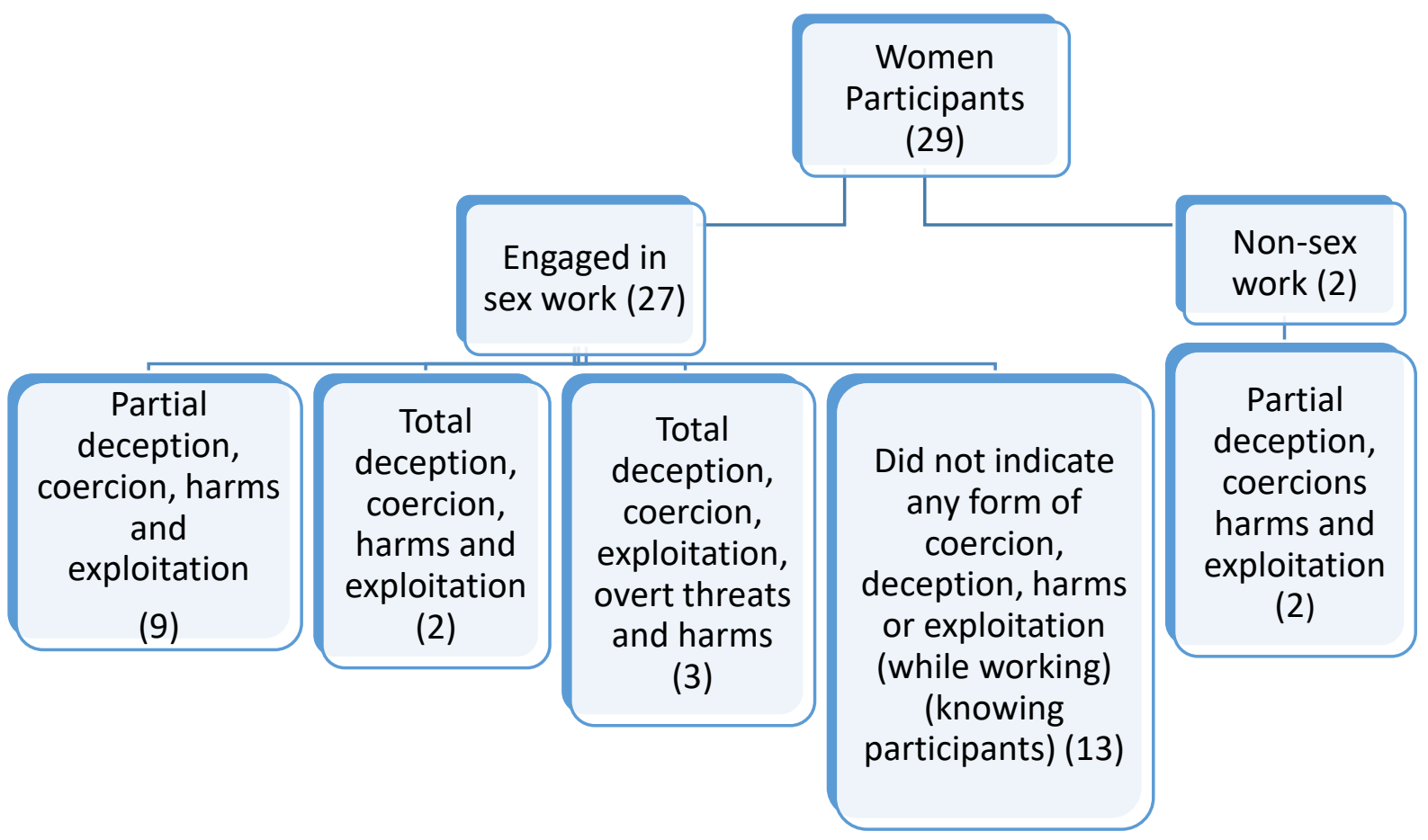

Figure 4: Women's Perception of their Migration Experience

The 14 women who were coerced, deceived, exploited and harmed fell into three distinct situations: 
(a) Women who were partially deceived, coerced, harmed and exploited $(n=9)$.

(b) Women who were totally deceived, coerced, implicitly threatened, harmed and exploited $(n=2)$.

(c) Women who were totally deceived, coerced, overtly threatened, harmed and exploited ( $n=3)$.

The above categorisations represent the multiplicities of women's victimisation. This was established through questions that asked the women if they voluntarily wanted to migrate and engage in sex work. It is not intended to undermine or compare the suffering of the women but to show that victimisation of women may occur in various forms, ranging from the subtle forms of coercion to more extreme forms of exploitation. It represents experiences in which women were not informed of their working conditions, working hours or salary before their migration. It indicates poor working conditions and non-payment or underpayment of wages. It shows how women can be psychologically harmed by their employers. In some cases, women had their passports withheld, they faced debt bondage, had limited freedom of movement, were not allowed to leave their place of employment, were underpaid or did not receive any wages. This was established through questions, which asked them if they voluntarily wanted to migrate and engage in sex work in Malaysia and the reasons for their decisions. Further details of the above categorisation are attached in Appendix 9. Thus, the below section will discuss women's migration experiences and how they navigate harms.

\section{Partial Deception, Coercion, Harms and Exploitation}

Nine out of 29 participants initially agreed to migrate and engage in sex work but were later subject to exploitative working conditions. This includes one or more of the following situations: passport confiscation, debt bondage, not being paid their salaries, not being allowed to leave the workplace, or having limited freedom of movement. One example is the case of Liana who voluntarily migrated to Malaysia and became a sex worker in a massage parlour. Liana said: 
My employer paid for my travelling expenses to Malaysia. I need to repay him the money but I am not sure of the amount. My Boss confiscated my passport and I was not allowed to leave my workplace. My charges were RM150 [NZD60] for sex only and RM450 [NZD180] if the customer hired me overnight. My boss takes all the RM150 [NZD60] I receive from the customer even though I am entitled to half of the amount. That was the initial arrangement but there was no written contract. He does not pay me any salary, but I can borrow money from him and send remittance to my family back home. I will only be given money when I am allowed to return to Indonesia. I feel victimised by my boss because he kept my passport and did not let me go anywhere, not even to buy food outside.

Similarly, Emi who was working in the same massage parlour as Liana said:

The Captain [boss] confiscated my passport when I arrived at the massage parlour. Although I paid for my own travelling expenses, I was not allowed to leave my workplace and they have not paid my salary.

Liana and Emi's cases show that although they were aware of the job they were going to be engaged in, they were deceived on their working conditions because their passports were confiscated, their salaries were not paid, their movement was restricted to their workplace, and there was a debt bondage. As a result, the women became trapped in exploitative working conditions and became subservient to their traffickers. The remaining seven women narrated similar accounts to those of Emi and Liana and only received a meagre amount of salary from their employers. Many of them depended on tips given by the customers. All nine women remained subservient to their traffickers while they were working, but were aware that they were deceived because their salaries were not being paid as earlier promised. They also felt restrained because they had limited freedom of movement and felt trapped in a cycle of debt which restricted them from leaving the workplace. 


\section{Total Deception, Coercion, Harms, Exploitation and Implied Threats}

Two women were totally deceived from the initial stage of recruitment and were further coerced to engage in sex work and exploited when they arrived in Malaysia. They complained of being totally deceived by either their friends, acquaintances, or agents about their work and were subject to exploitative working conditions. The women were promised high paying jobs such as therapeutic masseurs (non-sexual) and factory workers, but were forced to engage in sex work and held under a debt bondage. Along with this, the women also experienced one or more of the following situations: passport confiscation, not being paid their salaries, not being allowed to leave the workplace, or having limited freedom of movement. For example, Fon said:

I felt sad because my friend tricked me into believing that I was going to work as a therapeutic masseur in a spa, but I ended up working as a prostitute in a brothel in Malaysia. I had no choice but to obey her instructions because I owed her RM3000 (NZD1250) and needed to repay my debts. I was informed by the Captain [pimp] that I could earn about RM150 [NZD54] per customer, but I did not receive any money for my services apart from tips from the customers. I was also not allowed to leave the workplace.

Ngoc also had a similar story to tell. According to her:

I was offered work in a garment factory in Malaysia by a friend. She said that I could earn about USD1000 per month. However, I was shocked to discover that I had to work as a masseur in a massage parlour in Kuala Lumpur. I had no other choice but to comply with her instructions because I owed the massage parlour RM3000 [NZD1100] for my travelling expenses. I continued working because I wanted to pay off my debts and support my family back home. The Captain [pimp] kept my passport, and I was not allowed to leave my workplace unaccompanied by him. 
Debt bondage became a method of control in both cases, and the participants had no other choice but to engage in sex work. Furthermore, the recruiters were their friends which made it easier for the participants to be deceived and coerced into sex work. In some cases, participants even cooperated with their traffickers because they were more concerned about sending money back home to their families. For example, Fon said:

I didn't run away from the brothel because I do not have a passport and I am scared of being arrested. I entered Malaysia illegally through the jungle bordering Thai and Malaysia, guided by a middle-aged man. Although I disliked my job, I had to do it because I had no other choice. I needed to work to pay my debt and support my family. My mother is ill, and I have a five-yearold daughter who are both dependent on me.

Fon and Ngoc's cooperation should not be viewed as compliance but as a strategy to minimise harm (Brennan, 2016). It is also an example of limited agency given that both of them had limited choice and needed to work and pay off their debts. It also shows how Fon and Ngoc tried to overcome their emotions by prioritising their responsibilities as breadwinners of their families. Overall, the cases demonstrates how deception can be used throughout the whole trafficking process to control women and ensure that women remain subservient to their traffickers and employers.

\section{Total Deception, Coercion, Exploitation, Overt Threats and Harms}

In some cases, traffickers may use overt threats and physical harm to instil fear in the women. Three participants who were deceived by their neighbours $(n=2)$ and boyfriend $(n=1)$ into the sex trade also complained of experiencing extreme levels of coercion and abuse. This included debt bondage, threats, restraint, assault, isolation, and abuse inflicted by their traffickers. There was an ongoing threat and a continuum of harm from the time they arrived in Malaysia until the time they were rescued. In some cases, the threats were carried out in the form of forcing the women to make an oath pledging their future compliance, or swearing before a priest or a shrine referred to as 'Juju'; this became a major psychological instrument to control women (Ikeora, 2016). This practice is particularly prevalent in West African culture, alongside 
other religions such as Christianity (Bell, 2011). For example, Angel was continuously threatened and harmed by her trafficker boyfriend and his friends. She recounted:

I was tricked into coming to Malaysia by Emmanuel [boyfriend] who promised me that he would enrol me in a college. He told me that the travelling and visa expenses cost 2 million Naira [NZD9,968] and a woman he knew have volunteered to pay the money for me. He said that he has paid 1 million Naira to the woman and that I should continue paying the woman [1 million Naira (NZD4,984)] when I arrive in Malaysia. I agreed to such arrangements because I thought that I could study in Malaysia. Before coming to Malaysia, Emmanuel's family took me to a church in Lagos and asked me to swear before a priest that I will not run away and remain obedient to Emmanuel, which I did. When I arrived in Malaysia, I was shocked to discover that I had to do sex work and earn money for Emmanuel and his new girlfriend.

Emmanuel said that I knew what I came here to do and that I should pay him back my debt before he returned my passport. I was not sure what he meant until he forced me to start working for him. Emmanuel threatened to beat me up and kill my family if I did not obey his orders. He also confiscated my passport and return ticket to Nigeria. I had no choice but to engage in sex work and earn money to repay my debts. My charges were RM100 [NZD36] per shot and RM200 [NZD71] per night and I had to work long hours every day. I think that I have paid him RM25,000.00 [NZD9,140] after working for him for a year. However, I was not paid any salary and just lived on tips. Emmanuel treated me very badly. I was scared that he would poison my food. I had to sleep outside of the house at times because he would not let me into the house.

I tried to run away from him by seeking help from a Malay man, but the man surrendered me back to Emmanuel. As a punishment, I was taken to an unknown house by five Nigerian men where I was stripped naked, beaten, sexually abused and videoed. One of them cut my finger and smeared my 
blood on a piece of white cloth, and warned me that they had cast a curse upon me. Therefore, I should not attempt to run away again otherwise my family would be killed. After that incident, I was too scared to run away and kept working for him [Emmanuel] until I was rescued by the police.

Ikeora (2016) asserts that victims of 'Juju' rituals genuinely believe that the 'juju' magic would cause them illness, madness, infertility, and death if they break their oath. Angel feared for her life after she was forced to take such an oath and was cursed by her traffickers.

Another example is the case of Nisa and Tammi who were cousins and were both deceived, abused, threatened and harmed by their traffickers. Nisa arrived one month earlier from Indonesia than Tammi and was forced to engage in sex work. Nisa said:

Eka [neighbour] offered me a job as a waitress in a restaurant in Klang where I could earn up to RM1,500 [NZD529]. I accepted the offer because I needed the money to support my family. My parents were poor, and I only earned about RM300 [NZD107) per month selling cigarettes in Indonesia which wasn't enough to support my siblings who were still schooling. I travelled to Malaysia by ferry and was greeted by a middle-aged Chinese man and an Indonesian lady in her 40's who I refer to as 'Ibu'. They brought me to a shophouse, and I was forced to do sex work to pay my debt of RM3,500 [NZD1250]. I had no choice but to comply with their instructions because they threatened to beat me up if I disobey them.

Tammi had a similar experience as Nisa. She said:

I have four siblings, two of them are still schooling and need financial support. My father sells coffee at a coffee shop and my mother is not working. I used to work in a Honda motorcycle showroom and earned INR750,000 (NZD81) per month before coming to Malaysia. My earnings was not enough to support my family's expenses and I wanted to find another job that pays more. Eka [neighbour] offered me a job as a waitress in Malaysia and I 
accepted her offer. She [Eka] told me that I could earn up to RM2000 (NZD714) including tips. Before leaving to Malaysia, Eka gave my parents INR1,500,000.00 (NZD162) for their expenses and Ah Kong [employer] paid for my travel expenses to Malaysia. I was told that I needed to work and repay my debt of RM1000 (NZD366) to Ah Kong. Upon arrival in Malaysia, I was greeted by a middle-aged Chinese man known as Ah Kong and he took me to a shop house in Klang where I was greeted by Ibu [Ah Kong's girlfriend] who confiscated my passport. I was shocked to find out that I owed them RM5000 (NZD1828) for all my expenses and that I had to engage in sex work to repay my debts.

Tammi and Nisa's passports were confiscated by Ibu when they arrived in Malaysia and they were not allowed to leave their workplace. Both were forced by Ah Kong and Ibu (pimp/trafficker) to engage in sex work when they arrived in Malaysia. Ibu also threatened to beat them up if they did not abide with her instructions. According to Tammi:

I refused to engage in sex work and tried to run away the night I arrived at Ibu's house but the main grill was locked and they [traffickers] hid the keys. Ibu warned me to not run away and said that she will beat me up if I try to leave the house again.

Nisa also received similar threats. According to Nisa:

Ibu told us [Nisa and Tammi] that we need to entertain at least eight to nine customers per day, and were required to meet a target of at least 200 customers per month. Our working hours were from 9 am till 1 am the next day and we were not given any off days. We were also treated very roughly by their customers. I had to entertain request for anal sex and have unprotected sex with customers who refused to wear condoms. There were times where I felt a lot of pain and bled from my vagina and anus, but lbu did not allow me to rest. Instead, I was only given some soothing balm to apply to my private parts and an 'antibiotic' drink, and was forced to continue working. 
As for Tammi, she used to plead with her customers to stop hurting her. Tammi said:

Some customers were very rough. I bled from my vagina sometimes and it felt very painful and sore. I used to beg for sympathy from my customers but they would not listen to my plea because they said that they paid for my services. Some of them call me derogatory names like 'pelacur' [whore] or 'sundal' [slut]. I felt very cheap and dirty. All payments were made directly to Ibu and I was not allowed to keep any money. I worked there for a week until I was rescued by the immigration officers.

According to Nisa:

Charges for our sexual services were RM120 (NZD44) per hour and the customers made payment directly to Ibu. I was not allowed to receive any money from the customers but I received some tips which I quietly hid in my shirt. Although I am supposed to receive RM50 (NZD18) per month but I have not been paid any salary since I started working. I worked in the brothel for one month before I was rescued by the immigration officers.

Angel, Tammi and Nisa suffered multiple injuries and were constantly threatened by their traffickers. Their traffickers threatened, deceived, and abused them in order to control and exploit them. They were also abused by their customers and were called derogatory names. Angel, Tammi and Nisa's experiences represent an extreme form of treatment used by traffickers to control women in order to exploit them. Such experiences of violence and brutality do not represent the majority of women's experiences in this study, but they reflect the most commonly reported experiences of sex-trafficking in mainstream media (Greer, 2007).

Often, journalists portray trafficked women as weak, helpless and without agency (Ibid) while men are cast as the villains/traffickers who are overly violent and hypersexual (Mahdavi, 2015). This perception is flawed, because most women were reported to have exercised their agency at certain points in time (discussed further below) and many traffickers were females 
or persons related to the women. For instance, in Nisa's case, her trafficker was a woman and the fact that she hid the tips is a compelling example of how she exercised agency in such a disempowering, violent and exploitative situation. This is supported by Goodmark (2012) who argues that women who are subjected to abuse are still capable of exercising some form of agency. Thus, Russell (2014) argues that the portrayal of women as passive or weak is a useful construction for the state to remove victim's agency for those who have wilfully crossed the border. Such a construction becomes problematic because it assumes that women are incapable of making their own life choices while those who visibly show that they made their own choices are cast as immoral or criminals.

\section{Complexities of Trafficking}

In human trafficking discourse and practice, state assumptions about gender, migration and vulnerability have been overemphasised to the extent that female migrants engaged in sex work are often conceptualised as sexually trafficked (Chin, 2013; Uy, 2011). This may also be attributed to the absence of the definition of a 'victim' in the Palermo Protocol and the ATIP. Although the ATIP does specify that trafficked persons would mean 'any person who is the victim or object of an act of trafficking in persons' (s2 ATIP), the definition of a victim is unclear and is subject to individual interpretation. Given the prohibitionist approach to sex work in Malaysia, the state usually conflates voluntary sex work and coerced sex work which makes the definition of trafficking problematic.

\section{The Official Conflation of Coerced and Voluntary Sex Work}

Unlike the common conflation between voluntary sex work and coerced sex work, women's experiences were much more complicated. In this study, 13 out of 29 participants claimed to engage in commercial sexual activities voluntarily and did not indicate any situation of deception, coercion, debt bondage, threat, abuse or fraud. Instead, they were allowed to keep their own passports, had freedom of movement, could exercise their own agency and make their own decisions while they were working. However, the women were officially viewed as needing to be 'rescued' because they worked in massage parlours, brothels or nightclubs. 
For example, Mickey said:

I travelled to Malaysia from Laos with a friend to work as a masseur in a Kuala Lumpur parlour. I used to earn about RM400 (NZD143) to RM500 [NZD178] per week, and could send remittance money to her family. I was allowed to keep my passport and move about freely. I was 'living my life' and was happy working in the massage parlour until I was rescued by the police. I don't understand why they [police] need to rescue me from my workplace.

Similarly, Nun had worked in a nightclub as a social escort (bar hostess) in Sg Petani, Kedah, for over a year. Nun said:

I chose to work in the nightclub because I could earn about RM4000 (NZD1426) to RM5000 (NZD1760) per month. I could send remittances to my family and my eight-year-old son who is under my parent's care. I could keep my own passport and would frequently travel to Danok (on the Thai border) every month to get my social visit pass renewed. I don't understand why I have been categorised as a sex trafficked victim and I do not want to be rescued by the police.

Neither Mickey nor Nun indicated that they were victimised during their migration process. They did not report having suffered any coercion, force, fraud or deceit. However, they were still categorised as sex trafficked victims because of their nature of work which is presumed to include sexual intimacy with customers. Since trafficked women's consent is irrelevant under law, enforcement officers are given wide discretion to assess a particular situation according to their own understanding of sex work. Given this, voluntary sex work is likely to be equated as coerced sex work (Davidson, 2006; Peach, 2005). This shows how voluntary migrant sex workers are likely to be regarded as victims of sex trafficking, reiterating the stereotype that all female migrants who engaged in sex work are trafficked. 


\section{Presumption of Sex Trafficking}

Apart from the 14 women who were established as sexually trafficked in this study (because of the existence of coercion and exploitation), two participants were trafficked for different purposes: one was labour trafficked, and the other was student trafficked. However, both were categorised as sex trafficked victims by the police because they were arrested at a massage parlour and a brothel. In this instance, women who were found to be working in establishments that provided sexual services were generally categorised by police as sex workers even if they were not engaged in sex work. In this study, police officers misidentified non-sex trafficking as sex trafficking.

An example of how labour trafficking can be regarded as sex trafficking can be seen in the case of Da who recounted:

I travelled to Malaysia from Vietnam to take over my sister's job as a cook and a cleaner in a massage parlour in Kuala Lumpur. My travelling expenses was borne by my employers, and I entered Malaysia using a social visit pass, which only allowed me to reside in Malaysia as a tourist for one month. My employer kept my passport and he used to renew my social visit pass every month. I was not involved in sex work and was only doing domestic work in the massage parlour such as cleaning, cooking and buying groceries. I wanted to return home after working there for five months but I could not go home until I could find someone to replace me. I had no choice but to continue working in the massage parlour until I was rescued by the police. Upon rescue, the police told me that my monthly social visit pass was fake and that my passport had expired.

Although Da was rescued from a massage parlour providing sex services, she clearly indicated that she was not involved in sex work and was only doing domestic work in the massage parlour such as cleaning, cooking and buying groceries. Da's case also shows a common strategy used by traffickers to manipulate women by demanding that they find a replacement in order to be released, and assuring women that their social visit passes will be renewed monthly. 
For the case of student trafficking, Mon was tricked by an agent into coming to Malaysia to pursue her studies. Mon said:

I travelled from Dhaka to Kuala Lumpur to pursue Diploma studies in Nursing in a private college in Kuala Lumpur. My father paid about two lakhs 80,000 (Bangladesh currency), and a further sum of RM8,700 (altogether about NZD4394.43) to the agent for my college fees. When I arrived in Malaysia, I was told that I could not enrol in the course I wanted and needed to pay more fees. My passport was confiscated by the college as a guarantee for payment of my college fees. I could not renew my student visa which was about to expire. My friend offered to help me get a job as a waitress where I could earn RM1,500 [NZD535] a month. I accepted the offer and went to my friend's workplace but was shocked to find out that I had to work in a brothel. I refused to work in the brothel and was asked by my friend to wait in a room. After a few minutes, the police raided the brothel and I was arrested. I told the police that I was a student and that I was only waiting for my friend to clarify the job offer but they still arrested me.

In this case, it appears that Mon was deceived by her friend who offered her a job but had not started working in the brothel. Therefore, she did not indicate any form of exploitation or debt bondage. She identified herself as a student and did not identify herself as a victim. Although she was classified as a suspected trafficked victim when she first entered the shelter, and during the time of interview, she did not obtain a temporary Protection Order because she was not considered as trafficked. Instead, she was sent to the immigration detention camp for deportation. However, the fact that her passport was confiscated by the college and that she was required to pay more fees indicates the presence of coercion and debt bondage. Mon's case shows how agents deceive potential students by offering them courses abroad, but later telling them that they need to pay more fees to enrol in their intended course. This is notwithstanding the fees that have already been paid to the agent before their travel. Students who are trapped in this type of situation are sometimes lured or deceived to work in the sex industry to enable them to pay their fees and visa. 


\section{Perspectives of Migration and Sex Work}

The abolitionist rhetoric on prostitution presumes that women are incapable of consenting to sex work and are totally deprived of their agency (Bindman, Doezema, \& Anti - Slavery International, 1997; Meyers, 2013). However, the findings of this study show that women were able to make some decisions at certain points in time. For example, nine women (those who were partially deceived in sex work) were able to send remittances to their family while they were working and they viewed this as a form of power even though they were under a debt-bondage and/or had their passport confiscated. One example can be seen in the case of Mei-Mei who said:

I was under a debt bondage and had to repay RM4,473 (NZD1,635) to my Boss. He confiscated my passport and I could not leave the workplace.

Mei-Mei was also abused and harmed by her customers. She said:

Some customers were quite rough. They would treat me like an animal. They would beat me, thump me about and pull my hair. Some want to have sex again after they have ejaculated. Some customers do not want to use condoms. I have the right to refuse these types of requests because I need to take care of my health. I will report to the Captain if I don't feel comfortable with the customer. When this happens, other women will not service him too.

Although Mei -Mei had to endure beatings from the customers, she felt empowered because she was able to refuse certain types of customers and prevent other women from experiencing harm.

Another example can be seen in the case of Efa who felt empowered because she could remit money to her family: 
I wanted to go back to Indonesia, but my Boss kept delaying my return and kept my passport. I usually ask for my salary once a week from my Boss. I befriended a hawker near my workplace, and she taught me how to use the ATM machine. I used to remit money to my children every week through telegraphic transfer with the help of my friend.

The cases of Efa and Mei-Mei show that although they had limited choices, they were not totally helpless and passive as they were able to make certain decisions. It also shows that women were resourceful and able to find ways to exercise their agency and adapt to their current situation.

Most of the women in this study felt empowered when they were able to work and earn money to support their family. Of the 29 participants, 11 were in a relationship while 11 others were either separated, divorced or widowed. The remaining seven did not identify themselves as being in a relationship. Fifteen women had children to support, 13 were working to support their families while another wanted to study for a brighter future. In all instances, the women felt that they had a purpose in life and migrated to improve their economic condition. In the case of Kim, she voluntarily worked in a massage parlour and engaged in sex work to support her two children, who were under her parent's care in Vietnam. She did not indicate any form of coercion or exploitation and felt that she made her own decisions to migrate and engage in sex work. Kim said:

I don't feel shy engaging in sex work because I worked to support my family and I don't care about anything else. I just wanted to earn money. I am telling you everything from my heart. I was happy working because I had money. Won't you be happy if you had money? I am sure you will.

Kim was determined to earn money for her family and the fact that she was doing sex work did not affect her. However, some women felt guilty, ashamed and remorseful about the nature of work they were engaged in. Others had mixed feelings and ambivalence about being a sex worker. Those who felt ashamed for engaging in sex work did not disclose their type of work to their family for fear of being stigmatised. 


\section{Stigma and Shame}

The women had differing views about sex work. Although some felt empowered because they were able to work and send remittance money to their families, ${ }^{55}$ others felt guilt and shame that they had engaged in sex work. Six women (namely Mei-Mei, Le-Heo, Emi, Rima, Hong Phan and Putri) stated that they felt guilty, ashamed and remorseful for engaging in sex work. Mei-Mei for example, who originated from Indonesia said:

I came from a poor family and have another two siblings who are still schooling. I chose to become a prostitute because I wanted to help my family financially. I worked as a prostitute for four months, and I used to send a lot of money to my mother every week. I gave my mother INR 2 million [NZD200] before I left Indonesia and further remitted a sum of RM1,000 [NZD354] two weeks after I started working. My mother felt very happy and proud because I could earn a lot of money but I feel very sad because the money is derived from a bad source. I did not tell my mother the nature of my job because I did not want her to feel sad and ashamed of what I was doing.

Mei-Mei felt guilty and deeply ashamed of herself because she engaged in sex work, even though simultaneously she was proud that she could remit money to her mother. Similarly, Putri, from Indonesia who claimed to be a freelance sex worker said 'I am very ashamed of my job. I pray to God that my friends, family and boyfriend won't find out what I am actually doing.....never, if not I will die....'

Putri and Mei-Mei were both Muslims and the feelings that they had were based on Islamic religious principles that prohibit illicit sexual intercourse (Sedyaningsih-Mamahit, 1999). Therefore, being a sex worker is considered shameful and 'sinful' (Ibid), because it goes against the religious principles of chastity and purity in Islam.

\footnotetext{
${ }^{55}$ See Mickey, Nun and Kim's cases (above).
} 
In another case, Le Heo recounted her life in Vietnam and her experiences of working in Malaysia:

I came from a poor family in Vietnam. My mother is not working and my step-father works in a seafood factory. I have three other siblings who are still schooling. I worked in a massage parlour in Malaysia for about a year to support my family before I returned to Vietnam. I lived in Vietnam for two years and wanted to work in Malaysia again. So, I contacted my friend who was working in Malaysia and she offered me to work in a brothel which I accepted because I needed the money to support my three siblings who were still schooling. I worked in the brothel for about two years before I was arrested by the police.

During the interview, Le Heo expressed feelings of shame and remorse:

I understand that a lot of people will hate me because I am a prostitute, but I have no other choice. I needed money to support my family. I used to remit monies to my family every week, but I have not been able to do so since I was arrested three months ago. I am stressed and worried about my mother's health as she needs to undergo a surgery. Actually, I intend to work here legally. I want to have a proper work visa where I can go to work every day and return home, and send money back home. Not the type of bad work that I am doing now. I want to earn money in a legal way.

In Vietnam, sex work has been linked with 'social evils' and considered as a dangerous and immoral force that needs to be controlled (Rydstrøm, 2006). 'Social evils' is a category widely associated with the types of sexual practices condemned as being 'dirty' (ban) (e.g., premarital and extramarital sex, pornography, and prostitution) because it is believed to be linked to HIV and AIDS (Ibid). So women who engage in sex work are stigmatised and will most likely be socially isolated because people will avoid having contact with a person with bad 'morality' (Ibid). Despite such consequences, the cases of Mei-Mei and Le Heo show how women prioritise their responsibility as the family breadwinner and even blame themselves for failing to provide for their family while they were detained in the shelter. 


\section{Self-Blame}

Of the 29 participants, 28 migrated to Malaysia to work with the intention of seeking a better life and economic opportunities to support themselves and their families back home. ${ }^{56}$ Women were often focused on paying for their children or sibling's education fees, household expenses, and medical expenses among other costs. Apart from the socio-economic imperative of assisting family members, some women also wanted to start a new life after going through a divorce or relationship breakup. In most cases, the women were the sole breadwinners of the family and needed to support their children. In this study, five women (Benz, Hanny, Le Heo, Emi and Efa) blamed themselves for failing to send money to their families after their 'rescue'.

For example, Benz felt very emotional and kept crying while narrating her experience. She said:

I am a divorcee and the sole breadwinner of my family. I have five children, and they are still schooling. Therefore, I needed a good paying job to support my family. My friend informed me of a massage job in Malaysia, and I decided to work here because I needed money to support my family. I used to earn about RM3,000 [NZD1,100] while I was working in the massage parlour and I used to remit monies to my children every month. However, I have not been able to send them any monies for the past three months because I have been detained in this shelter. I do not know what has happened to them. I am very worried about them. I blame myself for everything that has happened. I don't want to fail them as a mother.

Benz felt helpless, sad, and guilty after she was 'rescued' and detained by the authorities. She also blamed herself for failing to fulfil her responsibilities as a mother and the family breadwinner. This shows the tensions and conflicts some women experience as they try to fulfil their motherly obligations.

\footnotetext{
${ }^{56}$ Mon from Bangladesh migrated to Malaysia to study but was tricked by the agent.
} 


\section{Conclusion}

Legal definitions in anti-trafficking laws are blurry and do not specifically define the meaning of victims. As a result, state authorities are given vast powers to make decisions on who amounts to a victim of trafficking. However, the dominant representations of trafficked 'victims' (that they are passive objects of sexual exploitation without agency) have practical and troubling consequences when applied to real trafficking cases (O'Brien, 2013; Sikka, 2010). Even if the stereotypical 'ideal victim' (as envisioned and challenged by Christie (1986)), may bolster public support for assistance and the provision of resources, it has also reinforced the representation of human trafficking as a criminal justice issue by constructing victims as passive recipients of the criminal behaviours of offenders (Wilson \& O'Brien, 2016). In reality, women may exercise some amount of free will in trafficking scenarios. Although some participants were lured into sex work by unscrupulous agents and deceived by friends, the majority of participants voluntarily migrated to Malaysia to work in the sex industry. The findings in this chapter illustrate that women were able to make certain choices throughout their migration experience. However, the findings show that some women were more in control of their job aspects while others had to function under more limiting constraints (Weitzer, 2010).

As well as this, the research shows that all the women participants are 'dutiful daughters' and/or 'self-sacrificing mothers' who came from a background of poverty and had limited options for work in their home country. Therefore, their intention to improve their livelihood should not be dismissed simply because they were categorised by the state as trafficked, or chose to work in the sex industry. However, the fact that consent becomes irrelevant in cases of trafficking (according to the law) represents the idea that victims are incapable of exercising their agency. On this account, migrant women who work in the sex industry are easily presumed to be victims of sexual exploitation who need to be rescued and sheltered (Srikantiah, 2007). As a result, voluntary 'sex workers' are transformed into 'trafficked victims' through state laws and policies. Although the state's focus on 'rescuing' women from being exploited appears to be benevolent, the discussion in this chapter has shown that it did not provide much support to women because they were unable to provide for their families after 
their 'rescue'. From this, we might envisage that women who feel victimised by their traffickers may be reluctant to cooperate with enforcement officers for fear that they will need to live in shelters and will not be able to work and support their families. This defeats the purpose of providing protection and relief to trafficking victims because the forms of protection that are offered seem to be incompatible with women's desire to work and their freedom to make their own decisions. This is because the purpose of state protection is aimed at securing the prosecution's case and does not take into account women's hardship and rights. As a result, the care and protection of trafficked women have been criticised by NGOs for being repressive and not complying with the Recommended Principles and Guidelines of Human Rights and Human Trafficking, which will be discussed in the next chapter. 


\section{Chapter Seven: Experiencing 'State Rescue'}

\section{Introduction}

Previous findings have shown the different techniques used by traffickers to coerce and harm women. In turn, women actively used strategies that could minimise harms. This chapter focuses on how women struggle to exercise their agency while in state custody. It explores how victim-protection policies are enforced in Malaysia, and women's experiences of state 'protection'. The discussion draws upon my interviews with trafficked women held in Shelter 5, Kuala Lumpur, as well as professionals from different state agencies and NGOs involved in the anti-trafficking structures (see Appendices 2 and 4). The chapter demonstrates that women are victimised during the post-trafficking process and that state practices have instead prolonged their victimisation and, in some cases, initiated their victimisation.

The chapter focuses on three main points. The first discusses the state's perception of trafficked women that has influenced policing (rescue, judicial process and protection). Terms such as 'rescue' instead of 'arrest', 'interview' instead of 'interrogation', 'protection' instead of 'detention', 'kept' or 'held' instead of 'detained' are often used by the police and immigration (enforcement officers), and shelter officers to deflect the realities of incarceration for trafficked women. Such practices fits with the theory of 'interpretive denial' developed by Cohen (2001) who argues that certain terms are given different meaning from what may seem apparent to others. In most cases, people 'accept the facts, but reject the meaning by interpreting them in a way that makes it 'safer' for their personal psychology' (Moon, 2013, p. 194). For instance, the punitive practices of the enforcement officers, or court and shelter workers, which act to police trafficked women, have been legitimised and rebranded as 'victim protection'. Through this re-branding, authorities are then at liberty to use their own discretion and execute policies which act to regulate women, rather than protect them.

State policing is, however, argued to protect women from their traffickers and thought to be in the best interest of the women (Lobasz, 2009). Such measures have exposed women to 
physical, emotional and psychological harms. For example, women have been reported to suffer severe stress, anxiety, depression, post-traumatic disorder, self-harm and suicidal tendencies while detained in shelters (Zweynert, 2015). Therefore, the second point of this chapter exposes and explores the various harms experienced by the women during the posttrafficking period and questions the victim protection mechanisms provided by the state. It discusses how enforcement officers, shelter officers, and judiciary override women's agency and disempowers them once they are in protective custody. It critiques the way women are being decided for, the lack of options given to women while they are in custody, and the lack of opportunity to consider their legal options and therefore their ability to make an informed choice. To analyse these two points, the chapter will examine how professionals enforce the anti-trafficking laws and victim protection policies.

\section{Rescue, Judicial Process, Shelter, and Repatriation}

Raid and rescue operations are usually conducted by the police and may include other enforcement agencies such as officers from Immigration, the Labour Department, or Maritime and Customs (according to section 27 of the ATIP). Figure 5 illustrates the standard processing of trafficked women in Malaysia during the post-trafficking phase.

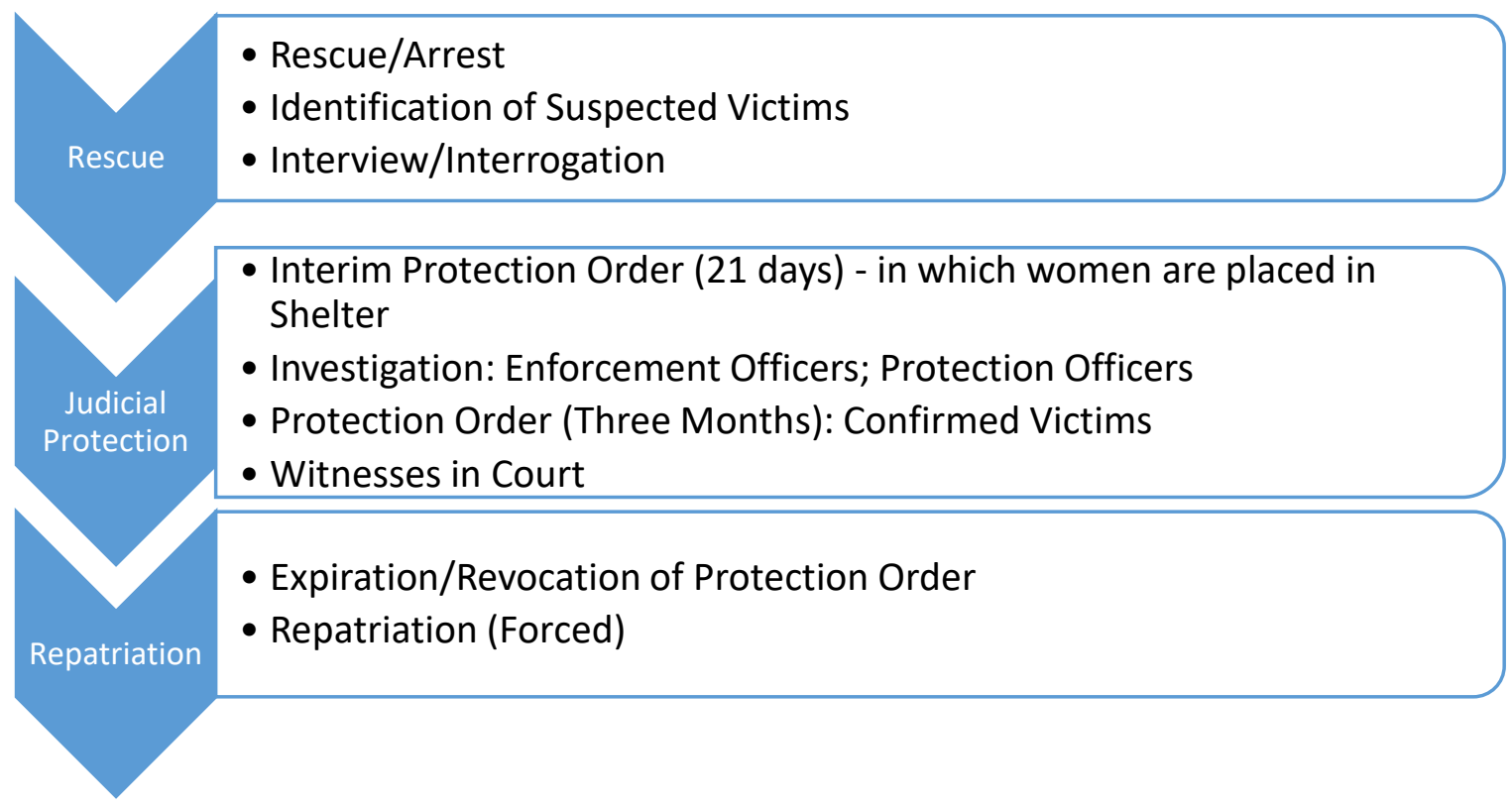

Figure 5: Flow chart of how sexually 'trafficked' women are policed and processed 
The policing of migrant women who are suspected of being sexually trafficked begins with the 'raid and rescue' of migrant women in establishments such as massage parlours, health spas, entertainment centres, nightclubs, or private residences which operate as brothels or makeshift brothels. In this regard, NSWP (2011) argue that these raids undermine sex workers' security and their agency. Furthermore, continuing raids on sex work venues, suggests a mistrust of sex workers (The Global Network of Sex Work Projects, 2011). According to Police Officer Jimrey:

Although most of the women who migrate and work in the sex industry came here on their own freewill, we will still rescue them because they are unaware that they are being exploited. Therefore, all migrant women working in establishments that provide sexual services are considered suspected trafficking victims. Therefore, we will need to rescue them and investigate further.

Similarly, Immigration Officer Shahrul Azlin said:

Most migrant women migrate and work in the sex industry voluntarily but they don't realise that they are being exploited. So, we will need to rescue them from their traffickers.

Based on this presumption, migrant women who are found working in establishments that offer sexual services will be 'rescued' from their workplace and transported to the police headquarters for questioning because they are considered potential witnesses (Das, 2017). Mainstream anti-trafficking discourse overlooks these varied dimensions of the politics and the practice of 'rescue' and 'protection' (Ibid). These terms are premised on the assumption that 'rescue' is the ultimate means to restore the rights of women (Ibid). However, the act of 'rescue' negates many women's free will and simplifies experiences of consent and coercion (Ibid), and is carried out through the arrest of women. In this context, Das (2017) argues that the act of 'rescue' often amounts to a kind of secondary trafficking of girls and women by state officials. This is because the state displaces women against their will and detain them in shelters which are under constant surveillance (Das, 2017). Therefore, Das (2017) argues that 
the term 'rescue' is problematic. From a feminist standpoint, 'rescue' would mean attending to existing power relations in support of an individual's safe, wilful social transition (Das, 2017). From an anti-trafficking standpoint however, 'rescue' would mean saving a person from bondage and rehabilitating them back into society (Das, 2017), which is currently practised in Malaysia. In this context, the thesis argues that the act of 'rescue' is underpinned by the presumption that all sex workers need to be 'rescued' and 'rehabilitated'. Such practices reflect the abolitionist strategies towards sex work in Malaysia, which results in the criminalisation of sex work. In other words, the act of 'rescue' is carried out through the arrest of women. Shelter Officer Aznida was sceptical about the term 'arrest' that is being used in police reports:

I sometimes argue with the police about the use of the term 'arrest' used in the police reports. Even the reports are referred to as 'Arrest Report'. I always tell them that they are not supposed to use that term. However, they told me that that is a standard practice and that the 'Arrest Report' is used as evidence in court.

Immigration Officer Shahrul clarified the intention of the state in rescuing women:

Our raids are focused on arresting the perpetrators and to obtain as many witnesses as we can. We are more focused on upholding the law.

Similarly, according to Shelter Officer Aznida:

The women are witnesses in court, their role is very important. We do not want them to refuse from testifying in court or commit suicide in the shelter. It will be difficult for us to prove the case.

Thus, the 'rescue' of women is carried out with the concentrated aim of providing witnesses for the prosecution, rather than having a centred concern for the welfare and well-being of the women. Those who are suspected of being 'trafficked victims' will be taken to Court where an Interim Protection Order (IPO) will be issued. The IPO gives the authorities the powers to detain the women in shelters for 21 days to complete investigations. According to Police Officer Jimrey: 
After obtaining the IPO for the victim, we will commence our investigation and interrogate the victims and the suspects. However, language barrier is a huge problem faced by the police especially when it involves nationals from Thailand, Vietnam and Myanmar. In the event that the victim cannot communicate in either Malay or English we will need to engage an interpreter. However, this is costly and we only do it if we really need to get the women's statement for very important cases. Otherwise, we will try to find someone among them who can communicate in our language and be our interpreter. We will also seize all possible evidence relating to the trafficking crime. If our investigation reveals that the women are not 'genuine victims', 57 they will be sent to an immigration depot where they will be deported to their home country. However, if our investigation reveals that the person is a 'genuine victim' of trafficking, we will request for further Protection Order (PO) from the Court which gives us the authority to detain the victim in the shelter for a further period of three months.

The language barrier suggests that the women are not provided with adequate assistance during interviews. This is because qualified interpreters will only be sought for important and exceptional cases. Language barriers also occur during interviews and communication in shelters. In this situation, Protection Officers and Shelter Wardens tend to use different ways and means to communicate with the women. Google Translate, sign language, and drawings, were amongst the modes of communication used for this purpose. For example, Shelter Warden Mawar said 'I communicate with the women through sign language because some of them do not understand Malay or English. Those who understand the language will assist the ones who don't by explaining certain things to them.'

The services of a qualified interpreter would only be sought in selected cases as the shelter does not employ or engage any in-house interpreters. The selected cases would usually involve situations where the women could not express herself through words, sign language

\footnotetext{
${ }^{57}$ Police Officer Jimrey did not indicate how many non-genuine victims were in the shelter because of ongoing investigations.
} 
or drawings. ${ }^{58}$ In this instance, individual $\mathrm{s}^{59}$ who are able to interpret and communicate in the women's language will be used to assist the Protection Officers in preparing their reports. ${ }^{60}$ However, these individuals may not be competent or fluent in the language. ${ }^{61}$ According to Shelter Officer Aznida:

Communication is a big problem here. We use sign language and Google Translate at times. However, Google Translate doesn't help much. The funny thing about Google Translate is the direct translation which translates into words that we don't actually mean. Therefore, the victim will tend to misunderstand our questions and will not answer us properly. So, I let them write their statement according to their language or in whatever language they understand and translate it using Google Translate later.

Despite the lack of clarity, the initial identification of victims will be done during 'rescue' and before obtaining the IPO. Police Officer Jimrey frequently used the term 'genuine victims' to refer to women who have been deceived, coerced or forced into sex work and exploited by the traffickers. The same term was also used by Immigration Officer Shahrul and Shelter Officer Aznida (see below). According to Police Officer Jimrey:

A 'genuine victim' would include those who were deprived of their passports, held under debt bondage or were not paid their salaries. Jimrey's understanding of a 'genuine victim' seems to fit with the earlier analysis in Chapter Six where 16 of $29^{62}$ women complained of being deprived of their passports, held under debt bondage and and/or were not paid their salaries.

\footnotetext{
58 In interview with Protection Officer, Irma.

${ }^{59}$ Individuals would refer to the women in the shelter, state officials, those who are suspected of being traffickers, and court officer who were not qualified interpreters.

${ }^{60}$ In an interview with Shelter Manager Ajanis.

${ }^{61} \mathrm{lbid}$.

${ }^{62}$ See also Appendix 9.
} 
The term 'interrogated' was used by Jimrey when referring to the process of questioning the women. The same term is also used when referring to the process of questioning the traffickers. The word 'interrogated' suggests that the questioning is tantamount to an intense oral examination to determine the guilt or innocence of the women. Such methods are based on the provisions of the Criminal Procedure Code (CPC) which acts as guidelines for enforcement officers when conducting the raid and rescue, and investigation process. According to Police Officer Hanif:

Our Standard Operating Procedures in human trafficking investigations are conducted according to the CPC. The victims and the offenders will have to give their statement under section 112 of the $\mathrm{CPC}^{63}$ or section $34(5)^{64}$ for cases under ATIP.

Section 34 (1) of the ATIP gives enforcement officers the power to examine any person and obtain any documents or statements related to the case being investigated. Any person who contravenes instructions given by the police is said to have committed an offence under section 34 (2) of the ATIP. The word 'person' in section 34 (5) of the ATIP refers to either a 'victim' or an 'offender' which suggests that victims are policed similarly to offenders. This corresponds with the proposition by Stephen-Smith (2008, p. 13) who views that 'women entering the country by deceptive means' are penalised regardless of the fact that they were trafficked, 'thereby neglecting the paramount status of victims' human rights'. Smith's contention is reflected in this research where women who have been arrested in a human trafficking raid may carry a dual identity in the eyes of the authorities (of suspected offender and suspected victim), until further investigations are completed. ${ }^{65}$

According to Immigration Officer Shahrul Azlin:

Women who have been rescued are not confirmed victims but only

\footnotetext{
${ }^{63}$ Section 112 of the CPC means that that the person being questioned shall be bound to answer all questions and legally bound to state the truth, but may refuse to answer any question which would have a tendency to expose the person to a criminal charge or penalty or forfeiture.

${ }^{64}$ Similar wordings to Section 112 of the CPC.

${ }^{65}$ Interview with Immigration Officer Shahrul Azlin.
} 
'suspected victims'. Their status will only be confirmed as 'victims of trafficking' if they are found to be 'genuine victims'. Otherwise, they may be categorised as offenders and charged in court if we find that they have breached the immigration laws.

However, no information was provided on the number of women who have been charged in court or on the change of status from suspected trafficking victims to offenders. What is available, however, is the number of persons arrested by the police for trafficking offences between 28 February 2008 and 31 March 2016 (n=1656). Of the 1656 individuals, 1309 arrested were Malaysian citizens while the remaining 347 were migrant men $(n=191)$ and women ( $n=156)$. This corresponds with the previous argument which states that most traffickers in the destination countries are either citizens of those countries, or have the same citizenship as the victim(s) they traffic (Brock et al., 2000; Molland, 2012; Samarasinghe, 2008).

According to the statistics given by the police and immigration, the number of persons rescued and granted an IPO from 28 February 2008 to 31 March 2016 was 7687. However, only 2407 migrants were given a PO. The data suggest that 5280 individuals (7687 [IPO] 2407 [PO]) might have either been charged in court for trafficking offences or deported. This shows the inclination of authorities to categorise migrants as trafficked victims during raids. According to Immigration Officer Shahrul Azlin:

Although we have 40 officers in the anti-trafficking unit in the headquarters, most of human trafficking matters are referred to me. I am not saying that I am an expert but I am one of the officers that has been trained abroad. We learn from case to case as we are in the learning process. This is something new for us as we do not have much experience on this. We have the Standard Operating Procedure [SOP] that teaches us how to do our work but we do need extra guidance on how to handle the victims, this is not included in the SOP. We are still in the learning process.

Sharul Azlin's statement indicates that the officers in the trafficking unit may not be 
adequately trained to identify and respond to trafficked victims. As a result, most who were initially categorised as trafficked victims and granted IPO were not identified as trafficked victims after further investigation, and thus, were not given the PO by the court. In this instance, those who are not given the PO will be categorised as illegal migrants and will not be entitled to immunity from prosecution. Shahrul Azlin explained the immunity from prosecution given to trafficking victims under section 25 of the ATIP. According to him 'the immunity of prosecution is only applicable to offences committed under the immigration laws such as overstaying, illegal entry, or not having a valid permit or passport. It does not include offences committed under other laws.'

Shahrul Azlin's statement confirms that trafficked women may still be charged in court if they are found to have committed other offences (apart from the ones mentioned above). Therefore, the immunity from prosecution would only apply to immigration breaches and may not apply to other crimes that have been committed under other laws.

Upon the expiry or revocation of the POs, women will be forcedly repatriated to their home countries. According to Toft (2007), there are two different ways to think about repatriation: (1) whether the repatriation is voluntary or involuntary (forced); and (2) whether it is organised or spontaneous. In Malaysia, the process of repatriation of trafficked women is being operationally undertaken as summary deportation of illegal migrants. This suggests that women are being forcibly repatriated. Therefore, the term 'forced repatriation' is used in this study because women are not given the option to remain in Malaysia upon the expiry or the revocation of their POs. However, most of the women in this study were eager to return to their home country, largely as they did not want to remain in the shelter. When asked about the difference between repatriation and deportation, Immigration Officer Sharul Azlin said:

Repatriation means the return of individuals to their country of origin. They will not be given any notice to leave the country and will not be blacklisted from returning to Malaysia. Deportation on the other hand applies to offenders or individuals who have violated the Malaysian immigration laws. A notice will be issued by the Director General of Immigration to the individual commanding him/her to leave the country and the person will be escorted by 
the police/immigration officers to the exit point. The person will also be blacklisted for two to five years. This would depend on the severity of the case.

In this instance, if women have been identified as being 'genuinely trafficked', the state acknowledges that the women are victims and does not blacklist them. However, women's repatriation is subject to the decisions made by immigration officials ${ }^{66}$ and so they are not at liberty to choose their own date of travel. For state officials, women's consent is irrelevant when it involves repatriation, which shows how the state controls the repatriation process. ${ }^{67}$

Similarly, in cases of trafficking, state officials seem to be aware that women can voluntarily agree to migrate and engage in sex work. ${ }^{68}$ However, they tend to insist that the women were unware that they were being exploited. ${ }^{69}$ These views correspond with abolitionists' views who equate sex work with sex trafficking and believe in a criminal justice solution (Kara, 2009). Thus, the process of rescuing and protecting trafficked victims is conducted alongside arresting and detaining the traffickers. As a result, the rescue and protection process resembles criminal law enforcement. Given that anti-trafficking laws conflate with the criminal laws, the victim-protection framework becomes punitive as it penalises trafficked victims. As a result, most women in this study felt traumatised and distressed with the rescue process and their experiences with the police.

\section{Women's Experiences of State Rescue}

Migrant women described the 'raid and rescue' process as traumatising and distressing. Most participants referred to the 'rescue' as 'arrest' because of the excessive force that was used and the harshness of the 'rescue' process. Many felt very scared during the rescue process:

\footnotetext{
${ }^{66}$ Section 51 (3) (ii) of the ATIP.

${ }^{67}$ In an interview with Police Officer Jimrey and Immigration Officer Shahrul Azlin.

${ }^{68}$ See earlier interview with Police Officer Jimrey and Immigration Officer Sharul Azlin.

69 Ibid.
} 
There was a knock on the door at first and suddenly the police just barged into the room. There were about five to six policemen and women in normal clothes. I was taken aback. I felt scared and nervous and I cried (Gena).

I felt scared during the arrest because there were many police officers around. They were shouting and making a lot of noise. I could not think of anything, I just kept quiet (Tang Mo).

I was scared. I felt that my workplace was safer than the police station (Hoar An).

Some of the participants also felt confused about the rescue process and didn't know why they were arrested:

I was surprised why I was arrested but felt nervous at the same time. When I asked the police, they said it's because I do not have any work permit. I didn't know I needed to have a work permit (Hong Phan).

I feel like a victim of the police as they arrested me, I wasn't even working at that time. I told them that I had a valid passport but they still arrested me. They arrested three of my Vietnamese friends because they found condoms in their possession (Emi).

Women were also humiliated during the 'rescue' process. There were instances where they were not properly dressed when the police barged into their rooms, and when they were forced to have their photos taken with the customers, unclothed at times:

The police took my photograph with the customer. Three of my friends were also photographed with their customers but they were not allowed to wear clothes. I don't know why. They [friend] were wearing clothes when the room door was opened. My friend told me that the police asked her to take off her 
clothes and just use her undergarments. ${ }^{70}$ When they [police] took my photo, the customer kept laughing. I asked him why he was laughing and why was I being photographed as I was angry. The customer then started shouting at me and asked me to show him where the massage oil was (Efa).

Besides being photographed by the police, local news channel and newspapers (see Chapter Four) also provide extensive coverage on 'raids and rescues' and expose women's faces, bodies and behaviours during the raids. When asked about the Ministry's perception of women being publicised in media, Protection Officer Irma said:

To me, it's alright even if the women are exposed in the media. Well, they only expose the Chinese culture which is sexy and open. Their [Chinese] culture does not require them to close their aurah ${ }^{71}$ or dress decently. We as women are exposed to crime when we are not dressed decently. Such exposure shows the government's initiatives to eradicate immoral acts such as sex trade or human trafficking activities or entertainment outlets. We with authority would like to prevent things from happening. To me the exposure can give awareness to the public and get the public to cooperate with the authorities.

Irma's response shows how state officials conflate sex work with sex trafficking. It also shows the paternalistic attitude she has towards migrant women engaged in sex work. There was also a strong prejudice directed towards the women and the Chinese culture that she insinuated as not being modest. She also blamed women who are 'indecently' dressed for being exposed to crime and harm. This shows a strong victim-blaming and patriarchal attitude that exists among state officials who are entrusted to protect women.

Besides being photographed, women were not treated with respect in various other ways. They were typically shouted and yelled at by the police during the raid:

\footnotetext{
${ }^{70}$ This was probably done by the police for the purpose of gathering evidence. The pictures are likely to be used as evidence in court to show that women were engaged in sex work.

${ }^{71}$ See Chapter Four.
} 
I noticed a policeman putting a condom on the bed which does not belong to me. I was trying to put it away and I got scolded by them [police]. The police then asked me to sit on the bed with the customer for almost an hour. The customer did not say anything and just cooperated with the police. The police then wrote some number on my arms and took us to the police station. They took my picture with the customer but did not handcuff me (Fon).

The above excerpt clearly shows how women were humiliated during the raid and rescue operations. Even though 'traffickers' are the ostensible target of the state, trafficked women were treated as if they were offenders (Day, 2009). Due to these types of experiences, the fear and trauma of being 'rescued' negatively affected the women psychologically. For example, Le Heo was deeply affected by the raid to the extent that she had difficulty in remembering things after the incident. She recalled:

It was the first time I encountered the police, I was so scared and I didn't know where to run or what to do. The police arrested eight persons working with me. Some of them had customers. I could not run away as I was surrounded by the police. My mind was empty and I just went blank. That happened a month ago and I still can't remember the road to the spa and the way inside the spa. I cannot even remember my mother's phone number because of the incident.

The harshness of the 'rescue' process was acknowledged by Police Officer Jimrey when asked about how women reacted to the raid and rescue process. He said 'some of them are in shock, sometimes they feel scared, some of them feel nothing. They have to listen to the police and the agencies who conduct the raid.'

Twenty-one participants complained of either being handcuffed, held in holding cells or having to change into police-provided orange coloured clothes during the rescue process. However, these practices were denied by Police Officer Jimrey and Immigration Officer Shahrul during 
the interviews. Women also complained that they were unable to take their money or belongings during the 'rescue'. For example, Yolo said:

I was crying during the raid. I could not even take my monies and belongings. They searched my bag and looked for my passport, but they couldn't find it. They asked for my name and date of birth. After that, I was asked to change into orange coloured clothes and they handcuffed me. I had to stay in the police station overnight before I was taken to court the next morning.

Six women (namely Kim, Ling, Thuy, Tuyen, Gena and Tang Mo) stated that they were put in a police holding cell before being taken to court. Tuyen described her experience:

I was handcuffed by the police during the arrest. The police kept yelling at me and took my passport from my suitcase. After that, I was brought to the police station where I was detained in a holding cell until the next morning. The holding cell was like a metal cage. The toilet was in the shape of a cubicle and had a small partition. The floor was concrete and we had to sleep on the floor without any pillows or blankets.

The above practices demonstrate that women are treated as criminals instead of victims. Such practices contravene the Recommended Principles and Guidelines on Human Rights and Human Trafficking which aims to promote and protect the human rights of trafficked persons (see Chapter Four). However, the authorities seem to ignore this fact, because they seem to solely focus on disrupting the human trafficking activities. Moreover, it is clear from the above descriptions, that this disruption is carried out with a significant disregard for the welfare of the women. This suggests that the protection of women remained secondary to prosecuting the offenders. 


\section{Detention}

Scholars argue that migrant women who have been 'rescued' from sexual exploitation are treated as criminals in most parts of Asia (Gallagher \& Pearson, 2010; South Asia Regional Initiative, 2006). Research has shown that there are clear parallels between the experience of trafficking victims in semi-carceral institutions and those in immigration detention and prisons (Bosworth, 2007; Gallagher \& Pearson, 2010; Lee, 2014). However, the practice of detaining victims of human trafficking in 'shelters' (which resembles a semi-carceral institution) is 'underreported' because the rescue and detention is carried out in the name of 'protection' (M. Lee, 2014). In this regards, 'protection' is seen as the key to a victim-centred approach in trafficking that incorporates the '3Rs' - 'rescue, rehabilitation and reintegration' (Ibid).

Similarly, in Malaysia, women who have been rescued are compelled to stay in the shelter and are subject to a plethora of rules and regulations. Twenty-three women participants were issued with Protection Orders ${ }^{72}$ while another six were issued with an IPO by the court. These shelters are administered by the Ministry and all the officers working in the shelter are gazetted as Protection Officers which gives them the authority to protect and guard the women. The ATIP does not specifically state the number of times an extension to a PO can be requested by the state, nor does it have a maximum period of time a person can be detained in the shelter. However, Police Officer Jimrey confirmed that the maximum period of time a trafficked person had been detained was for a year.

As previously discussed in Chapter Four, the ATIP allows trafficked women to work outside of the shelter. ${ }^{73}$ However, the approval is subject to the recommendation of the shelter and the police. ${ }^{74}$ Women who intend to work need to be assessed to ensure that they are free from diseases such as HIV and tuberculosis and would not be threatened or harmed by their

\footnotetext{
72 Section 44 of the ATIP.

${ }^{73}$ Section 51A of the ATIP allows women who have been given the IPO or PO to move freely or to be employed subject to the permission given by Council of Anti-Trafficking in Persons and Migrant Smuggling (MAPO).

${ }^{74}$ In interview with Shelter Officer Aznida.
} 
traffickers. ${ }^{75}$ Even if the women are considered safe from these diseases, they are still regarded as high-risk individuals. ${ }^{76}$ According to Shelter Officer Aznida:

Although victims are given the permission to work outside of the shelter, we will need to give our recommendations if we [Protection Officer and Investigating Officer] consider it safe for them to do so. The police are very sceptical on allowing victims to work out of the shelter. They view it as a security threat because the women are witnesses for human trafficking cases.

However, Aznida could not indicate the number of women awaiting trial in the shelter as that information is kept in individual files and, in some cases, trial dates would only be known closer to the time. Furthermore, each of the four shelter officers are designated with a certain number of files and there is no database available to check the status of the women's cases in court.

Given the risk involved in allowing women to work and reside outside the shelter, Shelter Manager Ajanis said:

We [MAPO] have given permission to four women to work outside of the shelter a few months ago but two of them have absconded while the other two decided to quit working. The assessment takes a long time and most women decline the offer to work because the salary is low and the application to work may prolong their detention in the shelter. Only those who are allowed to work can reside outside of the shelter and they will be subject to certain rules and regulations.

Although the liberty to work outside the shelter may seem consistent with women's human rights, the bureaucracy and procedures involved seem to discourage women from doing so. In this study, none of the participants were aware that they were entitled to work and reside

\footnotetext{
75 In interview with Shelter Manager Ajanis.

${ }^{76}$ In interview with Shelter Officer Aznida.
} 
outside of the shelter, as they have never been informed of that right by shelter workers. Women were kept under tight surveillance where all doors, grilles, and gates to the shelter were locked and barbed wire was placed along the perimeters of the shelter grounds resembling a prison-like structure. They were not allowed to accept visitors or communicate with anyone outside of the shelter except for interviews with the police and protection officers or embassy officials (if needed) and researchers (if approved by the Ministry). They had to wear colour-coded uniforms and were confined in the shelter building. Security personnel were placed in a security house adjacent to the main gate, which could only be opened for official purposes. A sign attached to the main gate delivers strict instructions to visitors who intend entering the premises. The instructions are shown in Figure 6. 


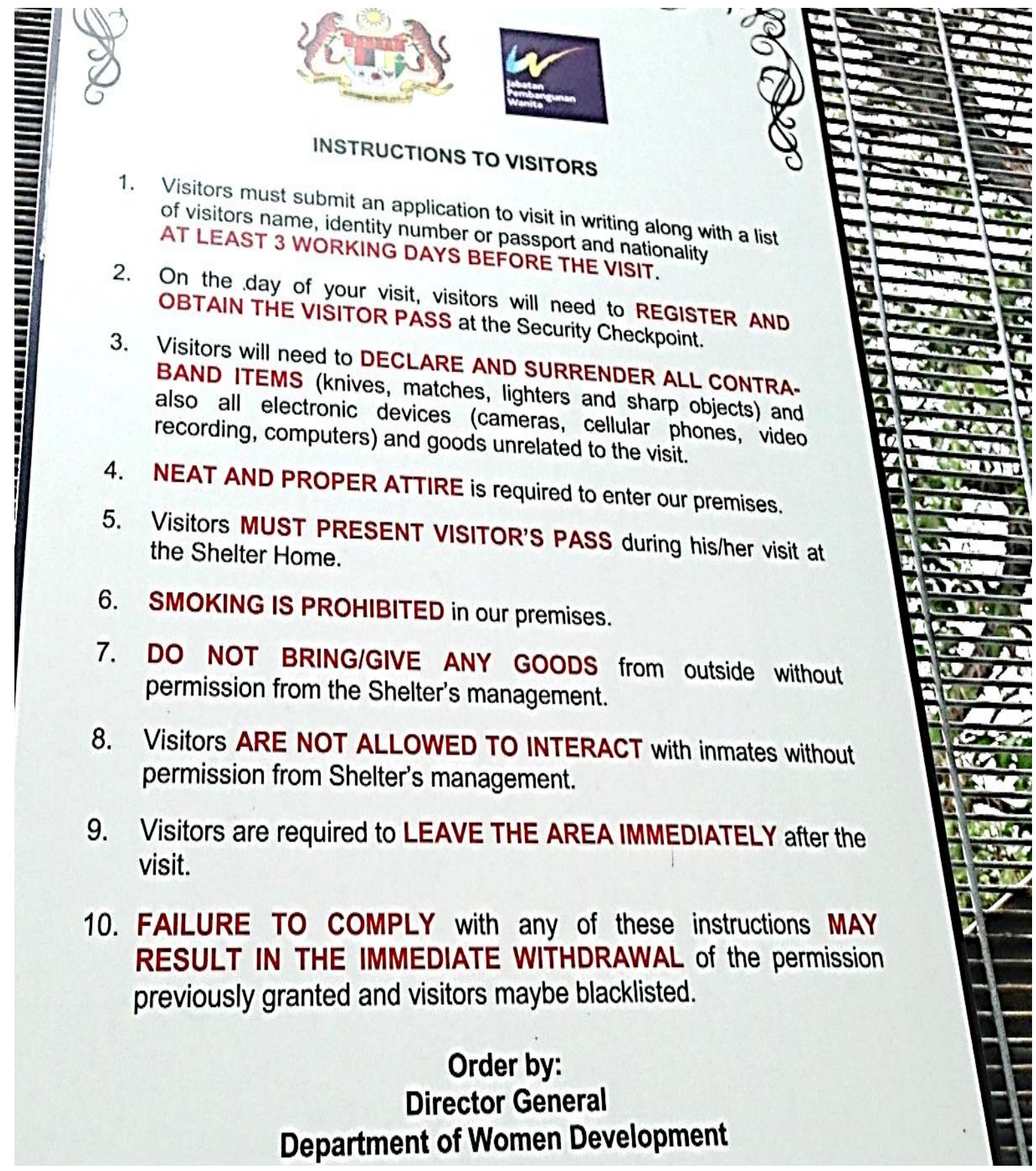

Figure 6: Signboard with instructions to visitors attached to the shelter gate

When asked about the reason for such instructions, Shelter Officer Aida said that it was for security purposes and to restrict the access of outsiders, particularly the traffickers. According to Aida: 
There were times where the police didn't notice that the women were still in possession of their mobile phones after the rescue. On one occasion, one of the woman contacted her trafficker for help and gave him the location of the shelter. Soon after, her trafficker came here and wanted to see her but we turned him away as we do not allow any outsiders. The trafficker refused to leave and kept waiting outside the gate near the guard post until we had to call the police. However, the police could not arrest him unless he trespassed into the shelter compounds. We [shelter] can't do much because the restricted zone is only from the gate inwards and we have no control outside of this gate.

The shelter officers also expressed concern over those who were not 'genuine victims' but were living in the shelter. According to Shelter Officer Aznida:

The police will not bear any responsibilities once they [trafficked women] are given the Protection Order. Therefore, the women will be under our control and we have to ensure that they do not run away. That's why we keep their personal belongings like mobile phones. When we allow them to make calls to their families, they converse in Vietnamese language and we do not understand what they are saying. There have been cases where we thought the woman was talking to her family, but it was someone else. It's not that we restrict their right to make phone calls, but we are afraid of those who are not genuine victims and those who do not feel like victims.

When asked to clarify about what Aznida meant by genuine victims, she said:

Some of the women do not want to be rescued but are forcedly rescued and forced to live in shelters. For example, the enforcement officers will raid a spa and arrest everyone in there. This is the standard practice in Malaysia. The police may have a good case against their perpetrators, but because they felt that they do not need to be rescued and placed in shelter, they would prefer 
to go off or abscond. It's a loss for the prosecution and also would endanger the security of the shelter.

As previously detailed (above), shelters for trafficked women are armed with high levels of security such as barbed wire fences and security guards, which are intended to prevent women from escaping rather than to protect them from harm (U.S Department of State, 2012b; United Nations Human Rights Council, 2015). Such conditions exist for Shelter Five, as the following photographs identify (Figures 7-10).

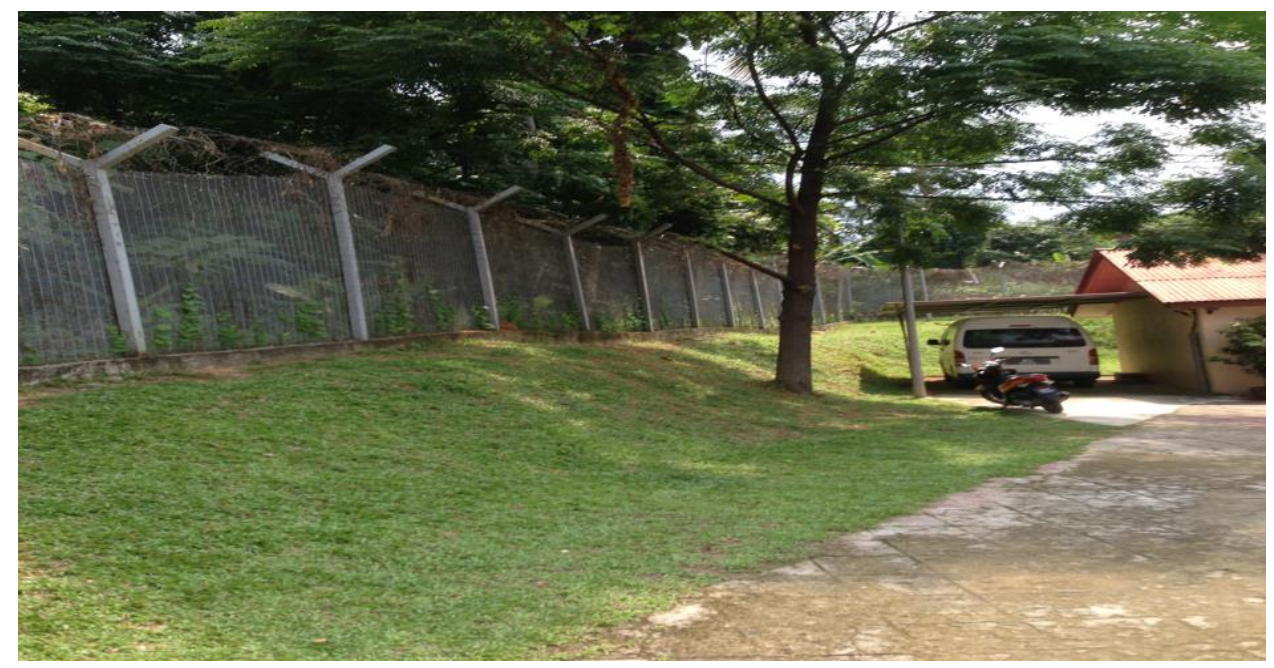

Figure 7: Barbed wire along perimeters of the shelter

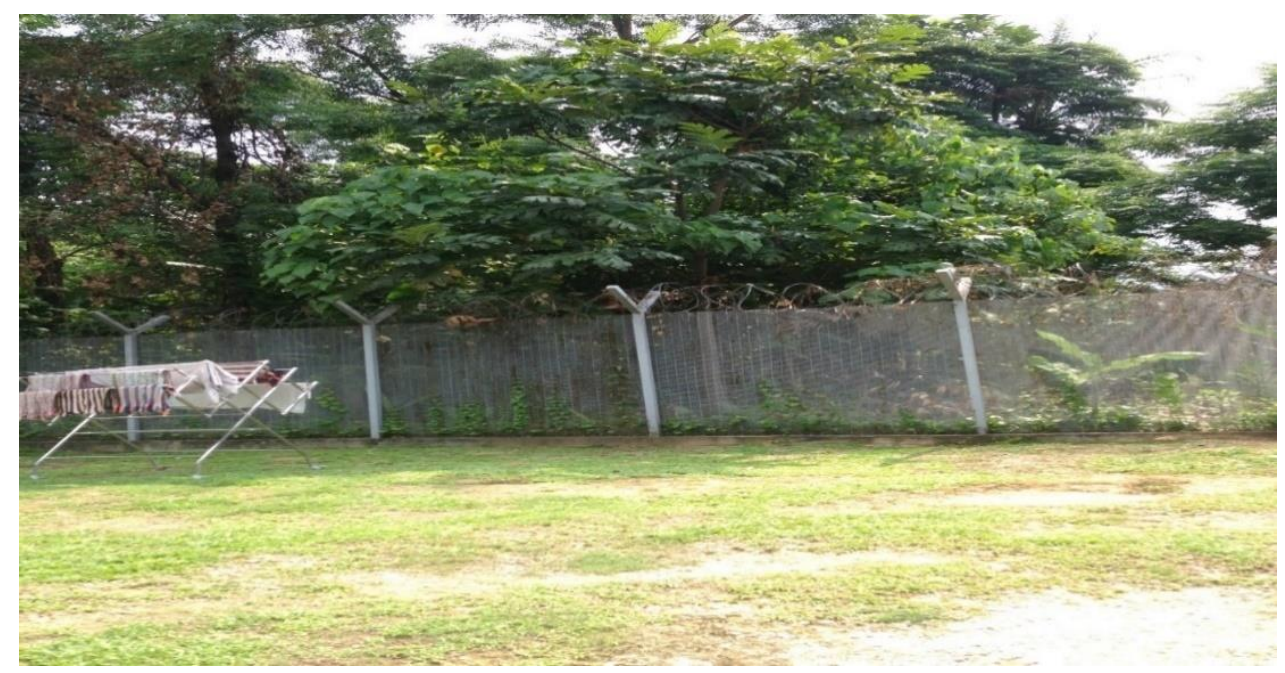

Figure 8: Barbed wire at the rear of the shelter 


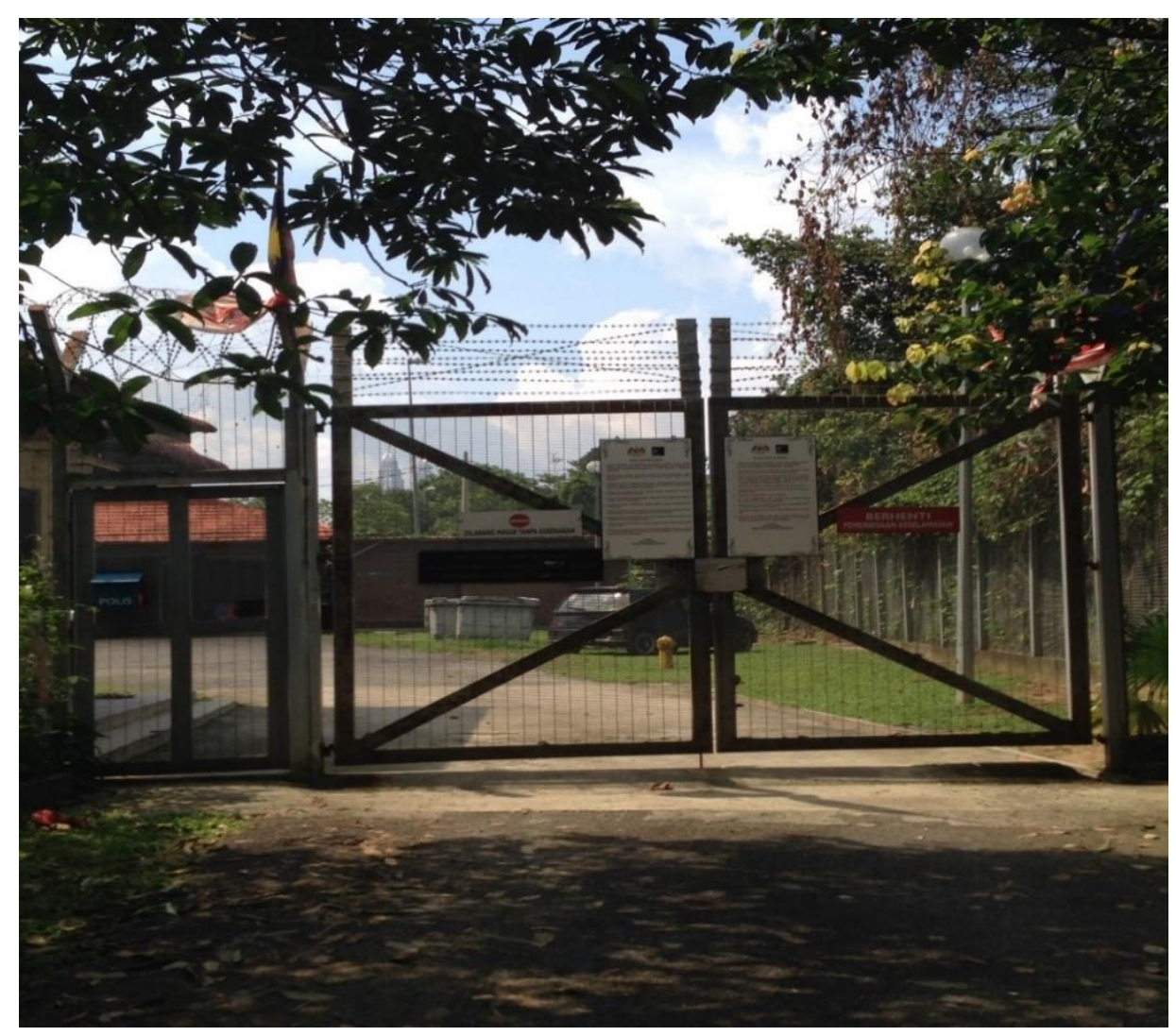

Figure 9: Outside view of the shelter, barbed wire and the partially hidden guard post on the far left

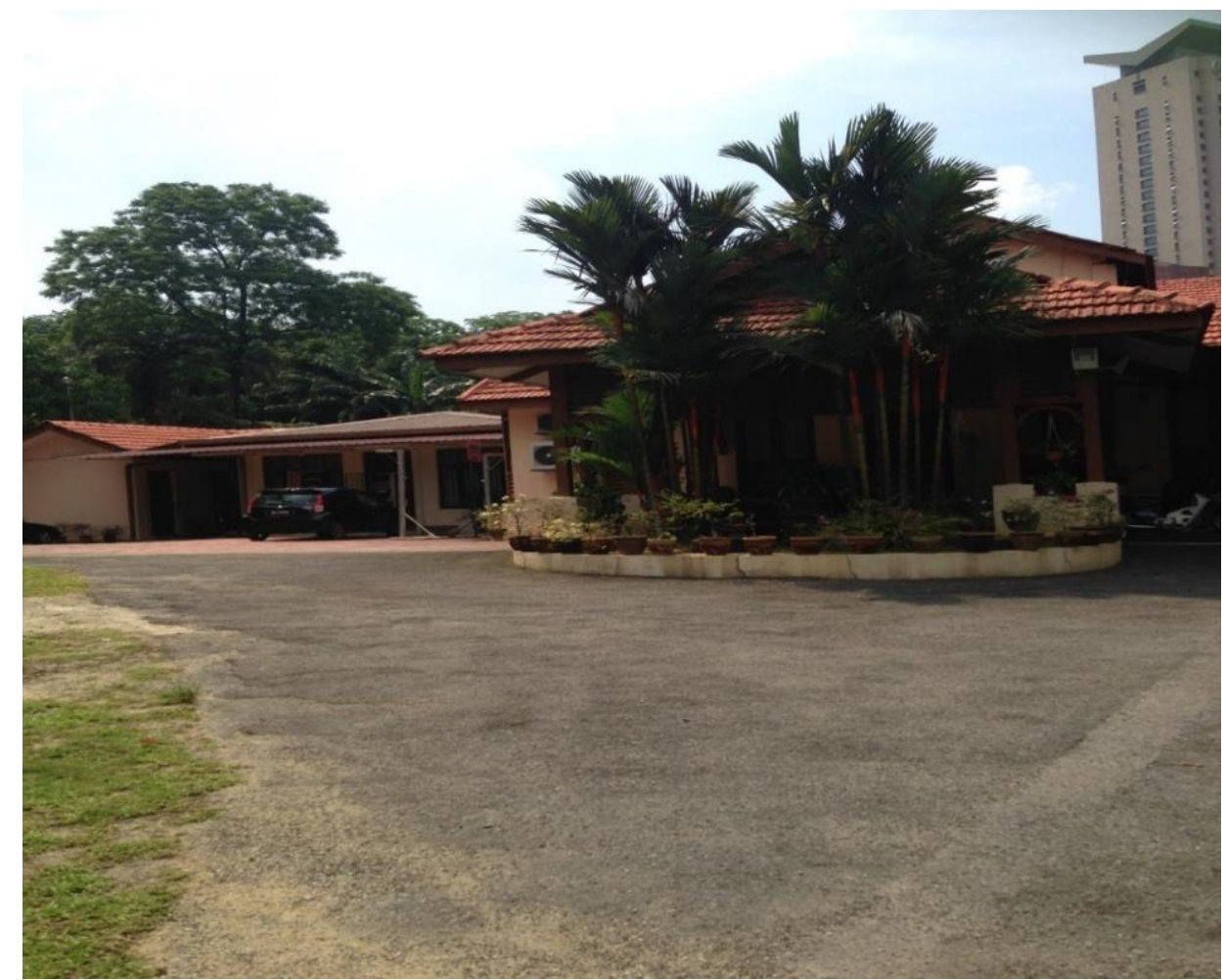

Figure 10: Front view of the shelter building partially hidden by trees 
The NGO Officer, Cecil favoured the barbed wire surrounding the perimeters of the shelter and said:

When it comes to ATIP related issues.....I think that there's a need for barbed wires because there were women who tried to escape from the shelter homes in the past.

While the security of the shelter becomes an important aspect to the safety of the women, greater concerns were raised about women 'absconding' from the shelter. This is because assisting trafficked women to 'escape' from a shelter is a criminal offence under ATIP. ${ }^{77}$ The shelter officers acknowledged that while some of the women in the shelter are 'victims of trafficking', there are also some who are not 'genuine victims'78 (as earlier discussed). In both instances, the language used to refer to the women seems disparaging. Terms such as 'inmates' and 'contraband' stated on the signboard in Figure 6, as well as 'abscond' or 'escape' as stated by Cecil and Aznida, suggests that occupants in the premises are identified as offenders and that the shelter is actually a prison. This reflects the dual identity women occupy: victims and offenders. Furthermore, women have to undergo certain procedures upon admission into the shelter which resemble the admission into a prison. According to Yolo:

When I first arrived the shelter, I had to take off all my clothes and there was a lady who came in to the toilet. There were a few of us and they checked us one by one. We were then given uniforms to wear and a number. They call us by our numbers and not our names. I was given a black t-shirt and black pants to wear when I first entered the shelter. ${ }^{79}$ However, I was asked to change the colour of my t-shirt to green after 21 days. ${ }^{80}$

\footnotetext{
77 Sections $26 \mathrm{~F}$ and $26 \mathrm{H}$ of the ATIP.

78 In interview with Shelter Officer Aznida.

${ }^{79}$ The black colour-coded uniform is meant for women who are given the IPO.

${ }^{80}$ Colour-coded uniforms including indicates that the women have obtained the PO. The colours represent the colour of the dorm they belong to.
} 
Yolo's statement shows that women were stripped naked and searched by the shelter security officers upon admission. Women were also identified by a number and not their names. As Rich (1978, p. 18) notes 'namelessness, denial, secrets, taboo subjects, erasure, false-naming, non-naming, encoding, omission, veiling, fragmentation and lying are some of the tragic and destructive forms of silencing'. Similarly in this study, the identification of women through their numbers and not their name positions women as merely subjects who are detained in shelters and not as an individuals who deserves to be respected.

NGO Officer Cecil responded to such practices and said:

This is not a detention centre, it's not a prison, it's a protection shelter. Therefore, the colour-coded uniforms are not necessary because it makes them feel like they are in prison, those are too much of a prison style. The women have been victimised and they have been victimised by our people [Malaysians] as well. Because our people are involved, I feel that we have to give them a better place to live in.

Shelter Manager, Ajanis acknowledged Cecil's perception and said:

Victims don't really look scared but sad when they arrive at the shelter because most of them think that this is a prison. So, we try to calm them down by telling them that this is not a prison but a shelter home.

Shelter Officer Aznida also felt that the shelter resembles a prison:

I felt stressed out when I first started working in the shelter [seven years ago] as I felt like I was working in a prison. However, I was told that the women were victims and not offenders. I used to argue with my superiors as to why women were locked up and treated like criminals.

The shelter where this study was conducted resembled a prison, and was securely locked and monitored at all times. While the security was meant to prevent traffickers from trespassing 
the shelter grounds and harming the women, it was also meant to confine women and prevent them from escaping from the state's custody. As a result of this 'heavy-handed' approach towards trafficked victims, most women in this study blamed the police for rescuing them from their workplace and depriving them from working and supporting their family.

\section{Women's Experiences of Detention}

The term 'rescue' provoked several responses from the women. Most of them understood 'rescue' as being saved from a torturous situation or a situation that they felt uncomfortable with. However, many of them did not feel like they were being rescued but were 'captured' or 'detained' by state officials. Of the 29 women in this study, only seven women wanted to be rescued by the authorities (police and immigration) while 20 others did not want to be rescued from their workplace. Two women were unsure if they wanted to be rescued by the authorities. This is illustrated in Figure 11 below.

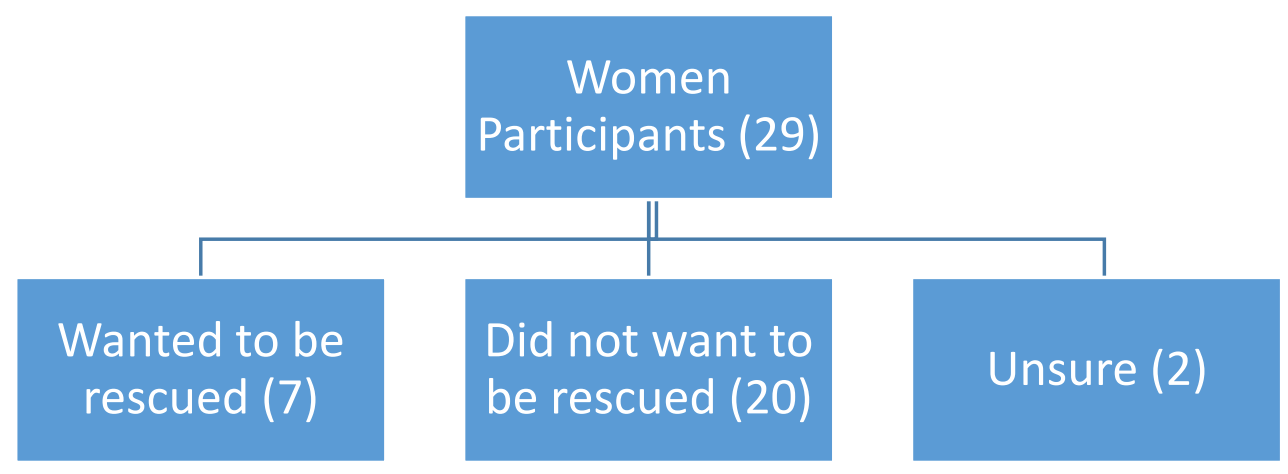

Figure 11: Women's feelings towards their rescue

Figure 11 shows the nuanced feelings the women had towards their rescue and challenges the presumption that migrant women are a homogenous group who want to be rescued by the police. Instead, all the women in the study felt helpless and disempowered because they were forced to live in the shelter. Women's consent was not sought before placing them in shelters. Because of this, participants were quick to vent their anger, disappointment, and frustration towards the police as they could not understand why they were 'rescued' or detained in a shelter for three months with the possibility of having their detention 
extended. Many blamed the police for depriving them from working and supporting their family. For example, Hanny said:

I feel what the police did to me is more torturous than what my Boss did to me [cry]. I quarrelled with the police while I was in Court because I felt cheated and persecuted. I can't even see the sky in this place [cry]. They say it is a safe house but it is not a safe house because it makes people stressed out. The police are liars [cry], yes they are liars...they told me that I could go back home after 21 days but I am still here. However, I was punished to stay here for three months.

While 20 of the 29 women did not want to be rescued from their workplace, seven were relieved to have been rescued by the authorities. For example, Ngoc said:

My friend promised me that I will be working in a garment factory in Malaysia but I was forced to work in a massage parlour and had to do body massage for men. I didn't like it. I wanted the police to rescue me so that I can go back to Vietnam as I do not have a clue on how to get back to Vietnam. I hope I can go home soon as I don't want to live here [shelter].

Ngoc's case indicates that she was not happy working in the massage parlour and wanted to be rescued by the police. However, she was not happy to be living in the shelter. In two similar cases, Mei-Mei and Hong Phan, who were not sure of the rescue process thought that they could return to Indonesia immediately after the rescue. Mei-Mei said:

I don't know if I wanted to be saved by the police. The police said that they wanted to save us and send us back to Indonesia in two weeks but we are supposed to stay here (shelter) for three months before we are allowed to go home.

Seven women (Kim, Efa, Musa, Hoar An, Tuyen, Ngoc and Gena) complained that they were not informed about the legal process to which they are subjected to. For example, Hoar An 
said 'the police, court and shelter officers did not tell me why I have been detained here [shelter] for so long. I don't know what is happening to my case and my date of repatriation.'

This shows that the police, courts, and shelter have not made enough effort to inform the women of the reasons for their lengthy detention. The women also complained of not knowing the progress of their case in court or their date of repatriation. This caused a lot of stress, confusion and anxiety for the women. Almost all the participants stated that they felt bored living in the shelter, because they were confined in the shelter space, and had not much to do except for some household chores: ${ }^{81}$

I feel very bored because I have nothing to do here. I am so stressed out. I cry most times because I keep thinking of my family (Efa).

I feel very sad living here. Nobody is able to tell me when I will be released from the shelter and would be able to go home (Fon).

I feel very sad and I feel like dying. I have been in here (shelter) for two months. I don't how long will they keep me here (Musa).

Efa and Fon's case reflects the sadness and uncertainty they felt living in the shelter. Musa had similar feelings and thoughts of dying. This is consistent with the studies that found that imposed conditions of adversity, including prolonged detention, poor living conditions in the shelter, restricted access to services, and lack of opportunities to work or study often results in women becoming emotionally unstable, stressed and even suicidal (Silove, Ventevogel, \& Rees, 2017).

In some cases, women felt like they were excessively punished for working in Malaysia illegally and did not seem to be aware that they were arrested because they were engaged in sex work. For example, Benz said 'I don't understand why they hold me up for this long. I feel it's unfair because I didn't do anything wrong but was punished for working here illegally.'

\footnotetext{
${ }^{81}$ Only some of the women had daily chores, and only twice a week.
} 
Women also complained of feeling socially isolated, vulnerable and traumatised. They were subject to flashbacks and found difficulty knowing whom to trust as a result of their trafficking and post-trafficking experiences (all issues raised also by Goodey, 2004). As a result, verbal arguments and physical fights frequently occurred in the shelter. As Hong Phan identified:

The women are always quarrelling and fighting here. I try to stay away from these fights. There is a hierarchy in this shelter and I need to respect the 'Tai Ka Che' (Big Sister) but I did not want to worship anyone. I just wanted to be on my own and did not want to be friends with anyone else. So they ganged up against me and tried to find fault with me. They tried to beat me up. There were 11 of them against three of us. I feel scared now. I am scared of being bullied.

This shows that there is an informal hierarchy (kingpin) system which operates to subjugate and control women in the shelter. Shelter Warden Lalli confirmed that there were gangs in the shelter:

There are two gangs in the shelter and they easily get into a fight if they are triggered by any issues such as spending a longer time in the bathroom or given extra food. Although some of the women were arrested together, they may give opposing statements in court and so they dislike each other. Therefore, I have to try and prevent the gangs from fighting with each other.

Besides the frequent fights, some women complained of psychological and emotional health problems such as having nightmares (Huda, 2006) and seeing 'spirits' in the shelter. Ngoc said:

Some of my friends here saw a spirit in the third room. It happened to me a few times, the room right at the end of this house. It's a female spirit who tells us the date we will be repatriated and the date we will be going home. The spirit appears in the middle of the night. There's a rumour amongst us that there was a female who committed suicide here by hanging herself and this spirit comes to hug us. 
In some cases, women displayed severe signs of post-traumatic disorders. According to Shelter Manager Ajanis:

There have been few cases of post traumatic disorder. For example, there was one lady who had OCD (Obsessive Compulsive Disorder) and used to take lots of showers. The reason why she behaved that way was because she was abused while she was working and told that she was not clean and everything she did wasn't clean. Another example is an abuse case where the woman was tortured by the employer. She was continuously threatened by her employer and told that she will be caught by the police if she left her workplace. She has never seen her passport and became frightened when she saw her passport, and said that it wasn't hers.

The experiences of the women living in the shelter provided some insight into how the shelter operates and the adverse impacts on the women. While the intention of providing protection for women may safeguard them from being harmed by their traffickers, prolonged detention often resulted in women becoming emotionally unstable and stressed (discussed in the next section). However, little attention is given to such consequences, because the government is focused on combating human trafficking and prosecuting offenders (Cho, 2015). Given this, the government does not want to be seen as assisting women who are involved in sex work or allocating extra funds to improve their living conditions while in detention. ${ }^{82}$ As a result, migrant women are forced to live in sub-standard shelters and are exposed to physical and psychological harms.

\section{Detention Conditions}

According to Das (2017), shelter homes are supposed to be spaces of rehabilitation for rescued trafficked victims. Their purpose is to restore victims' rights, and provide counselling and medical assistance, to help them overcome their experiences of exploitation (Ibid) pending their repatriation. However, this does not seem to apply to the women in Shelter

\footnotetext{
82 In interview with Shelter Manager Ajanis.
} 
Five. Women were not allowed to leave the shelter except for the purpose of attending court or hospital visits, when they would be escorted by the police, immigration, or protection officers. Access to the shelter yard was only allowed for the purpose of daily chores, games or activities conducted by NGOs such as Suka Society. The games and activities usually involved drawing, colouring activities, playing ball, and other types of indoor games. There were also spiritual classes organised by religious groups such as Persatuan Salimah and Good Shepherd. However, Putri and Emi stated that most women in the shelter did not participate in these activities as they considered them childish or boring.

Furthermore, there was limited space for the women to engage in any activities because the shelter was always overcrowded. ${ }^{83}$ Therefore, most of the women, particularly those originating from Vietnam and Thailand, preferred to occupy their time by making bracelets using plastic bags while the rest would usually congregate in the lounge and watch soap operas. The fact that women who are unrelated and often strangers to each other must try to live together in a confined space can only be described as difficult and stressful. Emi and Putri complained about the noise in the shelter and said that the shelter was always overcrowded. According to Putri 'we have to tolerate the noisiness in the shelter because it is always overcrowded. No matter how many people leave the shelter, there will be new ones coming in.'

When asked about the problems faced in the shelter, some of them complained about the shortage of food, the scarcity of water, and the cleanliness of the water in the lavatory:

There's not enough food for everyone here. The water supply in the lavatory is scarce and the smell is bad. It's difficult for me to urinate or pass motion as we can only use one scoop of water. There's only two toilets and both don't work properly (Putri).

We have limited use of toilets and bathrooms, and water supply is scarce. Even baths are taken in groups (Kim).

\footnotetext{
${ }^{83}$ In interview with Shelter Officer Aida.
} 
The drinking water is yellow here. When we drink the water, we get throat problem because the water is not clean and clear (Yolo).

The women's grievances on the poor living conditions in the shelter were affirmed by Shelter Manager Ajanis:

We don't have much facilities for the victims. As you have seen, we do not really comply with the international standards. We have three bedrooms and only two bathrooms and toilets. Our capacity is for 70 people but, as per today, we have 167 women and the number fluctuates from day to day. Most of them are sharing their beds and it's over capacity here in this shelter.

Women also complained about the shortage of food and the type of food served:

We are given three meals a day but there is always a shortage of food. It is not enough for me (Musa).

I can't eat the food here because it is too sweet (Mon).

They serve instant noodles for breakfast. I am not used to eating this type of food in the morning (Mei-Mei).

There were also complaints about the lack of medical care in the shelter. Based on the interviews, only nine women in this study stated that they had met a doctor either in the shelter or while they were in police custody. Sixteen women complained of not having enough medication, except for Paracetamol when they were sick and, in some cases, they were not given medicine at all. For example, Hong who had been in the shelter for two months stated that I was examined by a doctor who came to the shelter and was told that I have a heart problem. However, I have not been given any medicine till now.'

Nisa said: 
I had an operation day before yesterday. The doctor cleaned my vagina and anus because I had too much discharge. I am still in pain and there is white liquid coming out of my vagina. The doctor gave me some medicine but it has finished. I told the shelter officers but they only gave me Panadol which did not help to alleviate the pain.

Musa reflected her experience and stated that 'I am not given any medicine when I am, sick. There is not enough of medicine here.' Based on the interviews held with the shelter staff, it was apparent that there was no medical staff in the shelter. Because women are not medically screened before entering the shelter, the Shelter Officers were unaware of any existing illnesses the women have. ${ }^{84}$ However, the shelter staff perform body checks to try to identify any marks or suspected illnesses:

We perform a strip search on the women when they first enter the shelter. We need to check if they have any illnesses, burnt marks, or bruises. We use gloves when we perform body checks as we are afraid of contracting any disease. We identified two HIV cases from the body checks. In one particular case, the woman was very thin and had a lot of ringworms near the breast line. We asked her if she had AIDS to which she kept quiet. We informed the police and she was taken to a hospital for further checkup. She died less than a week after that at the Sungai Buloh hospital (Shelter Officer Aida).

The above remarks suggest that women will only be sent for hospital visits if they are suspected to have severe and advanced stage of illness. Despite the admission on the lack of facilities and poor living conditions by the Shelter Manager, there have not been any attempts to improve the situation because of the limited budget allocated to the shelters. ${ }^{85}$ The limited expenditure has also affected the medical care of the women. According to Shelter Officer Aida:

\footnotetext{
${ }^{84}$ In interview with Shelter Manager Ajanis.

85 In interview with Shelter Officer Aznida.
} 
The person who is in charge of us at JPW (Department for Women's Development) is not aware of the work we do. It is so difficult for them to give us the budget, even during critical times. We are only given RM20,000 [NZD7,350] per month which is not even enough to cover the women's expenses. One track pants costs RM30 [NZD11] and if there are 200 women here, I will need to provide 400 pants for them because we give them two sets each. There are also other items that we need to purchase such as toothbrush, shampoo, soap, towel and detergents and it all has to be covered under the budget of RM20,000 [NZD7,350].

The detention conditions as discussed above, do not comply with Guideline 6 of Recommended Principles and Guidelines on Human Rights and Human Trafficking which requires the state to provide adequate care and needs of trafficked persons. This includes access to medical and psychological care. The unsanitary and crowded living conditions, coupled with poor nutrition, and the lack of medical care shows the government's lack of care for trafficked victims. Although international organisations and NGOs have highlighted the poor living conditions in the shelter, there seems to be a lack of political will in addressing those issues. This is because having interest and political will in human trafficking will expose the magnitude and severity of corruption in Malaysia which are linked to top officials (Hodal, 2014). As pointed out by Agile Fernandez, director of Tenaganita:

The order of the day is profits and corruption. Malaysia protects businesses, employers and agents (not victims) - it is easier to arrest, detain, charge and deport the migrant workers so that you protect employers and businesses (as reported in The Guardian 20/6/2014).

In this instance, women may find it hard to trust the judicial system particularly if they know of certain police or immigration officers who were complicit in the trafficking of women. Nevertheless, women are still compelled to become witnesses for the prosecution in exchange for 'state protection' and before they can be repatriated. 


\section{Court Processes}

According to the United Nations Office On Drugs and Crime, it is essential to ensure that trafficked victims are provided with adequate care in shelters and that the provision of such shelter should not be made contingent on the willingness of the victims to give evidence in criminal proceedings (United Nations High Commissioner For Human Rights, 2002). However, this does not seem to be implemented in Shelter Five. Given that the role of witnesses and the evidence they provide in criminal proceedings is often crucial in securing the conviction of offenders, the women are detained in shelters in order to secure their attendance in court (United Nations Office of Drugs and Crime, 2019). As well as this infringement on their freedom, those who fail to satisfy or convince the court of the role of traffickers may be subject to 'victim blaming'. According to Shelter Officer Aznida:

Some women think that they might be able to return home earlier if they do not implicate their traffickers while giving testimony in court. However, they would actually end up staying much longer in the shelter because the Deputy Public Prosecutor will seek an extension for their stay in order to reinvestigate the case. In Musa's [participant] case for example, how could she have not recognised the Captain [pimp] when she has worked in the spa for eight months?

Women were blamed if they failed to assist the prosecution. This produces tension surrounding how to balance the needs, protections, and rights of victims while pursuing aggressive efforts to prosecute traffickers. This will be further discussed in the following chapter. Although women's refusal to cooperate with the authorities may be viewed as hostile to the prosecution, it should also be viewed as 'declining assistance' (Surtees, 2014, p. 120). Women may refuse to cooperate with the authorities because they may not require any assistance from the state (Surtees, 2014). This is because women make different decisions at different stages of their post-trafficking lives, as their individual situation evolves due to personal circumstances such as financial needs, own security (as they may fear reprisals), and family relationships (Ibid). However, women's choices and decisions continue 
to be neglected or viewed as detrimental to the state because of the officer's priority to prosecute traffickers.

\section{Women's Experiences of Court Processes}

Although women were compelled to testify in Court, their voices in relation to their personal experiences were not heard during court attendances. As such, most women complained that they were not given the opportunity to speak during the issuance of the Protection Orders:

After 21 days, I was taken to court but I was not asked to speak. It was just the court officials and the police who were talking. There was a Chinese woman who said something to me but it wasn't important, she just told me to go back to the house [shelter] I was staying (Kim).

Once the Protection Orders were issued by the court, the women were asked to sign a piece of paper without knowing the contents:

I was brought to court in a police truck. I knew it was a court because it was similar to Vietnam court, where the criminal stood. They told me to wait at the long bench and the police went in to do something. Later, he came out and asked me to sign a piece of paper. I signed it but I didn't know what it was for (Tuyen).

Although women were not given the opportunity to speak during the issuance of the Protection Orders, they were required to testify during trials. Of 29 women in this study, only Liana, Musa and Tang Mo had given evidence in court during trials. Those who testified in court complained of being disadvantaged by the court processes. Musa, for example, was subject to intense questioning by the prosecutor and the defence counsel:

They [interpreter and Deputy Public Prosecutor] asked me about my work and I told them everything I knew. They asked me to identify all four accused in court and their roles in the spa but I have no knowledge of that. They 
questioned me as to why I didn't know all the accused when I have been working there for eight months. I told them that I do not know many people in the spa because I was stationed in a room while working and I do not know what is happening outside. The Cashier will inform me through a microphone when I have a customer. I only knew the Cashier and the Cook but neither of them were in Court. It was silly because they kept asking me the same questions over and over again although I kept telling them that I didn't know anything. What's the purpose of questioning me repeatedly over something I do not know? (Musa).

Musa insisted that she did not recognise the accused or have any knowledge of their roles. She also did not indicate that she was threatened or asked to remain silent by anyone. Musa's experience shows how judicial proceedings in a trafficking case are conducted. Although the prosecution is duty bound to not re-traumatise the witness and respect the witness, Musa's experiences reflects the contrary. It generally shows how trafficked victims are subject to repeated questioning by the prosecutor and how attempts are made by Court officers to discredit their credibility as witnesses if they do not perform to the satisfaction of the prosecution. This is unlike other type of cases where witnesses are subject to repeated questioning and intense scrutiny by the defence counsel while the prosecution seek to lessen the impact of repeated questioning on the witness's recall of events (Zajac, Gross, \& Hayne, 2003).

In all the cases above, language barriers have often been a recurring problem because the services of interpreters are not available to the women at all times. Women who were unable to converse in either Malay or English were the most affected with the language barrier. Not only were they not given the right to speak in court, they also had no idea of what transpired in court and what was said to them. For example, Benz said:

There was no interpreter in the court room. I had no idea what was going on, I only understood when the police said that I will be placed here for 21 days and will be able to return home after that. 
Kim stated that she was not given access to any interpreter. She said 'they used Malay language in court and I didn't understand what they said. They did not provide me with a Vietnamese interpreter. Nobody asked me anything.'

Similar to the practices in the shelter, the use of Google Translate was even extended to the courtroom. Hong Phan narrated her experience and said 'I understood what was happening because there's Google Translate. The judge will Google Translate everything I said in court.'

Linguistic competence entails the ability to speak and the ability to understand (Du, 2015). Given that the language-related right in the legal proceedings is mostly associated with access to interpreting (Ibid), it is perplexing to note how the legal system allows and accepts ambiguous communication in preparing official reports and court proceedings ${ }^{86}$ It also denies women's ability to participate in legal processes and denies women as legal agents.

\section{Conclusion}

The above discussions have shown how the enforcement officers and protection officers carry out the victim-protection policies. The anti-trafficking framework has been structured in such a way that the acts of rescue, custody and protection are harsh, punitive and harmful towards the women. State actions in arresting women against their will and detaining them in shelters does not represent notions of protection and support (Das, 2017). Instead, the act of 'rescue' and 'protection' can be construed as a kind of secondary trafficking of women by state agents (Das, 2017). This is because the 'rescue' of women is premised on the assumption that it restores the rights of trafficked women (Ibid). However, in reality, such forms of 'rescue' negate women's free will and simplify their experiences of trafficking (Ibid). It restores the stereotypical presumption of a trafficked woman who is weak, powerless, devoid of agency, and in need of state protection. The incarceration of trafficked women by order of the Court suggests that it is forced and compulsory custody rather than refuge. The practice of detaining women who have been trafficked is in itself traumatic as they are under constant surveillance

\footnotetext{
${ }^{86}$ Providing trafficked persons with legal and other assistance in relation to any criminal, civil or other actions against traffickers/exploiters in a language they understand is contained in Guideline 6(5) of the Recommended Principles and Guidelines on Human Rights and Human Trafficking.
} 
with limited movement in the shelter, and are prohibited from establishing unsupervised contact with the outside world.

In this instance, state 'protection' has overriden women's agency, causing many trafficked women to feel dissatisfied, angry, stressed, humiliated and confused with the state's actions. Because policies and practices that humiliate, punish, and criminalise trafficking victims violate basic human rights, the US TIP Report (U.S Department of State, 2012b, 2014b, 2016, 2017) and local human rights organisations such as Suhakam and Tenaganita have criticised Malaysia for the standard of protection given to trafficked victims (Human Rights Commission of Malaysia SUHAKAM, 2004; Tenaganita, 2012; Yunus, 2014). From the interviews conducted with the women, it was clear that they were unhappy with the way they were treated by the state officials. At present, trafficked women are subject to prolonged victimisation and their plight remains unheard and unsolved. 


\section{Chapter Eight: Discussion}

\section{Introduction}

This chapter reflects on the main findings of the research. In particular, it returns to the key issues of victimhood and agency, and the state's harm of migrant women in the sex trade. These two issues challenge the mainstream perceptions of the 'ideal trafficked victim' and the victim-agent dichotomy. In this regard, the discursive erasure of women's agency, particularly when it involves sex work, acts to reinforce victim stereotypes. Such discourse, however, excludes women who have been rescued by state officials and held under state protective custody. Therefore, the women's experiences in this study provide a platform to explore nuanced understandings of agency and victimisation, as well as the different strategies used by women to navigate harms throughout their migration experience. It also questions the victim protection policies which have proven to be harmful to women.

The chapter begins by asserting that migrant women experience multiple harms throughout their migration period. Yet, women also use various strategies to prevent and minimise these harms. Silencing is one effective strategy to minimise harm. This is because the choice to publicly challenge the powerful ${ }^{87}$ is often harmful and sometimes extremely dangerous to the well-being and safety of the women. While silence may be used as a shield to avoid harm, it can also be used as a tool to control women. In this context, women are made/forced to remain silent as a way to control them and render them invisible. This excludes women from the public realm and devoid them of agency even in the struggle against violence, which directly concerns their bodies and livelihoods. Thus, the chapter discusses the literature around how silencing is used by male-dominated structures and institutions to deny women's agency and marginalise women.

Following this discussion, the chapter asserts and discusses women's continuum of harm. Women are victimised by various actors (traffickers/employers/customers) during the trafficking phase and are later victimised through the state's actions during the post-

\footnotetext{
${ }^{87}$ Powerful in this context would refer to traffickers, employers, and state officials.
} 
trafficking phase. In this context, the chapter argues that state 'rescue' does not particularly 'save' or protect women because it is not carried out in the women's interests. Instead, state rescue is focused on apprehending, prosecuting and convicting human traffickers. Given this aim, women who are rescued are detained in shelters in order to allow the state officials to use them as witnesses in court. Such detention allows the state to control migrant women and sustain their 'protection' policies.

The third part of the chapter highlights the fact that stereotypical images of trafficked victims are fictitious and do not correspond to the women's experiences of migration, sex work or victimisation. Based on these arguments, the chapter highlights five main points that contradict the characteristics of an 'ideal trafficked victim'. They are: the notions of action ('agency' and 'consent') which are presumed to be non-existent in the attributes of an 'ideal victim'; the interpretation of a 'respectable' project; the continuum of trafficking harms, beyond an isolated offence; the identity of the trafficker which does not fit into the 'ideal' offender image; and the notion of 'ideal victim' that does not correspond with the reality of women's experiences. These points reiterate the argument that the depiction of an 'ideal trafficked victim' is unrealistic and difficult to prove in a formal court setting. This shows that there is a gap between stereotypes (weak, vulnerable and innocent) and the reality of trafficking situations.

The final part of the chapter discusses the impact of state protection on global sex trafficking. It summarises how the criminalisation of sex work has legitimised repressive state action in the name of preventing 'sexual harm'. Thus, the chapter proposes several recommendations to help improve the current victim protection policies in Malaysia. These recommendations are focused on providing women with the assistance that they require and that respect their rights and agency. Given that the anti-trafficking laws which are intended to 'protect' women have harmed women, particularly those involved in sex work, responding to sex trafficking requires a more sophisticated account of women's needs and desires to improve their economic situation. 


\section{Silence and Survival}

Voice, or the act of speaking out, is often identified in the feminist literature as one of the key conditions demonstrating women's agency and empowerment (Gilligan, 1982; Olsen, 2003). Denying a woman her ability to speak also means denying her right to self-determination, participation, consent, dissent, life, participation, interpretations and narratives (Solnit, 2017). Conversely, silence is presumed to be a symbol of passivity and powerlessness (Mahoney, 1996). As Mahoney (1996, p. 604) argues, 'those who are denied speech cannot make their experience known and thus cannot influence the course of their lives'.

Despite the literature and laws which advocate the freedom of speech for women, the voices of women, particularly those involved in sex work, are often silenced by their status as 'victims' or sexualised 'others's8 (Andrijasevic, 2007, p. 41). In many instances, women are silenced through harmful ways such as being ridiculed, discriminated against, criminalised, stigmatised and treated as unworthy individuals (Counts, 2014; Pheterson, 1993; Sallman, 2010). Similarly, through trafficking, women are silenced and held in servitude. Although such forms of control are intended to transform women into passive and obedient individuals, the discussions in this thesis have shown that women have found ways to resist this imposition. In this instance, women often engage with their traffickers as a means to secure their wages (see cases of Liana and Ngoc in Chapter Six) and negotiate better working conditions (see case of Mei-Mei in Chapter Six).

At the same time, silence is a powerful and active component of resistance. The choice to publicly challenge the powerful (traffickers/employers) is often extremely dangerous, and may expose women to further harm (Parpart, 2010), therefore women choose to remain silent to prevent further harm (Ibid). Women's silence can also be used as a method of communication, and to provide space for renegotiating harmful gender relations and practices (Ibid). As Porter (2016) point outs, depending on motivation, silence may be a source of oppression, empowerment, pragmatism or agency. As in this study, some women (see the

\footnotetext{
${ }^{88}$ Sexualised 'others' in this context would mean 'constructions of women as posing temptations to, and ensnaring, local men, thereby threatening the fabric of the family' (Yeoh \& Huang, 2010, p. 38).
} 
cases of Angel and Nisa) have chosen to remain silent for fear of their safety or that of their families. In this context, self-chosen silence is an agentic act. This includes learning to suppress feelings, and negotiating better conditions for work. In some cases, speaking out is not an option and silence can be used as a systematic strategy to help women carry on with their lives (Bletzer, 2006).

More broadly, women may choose to remain silent and comply with their trafficker's instructions because they feel indebted to them or as a means to secure their income. This sentiment reflects the debt bondage most women find themselves in where they are told of the amount they need to repay before they can be 'free' or before they can start earning money. In addition, women may feel indebted to their family members, relatives, or friends who have paid for their travel expenses and/or assisted them in getting their jobs. Therefore, women tend to find ways to navigate harms so that they can continue working to earn money and support their families (see the case of Ngoc who continued working because she wanted to pay off her debts and support her family, in Chapter Six). Therefore, it seems unfair to dismiss these choices as passivity and disempowerment as they are often the best (and sometimes the only) tactics available for building internal strength and for negotiating survival (Sagot, 2005; Silber, 2005). Based on the above, it is clear that women's silence and actions should be assessed based on the situation they are in and not interpreted solely on their actions or inaction. As Win (2004, p. 76) concludes, 'any woman in a violent situation will tell you, there are no prizes for speaking out. If anything, you are branded a bad woman, or worse, you are violated all over again for daring to open your mouth'. Further, as the World Health Organization (2002, p. 95) study on health and violence pointed out:

Most abused women are not passive victims .... Some women resist, others flee, while others attempt to keep the peace by giving in to their husbands' demands. What may seem to an outside observer to be a lack of positive response by the women may, in fact, be a calculated assessment of what is needed to survive in the marriage and to protect herself and her children.

Based on the above examples, it is clear that women learnt to accept and live within their boundaries because of their determination to escape poverty and support their family. While 
women's actions or inactions may be seen as a form of empowerment and a survival strategy for women, actors who seek to silence, exploit, or enslave or hold women under servitude are clearly in violation of women's fundamental rights.

\section{Silencing of Women During the 'Post-trafficking' Phase}

Women continue to be silenced throughout the 'post-trafficking' phase. Their voices are hardly heard on the media and they are always being spoken for or about by the police, immigration or politicians. None of these versions address or sufficiently describe the situation as articulated by women themselves (Agustin, 2005) and, thus, women's experiences of victimisation are not properly understood by the state. The Ministry of Women Affairs and Family Development (Ministry) who is responsible for 'protecting' 'trafficked' women is equally liable in silencing women through its power relations. This is because the Protection Officers, Shelter officers and Shelter Wardens (who are under the Ministry) ensures women abide by the rules and regulations of the shelter. Although they were aware of the problems women face in the shelter such as overcrowding, poor living conditions, restricted movements, stress and lack of medical care, the officers were more concerned about the success of the prosecution's case rather than the women's well-being (see interview with Shelter Officer Aznida - Chapter Seven). Therefore, the harms against women remain unheard, and women have no choice but to live in the shelter and abide with the victim-protection policies. The denial of rights and women's voices shows how the act of 'silencing' can be conducted in the name of 'protection' (Agustin, 2005).

At present, the policies (of rescue, detention and repatriation) that are brought forth to 'save victims' overlooks the fact that they violate women's rights to freedom of speech, freedom of movement and residence, and free choice of employment. Unlike the TVPA and the Recommended Principles and Guidelines of Human Rights and Human Trafficking, there are no provisions in the ATIP that prohibit women's incarceration pending their repatriation. In Malaysia, women are also not given free legal advice after rescue and are therefore not aware of their rights. The fact that many of them did not understand the Malay or English language makes it easier for the state to exert control over women and maintain their silence. Without access to free legal advice, many of them do not understand their own status and presume 
that they are serving a prison sentence in the shelter. This shows the lack of justice in the legal framework and the difficulties in accessing justice.

Apart from the difficulties in accessing legal advice, women were rarely given the chance to speak during court attendance. Many were not informed of court processes, not provided with interpreters, and were not aware of what transpired in court. They were aggressively questioned during trials, and their testimony was expected to provide enough information to incriminate the trafficker. They were also required to prove their status as 'genuine victims' and provide clear and concise evidence which could implicate their traffickers. For example, in the case of Musa (see Chapter Seven), the prosecution's repeated and aggressive questioning over her testimony made her feel stressed and unhappy with the way she was treated in court. Instead of taking Musa's words at face value and allowing her to become an agent within the trial process, she is presumed to have been hiding facts and information. This shows how women were not given the space to control their own stories. Such segmented treatment of testimonies in court become sources of domination over women and may discourage women from enduring prosecution (Taslitz, 1996). In this regard, women are bound by the provisions contained in the Malaysian Evidence Act 1950 (section 60) which positions oral testimony as a form of primary evidence. Given this, women who testify are subject to questions that could discredit their ability as witnesses (sections 132, 135 and 137 Evidence Act). Although trafficked women are categorised as victims and are immune from being prosecuted under the ATIP, they are still subject to other legislation such as the Immigration Act (section 8) and the Passport Act 1966 (sections 2 and 9). Therefore, the legal protection of women in court processes is limited and does not necessarily translate into justice for women, but becomes more of an adversarial ground for prosecution and defence lawyers to prove their cases.

Although there has been an overwhelming emphasis on trafficked women as witnesses, they are also portrayed as a threat to society and the state (Mattar, 2006; Suppiah \& Kaur, 2018). This is because official responses revolve around perceptions that trafficked women are risky and this sustains the policies and laws of secure incarceration and detention, which are referred to as 'protection'. Such responses are short-sighted and unhelpful because it reinforces women as 'risky' victims and fails to recognise the various ways in which women 
are agents in their own ways (Nagy, 2008). As shown in this study, most of the women were concerned about their economic stability and their rescue has added to their financial constraints. Based on the above reasons, the thesis argues that there is a gender gap in the attempts to achieve justice in trafficking proceedings. Women who are 'rescued', 'questioned' and brought to court to relay their stories are then cast aside to deal with the next phase of repatriation. This shows how the victim protection framework acts to silence women by force. Therefore, this thesis argues that there is a prevailing silence about the violence against women, particularly trafficked women and the protection of their rights. This includes the harms they often face while in state custody. This is because the real objective is to control unwanted migration, control state borders, and penalise migrant sex workers in order to preserve the image and sanctity of the country.

\section{Continuum of Harms}

Beyond silencing, this thesis argues that women experience a continuum of harms throughout their migration process. Complex sets of personal and structural factors such as poverty, unemployment, low wages and gender disparities have contextualised women's journey into sex work and the circumstances in which they made decisions. These structural factors directly illustrate a power system wherein social structures or institutions cause harm to people in a way that results in mal-development or deprivation (B. Lee, 2016). As a result of these harms, women feel compelled to migrate and work in the sex industry to provide a better life for themselves and their families.

Sex work provides women with access to a type of work that generates far more income than other wage labour available to women, particularly for those from rural areas and with low education or skills sets (Molland, 2011). While this may serve as an opportunity for women to improve their financial situation, the illegality of sex work in most countries worldwide has pushed the activity underground (Samarasinghe \& Burton, 2007) putting women at a far greater risk of being abused or harmed due to lack of legal regulation (Global Network of Sex Work Projects, n.d.). These harms include debt bondage, threats, non-payment of wages or under-payment of wages, confiscation of documents, restrain of movement, physical, 
psychological and sexual harms. For example, Tammi, Nisa and Angel suffered multiple injuries and were constantly threatened by their traffickers. Their traffickers threatened, deceived, and abused them in order to control and exploit them (see Chapter 6). Women were also subject to assaults and abuse by their customers. This was evident through the interviews conducted with Tammi, Nisa and Mei - Mei recounted how they were called derogatory names, forced to endure rough sex and forced to have sex even when they were in pain. However, the harms and abuse experienced by women goes unabated because women are reluctant to report to the authorities, given their status as migrant sex workers. This prevents women from contacting and cooperating with the authorities. There are also no specific laws that penalise customers who abuse women in the sex industry.

Although women are susceptible to all forms of harm, many of them struggled with their emotions and expressed feelings of shame, guilt and self-blame when discussing their experience of working in the sex trade (Coy, 2009). Thus, Coy (2009) develops the continuum of sexual violence as a framework for exploring women's experience of sexual violation in sex work where her research reveals how women express the same feelings of 'shame, guilt, hating the body and alienation' (p. 201). As a result, most women do not disclose their jobs to their families for fear of being shamed and ostracised by their families (Bertone, 1999). Similarly, in this study, the women talked about having to lie about their work to family and friends and the shame they felt about being a sex worker. This was expressed by Le Heo, Putri and Mei-Mei who all felt ashamed of their work and did not disclose their actual work to their family for fear of being ostracised and bringing shame to the family. This is because patriarchal practices that are deeply embedded in moral, religion and social practices have made it easier for women to be blamed and shamed if they do not conform to the characteristics of an 'ideal' woman. Such responses show how traffickers have been successful in channelling the blame to women while they continue to deceive and exploit women with impunity (Riegler, 2007).

Despite the shame and stigma arising from sex work, women are expected to contribute to their households and maintain the traditional notion of 'good dutiful daughter' through acts of gifts and remittances (Molland, 2011, p. 239). Those who do not remit monies to their families or accumulate savings will be stigmatised by their families and local communities when they return home (Molland, 2011). This shows the difficulties and dilemma women face 
while trying to improve their financial conditions. As a consequence, women become continuously harmed either by their traffickers, families, or local communities, which makes it difficult for women to exit poverty. Although state rescue is thought to put an end to women's grief, women are unfortunately victimised through the state's action and protection.

\section{State Harm}

The practices of handcuffing women, making them wear uniforms, and detaining them in jails or confined spaces have been treated as part of the victim protection system (Miller, 2004). As a result, women's experiences of harm become well-hidden because the existing laws (ATIP) do not recognise or acknowledge the harms emerging from state practices. This provides an excuse for the state to deny any harmful state practices. The denial of harm is evident from the interviews conducted with the professionals where only one of the 12 professionals expressed concern about women being arrested and detained similar to offenders $)^{89}$ while the remaining 11 did not indicate or express their dissatisfaction about how women were policed or detained. This may be attributed to the fact that they are employees of the government who are expected to be loyal to the government and carry out their duties according to the policies given.

Although one of the police officer was aware that women were sometimes shocked or scared while being rescued, ${ }^{90}$ he did not express any sympathy towards the women because he felt that women were unware that they were being exploited. They also felt that the shelters were meant to safeguard women. Nevertheless, some officials expressed their concern that the women engaged in 'immoral' behaviour and therefore need to be rescued and detained in the shelter. ${ }^{91}$ This shows the paternalistic attitude of the state and how it exerts control over women. As Cohen (2001) argues, blocking out, turning a blind eye, shutting off, not wanting to know, or seeing what we want to see are all expressions of 'denial' (see Chapter Seven).

\footnotetext{
${ }^{89}$ See Shelter Officer Aznida's interview in Chapter Seven.

${ }^{90}$ See interview with Police Officer Jimrey in Chapter Seven.

${ }^{91}$ See interview with Protection Officer Irma in Chapter Seven.
} 
Applying Cohen's concept of interpretive denial to the current state's practices, it seems clear that the state is in denial that the protectionist policies victimise women.

Further, the aim of 'rescuing' women and making them ready and available as witnesses for the prosecution, ${ }^{92}$ violates the Recommended Principles and Guidelines of Human Rights and Human Trafficking which specifically prohibit the protection of women in shelters from being contingent on the willingness of the victims to give evidence in criminal proceedings (United Nations High Commissioner For Human Rights, 2002). However, women are blamed if they fail to assist the prosecution or cannot provide enough information to incriminate traffickers. This was evident in the case of Musa where she was blamed by the Shelter Officer Aznida for failing to identify her 'pimp' in Court (see Chapter Seven). This produces a tension surrounding how to balance the needs, protections, and rights of victims while pursuing aggressive efforts to prosecute traffickers. In Malaysia, it appears that women's interests become secondary to the prosecution of traffickers.

\section{Challenging the 'Ideal Victim' Narrative}

As discussed above, most women who were trafficked into the sex industry were able to make their own choices and decisions. Their ability to exercise their agency differed according to the situations they were in. Women were also able to use strategies to navigate harms. However, the media tend to depict trafficked women as women who are weak and totally deprived of their agency. In these descriptions, victims are constructed according to Christie's mapping of the 'ideal victim' (O'Brien, 2013). They are portrayed as a 'passive, unemancipated woman who came from a developing country' (Doezema \& Kempadoo, 1998, p. 44) and forced into sexual slavery. Although none of the women in this study were kidnapped, some of them were forced, coerced or deceived into sex work. The force usually occurred upon women's arrival to their workplace. In some cases, women were unable to resist the demand of their traffickers because of threat, fear or debts. However, they were able to use certain strategies to minimise harm. For example, they cooperated with their traffickers in

\footnotetext{
92 See interview with Immigration Officer Sharul Azlin and Shelter Officer Aznida (Chapter Seven). For example, Immigration Officer Shahrul Azlin was more focused on upholding the law and getting as many witnesses as possible while Shelter Officer Aznida was concerned about the role of the women as witnesses in court.
} 
order to establish trust with their traffickers so that they could pay their debts and remit money to their families.

Therefore, the findings of this study rebut the stereotypical image of an 'ideal victim' (as described in Chapter Two) for the following reasons: (i) women were able to exercise agency throughout their migration experience even though their agency may be limited at certain points of time; (ii) the term 'respectable project' remains somewhat vague and unclear (iii) the trafficking crime is a continuum of violence and not a 'one-off' crime; (iv) the perpetrators consist of individuals that do not fit into the stereotypical perception of an 'ideal offender'; (v) the notion of 'innocent' and 'blameless' is debatable and unrealistic. As well as this, women who are categorised as trafficked by the state are women of all ages and marital status and not virginal young woman, as imagined. Thus, the following discussions will demonstrate that the stereotypical images of trafficked victims are untrue because they do not reflect the reality of women's trafficking experiences.

First, the notions of 'agency' and 'consent' which are presumed to be non-existent in the attributes of an 'ideal victim' do not correspond with the reality of women's experiences. Instead, all of the women in this study were able to exercise agency and make decisions throughout their migration experience, even though they had limited agency at certain points of time. In such circumstances, women exercised caution and care in order to minimise harm so that they could continue working to earn a living. In many instances, women agreed to migrate and engage in sex work, but were then subject to exploitative practices at a later stage. Thirteen women in this study did not feel exploited by sex work but felt victimised by state responses.

Second, that sex work is unlikely to be regarded as a 'respectable project' given the stigma and negative perception attached to it. This is because sex work has frequently been associated with issues of morality. As Nussbaum (1999, p. $278-280)$ notes:

the special stigma reserved for prostitutes is derived from an 'aristocratic prejudice against earning wages' that has been overcome in most fields outside of prostitution...and the general anxiety about the female body. 
Therefore, sex work contradicts the attributes of an 'ideal' woman. However, most of the women in this study engage in sex work because they needed money to support their family. The fact that the women were breadwinners and were responsible enough to take care of their family should be considered as 'a respectable project'. This shows their active sense of responsibility and the caring nature they had towards their family. Third, that the trafficking crime is not a 'one-off' incident, unlike most conventional crimes, as it may be committed over a period of time. Earlier discussions have shown the continuum of harms women face throughout their migration experience. Women were victims of poverty, economic disparities and unemployment before migration and were victimised by their traffickers/employers and customers while they were working. They were also harmed by the state throughout the posttrafficking phase: from their rescue and detention to their repatriation. This continuity of harm differs from the depiction of an 'ideal victim', which presumes that the incident should only occur once (Christie, 1986). In many cases such as those evidenced in this study, women were victimised by their traffickers over a period of days, weeks, months to even a year. Women who have been 'rescued' also find themselves victimised again as a result of the treatment they receive at the hands of the authorities (Pearson, 2002).

Fourth, that the perpetrators of the trafficking crime do not fit the image of an ideal offender' that is typically presented as an 'unknown stranger' (Christie, 1986b). This is because the categories of offender do not include the state as a perpetrator. In this study, the recruiters consisted of family members, partners, relatives, neighbours, friends, and acquaintances who were either male or female, and had connections with the traffickers or their agents. Through this relationship, participants were easily manipulated by people they trusted, and many of them did not even feel that they were exploited. This knowledge slightly changes the constructed, popular idea of 'traffickers'. According to Agustin (2007, p. 107), the assumption that 'evil' traffickers (strangers) are behind trafficking makes it easier for some NGOs to advocate for the need to 'save' women working in the sex trade. It also makes it easier for agencies to gain support from the public by arguing that they are helping victims rather than improving the existing victim protection framework (Doezema \& Kempadoo, 1998). 
Fifth, the notion of the 'ideal victim', which presumes victims to be 'innocent' and 'blameless', does not correspond with the findings of this research. This is because most of the women in this study willingly migrated and engaged in sex work in Malaysia, but were later victimised by their traffickers and/or state authorities. Therefore, the notion of innocence and blamelessness is not able to take into account the complexities of women's experiences. As well as this, almost all of the 29 participants had to cooperate with their traffickers/employers at some point. In the case of Nisa and Fon, they had to cooperate with their traffickers and obey their traffickers even though they realised that they were deceived to work in the sex trade. This does not in any way render them docile (Brennan, 2016), guilty or culpable for the trafficking crime. Instead, their cooperation was meant to avoid them from being harmed by their traffickers (Brennan, 2016). As well as this, the depiction of a young virginal woman as an 'ideal victim of trafficking' (Doezema, 1996) does not fit with the findings of this research as women's ages in this study ranged from 18 to 44 years at the time of interview. This is because blame is often wrapped around ideas of sexual respectability and ideas of innocence. Women were either married, divorced, widowed or had children to look after (see Chapter Six). Trafficking occurs regardless of women's relationship status or 'chastity'. Furthermore, the findings of this study also show that women were patronised by men regardless of their relationship status.

Based on the above discussions, the thesis argues that the use of the 'ideal victim' concept is perpetuated through many anti-trafficking campaigns and narratives ( $O^{\prime}$ Brien, 2013). These 'can act as a significant hindrance to attempts to combat trafficking, by misrepresenting the nature of the problem' (O'Brien, 2013, p. 2). This is because experiences of migrant women are far more complicated than is presented in the literature, human trafficking campaign awareness and the media. Migrant women are independent individuals who are able to confront extreme circumstances and do not necessarily want to be rescued and sheltered by the state. However, given that media (newspapers, magazines and television) are the main source of information for the majority of the population (Muraszkiewicz, Georgiou, \& Constantinou, 2014), images portraying trafficked women as weak, passive, vulnerable, and in need of state protection have become the stereotypical image of a trafficked woman in Malaysia. Such depiction serves as a basis for public to (mis)interpret the reality of trafficking and make certain judgments that do not adequately reflect the lived experiences of trafficked 
women. While women are expected to fulfil their roles and duties as a carer and breadwinner for the family, their decisions to engage in sex work are not viewed as 'normal' but deviant, irrational, immoral and illegal (M. Lee, 2007; Marmo \& Forgia, 2008). Given this, women's decisions to engage in sex work are subject to scrutiny, particularly as state authorities do not believe that women are capable of consenting to sex work (see Chapter Three). Because women rarely fit into the ideal script, they are then represented and responded to as risks/threats. It is either ideal victims status or criminalisation and punishment As a result, women are denied their agency and continue to be harmed by the state.

\section{Impact on global sex trafficking}

The dualistic approach taken by the state on migrant sex workers as 'victims to be saved' but also showcasing them as overly sexual, deviant and promiscuous has only reinforced stigma, racism and blame of women (Desyllas, 2007). It has also led to criminalisation and punishment of migrant sex workers. This is evident through the use of terms such as 'sex slaves', which are used together with the terms 'prostitute' or 'illegal immigrants' to blur the understanding of trafficking (see Chapter Four). In this instance, the media plays a major role in the construction of images that reinforce power hierarchies (Desyllas, 2007). Journalists can portray migrant sex workers as 'preying on men' (see Chapter Four) or present women as 'victims' of male violence (Kempadoo, 2001). However, they fail to take into account that many women migrate out of their own free will and with the intention to work and earn an income. As a result, the difference between trafficking and voluntary migration becomes blurry, and women's voluntary migratory movement is often associated with trafficking (Kapur, 2005).

The international pressure faced by Malaysia through the US Tier Ranking has resulted in massive raids and rescue. The implementation of ATIP and other laws and policies have penalised and criminalised migrant women who are engaged in sex work. By implementing anti-trafficking measures, governments can isolate, stigmatise, marginalise and criminalise sex workers and migrants on the grounds of security (Murray, 2014; Wijers, 2001). Although 
international laws ${ }^{93}$ are meant to protect and improve the status of women's conditions and rights, migrant sex workers women in particular are still denied their basic rights by state agencies because they are not regarded as rational and competent individuals. In various instances, domestic laws such as the ATIP, the Immigration Act and the Criminal Procedure Code frequently overlook the voice and rights of women. Thus, there has been a significant lapse in the functioning of government agencies to ensure these rights.

Apart from the above, it is to be noted that many countries strategically choose to focus on prevention of human trafficking instead of victim protection because prevention simply uses existing resources (Cho \& Vadlamannati, 2012). The United States, for example, establishes 'a sanctions regime authorising the President to withdraw U.S. (and certain multilateral) nontrade-related, non-humanitarian financial assistance from countries deemed not sufficiently compliant with the US government's 'minimum standards for the elimination of trafficking' (Chuang, 2006b, p. 439). In this context, the United States focuses its sanctions on the sending country, that is, those countries that have a lower GDP, without focusing on the receiving and destination countries or those countries with higher GDPs (Chuang, 2006). This results in economic disparities and the abuse of power by rich nations to developing nations (Ibid). Traffickers take advantage of such situations and exploit women for profits while women only receive meagre wages (S. Sen, 2005). Similarly in Malaysia, The US Tier Ranking has encouraged the police and immigration to embark on a massive crackdown on trafficking activities, but such responses do not address the underlying reasons for trafficking. Therefore, anti-trafficking advocates in Malaysia such as Tenaganita have often sought to target the root causes of trafficking through broader rights protections. This includes states' obligations under international human rights law to act with due diligence to prevent, investigate, punish, and protect trafficked victims against human rights violations. According to Tenaganita, factors such as cheating and unfair practices by agents (including those appointed by the immigration department), corrupt immigration personnel, irresponsible employers who do not ensure proper documentation for their migrant workers, and police officers will need to be addressed in order to effectively address human trafficking issues.

\footnotetext{
93 The Universal Declaration of Human Rights (UDHR) and the United Nations Convention on the Elimination of all forms of Discrimination Against Women (CEDAW) which seeks to ensure that women's rights are protected.
} 


\section{Recommendations}

Kempadoo (2001, p. 33) points out that 'criminalisation and stigmatisation ensure poor working conditions'. Therefore, sex work should be decriminalised to allow women in the sex industry to claim labour rights and insist on safe working conditions. In this regard, proper laws need to be enacted to ensure safer working conditions. However, this might be rather difficult to achieve given the Muslim majority population in Malaysia. At present, migrant sex workers are presented in derogatory terms (Weitzer, 2018) and often thought to be a risk to the state and society. Based on the arguments above, the thesis sets forth seven recommendations to improve its victim protection policies towards women who are categorised as trafficked. They are: the acknowledgement that migrant women are not offenders; the clarity of the trafficking definition; proactive efforts at the border; granting temporary visa to work; educating government officials; revamp the way migrant women are represented in the media; and decriminalise sex work.

First, to acknowledge the fact that migrant women are not offenders and should not be treated as criminals or processed as offenders. Although the Malaysian government has incorporated the Palermo Protocol into the ATIP, it has not adhered to most of the guidelines stated in the Recommended Principles and Guidelines on Human Rights and Human Trafficking. Incorporating and enforcing these guidelines could provide better support and assistance to women. This includes providing interpreters and translation services, counselling, medical care, legal advice and the option for women to choose if they want to live in the shelter or otherwise. Efforts should also be made to raise awareness among women about their rights while in state custody. Therefore, state authorities need to develop a comprehensive human rights approach when dealing with women.

Second, the definition of trafficking needs to be amended to clarify any ambiguities and uncertainty of the meaning of trafficking. At present the element of 'coercion' and 'exploitation' is subject to individual interpretation. Therefore, there do not seem to be clear guidelines on how coercion and exploitation are assessed by state officials. This has given the police and immigration wide discretionary powers to identify trafficked victims. Given this, state officials often conflate voluntary sex work and trafficked sex work. Such conflation not 
only victimises the women, but may also affect the prosecution's case in court because misidentification of victims may harm victims and they may be reluctant to testify in court. Furthermore, labelling all migrant sex workers as victims of trafficking effectively makes it impossible for sex workers to take a pro-active role in addressing human trafficking in the sex industry (Empower Foundation, 2012) because all sex workers will be at risk of being 'detained' or 'rescued'.

Third, it would be useful to place pamphlets and illustration of human trafficking at all border entry and exit points to create awareness among migrant women. This is because migrant women may not know their rights and may not understand the Malay language. Social clubs and groups such as Rotary Clubs and Neighbourhood Watch groups could also assist by creating campaign and awareness about human trafficking among their members and communities. This is because some establishments that employ migrant women are located in suburban areas as well as residential areas. Therefore, the awareness on trafficking would be useful in the event that women needed help and advice from the local community. These proactive efforts could let women recognise the signs that they might be trafficked and community groups could assist the women in getting help.

Fourth, to consider granting women temporary visas and the right to work and reside outside the shelter without any bureaucratic delay or supervision. This would not only reduce the overcrowding in the shelter but also give the opportunity for women to work and support their families. The granting of T-visas, for example, has been implemented in New Zealand, Australia, and the United States. This type of visa provides relief to immigrant victims of human trafficking by allowing them to stay and work in the country (Phillips, 2008).

Fifth, to educate government officials about the need to treat women with care, respect and dignity. Courses should include information about trafficking, the law, legal advice, medical aid, as well as the Ten Guiding Principles by WHO. More importantly, officers should be taught to respect women's rights and offer women the necessary advice regarding court processes, visa and work. Courses on human trafficking and handling victims should be provided to first responders and officials who are in contact with migrant women. These courses should 
include the participation of NGOs, as their involvement could assist the state officials in understanding women's needs.

Sixth, to revamp the current approach on how migrant women are presented in the newspapers and television. This is because the media serves as an authentic source of information and most people perceive the media as reliable and trustworthy (Suppiah et al., 2019). Therefore, the language of the journalists should be impartial and reflect the reality of women's experiences instead of portraying them as weak and helpless individuals that pose as a risk to society.

Seventh, to decriminalise sex work. This would, however, be difficult to do given the sentiment and religious belief towards sex work in Malaysia. However, the decriminalisation of sex work allows sex workers to work more safely, thereby reducing marginalisation and vulnerability (Albright \& D'Adamo, 2017). Decriminalisation can also help destigmatise sex work and help resist political, social, and cultural marginalisation of sex workers. This is opposed to criminalisation of sex work which leads to 'violence; police harassment; increased HIV and sexual transmitted disease risk; reduced access to services; psychological disease; drug use; poor self-esteem; loss of family and friends; work-related mortality; and restrictions on travel, employment, housing, and parenting' (Rekart, 2005, p. 2). In this context, the 'New Zealand Model' could be explored as New Zealand aims to uphold the human rights of sex workers and to decriminalise sex work (New Zealand Prostitutes Collective, n.d). Although decriminalisation does arguably provide a layer of protection against trafficking and other exploitative practices through the provision of rights, it should not be taken as a measure that will prevent these practices, since exploitation occurs in a range of work contexts that are not against the law. Furthermore, as this thesis has highlighted, criminal law is used to manage and control sex work, to reinforce other policies, such as immigration and border control, and 'to appear to be doing something about the "problem" of sex work without providing rights to sex workers' (Graham, 2017, p. 201). By framing sex work as an issue of crime, with migrant sex workers being both the perpetrators of crime and the potential victims of exploitative crime, the state is able to legitimise its actions against migrant sex workers, while ignoring the harm done to migrant sex workers by the state (Graham, 2017). Therefore, decriminalisation of sex work is important in ensuring that women are given the rights to work in safer 
conditions. Although the suggestion to decriminalise sex work is bound to be resisted by politicians and the larger public, efforts can be made to study how decriminalisation of sex work has worked in other countries so that steps can be taken to remove laws that criminalise sex work in Malaysia.

\section{Conclusion}

From the scholarly literature and findings of the study, it is apparent that most women migrate and engage in sex work to improve their financial situation and support their family. Many are breadwinners and strive to do what they can to assist their families in order to provide a better quality of life. However, trafficked women are often misunderstood and presented as individuals who are passive, vulnerable and deprived of agency. Such stereotypical images of trafficked victims are fictitious and unrealistic. Therefore, the findings of this study rebut the stereotypical images of an 'ideal victim' and assert that those images are untrue because they do not reflect the reality of women's trafficking experiences. Instead, the findings have shown that women are active transnational migrant subjects who are able to make rational decisions to migrate and work.

The discussion in this chapter has also highlighted how the women in this study were silenced and harmed throughout their migration experience. Despite the obstacles and barriers women face, women were determined to escape poverty and support their family. However, their actions or inactions do not necessarily mean that they were unaware of their present situation. Instead, they were quick to engage in strategies that could benefit them. This shows how women were able to exercise their agency even when they were being victimised. Thus, the thesis reiterates that migrant women who are categorised as trafficked are ordinary individuals who are able to make their own decisions. 


\section{Chapter Nine: Conclusion}

\section{Introduction}

The reported scale of sex trafficking is highly politicised and inflated figures are often used to justify policies which result in criminalisation or other adverse consequence for sex workers. This is because of the ambiguity in the definition of 'human trafficking' as a result of strong disagreement during the Protocol negotiations over the legitimacy of sex work (Gallagher, 2001). Nonetheless, sex trafficking is a significant problem and a crime that has been growing exponentially over the past few decades because of the opportunity for traffickers, agents and employers to gain lucrative profits (Salt, 2000; Salt \& Stein, 1997). Victims, mostly women and children, are deprived of their normal lives and compelled to provide sexual services (or sometimes labour), through a variety of coercive practices, all to directly profit others. In many cases, victims of trafficking are presumed to be deprived of agency and the ability to exercise their choice to migrate and work voluntarily in the sex trade.

However, based on the stories of 29 women in this study, it is evident that agency exists in relationship to women's victimisation. Even when women were trafficked (or presumed to be trafficked by the state), they retained their ability to challenge the structures or people who might be working against them. They demonstrated agency in understanding their identity, decision making, and actions. They also had the capacity to construct choices and navigate through difficult conditions and seek to increase their power over their own situations. Although they were eager to improve their economic situations, they took necessary precautions in guarding their personal safety and exercised certain strategies to minimise harms.

Therefore, depictions of an 'ideal victim of trafficking' as passive and in need of state rescue is not only inaccurate but also oversimplifies the problem of human trafficking. Thus, the discussions in the previous chapters have challenged such depictions and demonstrated that women did not want to be rescued and protected in the manner that has been carried out by 
the state. Instead many of them are also economic migrants who wish to secure their futures in safe and worthwhile ways.

\section{Addressing the Push and Pull Factors of Trafficking}

While the legal framework addresses trafficking as an act (or a series of acts) of violence, with the perpetrators to be punished and the victims to be protected, the broader causes of trafficking, such as poverty and socio-economic conditions, tend to be overlooked (Chuang, 2006a). This includes the 'push' factors such as unemployment, low wages, lack of opportunities, gender disparities, ideologies, geopolitics, politics and culture as well as the 'pull' factors such as demand, corruption, higher wages, and poor enforcement of the law (Newman \& Cameron, 2008; Sereni \& Baker, 2018). Prayag \& Ryan (2011) argue that the push and pull factors are inter-related, and they cause many individuals (particularly women) to be coerced and deceived by the traffickers. Strategies to reduce trafficking should include activities known to reduce those 'push and pull' factors. Thus, alongside the focused recommendations outlined in the previous chapter, there is a requirement to implement measures to reduce governmental corruption in both origin and destination countries, to embed population control measures, to work towards poverty reduction, and to tackle international inequalities in wealth (Bales, 2007; Nikolic-Ristanovic, 2002).

However, Dann (1977, p. 186) argues that 'analytically and often both logically and temporally, push factors precede pull factors'. In this context, Sereni \& Baker (2018) contend that women are more affected by the 'push' factors (lack of opportunities, discrimination and social exclusion) than are men, which makes women vulnerable to exploitation. This reiterates the fact that women are often excluded from legal migration routes on account of their structural disadvantage. Furthermore, the International Labour Organization reports that 70 percent of the 25 million people globally in forced labour are women (Sereni \& Baker (2018). As such, understanding the underlying causes of exploitation, the factors that render women vulnerable to exploitation, and how these situations of vulnerability occur, as well as gaps in regulation and enforcement, is vital to prevent exploitation effectively (Ibid). 
However, there are no substantial efforts from the state agencies to understand these complexities or address them.

While the above discussions have highlighted the significance of the push and pull factors, one important factor that sustains the trafficking activities throughout the globe is the demand and supply of women in the sex industry (Hotaling \& Levitas-Martin, 2002; Lagon, 2007). The demand for women, particularly in developing nations and in cities, has encouraged the growth of accessible sex markets, where there is a large demand for foreign and exotic women, as a new source of sexual stimulation (Levenkron \& Dahan, 2003). The stereotypes of Asian women in particular as 'exotic and erotic' (Kempadoo, 2001) has fuelled the demand for Asian women to enter the sex trade, which further inflates the demand for trafficking (Cwikel \& Hoban, 2005). According to Hotaling \& Levitas-Martin (2002), the demand is fuelled by men of all colours, races, cultures, educational, and socio-economic backgrounds, who learnt or were socialised to think that they have a right to sexual services.

According to Hotaling and Levitas-Martin (2002, p. 119), the recruitment into sex work flourishes in proportion to an increased demand, and the demand for women and girls increases due to a variety and combination of factors including:

Accessibility to and promotion of the multi-billion dollar sex industry; relaxed social norms concerning the sex industry; profitability for individuals, organised groups, and governments (estimated to be between seven and twelve billion dollars annually); non-existent, weak, or uninforced legal interventions combating trafficking; criminal justice systems that focus on arresting and prosecuting women and girls involved in sex work but not their male customers; educational systems that lack interventions promoting equality between girls and boys/men and women and decrease misogyny; learned exploitation and violence; lack of adequate sex education in schools; collusion and among the exploiters.

Given the lucrative nature of this crime, anti-trafficking advocates suggest that efforts to stop human trafficking should focus more on those who supply victims while others insist that 
emphasis should be placed on those who demand and purchase women (Lagon, 2007; Levenkron \& Dahan, 2003). In both circumstances, women are removed from the conversation in terms of authority and do not have the right to make their own choices. Thus, women's voices remain unheard and their wishes to improve their economic status are trivialised and not given adequate attention.

\section{Addressing Trafficking Harms}

The traditional depiction of an 'ideal' trafficker or pimp is represented through a male figure who is violent and relentlessly brutal while the 'ideal' victim is represented through images of women who are weak, vulnerable, naive and powerless (Baker, 2014). Such representations demonstrate that human trafficking is predominantly represented as a crime committed by stereotyped notions of 'ideal' offenders against 'idealised' victims (Wilson \& O'Brien, 2016). However, this research has shown that women are recruited into the sex trade through various means and many continue to work despite the harms they experience because they need the money to support themselves and their families. While recruitment techniques vary, traffickers frequently target emotionally vulnerable and/or economically desperate women (UN.Gift, 2008). In some cases, traffickers seek to foster trust and dependency by feigning love or friendship (as in this study) (Toney-Butler \& Mittel, 2019). The response to these techniques is often complicated by what a woman may come to perceive as 'a unique and interdependent alliance where her pimp is an integral part of her social network and often her security system' (Faugier \& Sergeant, 1997, p. 123). In other words, traffickers and pimps pose as protectors to gain the trust of the women and women may continue to see them as protectors, even if they are exploited. In other cases, traffickers use overt acts of physical, sexual and psychological abuse (UN.Gift, 2008) to ensure women remain obedient to them. Some of the tactics include beatings, confiscation of documents, restraint of movement, threat and non-payment of wages.

In most instances, the understanding of trafficking harms is mostly concentrated during the trafficking process while the post-trafficking harms are ignored or thought to be non-existent. The women's experience of harm during detention is not acknowledged and recognised by 
the state because there is an assumption that women are adequately protected and assisted in the shelters (Caneppele \& Mancuso, 2013). This stems from the common (mis)belief that women are eager to be rescued from their workplace and that states are configured as masculine protectors of women (Soderlund, 2005). Such beliefs ultimately cast women as victims in need of protection from harm rather than individuals who deserve to be treated as capable adults and accorded their rights (Ibid). The stance taken by the state emphasises protection over autonomy and empowerment (Ibid). As a consequence, women's plight and experience of harm in state custody is ignored and not acknowledged. Therefore, the thesis argues that current policies and practices represent a continuing form of violence against migrant women in Malaysia and that 'state protection' needs to take into account women's 'agent' identities.

\section{The Three Ps}

Legal responses to the trafficking typically adopt a three-prong framework focusing on the three Ps: prosecution, protection, and prevention (Chuang, 2006a). Despite the stated mission, there remains a disconnect between the three goals as policymakers, law enforcement agencies, and non-governmental organisations that provide services to victims try to achieve their preferred individual missions (Sheldon-Sherman, 2012).

Although the prosecution and protection of victims are equally important, the Malaysian government is more focused on prosecuting the traffickers because human trafficking is considered to be a threat to national security (Mattar, 2006; Suppiah \& Kaur, 2018). Furthermore, prosecution is thought to be an effective strategy to prevent trafficking. There is also an assumption that women will collaborate with the law enforcement authorities and be eager to give relevant information on their offenders (Kelly, 2005). Based on the above aims, law enforcement agencies aggressively conduct raid and rescue operations to interrupt the trafficking activities. However, such acts may not be something women wanted or necessarily relieve them from their misery. For many women (as this study has shown), 'they are not "rescued" from their situation, but are "captured" by the authorities' (Pearson \& AntiSlavery International, 2002, p. 33). In this instance, the police and immigration may not be regarded as saviours, but oppressors (Ibid). This shows that the women may not always 
behave in the ways which officials would like them to. Furthermore, the act of 'rescue' and 'protect' have been viewed as a punishment or detention for many women. This is because women are incarcerated in shelters for months and are subjected to multiple rules and regulations that are similar to prison rules.

Although the state has amended its anti-trafficking laws by allowing women to work and reside outside the shelter (The Straits Times, 2014; U.S Department of State, 2018), in reality this does not happen, and women are still subject to strict rules and regulations and remain detained in the shelters. This goes against Guideline 1 of the Recommended Principles and Guidelines of Human Rights and Human Trafficking which stipulates that 'the human rights of trafficked persons shall be at the centre of all efforts to prevent and combat trafficking and to protect, assist and provide redress to victims'. Thus, current efforts to address and improve the victim protection framework need to accommodate women's needs and ensure that state protection would not harm them.

\section{Addressing the Weaknesses of Anti-trafficking Laws}

This study has shown that the ATIP has victimised women and failed to effectively protect women for two main reasons. Firstly, there is a lack of understanding of the definitions of 'trafficking', 'coercion' and 'exploitation'. Although these terms are explained in the ATIP (which is adopted from the Palermo Protocol), they are rather vague and are subject to various interpretation. Therefore, these terms ('coercion' and 'exploitation') are highly influenced by culture, religion and social practices (see Chapter Two). As a result, the interpretation of trafficking becomes blurry and indefinite, not least the uncertainty of the trafficking definition appears to have contributed to the conflation between voluntary sex work and trafficked sex work. In this regard, the trafficking definition becomes a doubleedged sword which can convert a non-trafficked victim into a sex-trafficked victim and vice versa. Therefore, there is an apparent gap between the law and trafficking discourse, and the events that are happening on the ground.

The second major issue that needs to be addressed is the failure of state agencies to respect women's agency or to implement certain provisions in the ATIP, such as freedom of 
movement, freedom of residency, or freedom to work. At present, those who intend to work and are given the freedom of movement will need to satisfy the strict requirements imposed by the state. Such requirements violate the Recommended Principles and Guidelines of Human Rights and Human Trafficking which stipulates that all human beings are to be treated equally in dignity and with rights. Therefore, to be effective, victim protection policies must take into account the feelings of women, the reasons for their migration, the impact of victimisation, and the assistance they need (Bernat \& Winkeller, 2011).

Aside from the criminal activities that are carried out by traffickers, human trafficking includes: immigration and migration concerns; economic inequality concerns; human rights as well as gender rights violations (Farrell \& Fahy, 2009). However, human trafficking is framed in the media only as a criminal activity or a transnational security threat (Ibid). Such framing of human trafficking has influenced policymakers and legislators to adopt less than helpful anti-trafficking responses, particularly responses focused on criminal justice system solutions (Austin \& Farrell, 2017). These criminal justice solutions have not been effective in combating human trafficking. Such framing does, however, elicit support from state governments so that simple solutions can be proposed (Chambliss, 1964; Charnysh, Lloyd, \& Simmons, 2015; Wilson \& O'Brien, 2016). However, this crime framing places a large amount of blame on 'deviant' individuals instead of on structural problems such as globalisation, migration conditions, the status of women, or poverty (Barnett, 2016; Chuang, 2014). These latter issues are much more complex and harder to address, and are less likely to resonate with the public compared to the simpler crime theme (Austin \& Farrell, 2017). Yet, studies have shown that structural problems such as poverty, social unrest, government corruption, population pressure, and the perception of opportunity (or lack thereof) are the determinants of trafficking. Unless and until these factors are adequately addressed, sex trafficking will continue to thrive.

Based on the discussions in the previous chapters, it is clear that the criminalisation of sex work in Malaysia affects how migrant sex workers are viewed and treated by the authorities. They are displayed as women who are weak, passive and powerless, but an overriding narrative is that they are women of ill-repute who pose a threat to societal values. Official responses revolve around perceptions that migrant women are risky and undeserving of 
protection or welfare. As a consequence, women are stigmatised and presumed to tarnish the image of the country. Their experiences of harms are considered to be inevitable and they are portrayed as deserving of victimisation. For appropriate actions to be taken to combat sex trafficking, the myths that misrepresent the 'trafficked victim' need to be corrected (Milivojevic \& Copic, 2010). The dichotomy of narratives (between Madonna and whore) between 'ideal victims' and security threat have created contradictory but damaging perspectives and actions towards those who are sexually trafficked. This results in state practices that (re)victimise women and deny women of their agency.

Although the Universal Declaration of Human Rights stipulates that all human beings are to be treated equally in dignity and rights, many women continue to struggle daily to have their most basic rights protected. This includes the right to make their own decisions, the right to be heard, the right to refuse, and the right to freedom of movement. International conventions such as the Universal Declaration of Human Rights and Convention on the Elimination of All Forms of Discrimination against Women which are meant to protect and preserve women's rights have not been able to supersede the patriarchal influences contained in cultures, religions and social practices in Malaysia. This reflects a locallyembedded patriarchal culture that sustains prejudiced, gendered and racialised relations of power and morality. In this regard, the state controls women and decides matters according to its beliefs, even if it violates women's rights. The notion of combating trafficking and protecting victims has been, and still is, used to justify the state's intervention in women's lives, while the real purpose is to 'protect' the state from illegal migrants and migrant sex workers (Demleitner, 2001; Doezema, 2000). Thus, the agenda of the Malaysian government stretches beyond protecting women from trafficking into using law enforcement strategies to control women and combat all forms of sex work in the name of victim protection. Therefore, it is imperative to analyse the effectiveness of the anti-trafficking laws and understand the definition of trafficking as contained in international and domestic legislations in order to combat human trafficking activities. This will be a good and promising start to improve the anti-trafficking legislation and victim-protection policies. Thus, a better anti-trafficking framework would enable the Malaysian government to develop the tools and responses necessary to curb and prevent sex trafficking. More importantly, this thesis argues that trafficked women are not individuals who are weak, powerless and lack agency. Although they 
may have experienced victimisation while they were working, they are also agents who are capable of making their own decisions and can exercise strategies to navigate harms. Thus, the thesis ends by asserting that the dichotomy between 'victim' and 'agent' reinforces the fictitious image of an 'ideal' victim, as it does not reflect women's actual experiences and situation, and further undermines other individuals who have been victimised. 


\section{Appendix 1: Women Participants in Shelter 5}

\begin{tabular}{|c|c|c|c|c|}
\hline No & Name (Pseudonym) & Age & Nationality & Date of Interview \\
\hline 1 & Kim & 29 & Vietnam & 22 April 2016 \\
\hline 2 & Rima & 20 & Indonesia & 22 April 2016 \\
\hline 3 & Emi & 26 & Indonesia & 22 April2016 \\
\hline 4 & Putri & 31 & Indonesia & 23 April 2016 \\
\hline 5 & Liana & 25 & Indonesia & 23 April 2016 \\
\hline 6 & Musa & 29 & Thailand & 24 April 2016 \\
\hline 7 & Angel & 24 & Nigeria & 24 April 2016 \\
\hline 8 & Efa & 34 & Indonesia & 24 April 2016 \\
\hline 9 & Yolo & 24 & Vietnam & 25 April 2016 \\
\hline 10 & Le Heo & 23 & Vietnam & 25 April 2016 \\
\hline 11 & Ling & 20 & Vietnam & 25 April 2016 \\
\hline 12 & Hoar An & 19 & Vietnam & 26 April 2016 \\
\hline 13 & Muoi & 19 & Vietnam & 26 April 2016 \\
\hline 14 & Thuy & 26 & Vietnam & 26 April 2016 \\
\hline 15 & Tuyen & 36 & Vietnam & 26 April 2016 \\
\hline 16 & Hong & 24 & Vietnam & 28 April 2016 \\
\hline 17 & Ngoc & 29 & Vietnam & 28 April 2016 \\
\hline 18 & Hong Phan & 24 & Vietnam & 29 April 2016 \\
\hline 19 & $\mathrm{Da}$ & 25 & Vietnam & 29 April 2016 \\
\hline 20 & Nun & 28 & Thailand & 30 April 2016 \\
\hline 21 & Gena & 26 & Thailand & 30 April 2016 \\
\hline 22 & Fon & 26 & Myanmar & 30 April 2016 \\
\hline 23 & Mickey & 18 & Laos & 30 April 2016 \\
\hline 24 & Benz & 44 & Thailand & 30 April 2016 \\
\hline 25 & Nisa & 20 & Indonesia & 03 May 2016 \\
\hline 26 & Tammi & 18 & Indonesia & 03 May 2016 \\
\hline 27 & Mon & 27 & Bangladesh & 09 May 2016 \\
\hline 28 & Mei-Mei & 19 & Indonesia & 11 May 2016 \\
\hline 29 & Tang Mo & 41 & Thailand & 11 May 2016 \\
\hline
\end{tabular}




\section{Appendix 2: Questions for Woman Participants in the Shelter}

Hello, my name is Reena, and what name shall I call you?

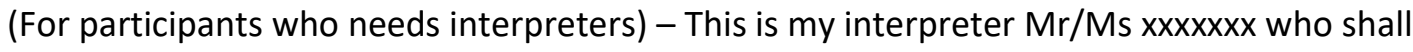
be interpreting the questions in your language. I will also like to inform you that whatever you say to the interpreter will remain confidential to him/her and my researcher team. Is that okay with you?

Have you read the Information Form?

Do you have any questions?

Do you consent to be interviewed?

Can you sign this?

Is it okay for me to interview you now?

How are you feeling? Have you had your breakfast/lunch?

As stated on the Information Sheet which has been explained to you, I am here to conduct a research on your migration experiences. Is that alright? Are there any questions you want to ask me before I start this interview?

I want to ask questions about how you came to be in this shelter. Going to start with your life in your home country and then progress through your different experiences to the present day. Is that okay with you? How long have you been living in the shelter?

What is your day like here? What are other people (women/wardens) like?

\section{Pre-trafficking and during trafficking period}

What was life like before coming to Malaysia?

Was it your intention to migrate to a foreign country for work? If so, how did you make that choice?

Was Malaysia your intended destination? Or did someone else make that decision? How did you feel about it?

Did you know anyone in Malaysia?

How did you feel when you had to leave your country to work?

How did you finance your trip to Malaysia? Did you pay a lot to travel to Malaysia?

How did you arrive into Malaysia? Can you tell me about your journey?

Did you travel alone? 
Can you tell me what happened after you arrived Malaysia?

Can you tell me about your life/working experience in Malaysia before coming to the shelter? How did you feel about it?

\section{Post-Trafficking Period}

Can you tell me about your encounter with the Malaysian authorities? Can you describe your experience with them?

Can you explain how you were arrested?

*(If the participant states that there was a raid, I will ask her to describe how it happened).

Do you know why you were arrested? How did you feel about it?

Do you know who was responsible for your arrest?

How were you treated?

How did it feel? Were you afraid? What were you afraid of?

Was there anyone else arrested with you? If yes, do you know what happened to them?

Can you tell me how you communicated with the police/immigration? Did you know what they said and what was happening?

- $\quad$ Can you tell me what happened after you were arrested?

- $\quad$ Can you describe your experience in police/immigration custody? What was it like and how were you treated?

- $\quad$ Did you know where you were?

How long were you there?

The authorities said that you were rescued during the raid, did you feel like you were rescued?

\section{Medical Process}

Have you been to the hospital/clinic while you are in custody? If so, why? Was it your decision?

- Can you describe your experience at the hospital/clinic? When and how did you get there? What was it like?

- $\quad$ Can you tell me about your experience with the doctor and nurses? How did you find them? Were you informed of any test/examination results? How did you feel about it? 


\section{Court Experience}

Have you been to the Malaysian Courts? If yes, do you know for what reasons?

Can you tell me about your experience in court?

Do you know which court you went to? Do you remember when?

Can you tell me how you went to court?

How did it feel when you arrived in court? Did you feel safe?

What did you do in court? What was it like?

How did you communicate with people in court?

Were you alone or with anyone else?

How long were you in court?

How did you find the people in the court? (Magistrate, police, interpreter) Did they treat you with respect?

How did you find your days in court?

Do you know what happened to your case?

Do you still need to go to court? Y/N? If yes, what have you heard about going to court? How do you feel about it?

\section{Shelter Life Experience}

I will ask you about your experiences living in the shelter. Your answers will remain confidential and I will not disclose any of the discussion held with the shelter warden or authorities. Are you okay with that?

Do you know why you are here?

What is it like living here? Do you have friends here?

Can you tell me about your experience when you first arrived to the shelter? How did it feel?

Was there anything you had to do when you first arrived here? Can you explain?

Did you know anyone here when you first arrived?

Are there any rules here? If so, can you briefly tell me about the rules here?

How do you find them?

What happens if you don't abide by the rules? What are the consequences? Any examples? How do you feel about it?

What is your relationship like with the warden and shelter staff? How do you find them? How do you communicate with them? 
Have you received any assistance here? (medical, legal, counselling) If so, what type of help did you receive and how often?

What other type of assistance do you need?

Has anyone visited you here? If yes, who were they? Were you happy with their visit? If no, how do you feel? Are you expecting anyone to visit you here? Who and why?

Do you know how long will you be here?

Are you happy living in the shelter? $\mathrm{Y} / \mathrm{N}-$ Why?

How do you perceive other women in the shelter? Do you see any differences?

The authorities say they have rescued you and saved you from a miserable life. So, do you think that's true? How do you view yourself?

\section{Future Repatriation}

Do you want to stay in Malaysia? Y/N - Why?

Are you looking forward to going back home? $\mathrm{Y} / \mathrm{N}-$ Why? Do you know when you will be sent home? $\mathrm{Y} / \mathrm{N}$ - If yes, can you tell me more about this? If no, can you tell me how you feel about this?

What do you intend to do when you return back home? What are your hopes for the future? Do you have any intentions to return to Malaysia?

Is there anything else you want to tell me before I end this interview?

\section{Personal Details}

Name (pseudonym):

Age:

Origin:

Address:

Status:

Do you have any children $(\mathrm{Y} / \mathrm{N})$ - If yes, how many? Ages?

Family Background: Father: (Name) Age: Profession:

Mother: (Name): Profession:

Siblings: Brother(s) .................

Sister(s)

Participant is child no.

Education Background: 


\section{Appendix 3: Professional Participants}

\begin{tabular}{|c|c|c|c|}
\hline No & Name & Designation & Date of Interview \\
\hline 1 & Jimrey a/k Hilary Chukan & $\begin{array}{l}\text { Enforcement Officer } \\
\text { Assistant Superintendant of Police } \\
\text { Anti-Trafficking in Persons Unit, Crime } \\
\text { Investigation Department (D7) Bukit } \\
\text { Aman, Kuala Lumpur }\end{array}$ & 21 April 2016 \\
\hline 2 & $\begin{array}{l}\text { Noor Aznida Binti Abdul } \\
\text { Hamid }\end{array}$ & $\begin{array}{l}\text { Protection Officer } \\
\text { Deputy Officer for Community } \\
\text { Development }\end{array}$ & $\begin{array}{l}27 \text { April } 2016 \text { and } \\
\text { continued interview on } \\
28 \text { April } 2016\end{array}$ \\
\hline 3 & Mawar & $\begin{array}{l}\text { Shelter Warden RP5 } \\
\text { Assistant Officer for Community } \\
\text { Development }\end{array}$ & 27 April 2016 \\
\hline 4 & Irmawaty Anida Ahmad Sani & $\begin{array}{l}\text { Protection Officer } \\
\text { Deputy Director, Department of } \\
\text { Women Affairs and Development }\end{array}$ & 28 April 2016 \\
\hline 5 & Ajanis Anak Ba-I & $\begin{array}{l}\text { Shelter Manager and Protection Officer } \\
\text { Department of Women Affairs and } \\
\text { Development }\end{array}$ & $\begin{array}{l}29 \text { April } 2016 \text { and } \\
\text { continued interview on } 5 \\
\text { May } 2016\end{array}$ \\
\hline 6 & Fatheen Erryanee Rosli & $\begin{array}{l}\text { Protection Officer } \\
\text { Assistant Director, Department of } \\
\text { Women Affairs and Development }\end{array}$ & 4 May 2016 \\
\hline 7 & Mohd Hanif bin Shukor & $\begin{array}{l}\text { Enforcement Officer } \\
\text { Inspector, Crime Investigation } \\
\text { Department, Serdang Police } \\
\text { Headquarters, Selangor }\end{array}$ & 4 May 2016 \\
\hline 8 & Shahrul Azlin bin Wahiduddin & $\begin{array}{l}\text { Enforcement Officer } \\
\text { Deputy Assistant Director of } \\
\text { Immigration II, Enforcement } \\
\text { Department, Immigration } \\
\text { Headquarters, Putrajaya }\end{array}$ & 6 May 2016 \\
\hline 9 & $\begin{array}{l}\text { Aida Noraziyanty Binti Mohd } \\
\text { Mustafa Kamal }\end{array}$ & $\begin{array}{l}\text { Protection Officer } \\
\text { Administration Assistant, RP5 }\end{array}$ & 10 May 2016 \\
\hline 10 & $\begin{array}{l}\text { Mohd Norhazly Mohamed } \\
\text { Nawi }\end{array}$ & $\begin{array}{l}\text { Enforcement Officer } \\
\text { Inspector, Crime Investigation } \\
\text { Department, Gurun Police } \\
\text { Headquarters, Kedah } \\
\end{array}$ & 11 May 2016 \\
\hline 11 & Tharini Cecil a/p Arunasalam & $\begin{array}{l}\text { NGO representative } \\
\text { Project Coordinator, Suka Society, } \\
\text { Petaling Jaya }\end{array}$ & 13 May 2016 \\
\hline 12 & Lalli & $\begin{array}{l}\text { Shelter Warden RP5 } \\
\text { Assistant Officer for Community } \\
\text { Development }\end{array}$ & 13 May 2016 \\
\hline
\end{tabular}




\section{Appendix 4: Interview Questions (Professionals)}

May I have your full name please:

Name of Govt Dept/Designation:

Can you tell me about your professional background/history?

What is your current job? Can you describe the nature of your work?

Can you tell me your role as a xxxxx?

- (For Protection Officers) Why are you called the Protection Officer? Who do you protect? (Trafficked women? State?).

How does your organisation view the issue of sex trafficking? How severe is the problem in Malaysia?

Does your organisation collate information about trafficked women?

- Can you describe/tell me more about the women?

- Who are they and where are they from?

- How did they get here?

o What type of work were they involved in? How did they end up in this situation?

O Who did they work for? Who took care of them?

- What is the role of your organization?

How does your organisation distinguish between trafficked women and other women who migrate to Malaysia for work purpose? Differences in terminology? Differences in approach?

- Do you think that trafficked women have broken the law? What is their legal status before and after being rescued?

\section{Policy Framework}

Can you tell me about your organisation's policies in dealing with trafficked women? Are there any standard guidelines?

- $\quad$ How were these policies developed?

- What do these policies intend to do? Are they focused on crime control? Focused on rescuing women? Alleviating harm to women? Something else? 
- Does your organisation work closely with any other departments/agencies on this issue?

- What is the nature of these relationships/practices? Do all these groups have the same focus in how they view or attend to trafficked women? If not, how do they differ?

\section{Organisation's Practices}

- What is your organisation's role in dealing with trafficked women? Nature of engagement? (e.g., involved in initial arrests; processing; detention and shelters; deportation?).

- How are trafficked women identified by your organisation?

- Does the Ministry communicate with trafficked women? If so, how? How do you get beyond language barriers?

- What do trafficked women tell you about their experiences? Do you think others (public; politicians; media; other agencies) understand these experiences?

- Does religion/moral values play a role in the organisation's policies and practices? How?

\section{If Involved In Arrests:}

How are the raid and rescue operations conducted? By who, what happens? How are the women treated in these operations by police/immigration services? Is it an arrest or a rescue?

- I've noticed that these raids are often shown on TV/newspaper. Does your organisation have a view on this media coverage?

- $\quad$ After initial arrest, what happens to the women? How are they processed? Are they detained (if so, where?) What is your perspective on how they are treated?

- How long will they remain in Malaysia after the arrest? What happens after that?

- What impact have these raid and rescue operations had? (e.g., succeeded in deterring or reducing sex trafficking activities?)

\section{Operations of the Shelter}

- Can you tell me about the shelters in Malaysia?

- How many are there and where are they located? Who runs them? 
- Can you tell me about RP5 shelter?

- Can you describe the facilities available to the women in the shelter? Does everyone have access to the facilities?

- Can you describe the infrastructure of the shelter?

- Who occupies these shelter?

- How did they get to be in the shelter? What are the procedures involved?

○ How long will they stay in the shelter?

- What happens to women in there? Medical Checks? Activities? Assistance? Legal advice?

- What happens to them after that?

- Are they allowed to leave the shelter during the Protection Order? Y/N? Why?

- Do you make visits to the shelter? For what purpose? Do you monitor conditions and treatment of women? Are the shelters monitored by any other agencies? Can I access any related reports?

- What is your organisation's view on how women are treated in shelters?

- Do you instil religious/moral values to the women who are in the shelter? If so, why?

- I understand that there is an NGO assisting you to deal with trafficked women in the shelter? Who are they and why do you require their assistance? What do they do?

- What is your organisation's view on the use of shelters?

\section{On Trafficked Women in RP5 (for Shelter Manager, Shelter Officers, Wardens, Officer from the Ministry)}

- Can you tell me about the women in the shelter?

- How do you communicate with them? How do you overcome language barriers?

- How did they get to be in the shelter? What are the procedures involved? Who brought them to the shelter?

- How long will they be here?

- What happens to them after that?

- What is your perception of them? (Victims? Survivors? Offenders?) Why?

- Have you encountered any problems with the women? If so, what are they?

- Do you know of any common problems faced by them? How do you deal with it?

- How is your relationship with the women in the shelter? How do you deal with it? 


\section{Legal/Court Processes}

- Do you give legal advice, or prepare legal documents/report for the women? If so, can you explain further? Are you required to be a witness in court? (e.g., witness protection officer). How do you feel about it?

- How do the courts treat trafficked women? Can you tell me about a recent case?

- $\quad$ Are women viewed as witnesses, victims, or offenders, in the court room?

\section{Repatriation}

- Who makes the decision for repatriation?

- Can you tell me about the repatriation process?

- Do they have any right to appeal? Does the organisation think that they should be repatriated?

\section{Conclusion}

- Do you think current practices of your organisation serves the interests of trafficked women? If not, how/why not?

- Do you think current practices by other organisations serve their interests? If not, how/why not?

- What do you think of the Tier Two Watch List ranking given by the US Department of State on the current situation of human trafficking and victim protection in Malaysia?

- What do you think needs to be improved?

- At present, the shelters are under the control of the Ministry of Women, Family and Community Development. What do you think of the proposed amendment of The AntiTrafficking Persons Act to allow shelters to be run by NGOs? Do you think it is an improvement to the present situation? Do you foresee any problems/issues?

- Is there anything else you want to tell me before I end this interview? 


\section{Appendix 5: Consent to Interview (Female Migrants)}

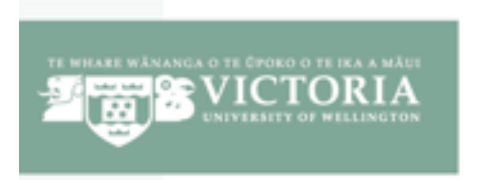

SCHOOL OF SOCIAL AND CULTURAL STUDIES

TE KURA MAHUNGA TANGATA

LEVEL 9, MURPHY BUILDING, KELBURN PARADE, KELBURN CAMPUS, WELLINGTON PO Box 600, Welington 6140, New Zealand

Phone + 64-4-4635317 Fax +64-4-4635064 Email sacs@ Quw. ac.nz Websitewnw.victoria.ac.nz/sacs

\section{CONSENT TO INTERVIEW (Female Migrants)}

\section{Research Project Title: Narratives of Female Migrants \\ Researcher: Haezreena Begum binti Abdul Hamid \\ Victoria University of Wellington, New Zealand}

- I have understood the Information Sheet and the project has been explained to me. My questions have been answered to my satisfaction. I understand that I can ask further questions at any time.

\section{I understand and agree to the following:}

- This interview will be audio/digitally recorded and notes will be taken during the interview.

- I am allowed to check, alter or make amendments to my statement at any point of time until the end of the interview.

- I may withdraw from this research at any time until the end of the interview on (.............../2016) by informing the researcher or the interpreter and any information that I have provided will be deleted or destroyed.

- Any information I provide will be kept confidential to the researcher, her two supervisors and the interpreter. All written, recorded and electronic information obtained from me shall be kept in a locked file and all electronic information will be password-protected and can only be accessed by the researcher and her supervisors. All audio recordings and interview scripts will be destroyed within three years of conclusion of the project. I understand that the results will be used for a PhD thesis. They may also be included in other academic articles or reports, conference presentations and publications. These outputs may be in English or Malay language.

- My name will not be used in reports, nor will any information identify me. A pseudonym of my choice will be used in all outputs.

- All information I have provided will be destroyed 3 years after the research is finished.

- I consent to information or opinions which I have given about myself being used for the research outputs:

Yes $\square \quad$ No $\square$

Signature of participant:

Name/Role of participant:

Preferred pseudonym:

|

Date: 


\title{
Consent to Interview (Professionals)
}

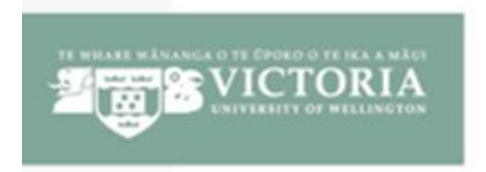

SCHOOL OF SOCLAL AND CULTURAL STUDIES

TE KURA MAHUNGA TANGATA

LEVEL 9, MURPHY BUILDANG, KEL BURN PARADE, KELBURN CAMAPUS, WELLINGTON

PO Box 600, Wellington 6140, New Zealand

Phone - 64-4-463 5317 Fax - 64-4-463 5064 Email sacsguuw. ac.nz

Webaitewrw. victoria.ac.nz/sacs

\section{CONSENT TO INTERVIEW (Professionals)}

\author{
Research Project Title: Narratives of Female Migrants \\ Researcher: Haezreena Begum binti Abdul Hamid \\ Victoria University of Wellington, New Zealand
}

- I have read the Information Sheet and the project has been explained to me. My questions have been answered to my satisfaction. I understand that I can ask further questions at any time.

I understand that:

- This interview will be audio/digitally recorded and notes will be taken during this interview.

- I am allowed to check, alter or make amendments to my statement at any point of time until the end of the interview.

- I may withdraw from this research at any time until the end of the interview (.............../2016) by informing the researcher and any information that I have provided will be deleted or destroyed.

- Any information I provide will be kept confidential to the researcher and her two supervisors. All written, recorded and electronic information obtained from me shall be kept in a locked file and all electronic information will be passwordprotected which may only be accessed by the researcher and her supervisors. All audio recordings and interview scripts will be destroyed within three years of conclusion of the project. I understand that the results will be used for a PhD thesis. They may also be included in other academic articles or reports, conference presentations and publications. These outputs may be in English or Malay.

- Unless I consent otherwise, my name will not be used in reports, nor will any information that would identify me, but my organisation may be named. In this instance a pseudonym of my choice shall be used or a role descriptor to describe my designation may be used.

- All information I have provided will be destroyed 3 years after the research is finished.

- I consent to my name being used in any outputs for this research:

- I would like a summary of the findings on completion:

Signature of participant:

Designation: 


\title{
Appendix 6: Information Sheets
}

\author{
UNIVERSITY LETTERHEAD \\ INFORMATION SHEET (Female Migrants) \\ Narratives of Female Migrants
}

Researcher: Haezreena Begum Binti Abdul Hamid

I am a PhD student in Criminology at Victoria University of Wellington, New Zealand. As part of this degree I am undertaking research that examines how female migrants think about their migration experiences. This research will analyse women's experience of being trafficked, rescued by the Malaysian authorities, detained in shelter-homes, their role as a witness in Court, and their hope for the future once they return to their home country. Your responses will be used to identify ways to upgrade and provide better care and protection services to help other women who have had similar experiences to you.

This research is an independent process and the discussions held between us will be treated with strict confidentiality and will have no impact on how you will be treated by the police, shelter wardens, government officers, $\mathrm{NGO}_{5}$ and the legal process.

This research project has received approval (Approval No. 21767) from the Victoria University Human Ethics Committee on 11 April 2016.

Invitation

I am inviting women in the shelter to participate in this research and you have been identified as someone with experiences in the area of my study. It will also provide an opportunity to give your own account on how you felt about your own migration experience which includes your experience with the police, legal and medical process, shelter, your immediate needs and expectations, and your hope for the future. Your identity will not be disclosed in the research and a pseudonym of your choice will be written in the thesis/report so that it will not be possible for you to be identified personally.

\section{What's involved?}

You will be interviewed by me with the assistance of an interpreter who will interpret the question and answers in the language you are able to understand and communicate. The interpreter will be fluent in your language and has been independently recruited by me for this study. With your permission, interviews will be digitally recorded and I may take further notes during the interview. You will be interviewed for one hour on your migration experiences.

Is this voluntary?

Yes, participation is voluntary. You are allowed to ask me or the interpreter any question at any time during the interview. You may take your time to answer the question or decline to answer any of the questions. You are allowed to end the interview at any time until the end of the interview. Should you feel the need to withdraw from the project, you may do so at any point of time until the end of the interview by informing me or the interpreter and no further questions or reasons need to be given.

\section{Is it confidential?}

Yes, your responses will remain confidential to the researcher, her supervisors and interpreter. No one from state authorities or the shelter will be able to access your interview data. All material collected will be kept confidential. No other person besides me, the interpreter, and my supervisors Dr Elizabeth Stanley and Dr Jan Jordan will see the interview scripts, notes or listen to the recording 
audio. All written material (which includes the information sheet, consent form, interview notes and all similar written materials) will be kept in a locked file; with access restricted to my supervisors, all electronic information will be password-protected; with access restricted to my supervisors. All audio recordings and interview scripts will be destroyed within three years of conclusion of the project.

The interview data will form the basis of a PhD thesis that will be marked by external scholars and deposited into the New Zealand's University library. I also intend to write one or more articles for publication in scholarly journals or books, and to present conference papers on the findings. In all of these outputs, your identity will not be disclosed. A pseudonym of your choice will be written in the report so that it will not be possible for you to be identified personally.

\section{If you want to find out more?}

If you have any further questions or would like to receive further information about the project, please email me at: Haezreena.Begum@vuw@ac.nz. You may also contact my supervisor Dr Elizabeth Stanley, Institute of Criminology, Victoria University, on +6444635338 (NZ landline) or email Elizabeth.Stanlev@vuw.ac.nz. For any ethical concerns, please contact A/Prof Susan Corbett, Chair of Human Ethics Committee at +644635480 (NZ landline) or email susan.corbettvuw.ac.nz.

Haezreena Begum Binti Abdul Ftamid 


\section{UNIVERSITY LETTERHEAD \\ INFORMation SHeEt (For Professionals) \\ Narratives of Female Migrants}

\section{Researcher: Haezreena Begum Binti Abdul Hamid}

I am a PhD student in Criminology at Victoria University of Wellington, New Zealand. As part of this degree I am undertaking research project that examines how female migrants think about their migration experiences. This research will analyse the women's experience of being trafficked, rescued by the Malaysian authorities, detaided in government run shelter-homes, their role as a witness in Court, and their hope for the future once they return to their home country. Your responses will be used to identify ways to upgrade and provide better care and protection services for migrant women who have been trafficked into Malaysia.

This research project has received ethics approval (Approval No. 21767) from the Victoria University Human Ethics Committee on 11 April 2016.

\section{Invitation}

I am inviting officials from the Malaysian Government Department/NGOs working with trafficked female migrants to participate in this study and you have been identified as someone who has experienced and/or knowledge in this subject matter. A pseudonym of your choice will be written in the report if you do not wish for your name to disclgsed and a role descriptor will be assigned to your name.

\section{What's involved?}

You will be interviewed by me in the Malay/English language. With your permission, interviews will be digitally recorded and I may take further notes during the interview. You will be interviewed for a duration of one hour on your experiences and knowledge of dealing with trafficked female migrants who has been exploited for sex work.

\section{Is this voluntary?}

Yes, participation is voluntary. You are allowed to ask me any question at any time during the interview. You may take your time to answer the question or decline to answer any of the questions. You are allowed to end the interview at any time until the end of the interview. Should you feel the need to withdraw from the project, you may do so at any point of time until the end of the interview by informing me and no further questions or reasons need to be given.

\section{Is it confidential?}

Yes, your responses will remain confidential to the researcher and her supervisors. No other person besides me and my supervisors Dr Elizabeth Stanley and Dr Jan Jordan will see the interview scripts, notes or listen to the recording audio. All written material (which includes the information sheet, consent form, interview notes and all similar written materials) will be kept in a locked file; with access restricted to my supervisors, all electronic information will be password-protected; with access restricted to my supervisors. All audio recordings and interview scripts will be destroyed within three years of conclusion of the project.

The interview data will form the basis of a PhD thesis that will be marked by external scholars and deposited into the New Zealand University library. I also intend to write one or more articles for 
publication in scholarly journals or books, and to present conference papers on the findings. In all of these outputs, your identity will not be disclosed. A pseudonym of your choice will be written in the report so that it will not be possible for you to be identified personally.

If you want to find out more?

If you have any further questions or would like to receive further information about the project, please email me at: Haezreena.Begum@vuw@ac.nz. You may also contact my supervisor Dr Elizabeth Stanley, Institute of Criminology, Victoria University, on +64 44635338 (NZ landline) or email Elizabeth.Stanley@vuw.ac.nz. For any ethical concerns, please contact A/Prof Susan Corbett, Chair of Human Ethics Committee at +644635480 (NZ landline) or email susan.corbettvuw.ac.nz.

Haezreena Begum Bint: Abdul Famid 


\section{Appendix 7: Confidentiality Agreement}

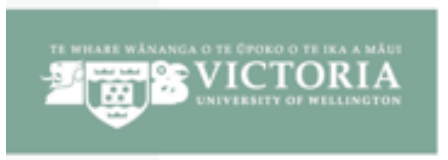

\section{Confidentiality Agreement}

Project Title: Narratives of Female Migrants

\section{Principal Investigator: Haezreena Begum Binti Abdul Hamid}

I, agree to ensure that the interviews held with the participants and audiotapes I interpret will remain confidential to Haezreena Begum Binti Abdul Hamid, her supervisors namely Dr Elizabeth Stanley and Dr Jan Jordan (collectively known as the "researcher team"), and myself.

I agree to take the following precautions:

1. I will ensure that no person, other than the researcher team and myself hears the recording.

2. I will not discuss any aspect of the recording with anyone except with Haezreena Begum Binti Abdul Hamid.

Signature of interpreter :

Name of interpreter

Date 


\section{Appendix 8: Ethics Approval Memorandum}

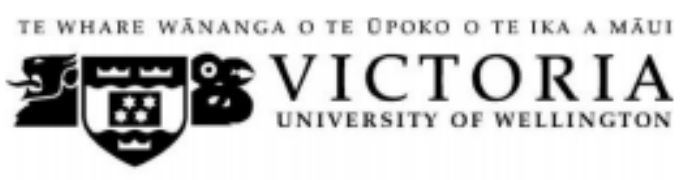
Phone $\quad 0-4-4635480$
Email susan.corbettøvuw.ac.nz

MEMORANDUM

\begin{tabular}{l|l}
\hline TO & Haezreena Begum Abdul Hamid \\
\hline COPY TO & \\
\hline FROM & AProf Susan Corbett, Convener, Human Ethics Committee \\
\hline DATE & 11 April 2016 \\
\hline PAGES & 1 \\
\hline SUBJECT & $\begin{array}{l}\text { Ethics Approval: 21767 } \\
\text { Narratives of Female Migrants }\end{array}$ \\
\hline
\end{tabular}

Thank you for your application for ethical approval, which has now been considered by the Standing Committee of the Human Ethics Committee.

Your application has been approved from the above date and this approval continues until 31 January 2018. If your data collection is not completed by this date you should apply to the Human Ethics Committee for an extension to this approval.

Best wishes with the research.

Kind regards

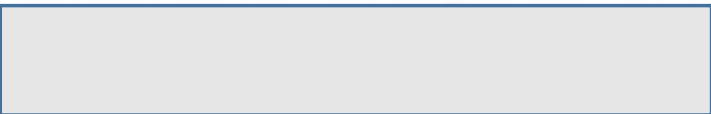

Susan Corbett

Convener, Victoria University Human Ethics Committee 


\section{Appendix 9: Categorisation of Women}

\begin{tabular}{|c|c|c|}
\hline Sex Work & Pseudonym & Total \\
\hline $\begin{array}{l}\text { Women who voluntarily engaged in sex work and did not indicate any form } \\
\text { of deception, coercion, harms or exploitation while working. } \\
\text { They could keep their passport, they could leave their workplace, and they } \\
\text { did not indicate any form of debt bondage or harm. They decided to } \\
\text { engage in sex work because they wanted to support their family. }\end{array}$ & $\begin{array}{c}\text { Benz } \\
\text { Musa } \\
\text { Nun } \\
\text { Gena } \\
\text { Tang Mo } \\
\text { Putri } \\
\text { Mickey } \\
\text { Hoar An } \\
\text { Hong } \\
\text { Kim } \\
\text { Ling } \\
\text { Le Heo } \\
\text { Muoi }\end{array}$ & 13 \\
\hline $\begin{array}{l}\text { Partial deception, coercion, harms and exploitation. } \\
\text { Women agreed to migrate and engage in sex work but were subject to } \\
\text { exploitative working conditions. This includes passport confiscation, debt } \\
\text { bondage, unable to leave their workplace, unpaid or underpaid wages. }\end{array}$ & $\begin{array}{c}\text { Hanny } \\
\text { Rima } \\
\text { Emi } \\
\text { Efa } \\
\text { Mei-Mei } \\
\text { Thuy } \\
\text { Yolo } \\
\text { Tuyen } \\
\text { Hong Phan }\end{array}$ & 9 \\
\hline $\begin{array}{l}\text { Total deception, coercion, harms and exploitation. } \\
\text { Women who were totally deceived about the nature of their work and had } \\
\text { their passport confiscated, debt bondage, unable to leave their workplace, } \\
\text { unpaid wages. They were angry that they were deceived by their friends } \\
\text { but chose to cooperate with the traffickers as a strategy to minimise harm. }\end{array}$ & $\begin{array}{l}\text { Ngoc } \\
\text { Fon }\end{array}$ & 2 \\
\hline $\begin{array}{l}\text { Total deception, coercion, exploitation, overt threats and harms. } \\
\text { Women who were totally deceived, threatened, harmed, had their } \\
\text { passport confiscated, debt bondage, unable to leave their workplace, } \\
\text { unpaid wages. They were continuously threatened and harmed by their } \\
\text { traffickers or customers. However, they chose to cooperate with their } \\
\text { employers as a strategy to avoid harm and danger to themselves and their } \\
\text { families. }\end{array}$ & $\begin{array}{c}\text { Tammi } \\
\text { Nisa } \\
\text { Angel }\end{array}$ & 3 \\
\hline & Total & 27 \\
\hline $\begin{array}{l}\text { Non-Sex Work } \\
\text { Partial deception, coercion, exploitation and harms. } \\
\text { Women who were deceived by work agent or employer and experienced } \\
\text { at least one of the following: passport confiscation, unpaid wages, or } \\
\text { unable to return home). }\end{array}$ & $\begin{array}{c}\mathrm{Da} \\
\text { Mon }\end{array}$ & 2 \\
\hline & Grand Total & 29 \\
\hline
\end{tabular}




\section{References}

Abdullah, K., Noor, N. M., \& Wok, S. (2008). The perception of women's roles and progress: A study of Malay women Social Indicators Research, 89(3), 439-455.

Abraye, E. (2014). The right to sexual self-determination is a myth. Juris Consult, 1(1), 1-10.

Abu-Odeh, L. (2010). Honor killing and the construction of gender in Arab societies. 58 Am. J. Comp. L, 1(911-952).

Adams, C. (2011). Re-trafficked victims: How a human rights approach can stop the cycle of re victimization of sex trafficking victims. Geo. Wash. Int'I L. Rev, 43(1), 201 - 234.

Agustin, L. M. (2005). Migrants in the mistress's house: Other voices in the "trafficking" debate. Social Politics: International Studies in Gender, State and Society, 12(1), 96-117.

Agustin, L. M. (2006). The disappearing of a migration category: Migrants who sell sex. Journal of Ethnic and Migration Studies, 32(1), 29-47.

Agustin, L. M. (2007). Sex at the margins: Migration, labour markets and the rescue Industry. New York: Zed Books.

Agustin, L. M. (2010). The (crying) need for different kinds of research. In M. Ditmore, A. Levy \& A. Willman (Eds.), Sex work matters (pp. 23-27). London: Zed Books.

Ahmed, A., \& Seshu, M. (2012). "We have the right not to be'rescued'..."*: When antitraffickingprogrammes undermine the health andwell-being of sex workers. Anti Trafficking Review, 1(1), 149-168.

Ahrens, C., Campbell, R., Ternier-Thames, N., Wasco, S., \& Sefl, T. (2007). Deciding whom to tell: Expectations and outcomes of rape survivors' first disclosures. Psychology of Women Quarterly, 31(1), 38-49.

Ajis, M. N. e., Askandar, K., \& Awang, S. (2015). International migration and human trafficking in Malaysia: A study on illegal immigrants. Asian Social Science, 11(25), 124-134.

Al-Sharmani, M. (2014). Islamic feminism: Transnational and national reflections. Approaching Religion, 4(2), 83-94.

Alamgir, A. (2014). Islam and women's rights: Discourses in Malaysia. Procedia-Social and Behavioral Sciences, 114(2), 872-876.

Albright, E., \& D'Adamo, K. (2017). Decreasing human trafficking through sex work decriminalization. AMA Journal of Ethics, 19(1), 122-126.

Aleinikoff, T. A., \& Klusmeyer, D. (2002). Citizenship policies for an age of migration. Washington, DC: Carnegie Endowment for International Peace.

Allen, C. (2004). The happy hooker? The British Journal of General Practice, 54(1), 504.

Altink, S. (1995). Stolen lives: Trading women into sex and slavery. London: Scarlet Press. 
Amir, M. (1971). Patterns in forcible rape. Chicago: University of Chicago Press.

Amirthalingam, K. (2005). Women's rights, international norms, and domestic violence: Asian perspectives. Human Rights Quarterly, 27(1), 683-708.

Andaya, B. W. (2001). Southeast asian studies: Gender. International Encyclopedia of the Social \& Behavioral Sciences, 1(1), 14676-14680.

Anderson, B., \& Davidson, O. C. (2003). Is trafficking in human beings demand driven? A multicountry pilot study. Geneva: International Organization for Migration.

Anderson, J. M. (2002). Toward a post-colonial feminist methodology in nursing research: Exploring the covergence of post-colonial and black feminist scholarship. Nurse Researcher, 9(3), 7-27.

Andrijasevic, R. (2007). Beautiful dead bodies: gender, migration and representation in antitrafficking campaigns. Feminist Review, 86(1), 24-44.

Angelis, M. I. D. (2012). Human trafficking: Women's stories of agency. (Doctorate of Philosophy), Hull, Kingston upon Hull. Retrieved from https://hydra.hull.ac.uk/assets/hull:5823a/content

Antrobus, P. (2008). Globalisation, human security, fundamentalism and women's rights: Emergent contradictions. In M. Cain \& A. Howe (Eds.), Women, crime and social harm: Towards a criminology for the global age (pp. 57-68). Oxford: Hart Publishing.

Aranguri, C., Davidson, B., \& Ramirez, R. (2006). Patterns of communication through interpreters: A detailed sociolinguistic analysis. Journal of General Internal Medicine, 21(1), 623-629.

Arasaratnam, S. (1979). Indians in Malaysia and Singapore. Kuala Lumpur, Malaysia: Oxford University Press.

Ariffin, R. (1986). The media and women : a study of prostitution and sex tourism in Malaysia AMICCWDS-UNESCO Consultation on women, media and prostitution. Singapore: Asian Mass Communication Research \& Information Centre.

Aronowitz, A. A., \& Koning, A. (2014). Understanding human trafficking as a market system: addressing the demand side of trafficking for sexual exploitation. Cairn.Info, 85(3/4), 669696.

Ashurst, P. (2011). Mother, madonna, whore: The idealisation and denigration of motherhood. British Medical Journal, 342(1), 7155.

Asian Development Bank. (2015). Summary of Indonesia's poverty analysis. Manila, Phillipines: Asian Development Bank.

Asian Development Bank. (2019). Poverty in Indonesia. Retrieved February 20, 2019, from https://www.adb.org/countries/indonesia/poverty

Aslam, M. M. b. M. (2018). Cross border crime in funding terrorism activities in Southeast Asia: Malaysia case. Advance Research Journal of Multi-Disciplinary Discoveries, 25(1), 64-75. 
Austin, K. F. (2017). Trading sex for security: Unemployment and the unequal HIV burden among young women in developing nations. International Sociology, 32(3), 343-368.

Austin, R., \& Farrell, A. (2017). Human trafficking and the media in the United States. Oxford Research Encyclopedia, Criminology and Criminal Justice, 1(1), 1-16.

Awang, H., \& Hariharan, S. (2011). Determinants of domestic violence: Evidence from Malaysia. Journal of Family Violence: Evidence from Malaysia, 26(6), 459-464.

Baker, C. N. (2014). An intersectional analysis of sex trafficking films. Meridians, 12(1), 208-226.

Baldwin, S. B., Fehrenbacher, A. E., \& Eisenman, D. P. (2015). Psychological coercion in human trafficking: An application of Biderman's framework. Qualitative Health Research, 25(9), 1171-1181.

Bales, K. (2007). What predicts human trafficking? International Journal of Comparative and Applied Criminal Justice, 31(269-279).

Banu, Ozkazanc-Pan (2012). Postcolonial feminist research: challenges and complexities. Equality, Diversity and Inclusion: An International Journal, 31 (5/6), 573-591.

Barberet, R. (2014). Theory and method. In R. Barberet (Ed.), Women, crime and criminal justice. Abingdon, Oxon: Routledge.

Barberet, R., \& Rodriguez-Spahia, D. (2017). Feminist criminology and human rights. In L. Weber, E. Fishwick \& M. Marmo (Eds.), The routledge international handbook of criminology and human rights. Abingdon, Oxon: Routledge.

Barmania, S., \& Aljunid, S. M. (2017). Transgender women in Malaysia, in the context of HIV and Islam: a qualitative study of stakeholders' perceptions. BMC International Health Human Rights, 1(1), 17-30.

Barnett, B. (2016). Dividing women: the framing of trafficking for sexual exploitation in magazines. Feminist Media Studies, 16(2), 205 - 222.

Basnyat, I. (2014). Lived experiences of street-based female sex workers in Kathmandu: implications for health intervention strategies. Culture, Health \& Sexuality., 16(9), 1040-1051.

Basri, N. H. (2018, March 31). Perangkap seks wanita asing. Kosmo Online. Retrieved from https://www.kosmo.com.my/jurnal/perangkap-seks-wanita-asing-1.638432

Basu, K. (2007). Coercion, contract and the limits of the market. Social Choice and Welfare, 29(4), 559-579.

Bauchspies, W. K. (2007). Methods, postcolonial. In G. Ritzer (Ed.), Blackwell Encyclopedia of Sociology (Vol. 6, pp. 2981-2986). Oxford: Blackwell Publishing.

Bazeley, P., \& Jackson, K. (2013). Qualitative data analysis with NVivo. London: Sage.

Becker, H. (1971). Sociological work. Chicago: Aldine. 
Bedoya, E., Bedoya, A., \& Belser, P. (2009). Debt bondage and ethnic discrimination in Latin America. In B. Andrees \& P. Belser (Eds.), Forced labor: Coercion and exploitation in the private economy. Colorado: Lynne Rienner Publishers, Inc.

Beeks, K., \& Amir, D. (Eds.). (2006). Trafficking and the global sex industry. Maryland: Lexington Books.

Bell, K. J. (2009). A feminist's argument on how sex work can benefit women. Inquiries Journal, $1(11), 1-2$.

Bell, C., \& O'Rourke, C. (2007). Does feminism need a theory of transitional justice? An introductory essay. International Journal of Transitional Justice, 1(1), 23-44.

Bell, S. (2011, July 7). Trafficked girls controlled by Juju magic rituals. BBC News. Retrieved https://www.bbc.com/news/uk-14044205

Benner, P. (2002). Creating compassionate institutions that foster agency and respect. American Journal of Critical Care, 11(2), 164-166.

Beran, K. (2012). Revisiting the prostitution debate: Uniting liberal and radical feminism in pursuit of policy reform. Law \& Inequality, 30(1), 19-56.

Bergelson, V. (2014). The Meaning of Consent. Ohio State Journal of Criminal Law 12 Ohio St. J. Crim. L, 12(17), 171-180.

Bergold, J., \& Thomas, S. (2012). Participatory Research Methods: A Methodological Approach in Motion. Forum: Qualitative Social Research Sozialforschung 13(1).

Bernat, F. P., \& Winkeller, H. C. (2011). Conclusion: Human sex trafficking: The global becomes local. In F. P. Bernat (Ed.), Human sex trafficking (pp. 185-191). Oxon: Routledge.

Bertone, A. M. (1999). Sexual trafficking in women: International political economy and the politics of sex. Gender Issues, 18(1), 4-22.

Bertone, A. M. (2004). Transnational activism to combat trafficking in persons. The Brown Journal of World Affairs, 10(2), 9-22.

Bettio, F., Giusta, M. D., \& Tommaso, M. L. D. (2017). Sex work and trafficking: Moving beyond dichotomies. Feminist Economics, 23(3), 1-22.

Beyrer, C. (2001). Shan women and girls and the sex industry in Southeast Asia: political causes and human rights implications. Social Science \& Medicine, 53, 543-550.

Beyrer, C., \& Stachowiak, J. (2003). Health consequences of trafficking of women and girls in southeast Asia. Brown Journal World Affair, 10(1), 105-118.

Bhavnani, K.-K. (1989). What's power got to do with it? Empowerment and social research. In I. Parker \& J. Shotter (Eds.), Deconstructing social psychology (pp. 141-152). London: Routledge. 
Bindel, J. (2013, April 22). Women sex trafficking other women: the problem is getting worse. The Guardian. Retrieved from https://www.theguardian.com/lifeandstyle/2013/apr/22/womensex-trafficking-women-problem

Bindel, J. (2019). The pimping of prostitution. London: Palgrave Macmillan UK.

Bindman, J., Doezema, J., \& Anti - Slavery International. (1997). Redefining prostitution as sex work on the international agenda. London: Anti-Slavery International.

Bjerkan, L., Dyrlid, L., Nikolic-Ristanovic, V., \& Simeunovic-Patic, B. (2005). A Life of One's Own : Rehabilitation of victims of trafficking for sexual exploitation L. Bjerkan (Ed.) Retrieved May 8, 2017, from http://www.ungift.org/doc/knowledgehub/resourcecentre/NGO_FAFO_A_life_on_ones_own_victim_recovery.pdf

Blackburn, S. (2001). Love, sex and power: Women in Southeast Asia. Clayton, Victoria, AU: Monash Asia Institute.

Bletzer, K. V. (2006). A voice for every woman and the travesties of war. Violence Against Women, 12(7), 700-705.

Bloom, L. R. (1998). Introduction. In L. R. Bloom (Ed.), Under the sign of hope: Feminist methodology and narrative interpretation. New York: State University of New York Press.

Blum, L. (2004). Stereotypes and stereotyping. Philosophical Papers, 33(3), 251-289.

Bongiorno, R., McKimmie, B. M., \& Masser, B. M. (2016). The selective use of rape-victim stereotypes to protect culturally similar perpetrators. Psychology Women Quarterly, 40(1), 398-413.

Boots, D., \& Heide, K. (2006). Parricides in the media: A content analysis of available reports across cultures. International Journal of Offender Therapy and Comparative Criminology, 50(1), 418-445.

Bose, B. (2008). Dangerous liaisons: Sex work, globalisation, morality and the state in contemporary India. In M. Cain \& A. Howe (Eds.), Women, crime and social harm: Towards a criminology for the global age (pp. 107-122). Oxford: Hart Publishing.

Bosworth, M. (2007). Immigration detention in Britain. In M. Lee (Ed.), Human trafficking (pp. 159177). Cullompton: Willan.

Bosworth, M., Campbell, D., Demby, B., Ferranti, S. M., \& Santos, M. (2005). Doing prison research: Views from inside. Qualitative Inquiry, 11(2), 249-26

Boyer, T., Allison, S., \& Creagh, H. (2018). Improving the justice response to victims of sexual violence: victims' experiences. Wellington: Gravitas.

Braun, V., \& Clarke, V. (2006). Using thematic analysis in psychology. Qualitative Research in Psychology, 3(1), 77-101.

Brennan, D. (2016). Life interrupted: Trafficking into forced labor in the United States. Durham, North Carolina: Duke University Press. 
Broad, R. (2015). 'A vile and violent thing': Female traffickers and the criminal justice response. British Journal of Criminology, 55(6), 1058-1075. doi: 10.1093/bjc/azv072

Brock, D., Gillies, K., Oliver, C., \& Sutdhibhasilp, M. (2000). Migrant sex work: a roundtable analysis. Canadian Women Studies, 20(2), 44-91.

Brooten, B. J. (2003). How natural is nature? Augustine's sexual ethics. Retrieved April 22, 2019, from http://www.brandeis.edu/projects/fse/christianity/docs/christianity/chris-articles/augbrooten.pdf

Brown, L. (2000). The Trafficking of Women in Asia. London: Virago.

Brown, V. (2015, March 9). UN special rapporteur: Malaysia's migrant workers often exploited, trafficked, prostituted. The Star Online. Retrieved from http://www.thestar.com.my/news/nation/2015/03/09/un-report-migrant-workers/

Brownmiller, S. (1975). Against our will: Men, women and rape. New York: Simon \& Schuster.

Bruinsma, G. J. N., \& Meershoek, G. (1999). Organized crime and trafficking in women from eastern Europe in The Netherlands. In P. Williams (Ed.), Ilegal immigration and commercial sex:The new slave trade (pp. 105-118). London: Frank Cass.

Brunovskis, A., \& Surtees, R. (2008). Agency or illness-The conceptualization of trafficking: Victims' choices and behaviors in the assistance system. Gender, Technology and Development, 12(1), 53 - 76.

Brunovskis, A., \& Surtees, R. (2012). Leaving the past behind? When victims of trafficking decline assistance: Summary Report. Oslo: Allkopi AS.

Buang, S. (2017, December 19). Memastikan KLIA bersih sepenuhnya. Utusan Online. Retrieved from http://www.utusan.com.my/rencana/utama/memastikan-klia-bersih-sepenuhnya-1.575419

Bumiller, K. (2009). In an abusive state: How neoliberalism appropriated the feminist movement against sexual violence. Durham, North Carolina: Duke University Press.

Burgess-Jackson, K. (1999). A most detestable crime: New philosophical essays on rape. New York: Oxford University Press.

Burt, M. (1983). A conceptual framework for victimological research. Victimology, 8(1), 261-269.

Caldwell, G., Galster, S., \& Steinzor, N. (1997). Crime \& servitude : an exposé of the traffic in women for prostitution from the newly independent states. Washington D.C.: Global Survivor Network.

Cambodian Women's Crisis Centre. (2005). Trafficking of Cambodian women and children: Report of the fact-finding in Malaysia. Retrieved November 8, 2017, from http://www.cwcc.org.kh/wp-content/uploads/2010/10/Cambodian-Women-Working-inMalaysia.pdf

Cambridge Dictionary. (n.d). Retrieved October 29, 2019, from https://dictionary.cambridge.org/dictionary/english/pidgin 
Campana, P., \& Varese, F. (2016). Exploitation in human trafficking and smuggling. European Journal on Criminal Policy and Research, 22(1), 89-105.

Campbell, R., \& Wasco, S. M. (2000). Feminist approaches to social science: Epistemological and methodological tenets. American Journal of Community Psychology, 28(6), 773 - 791.

Caneppele, S., \& Mancuso, M. (2013). Are protection policies for human trafficking victims effective? An analysis of the Italian case. European Journal on Criminal Policy Research, 19(3), 259-273.

Carland, S. (2012). Silenced: Muslim women commentators in the Australian media. La Trobe Journal, 89(1), 140-150.

Carrington, K., \& Hearn, J. (2003). Trafficking and the Sex Industry: from Impunity to Protection. 28, 1(Current Issues Brief).

Carter, M. J. (2014). Gender Socialization and identity theory. Social Sciences, 3(2), 242-263. doi: $10.3390 /$ socsci3020242

Case, D. A. D. (1990). Tool 9: Semi-structured interviews. In D. A. D. Case (Ed.), The community's toolbox: The idea, methods and tools for participatory assessment, monitoring and evaluation in community forestry. Rome: Food and Agriculture Organization of the United Nations.

Caspari, S. (2015). How sex traffickers in Malaysia and Thailand use Facebook to lure victims. Retrieved 01/09/2017, 2017, from http://www.businessinsider.com/sex-workers-lured-byfacebook-2015-7/?IR=T\&r=SG

Cauduro, A. (2009). Review of the Research Studies on the Demand for Prostitution in the European Union and Beyond. In A. Cauduro, A. D. Nicola, M. Lombardi \& P. Ruspini (Eds.), Prostitution and Human Trafficking: Focus on Clients. New York: Springer.

Cauduro, A., Nicola, A. D., Lombardi, M., \& Ruspini, P. (2009). Introduction. In A. Cauduro, A. D. Nicola, M. Lombardi \& P. Ruspini (Eds.), Prostitution and human trafficking: Focus on clients (pp. 3-4). New York: Springer.

Chambliss, W. J. (1964). A sociological analysis of the law of vagrancy. Social Problems, 12(1), 67-77.

Chan, J. (2019, May 13). Sisters in Islam urge Kelantan religious authorities to stop policing the way women dress. Malaymail. Retrieved from https://www.malaymail.com/news/malaysia/2019/05/13/sisters-in-islam-urge-kelantanreligious-authorities-to-stop-policingthe/1752471?fbclid=IwAR02GIYObyhdhUHepFE9PMJexn_xvLJ_gag9kXM68UC57PRX55PhRcEojA

Chan, N. Y. S. (2016, January 1). Unlicensed and '100 per cent illegal'. New Straits Times. Retrieved from https://www.nst.com.my/news/2016/01/119992/unlicensed-and-100-cent-illegal

Chandran, R. (2019). No sewing please, we're sex workers: Thai prostitutes battle stigma. Reuters.

Chapkis, W. (1997). The prostitution of sexuality. London: Cassell. 
Chapkis, W. (2003). Persectives: Trafficking, migration, and the law : Protecting innocents, punishing immigrants. Gender \& Society, 17(6), 923-937. doi: 10.1177/0891243203257477

Chappell, T. (2014). Augustine's ethics. In D. Meconi \& E. Stump (Eds.), The Cambridge companion to Augustine (Cambridge companions to philosophy) (pp. 189-207). Cambridge: Cambridge University Press.

Charmaz, K. (2000). Grounded theory: Objectivist and constructivist methods. In N. K. Denzin \& Y. S. Lincoln (Eds.), Handbook of Qualitative Research (2nd ed.). Thousand Oaks, California: Sage.

Charmaz, K. (2014). Constructing grounded theory (2nd ed.). London: Sage.

Charnysh, V., Lloyd, P., \& Simmons, B. A. (2015). Frames and consensus formation in international relations: The case of trafficking in persons. European Journal of International Relations, 21(2), 323-351.

Cheng, N. (2014, September 21). Bukit Aman: Ours is not sex industry. The Star Online. Retrieved from https://www.thestar.com.my/news/nation/2014/09/21/police-say-sex-activities-existbut-dont-call-it-industry/

Chesler, P. (2010). Worlwide trends in honor killings. Middle East Quarterly, 17(2), 3 - 11.

Chesney-Lind, M., \& Morash, M. (2013). Transformative feminist criminology: A critical re-thinking of a discipline. Critical Criminology, 21(1), 287-304.

Chin, C. B. N. (2013). Cosmopolitan sex workers: Women and migration in a global city. New York: Oxford University Press.

Chin, G. V. S., \& Daud, K. H. M. (2015). Negotiating difference: The trope of "anak derhaka" and ideological endings in Bruneian writings. The Journal of Commonwealth Literature, 50(2), 101-114.

Chin, G. V. S., \& Daud, K. M. (2018). The Southeast Asian woman writes back: Gender, identity and nation in the literatures of Brunei Darussalam, Malaysia, Singapore, Indonesia and the Phillipines. Singapore: Springer.

Cho, S.-Y. (2015). Evaluating policies against human trafficking worldwide: An overview and review of the 3p index. Journal of Human Trafficking, 1(1), 86-99.

Cho, S. Y., \& Vadlamannati, K. C. (2012). Compliance with the anti-trafficking protocol. European Journal of Political Economy(28), 249-265.

Christie, N. (1986). The ideal victim. In E. A. Fattah (Ed.), From crime policy to victim policy: Reorienting the justice system (pp. 17-30). London: Palgrave Macmillan.

Christopher, R. L. (2008). Should Being a Victim of a Crime be a Defense to the Same or a Different Crime - Symposium: Victims and the Criminal Justice System Pace Law Review 28(4), 739758.

Chuang, J. (2006a). Preventing human trafficking in the global economy. Indiana Journal of Global Studies, 13(1), 137-163. 
Chuang, J. (2006b). The United States as global sheriff: Using unilateral sanctions to combat human trafficking. Michigan Journal of International Law, 27, 437-494.

Chuang, J. A. (2014). Exploitation creep and the unmaking of human trafficking law. The American Journal of International Law, 108(4), 609-649.

Chudakov, B., Ilan, K., Belmaker, R. H., \& Cwikel, J. (2006). The motivation and mental health of sex workers. Journal of Sex and Marital Therapy, 28(1), 305-315.

Clarke, V., \& Braun, V. (2013). Teaching thematic analysis: Overcoming challenges and developing strategies for effective learning. The Psychologist, 26(2), 120-123.

Clough, P., \& Nutbrown, C. (2007). A student's guide to methodology : Justifiying enquiry (2 ed.). Los Angeles: Sage.

Coalition Against Trafficking in Women. (2011). Projects and campaigns: Redefining prostitution law. Retrieved November 29, 2019, from http://www.catwinternational.org/ProjectsCampaigns/Projects

Coalition Against Trafficking in Women. (2011). Who we are. Retrieved May 14, 2019, from http://catwinternational.org/WhoWeAre

Coffey, A., \& Atkinson, P. (1996). Making sense of qualitative data. Complimentary research strategies. Thousand Oaks, California: Sage.

Cohen, S. (2001). States of denial: Knowing about atrocities and suffering. Cambridge: Polity Press.

Colombini, M., Mayhew, S., Ali, S. H., Shuib, R., \& Watts, C. (2013). "I feel it is not enough..." Health providers' perspectives on services for victims of intimate partner violence in Malaysia. BMC Health Services Research, 13(65), 1-14.

Comte, J. (2014). Decriminalization of sex work: feminist discourses in light of research. Sexuality and Culture, 18(1), 196.

Connell, P. (1997). Understanding victimization and agency: Considerations of race, class and gender. Polar, 20(2), 115-143

Connell, R. W. (2005). Masculinities (2nd ed.). Cambridge: Polity Press.

Connelly, L. (2015). The 'rescue industry': The blurred line between help and hindrance. Graduate Journal of Social Science, 11(2), 154-160.

Conrad, B. K. (2006). Neo-institutionalism, social movements, and the cultural reproduction of a mentalité: Promise keepers reconstruct the madonna/whore complex. The Sociological Quarterly, 47(2), 305-331.

Cook, J. A., \& Fonow, M. M. (1986). Knowledge and women's interests: Issues of epistemology and methodology in feminist sociological research. Sociological Inquiry, 56(1), 2-29. 
Coomaraswamy, R. (2003). Fishing in the stream of migration : Modern forms of trafficking and women's freedom of movement. Paper presented at the International Association of Refugee Law Judges 5th Conference, Wellington, New Zealand.

Corbin, A. (1987). Commercial sexuality in nineteenth-century france: A system of images and regulations. In C. G. a. T. Laqueur (Ed.), The making of the modern body: Sexuality and society in the nineteenth century (pp. 209-219). Berkeley: University of California Press.

Counts, P. A. (2014). Self-concept and recovery: The effects of stigma on survivors of sex trafficking. (3667389 Psy.D.), Pepperdine University, Ann Arbor. Retrieved from http://search. proquest.com/docview/1646844441? accountid=14782

Covington, S. S., \& Bloom, B. E. (2006). Gender-responsive treatment and services in correctional settings. Women and Therapy, 29(3/4), 9-33.

Coy, M. (2009). Invaded spaces and feeling dirty: Women's narratives of violation in prostitution and sexual violence. In M. Horvath \& J. Brown (Eds.), Rape: Challenging contemporary thinking (pp. 184-207). Willan Publishing: Portland, Oregon.

Cunneen, C., \& Stubbs, J. (2004). Cultural criminology: Engaging with race, gender and post-colonial identities. In J. Ferrell, K. Hayward, W. Morrison \& M. Presdee (Eds.), Cultural criminology unleashed (pp. 97-108). Sydney: Glasshouse Press.

Cusveller, J., \& Kleemans, E. (2018). Fair compensation for victims of human trafficking? A case study of the Dutch injured party claim. International Review of Victimology, 24(3), 297-311.

Cwikel, J., \& Hoban, E. (2005). Contentious issues in research on trafficked women working in the sex industry: Study design, ethics, and methodology. The Journal of Sex Research, 42(4), 306316.

Dando, C. J., Walsh, D., \& Brierley, R. (2016). Perceptions of psychological coercion and human trafficking in the west midlands of england: Beginning to know the unknown. PLos One, 11(5), 1-13.

Dann, G. M. S. (1977). Anomie, ego-enhancement and tourism. Annals of Tourism Research, 4(4), 184-194.

Das, B. (2017). Rescue by 'force' or rescue by 'choice'. Retrieved April 18, 2018, from https://www.opendemocracy.net/beyondslavery/barnali-das/rescue-by-force-or-rescue-bychoice

Davidson, J. O. C. (2006). Will the real sex slave please stand up? Feminist Review(83), 4-22.

Davies, A. (2010). Liberal feminism. In A. J. Mills, G. Durepos \& E. Wiebe (Eds.), Encyclopedia of case study research (pp. 526-528). Thousand Oaks, California: Sage.

Davis, H. (2013). Defining 'pimp': Working towards a definition in social research. Sociological Research Online, 18(1), 1-11

Day, S. (2009). Renewing the war on prostitution: The spectres of 'trafficking' and 'slavery'. Anthropology Today, 25(3), 1-3. 
Dunne, J. L. (2012). Hijacked: How Efforts to Redefine the International Definition of Human Trafficking Threaten Its Purpose. Willamette Law Review, 48(1), 403-426.

Deccan Chronicle. (2017, August 8). 10 sex tourism destinations around the world. Deccan Chronicle. Retrieved from https://www.deccanchronicle.com/lifestyle/travel/080817/10-sex-tourismdestinations-around-the-world.html

Demleitner, N. (2001). The law at a crossroads: The construction of migrant women trafficked into prostitution. In D. Kyle \& R. Kowlowski (Eds.), Global human smuggling - Comparative perspectives (pp. 257-293). Baltimore: The John Hopkins University Press.

Dempsey, M. M. (2015). Decriminalizing victim of sex trafficking. American Criminal Law Review, 52(2), 207 - 229.

Department of Statistics of Malaysia. (2016). Salaries \& wages survey report, Malaysia, 2016. Retrieved May 5, 2017, from https://dosm.gov.my/v1/index.php?r=column/cthemeByCat\&cat=157\&bul_id=U3JoKzFiekE5 WFFKKOVMRWQ0a2FDQT09\&menu_id=U3VPMIdoYUxzVzFaYmNkWXZteGduZz09

Destefano, A. (2007). The war on human trafficking: U.S. policy assessed. New Brunswick: Rutgers University Press.

Desyllas, M. C. (2007). A critique of the global trafficking discourse and U.S. policy. Journal of Sociology \& Social Welfare, 34(1), 57-80.

Dobash, R., \& Dobash, R. (1979). The case against the patriarchy. New York: The Free Press.

Dodsworth, J. (2013). Sexual exploitation, selling and swapping sex: Victimhood and agency. Child Abuse Review, 23(3), 185 - 199.

Doezema, \& Kempadoo. (1998). Global Sex Workers: Rights, Resistance, and Redefinition. New York: Routledge.

Doezema, J. (1996). Choice in prostitution. In M. Jyrkinen (Ed.), Changing faces of prostitution: Conference book Helsinki 3 - 5 May 1995. Helsinki, Finland: Meripaino OY.

Doezema, J. (2000). Loose women or lost women? The re-emergence of the myth of 'white slavery' in contemporary discourses of trafficking in women. Gender Issues, 18(1), 23-50.

Doezema, J. (2002). Who gets to choose? Coercion, consent, and the UN Trafficking Protocol. Gender \& Development, 10(1), 20 - 27.

Doezema, J. (2010). Introduction: Positioning trafficking in women Sex slaves and discourse masters : The construction of trafficking (pp. 1-29). London: Zed Books Ltd.

Doğan, R. (2011). Is honor killing a "muslim phenomenon"? Textual interpretations and cultural representations. Journal of Muslim Minority Affairs, 31(3), 423-440.

Don, Z., \& Lee, C. (2014). Representing immigrants as illegals, threats and victims in Malaysia: elite voices in the media. Discourse and Society, 25(6), 687-705. 
Donner, W. (1993). John Stuart Mill's liberal feminism. Philosphical Studies, 69(1), 155-166.

Downes, D., Rock, P., \& McLaughlin, E. (2016). Understanding deviance: A guide to the sociology of crime and rule-breaking. Oxford: Oxford University Press.

Du, B. (2015). The silenced interpreter: A case study of language and ideology in the chinese criminal court. International Journal for the Semiotics of Law, 28(3), 507-524.

Dunn, J. L., \& Powell-Williams, M. (2007). "Everybody makes choices": Victim advocates and the social construction of battered women's victimization and agency. Violence Against Women, 13(10).

Dunton, B. C., \& Fazio, R. H. (1997). An individual difference measure of motivation to control prejudiced reactions. Personality and Social Psychology Bulletin, 23(3), 316-326.

Easteal, P. (2001). Women in Australian prisons: The cycle of abuse and dysfunctional environments. The Prison Journal, 81(1), 87-112.

Edgell, S. (1980). Middle-Class Couples. London: Allen and Unwin.

Edward, J. (2016, April 18). Shelter homes a temporary haven for sex-trafficking victims. Malaymail Online. Retrieved from http://www.themalaymailonline.com/malaysia/article/shelterhomes-a-temporary-haven-for-sex-trafficking-victims\#32uFbAVU4Euol1yQ.97

Edwards, R. (1998). A critical examination of the use of interpreters in the qualitative research process. Journal of Ethnic and Migration Studies, 24(1), 197-208.

Ehrenreich, B., \& Hochschild, A. R. (2002). Global woman: Nannies, maids and sex workers in the new economy. London: Granta Books.

Eigenberg, H., \& Garland, T. (2008). Victim Blaming. In L. J. Moriarty (Ed.), Controversies in Victimology (Second ed.). Newark, NJ: Elsevier Press.

Ejalu, W. A. E. (2006). From home to hell: The telling story of an African woman's journey and stay in Europe. In K. Beeks \& D. Amir (Eds.), Trafficking and the Global Sex Industry (pp. 165 - 188). Lanham: Rowman \& Littlefield Publishers, Inc.

Elmhirst, R. (2004). Labour politics in migrant communities: Ethnicity and women's activism In Tangerang, Indonesia. In R. Elmhirst \& R. Saptari (Eds.), Labour in Southeast Asia: Local processes in a globalized world (pp. 387 - 406). London: Curzon-Routledge.

Employment New Zealand. (n.d). Gender pay gap. Retrieved May 13, 2019, from https://www.employment.govt.nz/hours-and-wages/pay/pay-equity/gender-pay-gap/

Empower Foundation. (2012). Hit \& run: The impact of anti trafficking policy and practice on sex worker's human rights in Thailand. Retrieved November 8, 2019, from http://www.empowerfoundation.org/sexy_file/Hit\%20and\%20Run\%20\%20RATSW\%20Eng\% 20online.pdf

Empower Foundation. (2017). Sex workers and the Thai entertainment industry. Retrieved May 16, 2019, from 
https://tbinternet.ohchr.org/Treaties/CEDAW/Shared\%20Documents/THA/INT_CEDAW_NG O_THA_27511_E.pdf

Engstrom, D. W. (2006). Outsiders and exclusion: Immigrants in the United States. In D. W. Engstrom \& L. Piedra (Eds.), Our Diverse Society. Washington: NASW Press.

Erez, E. (2000). Immigration, culture conflict and domestic violence/woman battering. Crime Prevention and Community Safety, 2(1), 27-36.

Erez, E. (2013). Women as victims and survivors in the context of transnational human trafficking for commercial sex exploitation. Revue Internationale De Droit Pénal, 81(1), 551-562.

Ericsson, L. O. (1980). Charges against prostitution: An attempt at a philosophical assessment. Ethics, 90(3), 335-366.

Espinoza, M. C. (2014). Whose fault is it anyway? Comparison of victim blaming attitudes towards sex trafficking and sexual assault across gender and two ethnic groups. (Doctor of Psychology), Alliant International University, Sacramento, United States.

Estrich, S. (1987). Real rape: How the system victimizes women who say no. Cambridge, Massachusetts: Harvard University Press.

European Commission. (2010). Trafficking explained. Retrieved June 4, 2019, from https://ec.europa.eu/anti-trafficking/citizens-corner/trafficking-explained_en

Farley, M. (2003). Prostitution and the invisibility of harm. Women \& Therapy, 1(1), 247-280.

Farley, M., \& Seo, S. (2005). Prostitution and trafficking in Asia. Harvard Asia Pacific Review, 8, 9-12.

Farrell, A., \& Fahy, S. (2009). The problem of human trafficking in the U.S.: Public frames and policy responses. Journal of Criminal Justice, 37(6), 617-626.

Farrell, A., McDevitt, J., \& Fahy, S. (2010). Where are all the victims? Criminology and public policy. Criminology and Public Policy, 9(2), 201-233.

Farrell, A., Owens, C., \& McDevitt, J. (2014). New laws but few cases: Understanding the challenges to the investigation and prosecution of human trafficking cases. Crime, Law and Social Change, 61(2), 139-168.

Faruqi, S. S. (2005). The Malaysian constitution, the Islamic state, and Hudud laws. In K. S. Nathan \& M. H. Kamali (Eds.), Islam in Southeast Asia: Political, social and strategic challenges for the 21st century (pp. 256-277). Pasir Panjang: Institute of Southeast Asian Studies.

Fattah, E. A. (1991). Understanding criminal victimization (P. Buckley Ed.). Scarborough, Ontario: Prentice-Hall Canada Inc.

Faugier, J., \& Sergeant, M. (1997). Boyfriends, 'pimps' and clients. In G. Scrambler \& A. Scrambler (Eds.), Rethinking prostitution: Purchasing sex in the 1990s (pp. 121-138). London: Routledge.

Federal Constitution (Laws of Malaysia) (as at 1 November 2010). 
Fedorkó, B. (2019). The two-fronted fight of sex workers against trafficking. Retrieved November 3 , 2019, from https://www.opendemocracy.net/en/beyond-trafficking-and-slavery/twofronted-fight-sex-workers-against-trafficking/

Fergus, L. (2005). Trafficking in women for sexual exploitation. Paper presented at the Trafficking in women for sexual exploitation, Melbourne, AU.

Ferguson, A., Philipson, I., Diamond, I., Quinby, L., Vance, C., \& Snitow, A. (1984). Forum: The feminist sexuality debates. Journal of Women in Culture and Society, 10(1), 106-125.

Finckenauer, J. (2011). Organised crime. In M. G. McGuire (Ed.), Oxford handbook of crime and public policy (pp. 304-324). Oxford: Oxford University Press.

Finn, M. A., Muftić, L. R., \& Marsh, E. I. (2015). Exploring the overlap between victimization and offending among women in sex work. Victims \& Offenders, 10(1), 74-94.

Flood, M., \& Pease, B. (2009). Factors influencing attitudes to violence against women. Trauma Violence Abuse, 10(1), 125-142.

Flowers, R. B. (1998). The prostitution of women and girls. North Carolina: McFarland \& Company, Inc.

Fonow, M. M., \& Cook, J. A. (2005). Feminist methodology: New applications in the academy and public policy. Journal of Women in Culture and Society, 30(4), 2211-2236.

Forbes, J. (1995). Anti-romantic discourse as resistance: Women's fiction 1775-1820. In L. Pearce \& J. Stacey (Eds.), Romance revisited. Washington Square, New York: New York University Press.

Fredrickson, B., \& Roberts, T. (1997). Objectification theory: Toward understanding women's lived experiences and mental health risks. Psychology of Women Quarterly, 21(2), 173-206.

Gallagher, A. (2004). Human rights and human trafficking: A preliminary review of Australia's response. Paper presented at the Human Rights 2004: The Year in Review, The Capstran Centre for Human Rights Law, Monash University, Melbourne, AU.

Gallagher, A. (2010). International law of human trafficking. New York: Cambridge University Press.

Gallagher, A. (2015). Two cheers for the trafficking protocol. Anti Trafficking Review, 4(1), 14-32.

Gallagher, A. T., \& Karlebach, N. (2011). Prosecution of trafficking in persons cases: Integrating a human rights-based approach in the administration of criminal justice. Geneva: Bepress.

Gallagher, A., \& Pearson, E. (2010). The high cost of freedom: A legal and policy analysis of shelter detention for victims of trafficking. Human Rights Quarterly, 32(1), 73-114.

Gards, J. (2019). Should sex work be decriminalized? Some activists say it's time. Retrieved Jan 28 , 2020, from https://www.npr.org/2019/03/22/705354179/should-sex-work-bedecriminalized-some-activists-say-its-time. 
Gan, C., Ha, N. T. T., Kao, B., \& Poch, K. (2014). An assessment of the role of nongovernment organizations in combating trafficking of women and children in Cambodia and Vietnam. Journal of GMS Development Studies, 6(1), 71-91.

Garce's-Mascaren, B. (2008). Old and new labour migration to Malaysia: From colonial times to the present. In M. Schrover, J. V. D. Leun, L. Lucassen \& C. Quispel (Eds.), Illegal migration and gender in a global and historical perspective. Amsterdam: Amsterdam University Press.

Gauthier, J. (2011). Prostitution, sexual autonomy, and sex discrimination. Hypatia, 26(1), 166-186.

Gelsthorpe, L., \& Morris, A. (1990). Introduction transforming and transgressing criminology. In L. Gelsthorpe \& A. Morris (Eds.), Feminist perspective in criminology. Buckingham: Open University Press.

Gerstein, J. (2017). The one weird court case linking Trump, Clinton, and a billionaire pedophile. Politico. Retrieved November 8, 2017 from https://www.politico.com/story/2017/05/04/jeffrey-epstein-trump-lawsuit-sex-trafficking237983

Giallombardo, R. (1967). Interviewing in the prison community. The Journal of Criminal Law, Criminology and Police Science, 57(3), 318-324

Gibbs, G. R. (2007). Thematic Coding and Categorizing. In G. R. Gibbs (Ed.), Analyzing Qualitative Data (pp. 38-55). London: Sage.

Giddens, A. (1984). The constitution of society: Outline of a theory of structuration. Berkeley: Unviersity of California Press.

Gilfoyle, T. J. (1999). Prostitutes in history: From parables of pornography to metaphors of modernity. American Historical Review, 117-140.

Gilligan, C. (1982). In a different voice: psychological theory and women's development. Cambridge: Harvard University Press.

Giusta, M. D., Tommaso, M. L. D., \& Strom, S. (2008). Sex Markets: a denied industry. London: Routledge.

Glaser, B., \& Strauss, A. (1967). The discovery of grounded theory: Strategies for qualitative research. Chicago: Aldine Pub. Co.

Global Alliance Against Traffic in Women. (n.d). Who we are. Retrieved May 14, 2019, from https://gaatw.org/about-us

Global Migration Group. (2013). Exploitation and abuse of international migrants, particularly those in an irregular situation: A human rights approach. Vienna: United Nations Office on Drugs and Crime.

Global Network of Sex Projects. (2017). Sex work as work. Retrieved May 16, 2019, from https://www.nswp.org/sites/nswp.org/files/policy_brief_sex_work_as_work_nswp__2017.pdf 
Global Network of Sex Work Projects. (n.d.). The impact of criminalisation on sex workers' vulnerability to hiv and violence. Retrieved December 4, 2019, from https://www.nswp.org/sites/nswp.org/files/impact_of_criminalisation_pb_prf01.pdf

Goffman, E. (1963). Stigma: Notes on the management of spoiled identity. New York: Simon \& Schuster, Inc.

Goodey, J. (2004). Sex trafficking in women from central and east European countries: promoting a 'victim-centred' and 'woman-centred' approach to criminal justice intervention. Feminist Review, 76(1), 26-45.

Gordon, R. (1998). 'Girls cannot think as boys do': socialising children through the Zimbabwean school system. Gender \& Development, 6(2), 53 - 58.

Govier, T. (2015). Victims and victimhood. Winnipeg: Broadview Press Inc.

Govier, T., \& Verwoerd, W. (2006). How not to polarize 'victims' and 'perpetrators'. A Journal of Social Justice, 16(1), 371 - 377.

Gozdziak, E., \& Collett, E. (2005). Research on human trafficking in North America: A literature review. Special Issue of International Migration, 43(1/2), 99-128.

Grant, M. G. (2012). The truth about trafficking: it's not just about sexual exploitation. Retrieved September 1, 2017, from https://www.theguardian.com/profile/melissa-gira-grant

Graham, L. (2017). Governing sex work through crime: Creating the context for violence and exploitation. The Journal of Criminal Law, 81(3), 201-216.

Greenbaum, J., \& Bodrick, N. (2017). Global human trafficking and child victimization. Pediatrics, 140(6), 2017-3138.

Greer, C. (2007). News media, victims and crime. In P. Davies, P. Francis \& C. Greer (Eds.), Victims, crime \& society: Sage.

Grossberg, L. (1987). Critical theory and the politics of empirical research. In M. Gurevitch \& M. R. Levy (Eds.), Mass Communication Review Yearbook. London: Sage.

Grosu-Rădulescu, L.-M. (2016). Objectification of women and violence in what the body remembers. Rupkatha Journal On Interdisciplinary Studies in Humanities, VIII(1), 86-95.

Grubb, A. R., \& Turner, E. (2012). Attribution of blame in rape cases: A review of the impact of rape myth acceptance, gender role conformity and substance use on victim blaming. Aggression and Violent Behavior, 15(5), 443-452.

Guba, E. G., \& Lincoln, Y. S. (1989). Fourth generation evaluation. Thousand Oaks, California: Sage.

Habtezion, S. (2012). Gender and climate change: Gender and energy. New York: United Nations Development Programme.

Hagstedt, J., Korsell, L., \& Skagerö, A. (2009). In the land of prohibition? Clients and trafficked women in Sweden. In A. Cauduro, A. D. Nicola, M. Lombardi \& P. Ruspini (Eds.), Prostitution and human trafficking: Focus on clients (pp. 163-204). New York: Springer. 
Hales, L., \& Gelsthorpe, L. (2012). The criminalisation of migrant women. Cambridge: Institute of Criminology, University of Cambridge.

Halley, J., Kotiswaran, P., Shamir, H., \& Thomas, C. (2006). From the international to the local in feminist legal responses to rape, prostitution/sex work, and sex trafficking: four studies in contemporary governance feminism. Harvard Journal of Law \& Gender, 29(1), 335-424.

Ham, J., \& Gerard, A. (2013). Strategic invisibility: Does agency make sex workers invisible? Criminology \& Criminal Justice, 14(3), 298-313.

Hamid, Z. A., Aziz, N. A., \& Amin, N. M. (2018). Challenges encountered by Malaysian prosecutors in human trafficking. International Journal of Asian Social Science, 8(1), 21-27.

Hammersley, M. (1992). On feminist methodology. Sociology, 26(2), 187-206.

Harding, S. (1987). Introduction: Is there a feminist method? In S. Harding (Ed.), Feminism and methodology (pp. 1-14). Bloomington: Indiana University Press.

Harrington, C. (2005). The politics of rescue: Peacekeeping and anti-trafficking programmes in Bosnia-Herzegovina and Kosovo. International Feminist Journal of Politics, 17(2), 175-206.

Hasan, H. (2005). Malay women and prostitution in Kota Bharu, Kelantan, 1950s-1970s. Journal of the Malaysian Branch of the Royal Asiatic Society, 78(1 (288)), 97-120.

Haynes, D. F. (2007). (Not) found chained to a bed in brothel: conceptual, legal and procedural failures to fulfil the promise of the Trafficking Victims Protection Act. Georgetown Immigration Law Journal, 21(337).

Healy, C., Bennachie, C., \& Marshall, R. (2012). Harm reduction and sex workers: A New Zealand response: Taking the harm out of the law. In R. Pates \& D. Riley (Eds.), Harm Reduction in Substance Use and High-Risk Behaviour (pp. 252-262). Chichester: Blackwell Publishing Ltd.

Healey, L. (1999). Gender, power and the ambiguities of resistance in a malay community of peninsular Malaysia. Women's Studies International Forum, 22(1), 49-61.

Hedlin, S. (2016). Can prostitution law reform curb sex trafficking? Theory and evidence on scale substitution, and replacement effects. University of Michigan Journal of Law Reform, 50(2), 329-386.

Hearn, J. (1992). Men in the public eye: The construction and deconstruction of public men and public patriarchies. New York: Routledge.

Heath, M., Braimoh, J., \& Gouweloos, J. (2016). Judging women's sexual agency : Contemporary sex wars in the legal terrain of prostitution and polygamy. Signs, 42(1), $119-225$.

Hefner, R. W. (2001). Southeast asian studies: Culture. International Encyclopedia of the Social \& Behavioral Sciences, 1(1), 14666-14670.

Heidensohn, F. (2002). Gender and crime. In M. Maguire, R. Morgan \& R. Reiner (Eds.), The oxford handbook of criminology (3rd ed.). London: Oxford University Press. 
Heimer, K. (2000). The nature of crime: Continuity and change. Changes in the gender gap in crime and women's economic marginalization. Criminal Justice \& Popular Culture, 1(1), 427 - 483.

Hentig, H. v. (2009). The criminal and his victim. In B. Williams \& H. G. Chong (Eds.), Victims and victimisation: A reader. New York: Open University Press.

Hewson, M. (2010). Encyclopedia of case study research agency. Thousand Oaks, California: Sage.

Hirofumi, H. (1998). Japanese comfort women in Southeast Asia. Japan Forum, 10(2), 211-219.

Hirschman, C. (2016). Gender, the status of women, and family structure in Malaysia. Malaysian Journal of Economic Studies, 53(1), 33-50.

Hockett, J. M., Smith, S. J., Klausing, C. D., \& Saucier, D. A. (2016). Rape myth consistency and gender differences in perceiving rape victims. Violence Against Women, 22(2), 139-167.

Hodal, K. (2014, December 12). Suspected human trafficker and Thai 'baby factory' under investigation. Guardian. Retrieved from https://www.theguardian.com/globaldevelopment/2014/jun/20/malaysia-us-human-trafficking-persons-report

Hoijer, B. (2004). The discourse of global compassion: The audience and media reporting of human suffering. Media, Culture \& Society, 26(4), 513-531.

Holloway, I. (1997). Basic concepts for qualitative research. Oxford: Blackwell Science.

Holloway, I., \& Wheeler, S. (2010). Qualitative research in nursing and healthcare (Third ed.). Chichester, Sussex: Wiley-Blackwell.

Holmstrom, L. L., \& Burgess, A. W. (1991). The Victim of rape: Institutional reactions. London: Transaction Publishers.

Hotaling, N., \& Levitas-Martin, L. (2002). Increased demand resulting in the flourishing recruitment and trafficking of women and girls: Related child sexual abuse and violence against women. Hastings Women's Law Journal, 13(1), 117-125.

Howard, N., \& Lalani, M. (2008). The politics of human trafficking: St Antony's International Review, $4(1), 5-15$.

Hoyle, C., Bosworth, M., \& Dempsey, M. (2011). Labelling the victims of sex trafficking: Exploring the borderland between rhetoric and reality. Social \& Legal Studies, 20(3), 313-329.

Huda, S. (2006). Sex trafficking, public health and HIV/AIDS, sex trafficking in south Asia 378. International Journal Gynecology Obstetrics, 94(3), 374-381.

Hudson, B. (2002). Gender issues in penal policy and penal theory. In P. Carlen (Ed.), Women and punishment: The struggle for justice (pp. 21-46). Cullompton: Willan Publishing.

Hughes, D. (2005). The demand for victims of sex trafficking. Women's Studies Program, 26(1), 1-65.

Human Rights Commission of Malaysia. (2016). Annual Report 2016. Kuala Lumpur: Human Rights Commission of Malaysia. 
Human Rights Commission of Malaysia SUHAKAM. (2004). Trafficking In Women And Children: Report of the Human Rights Commission of Malaysia (SUHAKAM). Kuala Lumpur: Human Rights Commission Of Malaysia.

Hunter, M. (2015, July 28). Why Kuala Lumpur could be on its way of becoming the sex capital of Asia. Asian Correspondent. Retrieved from https://asiancorrespondent.com/2015/07/kualalumpur-prostitution-malaysia/\#Z0m1V1077gKBftyR.97

Idris, A. (2012). Malaysia and forced migration. Intellectual Discourse, 20(1), 31 - 54.

Ifechelobi, J. N. (2014). Feminism: Silence and voicelessness as tools of patriarchy in chimamanda adichie's purple hibiscus. African Research Review, 8(4), 17-27.

Ikeora, M. (2016). The role of African traditional religion and 'juju' in human trafficking: Implications for anti-trafficking. Journal of International Women's Studies, 17(1), 1-18.

Immigration Act, 8(3)(e) and 8(3)(f) Stat. (1959/63).

Ingraham, B. L. (1996). The right of silence, the presumption of innocence, the burden of proof, and a modest proposal: A reply to O'Reilly. The Journal of Criminal Law and Criminology, 86(2), 559 - 595.

International Centre for Criminal Law Reform and Criminal Justice Policy. (2011). Towards Human Trafficking Prevention: A Discussion Document. Retrieved April 4, 2019, from http://www.crime-preventionintl.org/fileadmin/user_upload/Publications/Towards_Human_Trafficking_Prevention_A_Dis cussion_Document_-_May_27.pdf

International Labour Office. (2014). Profits and Poverty: The Economics of Forced Labour. Retrieved April 4, 2019, from http://www.ilo.org/wcmsp5/groups/public/---ed_norm/--declaration/documents/publication/wcms_243391.pdf

International Labour Organization. (n.d). Sex industry assuming massive proportions in Southeast Asia. Retrieved May 16, 2019, from https://www.ilo.org/global/about-theilo/newsroom/news/WCMS_007994/lang--en/index.htm

International Organization for Migration. (2010). International Dialogue on Migration No. 16 Human Rights and Migration: Working Together for Safe, Dignified and Secure Migration. Geneva: International Organization for Migration.

Iselin, B., \& Adams, M. (2003). Distinguishing between human trafficking and people smuggling. Retrieved May 14, 2018, from https://www.embraceni.org/wpcontent/uploads/2006/06/Distinguishing[1]1.pdf

Islam, K. M. M., \& Asadullah, M. N. (2018). Gender stereotypes and education: A comparative content analysis of Malaysian, Indonesian, Pakistani and Bangladeshi school textbooks. PLos One, 13(1-24).

Jackson, J., Bradford, B., Hough, M., Myhill, A., Quinton, P., \& Tyler, T. R. (2012). Why do people comply with the law? British Journal of Criminology, 52(1), 1051-1071. 
Jahanfar, S., Kamarudin, E. B., Sarpin, M. A. B., Zakaria, N. B., Rahman, R. B. A., \& Samsuddin, R. D. B. (2007). The prevalence of domestic violence against pregnant women in Perak, Malaysia. Archives of Iranian Medicine, 10(3), 376-378.

Javaid, A. (2018). Male rape, masculinities, and sexualities. International Journal of Law, Crime and Justice, 52(1), 199-210.

Jayaratne, T. E. (1983). The value of quantitative methodology for feminist research. In G. Bowles \& R. D. Klein (Eds.), In Theories of Womens Studies (pp. 140-145). London: Routledge \& Kegan Paul plc.

Jayaratne, T. E., \& Stewart, A. J. (1991). Quantitative and qualitative methods in social sciences: Current feminist issues and practical strategies. In M. M. Fonow \& J. A. Cook (Eds.), Beyond methodology: Feminist scholarship as lived research (pp. 85-106). Bloomington: Indiana University Press.

Jean, R. (2015). Prostitution and the concept of agency. In H. Marway \& H. Widdows (Eds.), Women and violence: Genders and sexualities in the social sciences (pp. 52-67). London: Palgrave Macmillan.

Jeffreys, S. (1997). The idea of prostitution. Melbourne: Spnifex Press.

Jewkes, Y. (2002). Captive audience: Media, masculinity and power in prisons. London: Routledge.

Jomo, K. S. (2005). Malaysia's new economic policy and national unity. In Y. Bangura \& R. Stavenhagen (Eds.), Racism and public policy (pp. 182-214). London: Palgrave Macmillan.

Joo-Ee, G. (2016). Minimum wage and the hospitality industry in Malaysia: An analysis of employee perceptions. Journal of Human Resources in Hospitality \& Tourism, 15(1), 29-44.

Jordal, M., Wijewardena, K., Öhman, A., Essén, B., \& Olsson, P. (2014). Negotiating respectability: Migrant women workers' perceptions of relationships and sexuality in free trade zones in Sri Lanka. Health Care for Women International, 35(6), 658-676.

Jordan, A. D. (2002). The annotated guide to the complete UN trafficking protocol. Washington, DC: International Human Rights Law Group.

Jordan, J. (1993). "New Zealand prostitutes' collective". Women together: A history of women's organisations in New Zealand (A. Else Ed.). Wellington: Daphne Brassell Press.

Jordan, J. (2004). The word of a woman? Police, rape and belief. Houndsmill: Palgrave Macmillan.

Jordan, J. (2012). Silencing rape, silencing women. In J. M. Brown \& S. L. Walklate (Eds.), Handbook on sexual violence (pp. 253-286). Abingdon: Routledge.

Joseph, A. (2015, February 13). Harvard Law Professor Blames Victim in Child Trafficking Case. HUFFPOST. Retrieved from https://www.huffpost.com/entry/harvard-law-professorbla_b_6666038?guccounter=1\&guce_referrer=aHROcHM6Ly93d3cuYmluZy5jb20vc2VhcmNo P3E9SGFydmFyZCtMYXcrUHJvZmVzc29yKOJsYW1 cytWaWNOaWOraW4rQ2hpbGQrVHJhZmZ pY2tpbmcrQ2FzZSZzcmM9SUUtU2VhcmNoQm94JkZPUk09SUVTUjNO\&guce_referrer_sig=A QAAAHpSD7O5W8lulVqM5_iCUPahdZQI0mKEACnZrygEtfTkqAZ29o1Bqd3c_o5OmBDOYj- 
pxgpheoThyWyG20zraebnYP2Se7OZbM_iXYr_o5naLIXg7hm5U-

xBoRrKigsHCh9ubYYA7BHk3nflluJoA_2In9Yry7faF6ocaNou7EEV

Joseph, S. (1996). Patriarchy and development in the Arab world. Gender and Development, 4(2).

Kabeer, N. (1999). Resources, agency, achievements: Reflections on the measurement of women's empowerment. Development and Change, 30(3), 435-464.

Kabeer, N. (2005). Gender Equality and women's empowerment: A critical analysis of the third millenniumdevelopment goal. Gender and Development, 13(1), 13-24.

Kandiyoti, D. (1988). Bargaining with patriarchy. Gender and Society, 2(1), 274-290.

Kapur, R. (2005). Travel plans: Human rights of transnational migrants. Harvard Human Rights Journal, 18(1), 107-138.

Kara, S. (2009). Sex trafficking: An overview. In S. Kara (Ed.), Sex trafficking: Inside the business of modern slavery (pp. 1-44). New York: Columbia University Press.

Karandikar, S., \& Prospero, M. (2010). From client to pimp: Male violence against female sex workers. Journal of Interpersonal Violence, 25(1), 257-273.

Kassim, A., \& Zin, R. H. M. (2011a). Irregular migrants and the law. Philippine Journal of Development, 38(1/2), 85-104.

Kassim, A., \& Zin, R. H. M. (2011b). Policy on irregular migrants in Malaysia: An analysis of its implementation and effectiveness. Makati City: Philippine Institute for Development Studies.

Kaur, A. (2006a). Indian labour, labour standards, and workers' health in Burma and Malaya, 19001940. Modern Asia Studies, 40(2), 425-475.

Kaur, A. (2006b). Order (and disorder) at the border: mobility, international labour migration and border controls in Southeast Asia. In A. Kaur \& I. Metcalfe (Eds.), Mobility, labour migration and border controls in Asia (pp. 26-31). London: Palgrave Macmillan.

Kaur, A. (2010). Labour migration trends and policy challenges in Southeast Asia. Policy and Society, 29(4).

Kawulich, B. B. (2005). Participant observation as a data collection method. Forum: Qualitative Social Research, 6(2), 43-70.

Kaya, O., \& Erez, E. (2018). Migration, agency, and the sex industry: Practitioners' perspectives on foreign sex workers in Turkey. International Journal of Offender Therapy and Comparative Criminology, 62(10), 2954-2981.

Keller, E. F. (1985). Reflections on gender and science. New Haven, CT: Yale University Press.

Kelly, L. (1988). Surviving sexual violence. Oxford: Polity Press.

Kelly, L. (2003). The wrong debate: reflections on why force is not the only issue with respect to traffickinbg in women for sexual exploitation in the UK. Feminist Review, 73(1), 139-144. 
Kelly, L. (2005). "You can find anything you want": a critical reflection on research on trafficking in persons within and into Europe. International Migration, 43(1-2), 235-265.

Kelly, L., Coy, M., \& Davenport, R. (2008). Shifting sands: A comparison of prostitution regimes across nine countries. Retrieved May 12, 2019, from https://cwasu.org/wpcontent/uploads/2016/07/shifting-sands-published-version.pdf

Kelly, L., Lovett, J., \& Regan, L. (2005). A Gap or chasm? Attrition in reported rape cases. London: Home Office.

Kempadoo, K. (1998). Globalizing sex workers' rights. In K. Kempadoo \& J. Doezema (Eds.), Global sex workers. New York: Routledge.

Kempadoo, K. (2001). Women of color and the global sex trade: Transnational feminist perspectives. Meridians, 1(2), 28-51.

Kempadoo, K. (2005). Introduction: Abolitionism, criminal justice, and transnational feminism: Twenty first-century persepective on human trafficking. In L. Kempadoo, J. Sanghera \& B. Pattanaik (Eds.), Trafficking and prostitution reconsidered-New perspectives on migration, sex work, and human rights (pp. vii-xlii). Abingdon: Taylor \& Francis.

Kempadoo, K., Sanghera, J., \& Pattanaik, B. (2016). Trafficking and prostitution reconsidered: new perspectives on migration, sex work, and human rights (K. Kempadoo, J. Sanghera \& B. Pattanaik Eds. 1 ed.). Abingdon: Routledge

Khan, S. (2003). Zina and the moral regulation of Pakistani women. Feminist Review, 1(1), 75-100.

Kim, K. (2007). Psychological coercion in the context of modern-day involuntary labor: Revisiting United States v. Kozminski and understanding human trafficking. University of Toledo Law Review, 38, 941-972, 38(1), 941-972.

Kim, K. (2011). The coercion of trafficked workers. lowa Law Review, 96(2), 409.

King, N. (2004). Using templates in the thematic analysis of text. In C. Cassell \& G. Symon (Eds.), Essential guide to qualitative methods in organizational research (pp. 257-270). London: Sage.

Kingston, S., \& Thomas, T. (2018). No model in practice: a 'Nordic model' to respond to prostitution? Crime, Law and Social Change, 71(1), 423-439.

Kotiswaran, P. (Ed.). (2011). Toward a legal ethnography of sex work in an Indian red-light area (Vol. 7). New Delhi, India: Women Unlimited.

Kunze, E. I. (2010). Sex trafficking via the internet: How international agreements address the problem and fail to go far enough. Journal of High Technology Law, 10(1), 241 - 289.

Kuo, M. (2000). Asia's dirty secret. Harvard International Review, Cambridge, 22(2), 42 - 45.

LaCroix International. (2016, August 22). Malaysia is failing victims of human trafficking. LaCroix International. Retrieved from https://international.la-croix.com/news/malaysia-is-failingvictims-of-human-trafficking/3733\# 
Laczko, F., \& Danailova-Trainor, G. (2009). Trafficking in persons and human development: Towards a more integrated policy response Human development research paper (hdrp) series (Vol. 51). New York: United Nations Development Programme.

Laczko, F., \& Gramegna, M. A. (2003). Developing better indicators of human trafficking. The Brown Journal of World Affairs, 10(1), 179-194.

LaFree, G. D. (1980). The effect of sexual stratification by race on official reactions to rape. American Sociological Review, 45(1), 842-854.

LaFree, G. D. (1981). Official reactions to social problems: Police decisions in sexual assault cases. Social Problems, 28(1), 582-594.

Lagon, M. P. (2007). "Demand" and sex trafficking. Retrieved September 28, 2017, from https://2001-2009.state.gov/g/tip/rls/rm/07/94470.htm

Lalani, N. H. M. (2008). The Politics of Human Trafficking. St Antony's International Review, 4(1), 5 15.

Lam, E. (2018). Butterfly asian and migrant sex workers support network. Toronto: Butterfly Print.

Lam, E., \& Gallant, C. (2018). Migrant Sex Workers' Justice: Building alliances across movements. In E. M. Durisin, E. v. d. Meulen \& C. Bruckert (Eds.), Red Light Labour: Sex work regulation, agency, and resistance (pp. 293-304). Vancouver: University of British Columbia Press.

Lâm, M. C. (2002). Multicultural feminism: Cultural concerns. International Encyclopedia of the Social \& Behavioral Sciences, 1(1), 10163-10169. doi: ISBN: 0-08-043076-7

Lamb, L. (1996). The trouble with blaming. Cambridge: Harvard Unviersity Press.

Larcombe, W. (2002). The 'ideal' victim v succesful rape complainants: Not what you might expect. Feminist Legal Studies, 10(2), 131 - 148.

Larsen, J. J. (2010). Migration and people trafficking in Southeast Asia. Trends \& Issues in Crime and Criminal Justice, 401(1), 1 - 6.

Larsen, J. J., Andrevski, H., \& Lyneham, S. (2013). Experiences of trafficked persons: An Indonesian sample (pp. 1-8). Woden: Australian Institute of Criminology.

Lasimbang, H. B., Tong, W. T., \& Low, W. Y. (2016). Migrant workers in Sabah, east Malaysia: The importance of legislation and policy to uphold equity on sexual and reproductive health and rights. Best Practice \& Research Clinical Obstetrics \& Gynaecology, 32(1), 113-123.

Lean, L. L. (1998). The sex sector: The economic and social bases of prostitution in Southeast Asia (L. L. Lim Ed.). Geneva, Switzerland: International Labour Organization.

Lee, B. X. (2016). Causes and cures VII: Structural violence. Aggression and Violent Behaviour, 28(1), 109-114.

Lee, M. (2007). Human trafficking. Michigan: Willan. 
Lee, M. (2011a). Contested Definitions of Human Trafficking. In M. Lee (Ed.), Trafficking and Global Crime Control. London: Sage Publications Ltd.

Lee, M. (2011b). Constructing and denying victimhood in trafficking. In M. Lee (Ed.), Trafficking and global crime control (pp. 1-13). London: Sage.

Lee, M. (2014). Gendered discipline and protective custody of trafficking victims in Asia. Punishment \& Society, 16(2), 206-222.

Lee, P. P. (1978). Chinese society in nineteenth century Singapore. Kuala Lumpur: Oxford University Press.

Lee, R., Lai, A., \& Raman, A. (2013, January 14). "Health spa' offers well-endowed prostitutes at premium prices. The Star Online. Retrieved from

http://www.thestar.com.my/news/nation/2013/01/14/health-spa-offers-wellendowedprostitutes-at-premium-prices/

Lee, Y.-S., \& Hadeed, L. (2009). Intimate partner violence among Asian immigrant communities health/mental health consequences, help-seeking behaviors, and service utilization. Trauma, Violence \& Abuse, 10(2), 143-170.

Lehti, M., \& Aromaa, K. (2006). Trafficking for sexual exploitation. In M. Tonry (Ed.), Crime and Justice: A Review of Research (Vol. 34, pp. 133-227). Chicago: University of Chicago Press.

Leisenring, A. (2006). Confronting "victim" discourses: The identity work of battered women. Symbolic Interaction, 29(3), 307-330.

Lek, P. A. (2016, September 17). The dilemma of having foreign workers in Malaysia. The Straits Times. Retrieved from https://www.straitstimes.com/opinion/the-dilemma-of-havingforeign-workers-in-malaysia

Lempert, L. B. (1996). Women's strategies for survival: Developing agency in abusive relationships. Journal of Family Violence, 11(3), 269-289.

Leng, O. T. S., Khan, S., \& Rahim, R. A. (2014). Internet: The double-edged sword of trafficking of women in Malaysia. Pertanika Journal Social Science and Humanities, 22(S), 149-160.

Leong, T. (2017, May 27). KL police detain 100 over sabotage of immigration system. The Straits Times. Retrieved from https://www.straitstimes.com/asia/se-asia/kl-police-detain-100-oversabotage-of-immigration-system

Lepp, A., \& Gerasimov, B. (2019). Editorial: Gains and challenges in the global movement for sex workers' rights. Anti Trafficking Review, 12(1), 1-13

Lerner, G. (1987). The Creation of patriarchy. London: Oxford University Press.

Levenkron, N., \& Dahan, Y. (2003). Women as commodities: Trafficking in women in Israel 2003. Haifa: Haifa Feminist Center, and Adva Center.

Levy, J., \& Jakobsson, P. (2014). Sweden's abolitionist discourse and law: Effects on the dynamics of Swedish sex work and on the lives of Sweden's sex workers. Criminology \& Criminal Justice, 14(5), 593-607. 
Limoncelli, S. A. (2009). The trouble with trafficking: Conceptualizing women's sexual labor and economic human rights. Women's Studies International Forum, 32(4), 261-269.

Lin, M. M. (2019, January 16). Malaysia revises 'victim-shaming' school text book. BBC News. Retrieved from https://www.bbc.com/news/world-asia-46888332

Lobasz, J. K. (2009). Beyond border security: Feminist approaches to human trafficking. Security Studies, 18(2), 319 - 344.

Lodhi, D. M. S., \& Siddiqui, D. J. A. (2014). A sociological perspective on the issue of killing in the name of honor in Pakistan. IOSR Journal Of Humanities And Social Science, 19(12), 58 - 61.

Logan, T. K., Walker, R., \& Hunt, G. (2009). Understanding human trafficking in the United States. Trauma, Violence, \& Abuse, 10(1), 3-30.

Loos, T. (2009). Transnational histories of sexualities in Asia. The American Historical Review, 114(1), 1309-1324.

Lundgren, E. (2004). The process of normalising violence. Stockholm: National Organization of Battered Women's Shelters in Sweden.

Lyons, W. (2013). What is a representative sex worker? In: Feministe. Retrieved June 13, 2018 from http://www.feministe.us/blog/archives/2011/12/04/what-is-a-representative-sex-worker/

Lyons, L., \& Ford, M. (2013). Trafficking versus smuggling: Malaysia's Anti-Trafficking in Persons Act. In S. Yea (Ed.), Human trafficking in Asia: Forcing issues (pp. 35-48). London: Routledge.

MacKinnon, C. (1987). Feminism unmodified: Discourses on life and law. Cambridge, Massachusetts: Harvard University Press.

Madriz, E. (1997). Images of criminals and victims: A study on women's fear and social control. Gender and Society, 11(3), 342-356.

Mahathir, M. (2009). Fatal confluences? Islam, gender, and AIDS in Malaysia Islam and AIDS: between scorn, pity and justice (pp. 105-118). Oxford: One World.

Mahdavi, P. (2015). Migrating in the era of human trafficking. Asian Population Studies, 11(2), 111114.

Mahoney, M. A. (1996). The problem of silence in feminist psychology. Feminist Studies, 22(3), 603625.

Mahoney, M. R. (1994). Victimization of oppression? Women's lives, violence, and agency. In M. A. Fineman \& R. Mykitiuk (Eds.), The public nature of private violence: The discovery of domestic abuse (pp. 59-92). New York: Routledge.

Malaymail. (2015, May 31). Trafficking essential to Malaysia's economy, says Huffington Post. Malaymail. Retrieved from https://www.malaymail.com/news/malaysia/2015/05/31/trafficking-essential-to-malaysiaseconomy-says-huffington-post/906919 
Malaysian Bar Council. (2009). Submission of the Malaysian Bar Council for the 4th Universal Periodic Report. Geneva: OHCHR.

Malloch, M. (2015). Criminalising victims of human trafficking: State responses and punitive practices. In M. Malloch \& P. Rigby (Eds.), Human trafficking: The complexities of exploitation. Edinburgh: Edinburg University Press Ltd.

Manderson, L. (1997). Colonial desires: Sexuality, race, and gender in British Malaya. Journal of the History of Sexuality, 7(3), $372-388$.

Manimekalai, K., \& Veeramani, P. (2018). Gender and patriarchy. International Journal of Applied Research, 4(2), 85-88.

Marmo, M., \& Forgia, R. L. (2008). Inclusive national governance and trafficked women in Australia: Otherness and local demand. Asian Criminology, 3(1), 173-191.

Marshall, C., \& Rossman, G. B. (1989). Designing qualitative research. Newbury Park, California: Sage.

Martin, D. (1981). Battered women - scope of the problem. In B. Galaway \& J. Hudson (Eds.), Perspectives on crime victims (pp. 190-201). Toronto: C.V Mosby Company.

Marvasti, A. B. (2004). Data analysis. In A. B. Marvasti (Ed.), Qualitative research in sociology (pp. 81119). London: Sage.

Mason, G., \& Stubbs, J. (2011). Feminist criminological research and the meanings of violence. In L. Bartels \& K. Richards (Eds.), Qualitative Criminology: Stories from the field (pp. 158-166). Sydney: Hawkins Press.

Mattar, M. Y. (2006). Human security of state security - the overriding threat in trafficking in persons. Intercultural Human Rights Law Review, 1(1), 249-279.

Matthews, R. (2015). Female prostitution and victimization: A realist analysis. International Review of Victimology, 21(1), 85-100.

Maududi, A. (1991). Purdah and the status of women in Islam. Lahore: Islamic Publications.

McCabe, K. A., \& Manian, S. (2010). Introduction: Defining sex trafficking. In K. A. McCabe \& S. Manian (Eds.), Sex Trafficking (pp. 1-8). Plymouth: Rowman \& Littlefiled Publishers, Inc.

McDougall, G. J. (1999). How to end violence against women in war and armed conflict situations: Japan's military sexual slavery viewed from international law (Vol. 1, pp. 18). Tokyo: VAWWNET Japan.

McDowell, S. (2007). "Remembering': Victims, survivors and commemoration: Who are the victims? Debates, concepts and contestation in 'post - conflict' Northen Ireland. Retrieved February 19, 2018, from http://cain.ulst.ac.uk/victims/introduction/smcd07whoarethevictims.pdf

McFadyen, A. (2000). Bound to sin: Abuse, holocaust, and the Christian doctrine of sin. Cambridge: Cambridge University Press. 
McMenzie, L., Cook, I. R., \& Laing, M. (2019). Criminological policy mobilities and sex work: Understanding the movement of the 'Swedish Model' to Northern Ireland. The British Journal of Criminology, 59(5), 1199-1216.

Meier, B. (2015, December 12). Alan Dershowitz on the defense (his own). The New York Times. Retrieved from https://www.nytimes.com/2015/12/13/business/alan-dershowitz-on-thedefense-his-own.html

Merghati-Khoei, E., Ghorashi, Z., Yousefi, A., , \& Smith, T. G. (2014). How do Iranian women from Rafsanjan conceptualize their sexual behaviors? Sexuality and Culture, 18(3), 592-607.

Meyer, C. K., \& Boll, S. (2018). Irregular migrants, refugees or trafficked persons? Anti-Trafficking Review, 11(1), 1-16.

Meyers, D. T. (2011). Two victim paradigms and the problem of "impure" victims. Humanity: An International Journal of Human Rights, Humanitarianism, and Development, 2(2), 255 - 275.

Meyers, D. T. (2013). Victims, agency, and human rights. Retrieved February 9, 2018, from http://www.e-ir.info/2013/12/09/victims-agency-and-human-rights/

Meyers, D. T. (2014). Feminism and sex trafficking: Rethinking some aspects of autonomy and paternalism. Ethic Theory Moral Practice, 17(3), 427-441.

Miccio-Fonseca, L. C. (2017). Juvenile female sex traffickers. Aggression and Violent Behavior, 35(1), 26-32.

Michiko, N. (2001). Comfort women in Malaysia. Critical Asian Studies, 33(4), 581-589.

Miers, D. (1990). Positivist victimology : A critique part 2: Critical victimology. International Review of Victimology, 1(3), 219-230.

Mies, M. (1983). Towards a methodology for feminist research Theories of women's studies (pp. 117140). London: Routledge and Keagan Paul.

Mikkola, M. (2006). Elizabeth Spelman, gender realism, and women. Hypatia, 21(4), 77-96.

Milivojevic, S., \& Copic, S. (2010). Victims of sex trafficking: Gender, myths and consequences. In S. G. Shoham, P. Knepper \& M. Kett (Eds.), International handbook of victimology. Florida: Taylor \& Francis Group.

Miller, A. (2004). Sexuality, violence against women, and human rights: Women make demands and ladies get protection. Health and Human Rights, 7(2), 17-47.

Miller, S. C. (2009). Moral Injury and Relational Harm: Analyzing Rape in Darfur. Journal of Social Philosophy, 40(4).

Mishra, R. K. (2013). Postcolonial feminism: Looking into within-beyond-to difference. International Journal of English and Literature, 4(4), 129-134.

Moeller, S. D. (1999). Compassion fatigue: How the media sell disease, famine, war and death. New York: Routledge. 
Moghissi, H. (1999). Feminism and Islamic fundamentalism: The limits of postmodern analysis. London: Zed Books Ltd.

Mohajan, H. K. (2018). Qualitative research methodology in social sciences and related subjects. Journal of Economic Development, Environment and People, 7(1), 23-48.

Mohammad, A. (2015, 02 February). 100 wanita diselamatkan. Utusan Online. Retrieved from http://www.utusan.com.my/berita/jenayah/100-wanita-diselamatkan-1.55104

Mohanty, C.T. (1991), Under western eyes: feminist scholarship and colonial discourses. In Mohanty, C.T., Russo, A. and Torres, L. (Eds.), Third world women and the politics of feminism (pp. 5180). Bloomington, Indianapolis: Indiana University Press.

Molland, S. (2011). 'I am helping them':'Traffickers','anti-traffickers' and economies of bad faith. The Australian Journal of Anthropology, 1(22), 236-254.

Molland, S. (2012). Introduction The perfect business? Anti-trafficking and the sex trade along the Mekong. Honolulu: University of Hawai'i Press.

Moran, R. (2013). Paid for: My journey through prostitution. Dublin: Gill and Macmillan.

Montell, F. (1999). Focus group interviews: A new feminist method. NWSA Journal, 11(1), 44-71.

Moon, C. (2013). 'Looking without seeing, listening without hearing': Cohen, denial and human rights. Crime Media Culture, 9(2), 193-196.

Moossy, R. (2009). Sex trafficking: Identifying cases and victims. NIJ Journal, 262(1), 1-2.

Morgan, E. (2005). Mary and modesty. Christianity and Literature, 54(2), 209-233.

Moser, C. O. N., \& Clark, F. C. (2001). Introduction. In C. O. N. Moser \& F. C. Clark (Eds.), Victims, perpetrators or actors? Gender, armed conflict and political violence. New York: Zed Books.

Mstar. (2017, February 10). Imigresen tumpas sindiket pelacuran antarabangsa. MStar. Retrieved from https://www.mstar.com.my/lokal/semasa/2017/02/10/imigresen-tumpas-sindiketpelacuran

Mumtaz, Z., Shahid, U., \& Levay, A. (2013). Understanding the impact of gendered roles on the experiences of infertility amongst men and women in Punjab. Reproductive Health, 10(3), 1 9.

Munro, V. E. (2008). Of rights and rhetoric: discourses of degradation and exploitation in the context of sex trafficking. Journal Law Society, 35(2).

Muraszkiewicz, J., Georgiou, M., \& Constantinou, A. (2014). Review of the media framing of human trafficking. Retrieved May 26, 2019, from https://cris.cumulus.vub.ac.be/portal/files/5208711/TRACE_D1.2_Final.pdf

Murdoch, L. (2015, May 12). Human traffickers 'killing Rohingya and Bangladesh refugees' on Bay of Bengal route. The Sydney Morning Herald. Retrieved from 
https://www.smh.com.au/world/human-traffickers-killing-rohingya-and-bangladeshrefugees-on-bay-of-bengal-route-20150512-ggzoxl.html

Murray, C. (2014). Ending the stigma surrounding human trafficking: Series introduction. Retrieved March 26, 2014, from http://www.seethetriumph.org/blog/ending-the-stigma-surroundinghuman-trafficking-series-introduction

Musto, J. L. (2009). What's in a name? Conflations and contradictions in contemporary U.S. discourses of human trafficking. Women's Studies International Forum, 32(1), 281-287.

Nagaraj, S., \& Yahya, S. R. (1998). Prostitution in Malaysia. In L. L. Lim (Ed.), The sex sector. Geneva: International Labour Office.

Nagata, J. A. (1984). The reflowering of Malaysian Islam : modern religious radicals and their roots. Vancouver: University of British Columbia Press.

Nagy, R. (2008). Transitional Justice as a Global Project: Critical Reflections. Third World Quarterly, 29(2), 275-289.

Narlı, N. f. (1991). Unveiling the fundamentalist women : a case study of university students in Malaysia. Istanbul: Isis Press.

Nasira, R., Zamani, Z. A., Ismail, R., Yusooff, F., Khairuddin, R., \& Mohamad, L. Z. (2010). Self-esteem and cognitive distortion among women involved in prostitution in Malaysia. Procedia - Social and Behavioral Sciences, 5(1), 1939-1944.

Natalie, T. (2017). Practitioner knowledge and responsiveness to victims of sex trafficking in Aotearoa/New Zealand. 31(2), 77-96.

National Institute of Justice. (2017). Victims and Victimization. Retrieved 28 February, 2018, from https://www.nij.gov/topics/victims-victimization/Pages/welcome.aspx

New Straits Times. (2018). Higher minumum wage nationwide from Jan 1 2019. New Straits Times. Retrieved September 5, 2018, from https://www.nst.com.my/news/nation/2018/09/408642/higher-minimum-wagenationwide-jan-1-2019

New Zealand Prostitutes Collective. (n.d). The New Zealand Model. Retrieved May 27, 2019, from https://www.nzpc.org.nz/The-New-Zealand-Model

Newburn, T. (2013). Victims, victimisation and victimology. In T. Newburn (Ed.), Criminology (pp. 351-378). London: Routledge. (Reprinted from: 2nd).

Newman, E., \& Cameron, S. (2008). Introduction: Understanding human trafficking. In S. Cameron \& E. Newman (Eds.), Trafficking in Humans (pp. 1-17). Tokyo: United Nations University Press.

Nielsen, I., \& Sendjaya, S. (2014). Wellbeing Among Indonesian Labour Migrants to Malaysia: Implications of the 2011 Memorandum of Understanding. Social Indicators Research, 117(3), 919-938.

Nikolic-Ristanovic, V. (2002). Sex Trafficking in Women. In V. Nikolic-Ristanovic (Ed.), Social Change, Gender and Violence (10 ed., pp. 111-138). Dordrecht: Kluwer Academic Publishers. 
Nkrumah, K. (1965). Neo-Colonialism, The last stage of imperialism. London: Thomas Nelson \& Sons, Ltd.

Noor, A. M. (2010). A problem of crime classification in Islamic law. Arab Law Quarterly, 24(4), 417438.

Nowak, M. (2005). U.N. Covenant on civil and political rights: CCPR commentary (2nd ed.). Strasbourg: N. P. Engel, Publisher.

Nussbaum, M. (1999). Sex and social justice. New York: Oxford University Press.

Nussbaum, M. (2001). Upheavals of thought. Cambridge: Cambridge University Press.

O'Brien, E. (2013). Ideal victims in human trafficking awareness campaigns. In K. Carrington, M. Ball, E. O'Brien \& J. Tauri (Eds.), Crime, Justice And Social Democracy: International Perspectives (pp. 315 - 326). Basingstoke: Palgrave Macmillan.

O'Brien, E., Hayes, S., \& Carpenter, B. (2013). Causes of trafficking. In O'Brien, E., Hayes, S., \& Carpenter, B (Eds.), The politics of sex trafficking: A moral geography (pp. 132-165). London: Palgrave Macmillan.

O'Connell Davidson, J. (2005). Children in the global sex trade. Cambridge: Polity.

O'Connor, M. (2017). Choice, agency consent and coercion: Complex issues in the lives of prostituted and trafficked women. Women's Studies International Forum, 62(1), 8-16.

Oakley, A. (1981). Subject Women. Oxford: Pantheon.

Official Portal Human Rights Commission of Malaysia. (2013). Human trafficking. Retrieved Nov 6, 2017, from http://www.suhakam.org.my/human-trafficking/

Official Portal of Immigration Department of Malaysia. (2018). Visa requirement by country. Retrieved May 29, 2018, from http://www.imi.gov.my/index.php/en/visa/visa-requirementby-country.html

Oliver, C. (2012). Critical realist grounded theory: A new approach for social work research. British Journal of Social Work, 42(1), 371-387.

Olsen, T. (2003). Silences. New York: Feminist Press at the City University of New York.

Ong, A. (1990). State versus Islam: Malay families, women's bodies, and the body politic in Malaysia. Journal of the American Ethnological Society, 17(2), 258 - 276.

Orlova, A. V. (2004). From social dislocation to human trafficking: The Russian case. Problems of Post-Communism, 51(6), 14-22.

Östergren, P., \& Dodillet, S. (2011). The Swedish Sex Purchase Act: Claimed success and documented effects. Paper presented at the International workshop: Decriminalizing prostitution and beyond: Practical experiences and challenges', The Hague. 
Othman, N. (2006). Muslim women and the challenge of Islamic fundamentalism/extremism: An overview of Southeast Asian Muslim women's struggle for human rights and gender equality. Women's Studies International Forum, 29(4), 339 - 353.

Othman, Z. (2006). Human (In)security, human trafficking, and security in Malaysia. In K. B. a. D. Amir (Ed.), Trafficking and the global sex industry. Oxford: Lexington.

Outshoorn, J. (2015). The trafficking policy debates. In M. Dragiewicz (Ed.), Global human trafficking: Critical issues and contexts (pp. 7 - 22). New York: Routledge.

Parpart, J. L. (2010). Choosing silence: rethinking voice, agency and women's empowerment. In R. Ryan-Flood \& R. Gill (Eds.), Secrecy and silence in the research process: Feminist reflections. Abingdon, Oxon: Routledge.

Passport Act 1966 (Revised 1974) (Laws of Malaysia) Reprint Act 150.

Pastner, C. M. (1978). The status of women and property on a Baluchistan oasis in Pakistan. In L. Beck \& N. Keddie (Eds.), Women in the Muslim World (pp. 434-450). Cambridge, Massachusetts: Harvard University Press.

Peach, L. J. (2005). Sex slaves' or 'sex workers'? Cross-cultural and comparative religious perspectives on sexuality, subjectivity, and moral identity in anti-sex trafficking discourse. Culture and Religion: An Interdisciplinary Journal, 6(1), 107-134.

Pearce, J. (2010). Safeguarding young people from sexual exploitation and from being trafficked: Tensions within contemporary policy and practice. Youth and Policy, 104(1), 1 - 11.

Pearson, E., \& Anti-Slavery International. (2002). Human traffic, human rights: redefining victim protection. Horsham: The Printed World.

Perrin, B., Majumdar, S., Gafuik, N., \& Andrews, S. (2001). The future of Southeast Asia: Challenges of child sex slavery and trafficking in Cambodia. Phnom Penh: Motorola Printers.

Pheterson, G. (1993). The whore stigma: Female dishonor and male unworthiness. Social Text (Winter), 37(1), 38-64.

Phillips, J. (2008). People trafficking: an update on Australia's response. Retrieved May 27, 2019, from https://www.aph.gov.au/About_Parliament/Parliamentary_Departments/Parliamentary_Lib rary/pubs/rp/rp0809/09rp05

Picart, C. J. K. S. (2003). Rhetorically reconfiguring victimhood and agency: The violence against Women Act's Civil Rights clause. Rhetoric \& Public Affairs, 6(1), 97 - 126.

Pickering, S. (2011). Women and extra legal border crossing. In Women, Borders, and Violence : Current Issues in Asylum, Forced Migration and Trafficking (pp. 2-16). New York: Springer.

Pickering, S., Bosworth, M., \& Aas, K. F. (2014). The criminology of mobility. In S. Pickering \& J. Ham (Eds.), The Routledge Handbook on Crime and International Migration. New York: Taylor and Francis. 
Pickering, S., \& Ham, J. (2013). Hot pants at the border: Sorting sex work from trafficking. The British Journal of Criminology, 54(1), 2-19.

Pickering, S., \& Segrave, M. (2011). Policing the border within: Sex trafficking and the regulation of sex work. In S. Pickering (Ed.), Current issues in asylum, forced migration and trafficking (pp. 93-107). New York: Springer.

Piper, N. (2005). A problem by a different name? A review of research on trafficking in South-East Asia on trafficking in South East Asia and Oceania. International Migration, 43(1/2), 220.

Pitt-Rivers, J. (1965). Honour and social status. In J. G. Peristiany (Ed.), Honour and shame: The Values of Mediterranean Society (pp. 19-77). London: Weidenfeld and Nicolson.

Pollak, J. M., \& Kubrin, C. E. (2007). Crime in the news: How crimes, offenders and victims are portrayed in the media. Criminal Justice \& Popular Culture, 14(1), 60-83.

Porter, E. (2016). Gendered narratives: Stories and silences in transitional justice. Human Rights Review, 17(1), 35-50.

Poudel, M., \& Smyth, I. (2002). Reducing povrty and upholding human rights: a pragmatic approach. In R. Masika (Ed.), Gender, Trafficking, and Slavery (pp. 80-86). Oxford: Oxfam GB.

Prayag, G., \& Ryan, C. (2011). The relationship between the 'push' and 'pull' factors of a tourist destination: the role of nationality - an analytical qualitative research approach. Current Issues in Tourism, 14(2), 121-143.

Prince, M., Patel, V., Saxena, S., Maj, M., Maselko, J., Phillips, M., \& Rahman, A. (2007). No health without mental health. The Lancet, 370(1), 859-877.

Purcell, V. (1948). The Chinese in Malaya. London: Oxford University Press.

Quinney, R. (1975). Who is the victim? In J. Hudson \& B. Galaway (Eds.), Considering the victim. readings in restitution and victim compensation. Springfield: Charles $C$ Thomas.

Radio Free Asia. (2011). Trafficking victims sheltered ahead of trial. Retrieved May 14, 2019, from https://www.rfa.org/english/news/laos/sheltered-12162011181729.html

Radovanovic, M., \& Kartusch, A. (2001). Combat of trafficking for the purpose of forced prostitution Bosnia and Herzegovina Country Report. Vienna: Ludwig Boltzmann Institute of Human Rights.

Rahman, M., \& Jackson, S. (2010). Gender and sexuality. New York: Wiley.

Ramayal, S. P. R. G. A. L. (2013). Organised crime: Government initiatives, laws and investigations of human trafficking in persons and smuggling of migrants in Malaysia. Retrieved October 18, 2017, from http://wyf.org.my/wp-content/uploads/2015/08/j-Paper-Presentation-LawEnforcement-on-Human-Trafficking.pdf

Ramazanoglu, C. (1992). On feminist methodology: male reason versus female empowerment. Sociology, 26(2), 207-212. 
Ramazanoglu, C., \& Holland, J. (2002). Feminist methodology: Challenges and choices. Thousand Oaks: Sage.

Raymond, J. (2002). The New UN Trafficking Protocol. Women's Studies International Forum, 25(2), 491-502.

Raymond, J. (2003). Ten reasons for not legalizing prostitution and a legal response to the demand for prostitution. In M. Farley (Ed.), Prostitution, trafficking, and traumatic stress (pp. 315332). Binghamton, New York: Haworth.

Raymond, J. G. (2004). Introduction to "the case against the legalization of prostitution". Violence Against Women, 10(10), 1083-1086.

Raymond, J. G. (2019). Filling the sex trade swamp: Robert kraft and his predecessors. Dignity: A Journal on Sexual Exploitation and Violence, 4(2), 1-5.

Raymond, J., \& Hughes, D. (2001). Sex trafficking of women in the united states: International and domestic trends. Coalition against trafficking in women. Retrieved November 29, 2019, from https://www.ncjrs.gov/pdffiles1/nij/grants/187774.pdf/

Reisigl, M., \& Wodak, R. (2009). The discourse-historical approach (DHA). In R. Wodak \& M. Meyer (Eds.), Methods for critical discourse analysis (Second revised ed., pp. 87-121). London: Sage.

Reiss, A. J., \& Roth, J. A. (1993). Understanding and preventing violence. Washington DC: National Academy Press.

Rekart, M. L. (2005). Sex-work harm reduction. The Lancet, 366(9503), 2123-2134.

Resolution 20/3 on Human Rights of Migrants, A/HRC/RES/20/3 Stat. (2012 16/7/2012).

Reuters. (2010, March 23). Foreign prostitutes rent Malaysian husbands for visas. Reuters. Retrieved from https://www.reuters.com/article/us-malaysia-prostitutes/foreign-prostitutes-rentmalaysian-husbands-for-visas-idUSTRE62M0MD20100323

Rich, A. (1978). The transformation of silence into language and action (A Panel Discussion). Sinister Wisdom 6, 6(1), 17-25.

Richard, T. (2013). Qualitative versus quantitative methods: Understanding why qualitative methods are superior for criminology and criminal justice.

Richardson, D., \& May, H. (1999). Deserving victim?: sexual status and the social construction of violence. The Sociological Review, 47(2), 308-331.

Riegler, A. (2007). Missing the mark: Why the Trafficking Victims Protection Act fails to protect sex trafficking victims in the United States. Harvard Journal of Law \& Gender, 30(1), 231-256.

Rimonte, N. (1991). A question of culture: Cultural approval of violence against women in the PacificAsian community and the cultural defense. Stanford Law Review, 43(6), 1311-1326.

Rinehart, I. E. (2015). Malaysia: Background and U.S relations. Retrieved 30/03/2019, 2019, from https://fas.org/sgp/crs/row/R43505.pdf 
Ritchie, J., \& Lewis, J. (2003). Qualitative research practice: A guide for social science students and researchers. London: Sage.

Roces, M. (2009). Prostitution, women's movements and the victim narrative in the Philippines. Women' Studies International Forum, 32(4), 270-280.

Rodríguez-Hidalgoa, A. J. (2015). Peer-victimisation in multi-cultural contexts: A structural model of the effects on self-esteem and emotions. Psicologia Educativa, 21(1), 3-9.

Rome Statute of the International Criminal Court (adopted on 17 July 1998 and it entered into force on 1 July 2002).

Roux, P. L. (2010). A Lethal Funnel: Prostitution and trafficking in women for sexual exploitation in Southeast Asia (Thailand, Malaysia, Singapore). In L. R. Pierre, J. Baffie \& G. Beulier (Eds.), The trade in human beings for sex in Southeast Asia (pp. 111-150). Bangkok: White Lotus.

Rozanna, L., \& Chow, E. (2016, June 1). Malaysia uncovers immigration racket raising trafficking, security fears. Reuters. Retrieved from https://www.reuters.com/article/us-malaysiasecurity-idUSKCNOYN3O0

Ruether, R. R. (1998). Religion and sexism: Images of woman in the Jewish and Christian traditions. Eugene, Oregon: Wipf and Stock Publishers.

Russell, A. M. (2014). The boundaries of belonging: Gender, human trafficking and embodied citizenship. Journal of Gender Studies, 25(1), 1-14.

Russell, E. (2015). Revisiting the tasty raid: lesbian and gay respectabilty and police legitimacy. Australian Feminist Law Journal, 41(1), 121-140.

Ryan, C., \& Hall, C. M. (2001). Sex tourism: Marginal people and liminalities. London: Routledge.

Rydstrøm, H. (2006). Sexual desires and 'social evils': Young women in rural Vietnam. Gender, Place \& Culture, 13(3), 283-301.

Sagot, M. (2005). The critical path of women affected by family violence in Latin America: Case studies from 10 countries. Violence Against Women, 11(10), 1292-1318.

Sakalli, N. (2001). Beliefs about wife beating among Turkish college students: The effects of patriarchy, sexism, and sex differences. Sex Roles, 44(9/10), 599 - 610.

Saldana, J. (2009). An introduction to codes and coding. In J. Saldana (Ed.), The coding manual for qualitaticve researchers (pp. 1-31). London: Sage.

Sallman, J. (2010). Living with stigma: Women's experiences of prostitution and substance use. Journal of Women and Social Work, 25(2), 146-159.

Salt, J. (2000). Trafficking and human smuggling: A European perspective. International Migration, Special Issue, 1(1), 31-56.

Salt, J. (2005). Current trends in international migration in Europe. Strasbourg: Council of Europe Publishing. 
Salt, J., \& Stein, J. (1997). Migration as a business: The case of trafficking. International Migration, 35(4), 467 - 494.

Samarasinghe, V. (2008). Female sex trafficking in Asia, The resiliency of patriarchy in a changing world. New York: Routledge.

Samarasinghe, V., \& Burton, B. (2007). Strategising prevention: a critical review of local initiatives to prevent female sex trafficking. Development in Practice, 17(1), 51-64.

Sanders, T. (2001). Female street sex workers, sexual violence, and protection strategies. Journal of Sexual Aggression, 7(1), 5-18.

Sanders, T. (2008). Paying for pleasure : Men who buy sex. New York: Routledge.

Sandy, L. (2009). 'Behind closed doors': debt-bonded sex workers in Sihanoukville, Cambodia. The Asia Pacific Journal of Anthropology, 10(3), 216-230.

Sanford, R., Martínez, D. E., \& Weitzer, R. (2016). Framing human trafficking: A content analysis of recent U.S. Newspaper articles. Journal of Human Trafficking, 2(2), 139-155.

Sanghera, J. (2016). Unpacking the trafficking discourse. In K. Kempadoo, J. Sanghera \& B. Pattanaik (Eds.), Trafficking and prostitution reconsidered: New perspectives on migration, sex work, and human rights authors (Updated Second ed.). New York: Routledge.

Santos, B. D. S. (1995). Toward a new common sense: law, science, and politics in the paradigmatic transition. New York: Routledge.

Santos, B. D. S. (2010). The sexual trafficking of women : Representations of illegality and victimisation. RCCS Annual Review, 26(2), 195-210.

Saunders, P. (2005). Traffic violations: Determining the meaning of violence in sexual trafficking Versus Sex Work. Journal of Interpersonal Violence, 20(3), 343-360.

Scambler, G., \& Scambler, A. (Eds.). (1999). Rethinking prostitution: Purchasing sex in the 1990s. London: Routledge.

Schauer, E., \& Wheaton, E. (2006). Sex trafficking into the United States: A literature review. Critical Justice Review, 31(2), 146-149.

Schneider, E. M. (1993). Feminism and the false dichotomy of victimisation and agency. New York Law Review, 38(1), 387-399.

Schlosser, J. A. (2008). Issues in interviewing inmates: Navigating the methodological landmines of prison research. Qualitative Inquiry, 14(8), 1500-1525.

Schutt, R. K. (2012). Investigating the social world: the Process and practice of research. California: Sage.

Scutt, J. A. (1997). The incredible woman's power and sexual Politics. Melbourne: Artemis Publishing.

Schwarzenbach, S. (1991). Contractarians and feminists debate prostitution. Review of Law and Social Change, 18(1), 103-130. 
Sedyaningsih-Mamahit, E. R. (1999). Female commercial sex workers in Kramat Tunggak, Jakarta, Indonesia. Social Science \& Medicine, 49(8), 1101-1114.

Sangera, M. (2009). Order at the border: The repatriation of victims of trafficking. Women's Studies International Forum, 32, 251-260.

Segrave, M. (2013). Human trafficking. Surrey: Ashgate Publishing Company.

Segrave, M., Milivojevic, S., \& Pickering, S. (2009). Sex Trafficking : International context and response. Devon: Willan Publishing.

Sehlikoglu, S. (2018). Revisited: Muslim Women's agency and feminist anthropology of the middle east. Contemporary Islam, 12(1), 73-92.

Sen, A. (1999). Development as freedom. Oxford: Oxford University Press.

Sen, K (2005). Trafficking in women and children in India. Hyderabad: Orient Longman.

Sereni, A., \& Baker, C. (2018). Before the Harm is Done: Examining the UK's response to the prevention of trafficking. London: Anti-Slavery International for The Anti-Trafficking Monitoring Group.

Shafiee, N. (2018, April 3). 'Ayam Vietnam tak dan berkokok'. My Metro. Retrieved from https://www.hmetro.com.my/mutakhir/2018/04/326966/ayam-vietnam-tak-dan-berkokok

Shah, S. (2013). The Malaysian dilemma: negotiating sexual diversity in a Muslim-majority commonwealth state Human Rights, Sexual Orientation and Gender Identity in The Commonwealth: Struggles for Decriminalisation and Change (pp. 261-286). London: University of London.

Shahrudin, H. S., \& Asyraf, F. (2016, 21 March). Women and men offering sex online. New Straits TImes. Retrieved from https://www.nst.com.my/news/2016/03/134038/women-and-menoffering-sex-online

Shalit, A. D., Heynen, R., \& Meulen, E. v. d. (2014). Human trafficking and media myths: Federal funding, communication strategies, and Canadian anti-trafficking programs. Canadian Journal of Communication, 39(3), 385-412.

Shapland, J. (2009). The conceptual and theoretical basis of victimology: an introduction. In B. Williams \& H. G. Chong (Eds.), Vicitms and Victimisation: A Reader. Berkshire: Open University Press.

Sharma, N. (2005). Anti-trafficking rhetoric and the making of a global apartheid. NWSA, 17(3), 88111.

Shaw, S. A., Saifi, R., Lim, S. H., Saifuddeen, S. M., \& Kamarulzaman, A. (2017). Islam and HIV related social services in Malaysia. Journal of Religion \& Spirituality in Social Work: Social Thought, 36(1-2), 133-145. 
Sheldon-Sherman, J. A. L. (2012). The missing P: Prosecution, prevention, protection, and partnership in the Trafficking Victims Protection Act. Pensn State Law Review, 117(1), 443501.

Shelley, L. (2007). Human trafficking as a form of transnational crime. In M. Lee (Ed.), Human Trafficking (pp. 116-137). Abingdon, Oxon: Routledge.

Siddharth, K. (2017). Sex trafficking: An overview. In K. Siddharth (Ed.), Sex trafficking: Inside the business of modern slavery (pp. 1-44). New York: Columbia University Press.

Sikka, A. (2010). Trafficking of aboriginal women and girls in Canada. Aboriginal Policy Research Consortium International, 57(1), 201-231.

Silber, I. C. (2005). Mothers/fighters/citizens: Violence and disillusionment in post-war El Salvador. In S. D'Cruze \& A. Rao (Eds.), Violence, vulnerability and embodiment: Gender and History (pp. 67-93). Oxford: Blackwell.

Silberschmidt, M. (2001). Disempowerment of men in rural and urban East Africa: Implications for male identity and sexual behaviour. World Development, 29(4), 657 - 671.

Silove, D., Ventevogel, P., \& Rees, S. (2017). The contemporary refugee crisis: an overview of mental health challenges. World Psychiatry, 16(2), 130-139.

Silvey, R. (2004). Transnational migration and the gender politics of scale: Indonesian domestic workers In Saudi Arabia. Singapore Journal of Tropical Geography, 25(2), 1 - 16.

Silverman, S. J. (2015). Carceral spaces: mobility and agency in imprisonment and migrant detention. Social \& Cultural Geography, 16(7), 863-864.

Sim, F. K. (1984). Women in Malaysia - A Bibliography. In H. A. Yun, N. S. Karim \& R. Talib (Eds.), Women in Malaysia (pp. 234-244). Petaling Jaya: Pelanduk Publications (M) Sdn Bhd.

Simpkins, D. (1998). Rethinking the sex industry: Thailand's sex workers, the state, and changing cultures of consumption. Unequal Exchange: Gender and Economies of Power, 12(1), 1 - 3.

Sinar Harian. (2016, February 15). Pelacuran cemar imej Kuantan. Kumpulan Media Karangkraf. Retrieved from https://www.karangkraf.com/berita/pelacuran-cemar-imej-kuantan1.485271

Sinar Harian. (2018, November 28). Tujuh pelacur warga asing ditahan. Sinar Harian. Retrieved from https://www.sinarharian.com.my/article/1256/KHAS/Isu/Tujuh-pelacur-warga-asing-ditahan

Sisters in Islam. (n.d). The SIS story. Retrieved May 15, 2019, from

http://www.sistersinislam.org.my/page.php?35

Skilbrei, M.-L. (2010). Taking trafficking to court. Women \& Criminal Justice, 20(1), 40 - 56.

Skrobanek, S., Sakhrōbānēk, S. n., Boonpakdi, N., Jantateero, C., Čhanthathīrō, C., \& Janthakeero, C. (1997). The traffic in women. Human realities of the international sex trade. London: Zed Books. 
Slee, N. (1989). Women's silence in religious education. British Journal of Religious Education, 12(1), 29-37.

Smart, C. (1990). Law's truth/women's experience. In R. Graycar (Ed.), Dissenting opinions: Feminist explorations in law and society (pp. 1-20). Sydney: Allen and Unwin.

Smart, C. (1995). Law, crime and sexuality: Essays in feminism. London: Sage.

Smart, C. (2013). Women, crime and criminology (First ed.). London: Routledge.

Smith, C. (2005). Gender and crime. In C. Hale, K. Hayward, A. Wahidin \& E. Wincup (Eds.), Criminology. Oxford: Oxford University Press.

Smith, L., \& Vardaman, S. H. (2010). The problem of demand in combating sex trafficking. Revue Internationale De Droit Pénal, 81(3), 607-624.

Smith, T. (2012). Decolonizing methodologies: Research and indigenous peoples (Second ed.). New York: Zed Books.

Socialstyrelsen. (2008). Prostitution in Sweden 2007. Retrieved November 6, 2019, from http://www.Socialstyrelsen.se/Lists/Artikelkatalog/

Soderlund, G. (2005). Running from the rescuers: new U.S crusades against sex trafficking and the rhetoric of abolition. Fem Form, 17(3), 64-87.

Soh, C. S. (1996). The Korean "comfort women": Movement for redress. Asian Survey, 36(12), 12261240.

Solnit, R. (2017, March 8). Silence and powerlessness go hand in hand - women's voices must be heard. The Guardian. Retrieved from https://www.theguardian.com/commentisfree/2017/mar/08/silence-powerlessnesswomens-voices-rebecca-solnit

Sopapong, A. (2012, 21 May). New trafficking route ends in Malaysia. Radio Free Asia. Retrieved from http://www.rfa.org/english/news/laos/route-05212012153608.html/

South Asia Regional Initiative. (2006). Minimum standards of care and support for the victims of trafficking and other forms of violence in South Asia. Retrieved April 17, 2018, from https://pdf.usaid.gov/pdf_docs/PNADJ785.pdf

Spalek, B. (2006). Crime victims: Theory, policy and practice,. International Journal of the Sociology of Law, 35(4), 163-212.

Spelman, E. V. (1988). Inessential woman: Problems of exclusion in feminist thought. Boston: Beacon Press.

Srikantiah, J. (2007). Perfect victims and real survivors: The iconic victim in domestic human trafficking law. Boston University Law Review, 28(1), 158 - 211.

Stanko, E. (1990). Everyday violence. London: Virago. 
Stanley, L. (1990). Feminist praxis : research, theory, and epistemology in feminist sociology. London: Routledge.

Stanley, L., \& Wise, S. (1993). Breaking out again. London: Routledge.

Stanslas, P. T. (2010). Transborder human trafficking in Malaysian waters: Addressing the root causes. Journal of Maritime Law \& Commerce, 41(4), 595-606.

Stella. (2013). Language matters: Talking about sex work. Retrieved January 28, 2020 from Tenaganita. (2012). TENAGANITA: The Truth About Migrants in Malaysia. Retrieved October 8, 2015, from https://www.nswp.org/sites/nswp.org/files/StellaInfoSheetLanguageMatters.pdf

Stephen-Smith, S. (2008). Prisoners with no crime. Detention of trafficked women in the UK. London: The Poppy Project.

Stevenson, L. (2019). Rights not rescue for migrant sex workers. Retrieved November 3, 2019, from https://www.opendemocracy.net/en/beyond-trafficking-and-slavery/rights-not-rescuemigrant-sex-workers/

Stoebenau, K., Heise, L., Wamoyi, J., \& Bobrova, N. (2016). Revisiting the understanding of "transactional sex" in sub-Saharan Africa: A review and synthesis of the literature. Social Science \& Medicine, 168(1), 186-197.

Stoler, A. L. (1997). Making empire respectable: The politics of race and sexual morality in twentiethcentury colonial cultures. In A. McClintock, A. Mufti \& E. Shohat (Eds.), Dangerous and liaisons: Gender nation, and postcolonial perpectives (pp. 344-373). Minneapolis: Univeristy of Minnesota Press.

Straus, M. A. (1992). Sociological research and social policy: The case of family violence. Sociological Forum, 7(1), 211-237.

Stringer, R. (2013). Vulnerability after wounding: Feminism, rape law, and the differend. SubStance, 42(3), 148 - 168.

Stringer, R. (2014). Knowing victims : Feminism, agency and victim politics in neoliberal times. London: Routledge.

Strobl, R. (2004). Constructing the victim: Theoretical reflections and empirical examples. International Review of Victimology, 11(1), 259 - 311.

Strobl, R. (2010). Becoming a victim. In S. G. Shoham, P. Knepper \& M. Kett (Eds.), International handbook of victimology. Boca Raton, Florida: CRC Press.

Stromberg, P. (Writer). (2014, August 4). Sex workers cry: Rights not rescue in Cambodia. In W. s. N. f. U. (WNU) \& P. Stromberg (Producer). Phnom Penh. Retrieved from https://www.youtube.com/watch?v=cgPfz9ydEp4\&t=23s

Stromquist, N. P. (1991). Educating Women: the political economy of patriarchal states. International Studies in Sociology of Education, 1(1), 111-128. 
Stumpf, J. (2006). The crimmigration crisis: Immigrants, crime \& sovereign power. American University Law Review, 56(2), 367-419.

Sugimura, M. (2016). What predicts a country's ability to prosecute and combat human trafficking? Governance indicators? Economic success? Or does it come down to focusing on antitrafficking efforts? (Master of Public Policy), Georgetown University, Washington, DC.

Sukach, T., Gonzalez, N., \& Pickens, J. C. (2018). Experiences of female sex trafficking survivors: A phenomenological analysis. The Qualitative Report, 23(6), 1422-1440.

SUKA Society. (2015). Protecting trafficked survivors. Retrieved October 7, 2015, from http://www.sukasociety.org/protecting-trafficked-survivors/

Sullivan, B. (2007). Rape, prostitution and consent. The Australian and New Zealand Journal of Criminology, 40(2), 127-142.

Sultana, A. (2012). Patriarchy and women's subordination: A theoretical analysis. Arts Faculty Journal, 4(1), 1-18.

Suppiah, P. C., \& Kaur, S. (2018). An intertextual analysis of sex-trafficking victims' representation in Malaysian news media. Journal of Language and Communication, 5(2), 161-172.

Suppiah, P. C., Kaur, S., Arumugam, N., \& Shanthi, A. (2019). News coverage of foreign sex workers in Malaysia: A critical analysis. GEMA Online Journal of Language Studies, 19(1), 136-152.

Surtees, R. (2003). Female migration and trafficking in women: The Indonesian context. Society for International Development, 46(3), 99-106.

Surtees, R. (2008). Traffickers and trafficking in southern and eastern Europe: Considering the other side of human trafficking. European Journal of Criminology, 5(1), 39-68.

Surtees, R. (2014). Another side of the story: Challenges in research with unidentified and unassisted trafficking victims. In S. Yea (Ed.), Human Trafficking in Asia (pp. 118-138). Abingdon, Oxon: Routledge.

Suzanne L. J. Kragten-Heerdink, Dettmeijer-Vermeulen, C. E., \& Korf, D. J. (2017). More than just "pushing and pulling": Conceptualizing identified human trafficking in the Netherlands. Crime \& Delinquency, 64(13), 1765-1789.

Swaine, J. (2015). Alan Dershowitz tried to discredit girl who accused Jeffrey Epstein of rape. The Guardian. Retrieved from https://www.theguardian.com/us-news/2015/jan/08/alandershowitz-girl-jeffrey-epstein-teenager

Syariah Criminal Offences (Federal Territories) Act (1997).

Tarar, M. G., \& Pulla, V. (2014). Patriarchy, gender, violence and poverty amongst Pakistani women: A social work inquiry. International Journal of Social Work and Human Services and Practice, $2(2), 56-63$.

Taslitz, A. E. (1996). Patriarchal stories: Cultural rape narratives in the courtroom. Review of Law and Women's Studies, 5(1), 387 - 500. 
Tenaganita. (2012). TENAGANITA: The Truth About Migrants in Malaysia. Retrieved October 8, 2015, from

http://www.wao.org.my/news_details.php?nid=243\&ntitle=TENAGANITA:+The+Truth+Abou t+Migrants+in+Malaysia

The Coalition of Malaysia NGO's in the UPR Process. (2009). Universal periodic review on Malaysia for the 4th Session of UPR 2009. Geneva: OCHCR.

The Global Network of Sex Work Projects. (2011). Sex work is not trafficking. Retrieved November 11, 2019, from https://www.nswp.org/sites/nswp.org/files/SW\%20is\%20Not\%20Trafficking.pdf

The Global Network of Sex Work Projects. (2015). Impacts of the sex purchase law: street-based sex work and levels of sex work. Retrieved November 6, 2019, from https://www.nswp.org/sites/nswp.org/files/2.\%20Impacts\%20of\%20the\%20Sex\%20Purchas e\%20Law\%20-\%20Street-

Based\%20Sex\%20Work\%20and\%20Levels\%20of\%20Sex\%20work\%2C\%20Swedish\%20Model \%20Advocacy\%20Toolkit\%2C\%20NSWP\%20-\%20December\%202014.pdf

The Star Online. (2016, June 1). Zahid: Only illegal immigrants, not terrorist slipped through KLIA immigration. The Star Online. Retrieved from https://www.thestar.com.my/news/nation/2016/06/01/zahid-no-terrorists-only-illegalimmigrants-slipped-through-klia-immigration/

The Star Online. (2019, February 26). Prostitutes with degrees charge up to RM500 an hour. The Star Online. Retrieved from https://www.thestar.com.my/news/nation/2019/02/26/educatedhookers-cost-more-prostitutes-with-degrees-charge-up-to-rm500-an-hour/

The Straits Times. (2014, June 22). Malaysia urges US to review human trafficking blacklist. The Straits Times. Retrieved from https://www.straitstimes.com/asia/se-asia/malaysia-urges-usto-review-human-trafficking-blacklist

The Sun Daily. (2014, October 14). Human trafficking, a booming the invisible industry in Malaysia. The Sun Daily. Retrieved from https://www.thesundaily.my/archive/1197973FRARCH276611

The World Bank. (n.d). Overall Global gender Gap Index. Retrieved June 13, 2019 from https://tcdata360. worldbank.org/indicators/af52ebe9?country=BRA\&indicator=27959\&viz=1 ine_chart\&years $=2006,2018$

Thiemann, I. K. (2018). Beyond victimhood and beyond employment? Exploring avenues for labour law to empower women trafficked into the sex industry. Industrial Law Journal, 1(1), 1-26. doi: 10.1093/indlaw/dwy015

Tippett, E. C. (2018). The legal implications of the MeToo Movement. Minnesota Law Review, 103(1), 229-302.

Toft, M. D. (2007). The myth of the borderless world: Refugees and repatriation policy. Conflict Management and Peace Science, 24(1), 139-157.

Toney-Butler, T. J., \& Mittel, O. (2019). Human Trafficking. Bethesda, MD: StatPearls Publishing LLC. 
Trading Economics. (2019). Indonesia average monthly wages in manufacturing. Retrieved May 15, 2019, from https://tradingeconomics.com/indonesia/wages-in-manufacturing

Translation of the meanings of the noble Qur'an in the English language. (1984). The noble Qur'an: English Translations of the meanings and commentary. Medina: King Fahd Complex for the Printing of the Holy Qur'an.

Transparency International. (2018). Breaking the chain: corruption and human trafficking. Retrieved June 2, 2018, from

https://www.transparency.org/news/feature/breaking_the_chain_corruption_and_human_ trafficking

Treacher, A. (2005). On postcolonial subjectivity. Group Analysis, 38(1), 43-57.

Treleaven, J. (1995). Sex workers and sexual assault: A national perspective. Paper presented at the Legalising Justice for All Women: National Conference on Sexual Assault and the Law, Melbourne, Australia.

Tumanov, V. (2011). Mary versus eve: Paternal uncertainty and the Christian view of women. Neophilologus: An International Journal of Modern and Mediaeval Language and Literature, 95(4), 507-521.

Tyldum, G., \& Brunovskis, A. (2005). Describing the unobserved: Methodological challenges in empirical studies on human trafficking. International Migration, 43(1/2), 17-34.

Tyler, T. R. (2006). Why people obey the law. Princeton: Princeton University Press.

Tyler, T. R. (2007). Psychology and the design of legal institutions. Nijmegen: Wolf Legal Publishers.

U.S Department of State. (2001). Trafficking in Persons Report 2001. Retrieved May 15, 2019, from http://www.state.gov/j/tip/rls/tiprpt/

Trafficking Victims Protection Act: Minimum standards for the elimination of trafficking in persons, U.S State Department (2011). Retrieved April 26, 2018, from https://20092017.state.gov/j/tip/rls/tiprpt/2013/210553.htm

U.S Department of State. (2012a). Definitions and methodology. Retrieved May 25, 2018 from https://2009-2017.state.gov/j/tip/rls/tiprpt/2013/210543.htm

U.S Department of State. (2012b). Trafficking in persons report - Malaysia. Retrieved October 27, 2017, from https://www.state.gov/documents/organization/192596.pdf

U.S Department of State. (2014). Malaysia: Office to monitor and combat trafficking in persons: 2014 Trafficking in persons report: Tier 3. Retrieved May 8, 2015, from http://www.state.gov/j/tip/rls/tiprpt/countries/2014/226770.htm

U.S Department of State. (2015). Trafficking in persons report 2015 - Malaysia. Retrieved September 29, 2016, from http://www.state.gov/documents/organization/243560.pdf

U.S Department of State. (2016). Trafficking in persons report 2016 - Malaysia. Retrieved April 3, 2019, from https://www.state.gov/documents/organization/258880.pdf 
U.S Department of State. (2017). Trafficking in persons report 2017 - Malaysia: Retrieved October 30, 2017, from https://www.state.gov/j/tip/rls/tiprpt/countries/2017/271235.htm

U.S Department of State. (2018). Trafficking in persons report 2018 - Malaysia. Retrieved October 30, 2018, from https://www.state.gov/documents/organization/282802.pdf

Ullah, A. K. M. A. (2009). Theoretical rhetoric about migration networks: A case of a journey of Bangladeshi workers to Malaysia. International Migration, 51(3), 151 - 168.

UN.Gift. (2008). An introduction to human trafficking: Vulnerability, Impact and action. New York: United Nations

UNHCR. (n.d). Interviewing Applicants for Refugee Status (RLD 4). Retrieved November 13, 2019, from https://www.unhcr.org/4d9485a69.pdf

UNICEF. (2011). Yemen: Mena gender equality profile status of girls and women in the middle east and north Africa. Retrieved May 13, 2019, from https://www.unicef.org/gender/files/Yemen-Gender-Eqaulity-Profile-2011.pdf

United Nations. (1948). Universal Declaration of Human Rights. Retrieved February 27, 2018, from http://www.un.org/en/universal-declaration-human-rights/

United Nations. (2000). Secretary-General, In address to "women 2000 " special session, says future of planet depends upon women. Retrieved February 27, 2018, from https://www.un.org/press/en/2000/20000605.sgsm7430.doc.html

United Nations. (2003). Protocol to Prevent, Suppress and Punish Trafficking in Persons, Especially Women and Children (Palermo Protocol) (entered into force on 25 Dec 2003). Paper presented at the Protocol to Prevent, Suppress and Punish Trafficking in Persons, Especially Women and Children, Geneva. Retrieved May 3, 2015 from https://www.ohchr.org/EN/Professionallnterest/Pages/ProtocolTraffickingInPersons.aspx

United Nations. (2006). Malaysia needs new laws aimed specially at ending discrimination on basis of sex, gender, say committee's expert members. Retrieved September 3, 2017, from https://webcache.googleusercontent.com/search?q=cache:S-

XX6cWkM_wJ:https://www.un.org/press/en/2006/wom1562.doc.htm+\&cd=1\&hl=en\&ct=cl $n k \& g l=n z$

United Nations. (2017). United Nations glossary on sexual exploitation and abuse: Thematic glossary of current terminology related to sexual exploitation and abuse (sea) in the context of the united nations. New York: United Nations.

United Nations Development Programme. (2016). Human development reports: Gender inequality index (GII). Retrieved February 28, 2018, from http://hdr.undp.org/en/content/genderinequality-index-gii

United Nations Global Initiative to Fight Human Trafficking. (2008). 023 Workshop: The effectiveness of legal frameworks and anti-trafficking legislation. Paper presented at the The Vienna forum to fight human trafficking, Vienna. Retrieved May 6, 2016, from https://www.unodc.org/documents/humantrafficking/2008/BP016ProfilingtheTraffickers.pd $f$ 
United Nations High Commissioner For Human Rights. (2002). The recommended principles and guidelines on human rights and human trafficking. E/2002/68/Add. 1. Retrieved September 3, 2017, from http://www.ohchr.org/Documents/Publications/Traffickingen.pdf

United Nations Human Rights. (2014). Gender stereotypes and stereotyping and women's rights. Retrieved May 13, 2019, from https://www.ohchr.org/documents/issues/women/wrgs/onepagers/gender_stereotyping.p df

United Nations Human Rights Council. (2015). Report of the Special Rapporteur on trafficking in persons, especially women and children, Maria Grazia Giammarinaro: Mission to Malaysia. Geneva: United Nations Human Rights Office of The High Commissioner.

United Nations Human Rights Office of the High Commisioner. (2014). Human rights and human trafficking: Fact Sheet No. 36. Geneva: Office of the United Nations High Commissioner for Human Rights.

United Nations Office of Drugs and Crime. (2019). Tool 5.17: Witness protection. Retrieved 28/02/2019, 2019, from https://www.unodc.org/documents/human-trafficking/Toolkitfiles/08-58296_tool_5-17.pdf

United Nations Office On Drugs And Crime. (2006). Trafficking in persons: Global patterns.

Retrieved April 9, 2017, from

http://www.unodc.org/pdf/traffickinginpersons_report_2006ver2.pdf

United Nations Office On Drugs And Crime. (2008). Trafficking in human beings in Brazil (Case Study 11 at p. 75). UNODC's Trafficking in Persons: Global Patterns Report. Retrieved April 9, 2017, from www.unodc.org/pdf/brazil/folder_tsh_ing_port.pdf

United Nations Office On Drugs and Crime. (2009). Model law against trafficking in persons. Vienna: United Nations Publications.

United Nations Office On Drugs And Crime. (2012). Global report on trafficking in persons. Vienna: United Nations Office On Drugs And Crime.

United Nations Office On Drugs and Crime. (2014). The role of 'consent' in the Trafficking Protocol. Vienna: United Nations Office on Drugs and Crime.

United Nations Office On Drugs And Crime. (2015a). Smuggling of migrants in Southeast Asia. In U. N. O. O. D. A. Crime (Ed.), Migrant Smuggling in Asia: Current Trends and Related Challenges. Vienna, Austria: United Nations Office of Drugs and Crime.

United Nations Office On Drugs And Crime. (2015b). UNODC on human trafficking and migrant smuggling. Retrieved October 9, 2015, from http://www.unodc.org/unodc/humantrafficking/

United Nations Office On Drugs and Crime. (2016). Human trafficking toolkit for journalists. Abu Dhabi: United Nations Publications.

United Nations Office On Drugs and Crime. (2017a). Evidential issues in trafficking in persons cases: Case digest. Vienna: United Nations Office on Drugs and Crime. 
United Nations Office On Drugs And Crime. (2017b). UNODC report on human trafficking exposes modern form of slavery. Retrieved October 18, 2017, from http://www.unodc.org/unodc/en/human-trafficking/global-report-on-trafficking-inpersons.html?ncid=edlinkushpmg00000313

United Nations Office on Drugs and Crime. (2019). Human trafficking. Retrieved March 24, 2019, from https://www.unodc.org/unodc/en/human-trafficking/faqs.html

United Nations Office of Drugs and Crime. (2019). Tool 7.3: Understanding the challenges for returnee victims of trafficking. Retrieved November 27, 2019, from https://www.unodc.org/documents/human-trafficking/Toolkit-files/08-58296_tool_7-3.pdf

United Nations Population Fund. (2011). Socio-cultural influences on the reproductive health of migrant women: A review of literature in Cambodia, Lao PDR, Thailand and Vietnam. Bangkok: UNFPA Asia Pacific Regional Office.

United Nations Statistics Division. (2015). Poverty. In United Nations Statistics Division (Ed.). The world's women 2015: Trends and statistics (pp. 179-199). New York: United Nations.

Universal Declaration of Human Rights (1948). (General Assembly resolution 217 A). Retrieved May 7, 2016 from http://www.un.org/en/universal-declaration-human-rights/

Uy, R. (2011). Blinded by red lights: Why trafficking discourse should shift away from sex and the perfect victim paradigm. Berkeley Journal Of Gender, Law \& Justice, 26(1), 204 - 219.

VeneKlasen, L., \& Miller, V. (2002). A new weave of people, power and politics: The action guide for advocacy and citizen participation (Vol. 37). Oklahoma: World Neighbours.

Vicinus, M. (1972). Suffer and be still: Women in the Victorian age. Indiana: Indiana University Press.

Vickery, A. (1993). Golden age to separate spheres? A review of the categories and chronology of English women's history. The Historical Journal, 36(1), 383-414.

Villacampa, C., \& Torres, N. (2015). Trafficked women in prison: The problem of double victimisation. European Journal Policy Research, 21(1), 99-115.

Walby, S. (1990). From private to public patriarchy: The periodisation of British history. Women's Studies International Forum, 13(1 - 2), 91 - 104.

Walklate, S. (1989a). Victimology: The victim and the criminal justice process. London: Unwin Hyman.

Walklate, S. (1989b). Victims And The criminal justice process. In S. Walklate (Ed.), Victimology: The victim and the criminal justice process (pp. 108-131). London: Unwin Hyman Ltd.

Walklate, S. (Ed.). (2007). Handbook of victims and victimology. Cullompton: Willan Publishing.

Walklate, S. (Ed.). (2013). Victimology: The victim and the criminal justice process. Abingdon, Oxon: Routledge.

Walmsley, T., Aguiar, A., \& Ahmed, S. A. (2013). Labor migration and economic growth in east and southeast Asia. Retrieved May 17, 2019, from https://elibrary.worldbank.org/doi/pdf/10.1596/1813-9450-6643 
Ward, T., \& Fouladvand, S. (2018). Human trafficking, victims' rights and fair trials. The Journal of Criminal Law, 82(2), 138-155.

Warnock, K. (1990). Women's position in traditional society. In K. Warnock (Ed.), Land before honour: Women in society (pp. 19-34). London: Palgrave Macmillan.

Weitzer, R. (2005). Flawed theory and method in studies on prostitution. Violence Against Women, 11(7), 934 - 949.

Weitzer, R. (2007). The social construction of sex trafficking: Ideology and institutionalization of a moral crusade. Politics and Society, 35(3), 447-475.

Weitzer, R. (2010). Sex for sale: Prostitution, pornography, and the sex industry (Second ed.). New York: Routledge.

Weitzer, R. (2018). Resistance to sex work stigma. Sexualities, 21(5-6), 717-729.

West, A., \& Loeffler, D. N. (2015). Understanding victim resistance: An exploratory study of the experiences of service providers working with victims of child trafficking. Journal of Applied Research on Children: Informing Policy for Children at Risk, 6(1), 1-25.

West, C., \& Zimmerman, D. H. (1991). Doing gender. In J. Lorber \& S. A. Farrell (Eds.), The social construction of gender (pp. 13-37). Newbury Park, California: Sage.

Wickramasekara, P. (2002). Asian labour migration: Issues and challenges in an era of globalization. In I. L. Office (Ed.), International Migration Programme (Vol. 57). Geneva: International Labour Office.

Wijers, M. (2001). Criminal, victim, social evil or working girl: Legal approaches to prostitution and their impact on sex workers. Paper presented at the International Seminar on Prostitution, Madrid.

Wijers, M., \& Lap-Chew, L. (1997). Trafficking in women, forced labour and slavery-like practices in marriage, domestic labour and prostitution. Utrecht: STV.

Wijk, J. v. (2013). Who is the 'little old lady' of international crimes? Nils Christie's concept of the ideal victim reinterpreted. International Review of Victimology, 19(2), 159-179.

Wilcox, P. (2006). Surviving domestic violence: gender, poverty and agency. Basingstoke: Palgrave Macmillan.

Williams, B. (2002). Reparation and victim-focused social work. London: Jessica Kingsley.

Williams, M. E. (2015). When a sex worker is raped, it's rape - not "theft of services". Salon. Retrieved May 13, 2019

Williamson, C., \& Cluse-Tolar, T. (2002). Pimp-controlled prostitution. Violence Against Women, 8(9), 1074-1092.

Willig, C. (2017). Interpretation in qualitative research. In W. S. Rogers \& C. Willig (Eds.), The Sage handbook of qualitative research in psychology (pp. 276-290). London: Sage. 
Wilson, B., \& Butler, L. D. (2014). Running a gauntlet: A review of victimization and violence in the pre-entry, and peri-/post-exit periods of commercial sexual exploitation. Psychological Trauma: Theory, Research, Practice, and Policy, 6(5), 494-504.

Wilson, M., \& O'Brien, E. (2016). Constructing the ideal victim in the United States of America's annual trafficking in persons reports. Crime, Law and Social Change, 65(1-2), 29-45.

Win, E. J. (2004). Open letter to Nkosazana Dlamini-Zuma and other women in the South African cabinet. Feminist Africa, 3(1), 74-76.

Wok, S., \& Mohamed, S. (2017). Internet and social media in Malaysia: Development, challenges and potentials. In D. B. P. Acuña (Ed.), The evolution of media communication. Rijeka, Croatia: IntechOpen.

Wolf, N. (1993). Fire with fire: the new female power and how it will change the 21st century. New York: Random House.

World Bank. (2018). Ending violence against women and girls: Global and regional trends In women's legal protection against domestic violence and sexual harassment. Retrieved April 2, 2019, from http://pubdocs.worldbank.org/en/140781519943384134/EndingViolenceAgainstWomenand GirlsGBVLawsFeb2018.pdf

World Health Organisation. (2001). STI/HIV: Sex work in Asia. Retrieved March 23, 2018, from http://iris.wpro.who.int/bitstream/handle/10665.1/5578/Sex_work_Asia_eng.pdf

World Health Organization. (2002). World report on violence and health. Geneva: World Health Organization.

Yeoh, B. S. A., \& Huang, S. (2010). Sexualised politics of proximities among female transnational migrants in Singapore. Population, Space and Place, 16(1), 37-49.

Young, C. (1993). The new madonna/whore syndrome. New York Law School Law Review, 38(1).

Yount, K. M., VanderEnde, K. E., Dodell, S., \& Cheong, Y. F. (2016). Measurement of women's agency in Egypt: A national validation study. Soc Indic Res, 128(1), 1171-1192.

Yunus, A. (2014, 22 June). Suhakam: Significant improvement needed after Malaysia sinks to lowest ever ranking in human trafficking report. The Star Online. Retrieved from https://www.thestar.com.my/news/nation/2014/06/22/suhakam-anti-trafficking-report/

Yusof, T. A., \& Shah, A. (2018, July 29). Agents to blame for huge number of illegal foreign workers. New Straits Times. Retrieved from https://www.nst.com.my/news/exclusive/2018/07/395563/agents-blame-huge-numberillegal-foreign-workers

Zajac, R., Gross, J., \& Hayne, H. (2003). Asked and answered: Questioning children in the courtroom. Psychiatry, Psychology and Law, 10(1), 199-209.

Zakar, R., Muhammad, Z., \& Krämer, A. (2012). Voices of strength and struggle: Women's coping strategies against spousal violence in Pakistan. Journal of Interpersonal Violence, 27(16). 
Zedner, L. (2002). Victims. In M. Maguire, R. Morgan \& R. Reiner (Eds.), The Oxford handbook of criminology (Third ed., pp. 419-456). Oxford: Oxford University Press.

Zhang, W. (2000). An interdisciplinary synthesis of framing. Paper presented at the AEJMC Conference, Phoenix, Arizona.

Zheng, T. (2010). Sex trafficking, human rights, and social justice. London: Routledge.

Zimmerman, C., Hossain, M., \& Watts, C. (2011). Human trafficking and health: A conceptual model to inform policy, intervention and research. Social Science and Medicine, 73, 327-335.

Zimmerman, C., Hossain, M., Yun, K., Roche, B., Morison, L., \& Watts, C. (2006). Stolen smiles: Report on the physical and psychological health consequences of women and adolescents trafficked in Europe. London: The London School of Hygiene and Tropical Medicine.

Zimmerman, C., Hossain, M., Yun, K., \& Watts, C. (2008). The health of trafficked women: a survey of women entering post trafficking services in Europe. American Journal of Public Health, 98(1), 55 - 59.

Zimmerman, C., \& Watts, C. (2003). WHO ethical and safety recommendations for interviewing trafficked women. In W. H. Organization (Ed.), World Health Organization (Vol. LC/NLM classification HQ 281, pp. 1-29). Geneva: World Health Organization.

Zimmerman, D. (2011). Coercive wage offers. Philosophy \& Public Affairs, 10(1), 121-145.

Zinin, M. B. M. (2010). Jenayah dan isu pemerdagangan orang di kalangan warga asing. Paper presented at the Proceedings Seminar on on National Resilience 2010: "Political Managements and Policies in Malaysia", Kedah, Malaysia.

Zweynert, A. (2015). Violence, self-harm and suicide common among trafficked children: researchers. Retrieved April 11, 2018, from https://www.reuters.com/article/us-healthtrafficking-children/violence-self-harm-and-suicide-common-among-trafficked-childrenresearchers-idUSKCNOR81WP20150908 
